\title{
HYDROGEN PRODUCTION AND DELIVERY INFRASTRUCTURE AS A COMPLEX ADAPTIVE SYSTEM
}

RCF Economic and Financial Consulting, Inc. Argonne National Laboratory

\author{
Final Report \\ Award Number DE-FG36-05G015034
}

June 2010 


\section{TABLE OF CONTENTS}

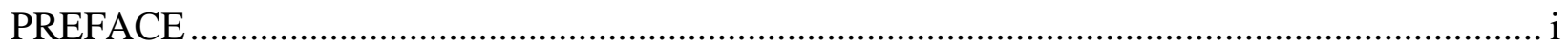

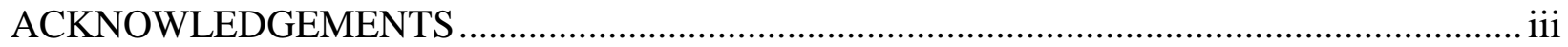

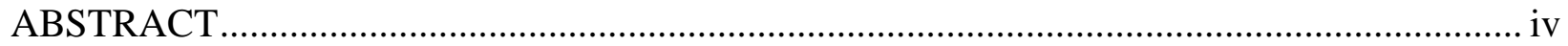

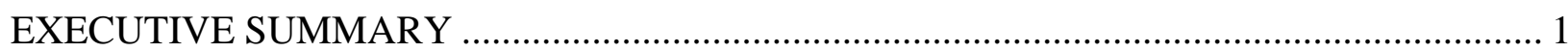

PART ONE: INTRODUCTION

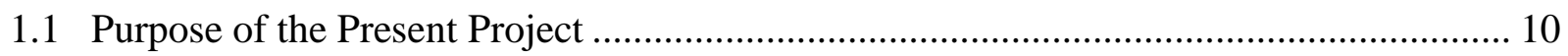

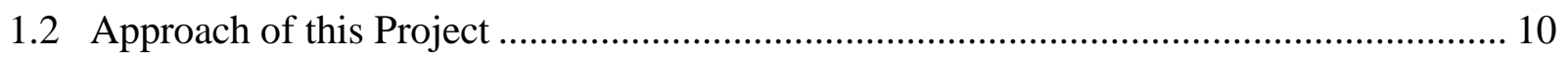

1.3 Relation of this Project to Other Applied Agent-based Modeling Work........................... 11

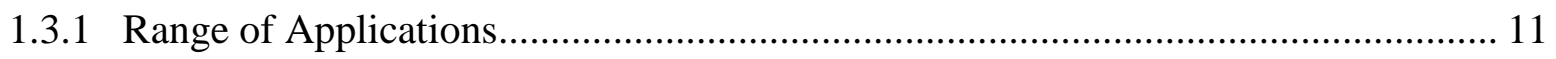

1.3.2 Institutes Devoted to Agent-based Modeling Applications ...................................... 11

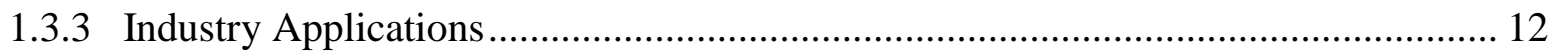

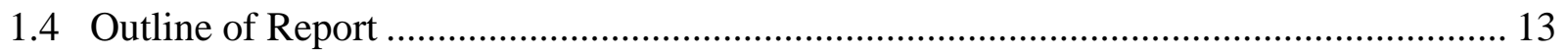

\section{PART TWO: THE MODEL}

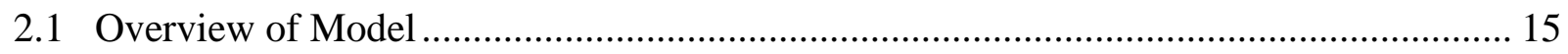

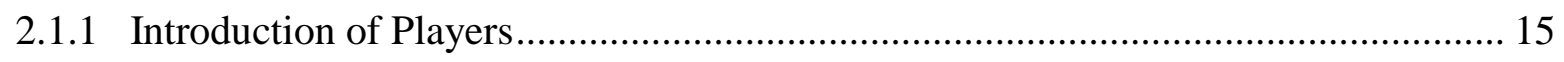

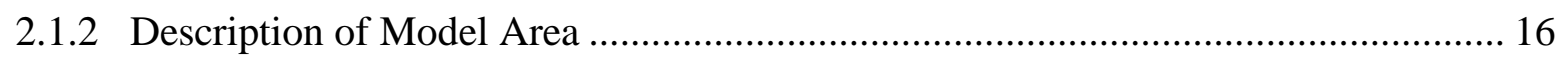

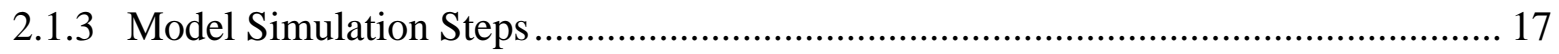

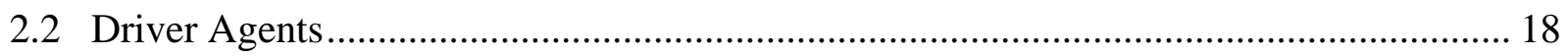

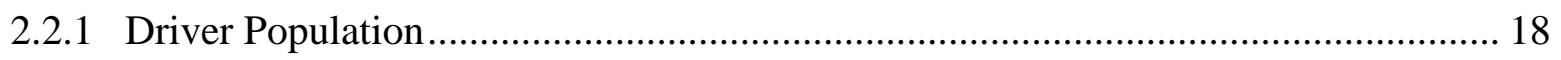

2.2.2 Vehicle Purchasing and the Driver Utility Function................................................. 19

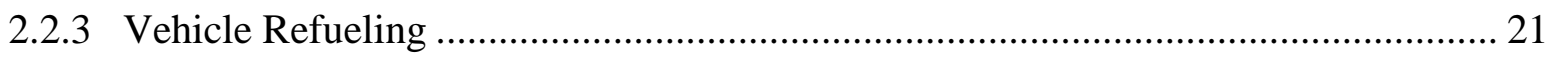

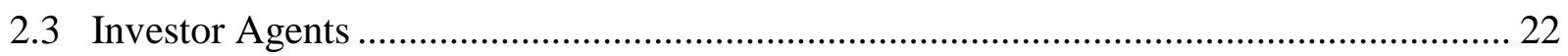

2.3.1 Hydrogen Fuel Production Technologies ............................................................. 23

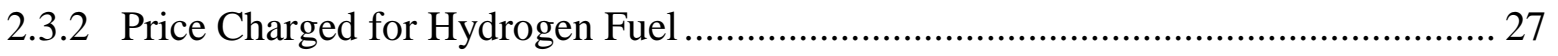

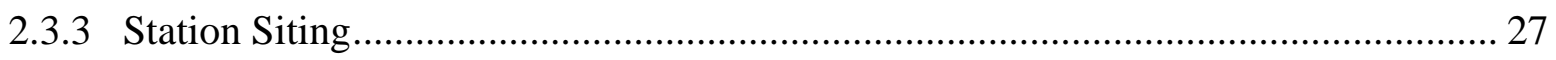

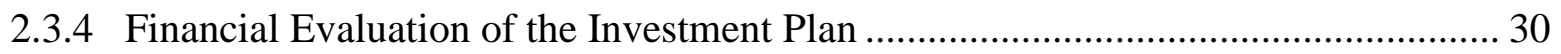

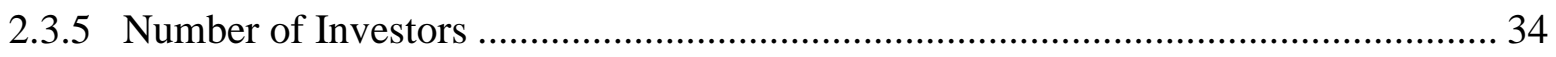

\section{PART THREE: SENSITIVITY TO MODEL PARAMETERS}

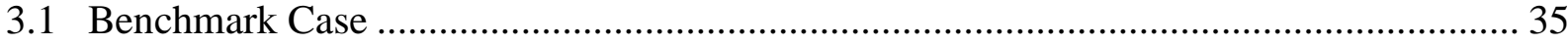

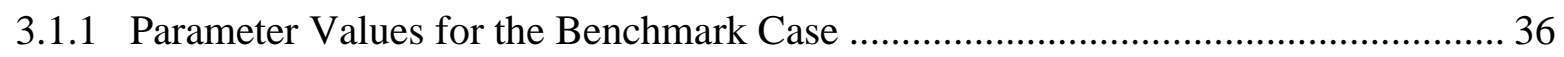

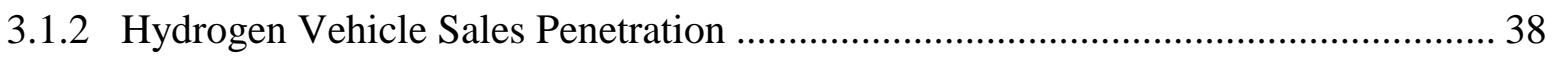

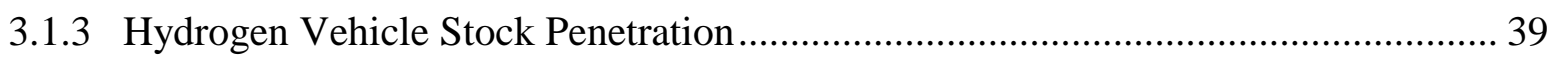

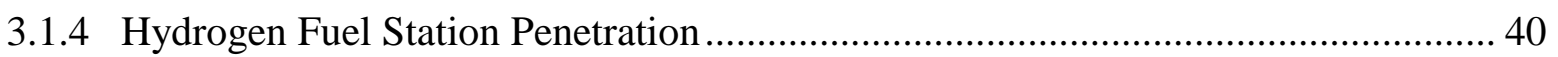

3.1.5 Location of Fuel Stations ............................................................................ 41 


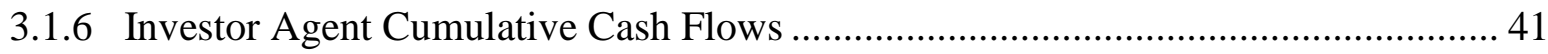

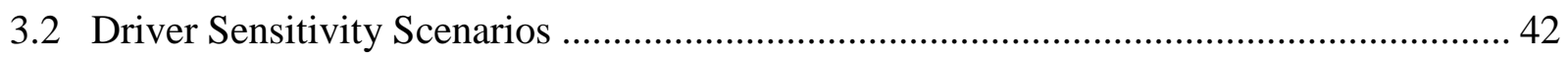

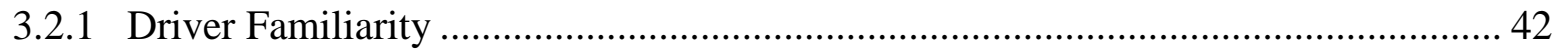

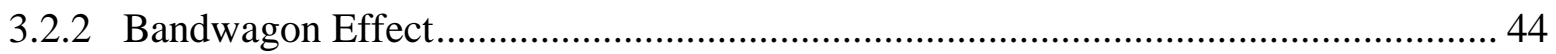

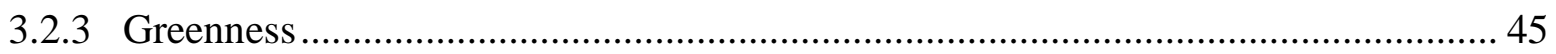

3.2.4 Conclusions on Model Sensitivity to Driver Behavior ............................................ 48

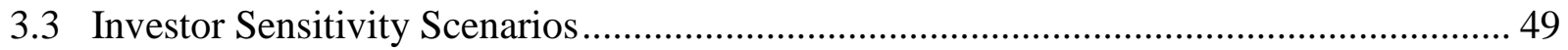

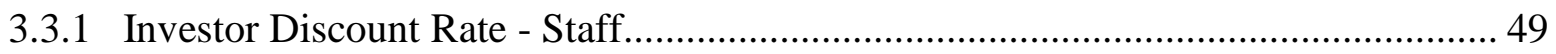

3.3.2 Investor Discount Rate - Upper Management ……….............................................. 50

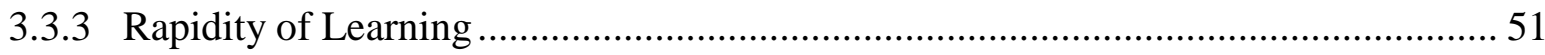

3.3.4 First Year Demand Estimation at Potential Station Locations ................................. 52

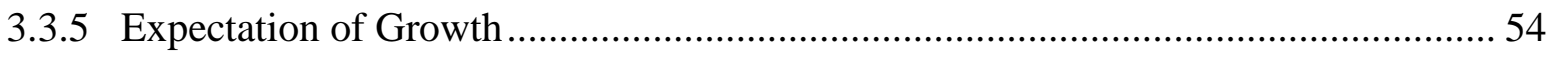

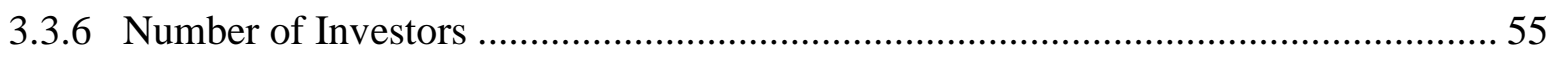

3.3.7 Conclusions on Model Sensitivity to Investor Behavior ......................................... 56

3.4 Use of Realistic Approximative Decisions ................................................................. 57

\section{PART FOUR: SENSITIVITY TO MARKET AND POLICY INFLUENCES}

4.1 Market Developments: Sticker Price Difference .............................................................5 59

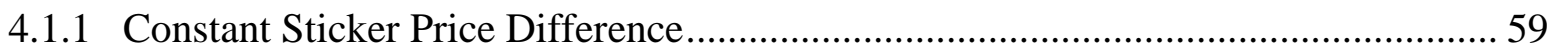

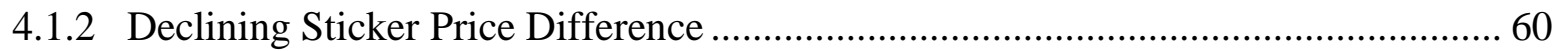

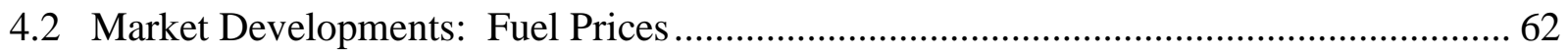

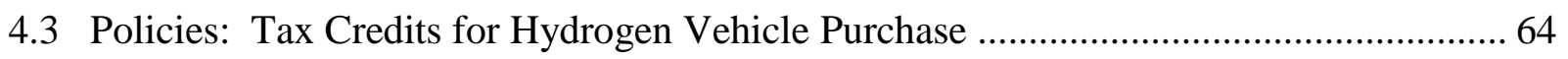

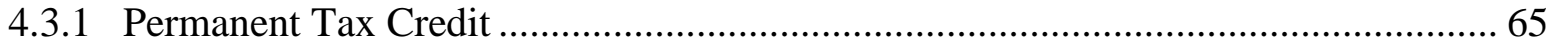

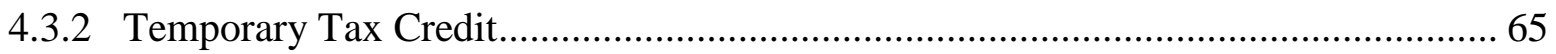

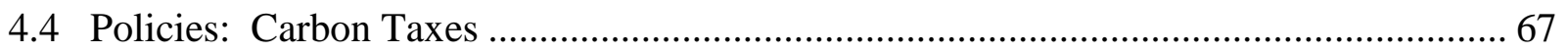

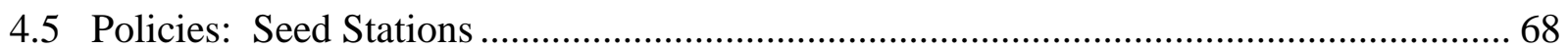

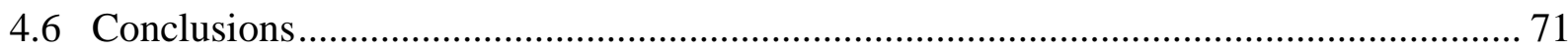

\section{PART FIVE: VALIDATION}

5.1 Relation of Adoption Paths of this Study to Previously Estimated Adoption Paths ........ 72

5.1.1 The Logistic Function and the Comparison of Adoption Paths................................ 73

5.1.2 Comparison of Hydrogen Vehicles with Consumer Durables as a Whole ................ 74

5.2 Adoption Experience under Other Vehicle Information.................................................... 76

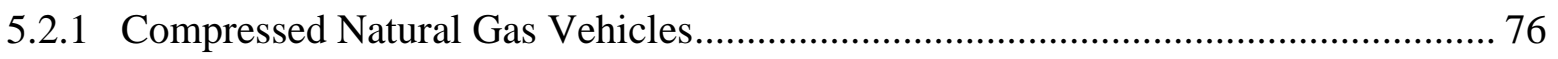

5.2.2 The Market Penetration of Japanese Vehicles in the United States........................... 79

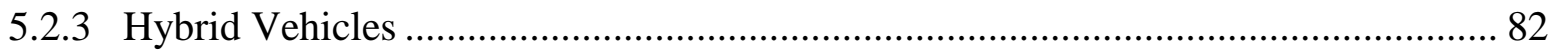

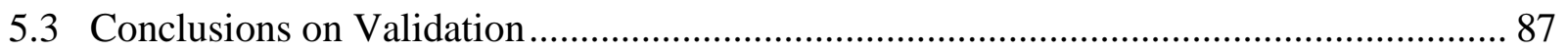


PART SIX: SUMMARY AND CONCLUSIONS

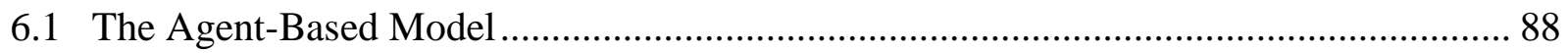

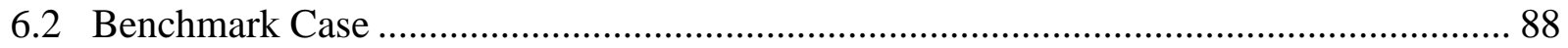

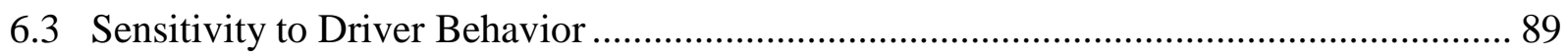

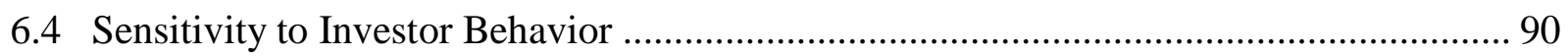

6.5 Effect of Realistic Approximative Decisions in the Agent-based Model......................... 90

6.6 Use of the Model to Examine Market Developments.......................................................... 91

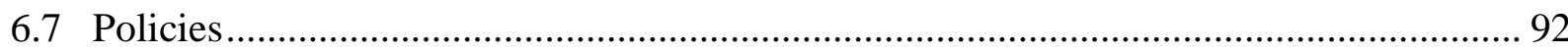

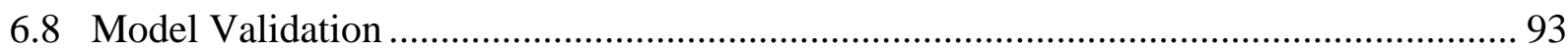

6.9 Bottom Line Issue of this Study: Adequacy of Private Sector Infrastructure Supply ..... 93

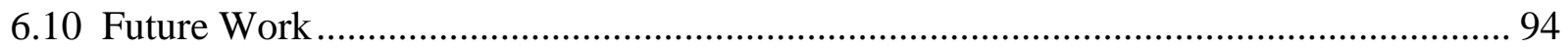

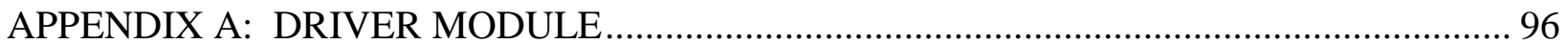

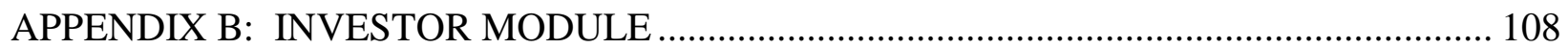

APPENDIX C: FACTORS AFFECTING FUTURE COSTS OF PRODUCING HYDROGEN

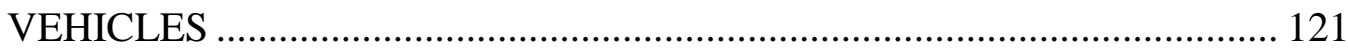




\section{PREFACE}

In 2005, the Hydrogen, Fuel Cells and Infrastructure Technologies Program of the Office of Energy Efficiency and Renewable Energy of the U.S. Department of Energy contracted with RCF Economic and Financial Consulting, Inc. to develop an Agent-based Model (ABM), in cooperation with Argonne National Laboratory, on the construction of hydrogen infrastructure as hydrogen vehicles penetrate the U.S. light-duty vehicle market. Industry cooperators were Ford Motor Company, BP, Protium Energy Technologies, and John E. Johnston (formerly Planning Executive for ExxonMobil's Corporate Strategic Research Laboratories).

A principal product of this project is the agent-based model "Hydrogen Infrastructure Complex Adaptive Systems" (H2CAS). The model benefitted from earlier work on other topics using agent-based modeling at the Center for Energy, Environmental, and Economic Systems Analysis (CEEESA) at Argonne National Laboratory, and from a similar model previously developed at Ford Motor Company. Conventional methods to address technology introduction rely on traditional optimization procedures such as simple cost minimization assuming perfect knowledge. There are too many interactions among the participating entities in the hydrogen transition to be captured with these techniques. The agent-based model simulates the behavior and interactions of a large number of individuals (agents) and studies the macro-scale consequences of these interactions. The agents represent a diverse group of actors with different tastes, resources, strategies, and risk preferences. Agents use rules of thumb and other realistic informal estimation techniques. They may be biased. Corrective actions occur as agents learn from their experience. They adapt over time.

The study team was charged with answering the questions, "Will the private sector be likely to undertake this infrastructure investment on its own, and with sufficient promptness to satisfy national energy and foreign policy goals?" and "If not, what policy actions would be effective?"

To answer these questions, projections are given of how hydrogen infrastructure will grow and how hydrogen vehicles will penetrate the market under alternative conditions. Sensitivity scenarios are presented pertaining to such influences as the cost of hydrogen vehicles relative to non-hydrogen vehicles, the price of gasoline, risk attitudes of senior managers at companies involved in hydrogen supply technologies, and behavior of consumers. The effectiveness of policies that would affect adoption is estimated.

Part One introduces the report and discusses other applications of agent-based modeling.

Part Two gives an overview of the model. The model offers the ability to introduce a variety of characteristics of people who might purchase hydrogen vehicles (driver agents). On the infrastructure side of the problem, the agent-based approach allows the firms that provide hydrogen for vehicles (investor agents) to make investment decisions that are not strictly maximizing. Instead they use satisficing rules of thumb and other approximations, making decisions that are "good enough" if not perfect. This allows investor agents to behave more like real business people, who face circumstances that are too complicated to allow perfect maximize. 
Part Three reports simulation results of the model with, first, a benchmark set of parameters and then with variations allowing study of sensitivity to numerical values of model parameters.

Part Four reports results of simulations examining a number of market and policy parameters, including the sticker price of the hydrogen vehicle, vehicle fuel prices, tax credits, carbon taxes, and seed stations at the beginning of the simulation provided with policy help.

Part Five is concerned with validation. The simulations of the present study are compared to experiences with a number of other innovations, many of which have encountered chicken-oregg effects that characterize the introduction of hydrogen. The investigation includes a variety of consumer durables plus experiences with compressed natural gas vehicles, Japanese imports, and hybrid vehicles.

Part Six summarizes the results of the study and draws conclusions regarding ability to supply infrastructure that will permit market penetration of hydrogen vehicles..

Technical appendices report the mathematical structure of the driver module (Appendix A) and investor module (Appendix B) and summarize major influences on the future price of hydrogen vehicles (Appendix C). 


\section{ACKNOWLEDGEMENTS}

The team at RCF was led by George Tolley and included Donald Jones, Naveen Singhal, Mihai Sturdza, Catherine Mertes, Mark Grenchik, David Jarvis, and several other RCF staff members. The team at Argonne National Laboratory was led by Guenter Conzelmann, and included Marianne Mintz, Craig Stephan (formerly of Ford), Matthew Mahalik, Thomas Veselka, and Audun Botterud. The hydrogen model made use of the Argonne team's experience with agent-based modeling and an earlier model of hydrogen vehicle adoption developed at Ford Motor Company by Craig Stephan and John Sullivan.

Generous and valuable contributions were made by the industry cooperators, who included Dean Fry of BP; Craig Stephan and John Sullivan of Ford Motor Company; John Johnston formerly of ExxonMobil; and Venki Raman of Protium Energy Technologies.

Very helpful comments on the draft report were provided by the peer reviewers, who were Shannon Baxter-Clemmons of the South Carolina Hydrogen and Fuel Cell Alliance, Maria Curry-Nkansah of the Imago Energy Consultancy Group, and George Parks of FuelScience LLC.

Fred Joseck of DOE was a constant source of valuable feedback and help. Midterm decisions benefitted greatly from comments in semi-annual Fuel Pathways Integration Technical Team (FPITT) meetings in Washington, D.C., Golden, CO, and Naperville, IL over the course of the project. 


\begin{abstract}
An agent-based model of the transition to a hydrogen transportation economy explores influences on adoption of hydrogen vehicles and fueling infrastructure. Attention is given to whether significant penetration occurs and, if so, to the length of time required for it to occur. Estimates are provided of sensitivity to numerical values of model parameters and to effects of alternative market and policy scenarios. The model is applied to the Los Angeles metropolitan area
\end{abstract}

In the benchmark simulation, the prices of hydrogen and non-hydrogen vehicles are comparable. Due to fuel efficiency, hydrogen vehicles have a fuel savings advantage of 9.8 cents per mile over non-hydrogen vehicles. Hydrogen vehicles account for $60 \%$ of new vehicle sales in 20 years from the initial entry of hydrogen vehicles into show rooms, going on to $86 \%$ in 40 years and reaching still higher values after that. If the fuel savings is 20.7 cents per mile for a hydrogen vehicle, penetration reaches $86 \%$ of new car sales by the $20^{\text {th }}$ year. If the fuel savings is 0.5 cents per mile, market penetration reaches only $10 \%$ by the $20^{\text {th }}$ year. To turn to vehicle price difference, if a hydrogen vehicle costs $\$ 2,000$ less than a non-hydrogen vehicle, new car sales penetration reaches $92 \%$ by the $20^{\text {th }}$ year. If a hydrogen vehicle costs $\$ 6,500$ more than a non-hydrogen vehicle, market penetration is only $6 \%$ by the $20^{\text {th }}$ year. Results from other sensitivity runs are presented.

Policies that could affect hydrogen vehicle adoption are investigated. A tax credit for the purchase of a hydrogen vehicle of $\$ 2,500$ tax credit results in $88 \%$ penetration by the $20^{\text {th }}$ year, as compared with $60 \%$ in the benchmark case. If the tax credit is $\$ 6,000$, penetration is $99 \%$ by the $20^{\text {th }}$ year. Under a more modest approach, the tax credit would be available only for the first 10 years. Hydrogen sales penetration then reach $69 \%$ of sales by the 20 th year with the $\$ 2,500$ credit and $79 \%$ with the $\$ 6,000$ credit.

A carbon tax of $\$ 38$ per metric ton is not large enough to noticeably affect sales penetration. A tax of $\$ 116$ per metric ton makes centrally produced hydrogen profitable in the very first year but results in only $64 \%$ penetration by year 20 as opposed to the $60 \%$ penetration in the benchmark case. Provision of 15 seed stations publicly provided at the beginning of the simulation, in addition to the 15 existing stations in the benchmark case, gives sales penetration rates very close to the benchmark after 20 years, namely, $63 \%$ and $59 \%$ depending on where they are placed. 


\section{EXECUTIVE SUMMARY}

\section{INTRODUCTION}

This final report presents results of the Analysis of the Hydrogen Production and Delivery Infrastructure as a Complex Adaptive System (Award Number E-FC36-05GO15034), conducted for the Fuel Cell Technologies Program of the Office of Energy Efficiency and Renewable Energy of the U.S. Department of Energy.

The project is concerned with the ability to provide infrastructure necessary to support a hydrogen transportation system. The start-up of a hydrogen transportation system encounters a chicken-or-egg problem of what comes first, drivers of hydrogen cars or investors in hydrogen fueling infrastructure. The central purpose is to answer:

Whether the private sector will supply the infrastructure to permit a transition to hydrogen consistent with national goals and, if not, what policy actions would be effective.

\section{APPROACH}

The methodology used is Agent-based Modeling (ABM). ABM actors use realistic approximations in making decisions, rather than using perfect optimization that assumes impossible requirements of complete knowledge. ABM permits the introduction of great variety in the analysis of interactions among the many different actors in an economic system. The model in this study was developed jointly between RCF Economic and Financial Consulting, Inc. and Argonne National Laboratory.

The model simulates the interactions of drivers of hydrogen vehicles and investors providing hydrogen fueling infrastructure, during years when adoption of hydrogen vehicles is occurring. It provides a tool for estimating how different circumstances will affect the growth of the hydrogen economy.

\section{OUTLINE OF REPORT}

Part One of the report provides an introduction. Part Two provides an overview of the model including a description of the geographic area, driver agent and investor agent behavior, the model simulation process, hydrogen production technology, and the hydrogen fuel station siting process. Part Three describes the study's benchmark adoption scenario and reports on sensitivity to numerical estimates of driver and investor behavioral parameters. Part Four reports on the sensitivity to market influences and policies. Part Five is concerned with validation of the model through comparison of its prediction of hydrogen vehicle adoption with observed adoption of previous innovations for durable goods. Part Six summarizes the major empirical findings of the study, presents conclusions on the central question of prospects for adequate provision of hydrogen infrastructures, and discusses the usefulness of the study in the future. Appendix A contains further details regarding driver agents. Appendix B contains further on investor agents. 
Appendix $\mathrm{C}$ presents an analysis of the sources of declines in cost of producing hydrogen vehicles that would allow them to enter the mass market.

\section{OVERVIEW OF THE MODEL}

As discussed in Section 2.1, the Agent-based Model (ABM) developed for the study contains 130 parameters which consist of 92 cost parameters from DOE's H2A model, 17 driver behavior parameters, 10 investor behavior parameters, and 11 price and policy variables.

The model area is a 100-by-50-mile rectangular area centered on the Los Angeles, California, metropolitan area. Within the model area, there are two types of agents: potential buyers of hydrogen vehicles (driver agents) and potential investors in hydrogen fuel infrastructure (investor agents).

Driver agents make decisions regarding whether or not to purchase hydrogen vehicles each quarter within each simulation year. At the beginning of a simulation, driver agents own only non-hydrogen vehicles. Driver agents observe the few hydrogen fueling stations which are sited as seed stations as part of the model. Driver agents then decide whether to replace their non-hydrogen vehicles with hydrogen-powered vehicles depending on their individual differences and on the location of stations where they can buy hydrogen fuel. Those hydrogen vehicles are then fueled throughout the simulation year. Investor agents observe the fueling behavior of driver agents, revise their expectations regarding the strength of demand based on the sales they observe, and then decide where and how many new fuel stations to build in the next simulation year. Driver agents then view the stations that have been added and once again make decisions about purchasing hydrogen vehicles. The process repeats for each year of the simulation.

\section{DRIVER AGENTS}

As discussed in Section 2.2, driver agents represent vehicle drivers living and working in the model area. The driver agents live and work in different locations, have different incomes, varying knowledge about hydrogen vehicles, varying attitudes toward the environment, and other characteristics. Drivers differ in their proclivities to buy hydrogen vehicles and in their proximity to hydrogen stations. The adoption path of hydrogen vehicles will depend on how driver agents react to hydrogen fuel stations supplied by investor agents.

The model contains approximately 7 thousand drivers, each representing 1,000 vehicles in order to approximate 7 million vehicles in the model area. At the beginning of the simulation, nearly all driver agents own only conventional vehicles. In each simulation, drivers make trips, refueling as needed. Drivers replace some part of the vehicle fleet each period during a simulation, using the driver utility function to determine whether they would consider themselves better off with a new hydrogen vehicle or another non-hydrogen vehicle.

The driver agent utility function has seven terms:

1. Sticker price difference 
2. Fuel cost advantage

3. Disadvantage due to limited familiarity

4. Bandwagon effect

5. Greenness

6. Inconvenience

7. Worry

The sticker price difference is the price of a hydrogen vehicle minus the price of a comparable non-hydrogen vehicle. The fuel cost advantage is the present value of any fuel cost savings resulting from driving a hydrogen vehicle. The disadvantage due to limited familiarity results from a driver agent's hesitation to purchase a hydrogen vehicle due to a lack of knowledge about it. The bandwagon effect occurs when a potential buyer's beliefs about the performance of a new product are influenced by those who have already purchased the product. Greenness represents driver agent preferences, if any, toward hydrogen vehicles due to environmental considerations. Inconvenience may result from a limited availability of hydrogen refueling options. Worry may result from concern for running out of fuel because of limited availability of hydrogen refueling options.

When few hydrogen stations are available in early periods, inconvenience and worry figure noticeably in utility calculations. As a simulation proceeds, more fueling stations are sited and these concerns lessen. As drivers buy hydrogen vehicles, other drivers who are able to observe their performance become more comfortable with them in subsequent periods as the disadvantage due to unfamiliarity is reduced.

\section{INVESTOR AGENTS}

As discussed in Section 2.3, investor agents supply the hydrogen infrastructure necessary for refueling hydrogen vehicles purchased by the driver agents. Investor agents cannot foresee hydrogen fuel sales with certainty. Realistically investors must resort to simplifications and approximations. These are a central feature of the model in the present study, providing a contrast to many traditional economic theories that assume perfect foresight or depart from reality in modeling behavior toward the future in other ways. The simplifications and approximations take a variety of forms. They include back-of-the-envelope calculations and rules of thumb. An investor agent is subject to over- or under-optimistic biases. An investor learns from experience and may change in degree of optimism or pessimism from one period to the next. Decisions are influenced by broader corporate goals of upper management, such as near-term earnings performance that affects share values of the company regardless of the longterm promise of an investment. The terms satisficing and bounded rationality are sometimes used to describe these types of influences on decisions departing from the assumption of perfect maximization.

\section{HYDROGEN PRODUCTION TECHNOLOGIES}

Also discussed in Section 2.3, several potential hydrogen production technologies were evaluated during this study. The major technologies included in the model are distributed stream methane reforming and centralized stream methane reforming. Alternative technologies include 
electrolysis, coal gasification and biomass gasification. Steam methane reforming (SMR) consists of heating methane to $700^{\circ}-1,100^{\circ} \mathrm{C}$ which separates it into carbon monoxide and hydrogen.

Steam methane reforming is used in the model because our evaluation shows that it is the most likely hydrogen production technology for the model area centered on the Los Angeles metropolitan area. H2A models indicate that SMR is less expensive than either electrolysis or coal gasification. It is unlikely that sufficient volumes of biomass would be available to produce all the hydrogen needed in the latter years of the simulation via biomass gasification. Analysis in this study indicates that switching technologies midway through the simulation period, from biomass to SMR, would entail a higher cost than starting with SMR. Modeling the use of both biomass gasification and SMR is possible but is beyond the scope of the present study.

With distributed SMR production, small reforming units are located at each refueling site. With centralized SMR production, a large reformer serves many refueling sites by pipeline or truck delivery.

The investor faces a choice between building distributed SMR stations, and building centralized plants along with a pipeline infrastructure for delivery of fuel. To make the choice between the two technologies, the investor compares the levelized cost of producing hydrogen using the centralized technology with the levelized cost using distributed stations. Investor agents choose the method of production based on projected sales volume and the lowest-cost method for that volume. The investor charges a price for fuel that is equal to the average cost of producing hydrogen.

\section{STATION SITING}

As further discussed in Section 2.3, the model area is divided into 5,000 1x1-mile cells. The investor agent is restricted to siting stations in 156 cells located at major highway intersections and at the midpoints of highway segments. Each cell may have as many stations as the investor chooses to site there.

In the first year of the simulation, it is assumed there are only seed stations. Investor agents consider siting stations annually from the second year onward. The procedure used to make decisions regarding how many stations to site and at which locations uses a process to forecast the expected hydrogen fuel sales and profitability of all possible new station locations, ranks locations, and calculates the effect of siting a station. The procedure is repeated each year of the simulation for all possible new station locations.

\section{THE BENCHMARK SCENARIO}

As discussed in Section 3.1, the benchmark case represents a 40 year scenario where hydrogen vehicles and fuel become competitive with traditional vehicles. The benchmark case provides an example of a set of prices of vehicles and fuels for hydrogen and non-hydrogen vehicles that would result in cost competitiveness and allow the beginning of a take-off. It is to be emphasized that the model does not attempt to predict the exact year when the required 
competitiveness will be achieved. The benchmark scenario is presented as a baseline estimate using the parameters in the following table:

\section{Main Parameters Used in Benchmark Scenario}

\begin{tabular}{|c|c|}
\hline Parameter & Value \\
\hline \multicolumn{2}{|l|}{ Driver Agent Parameters } \\
\hline Disadvantage Due to Limited Familiarity ${ }^{\text {a,f }}$ & $\$ 12,000$ \\
\hline Bandwagon Effect Coefficient ${ }^{\mathrm{a}}$ & 0.1 \\
\hline Bandwagon Effect Dispersion ${ }^{a}$ & 2.2 \\
\hline Greenness Central Tendency ${ }^{\mathrm{b}, \mathrm{f}}$ & $\$ 250$ \\
\hline Greenness Dispersion $^{\mathrm{b}}$ & 10 \\
\hline \multicolumn{2}{|l|}{ Investor Agent Parameters } \\
\hline Fueling Station Capital Cost ${ }^{\mathrm{c}, \mathrm{f}}$ & $\$ 4,806,357$ \\
\hline Fueling Station Fixed O\&M Costs ${ }^{\mathrm{c}, \mathrm{f}}$ & $\$ 236,598$ \\
\hline Fueling Station Salvage Value $^{\mathrm{c}}$ & 0 \\
\hline Investor Discount Rate $^{\mathrm{d}}$ & $10 \%$ \\
\hline Hydrogen Selling Price ${ }^{\mathrm{e}, \mathrm{f}}$ & $\$ 3.63 / \mathrm{kg}$ \\
\hline Fueling Station Operating Capacity $^{\mathrm{c}}$ & $1,278 \mathrm{~kg} /$ day \\
\hline \multicolumn{2}{|c|}{$\begin{array}{l}\text { a For additional discussion see Section A.2.3 in Appendix A, "Disadvantage Due to Limited } \\
\text { Familiarity and Bandwagon Coefficient, } P_{j t}^{F} \text { and } \mathrm{q}_{\mathrm{j}} \text {." } \\
\text { b } \text { For additional discussion see Section A.2.4 in Appendix A, "Greenness, T,." } \\
\text { c } \text { Station nameplate capacity of 1,500 kg/day from DOE H2A model. } \\
\text { d } \text { DOE H2A model. } \\
\text { e } \\
\text { for additional discussion see Section B.1 in Appendix B, "Price Charged for Hydrogen Fuel." } \\
\text { f In } 2009 \text { dollars. }\end{array}$} \\
\hline
\end{tabular}

Using these baseline estimates, the figure below shows annual hydrogen vehicle sales as a percent of all light-duty vehicle sales over a forty year simulation period. Hydrogen vehicle sales under the benchmark scenario reach a market penetration of $86 \%$ after 40 years. 


\section{Benchmark Hydrogen Vehicle Sales Penetration over 40 Years}

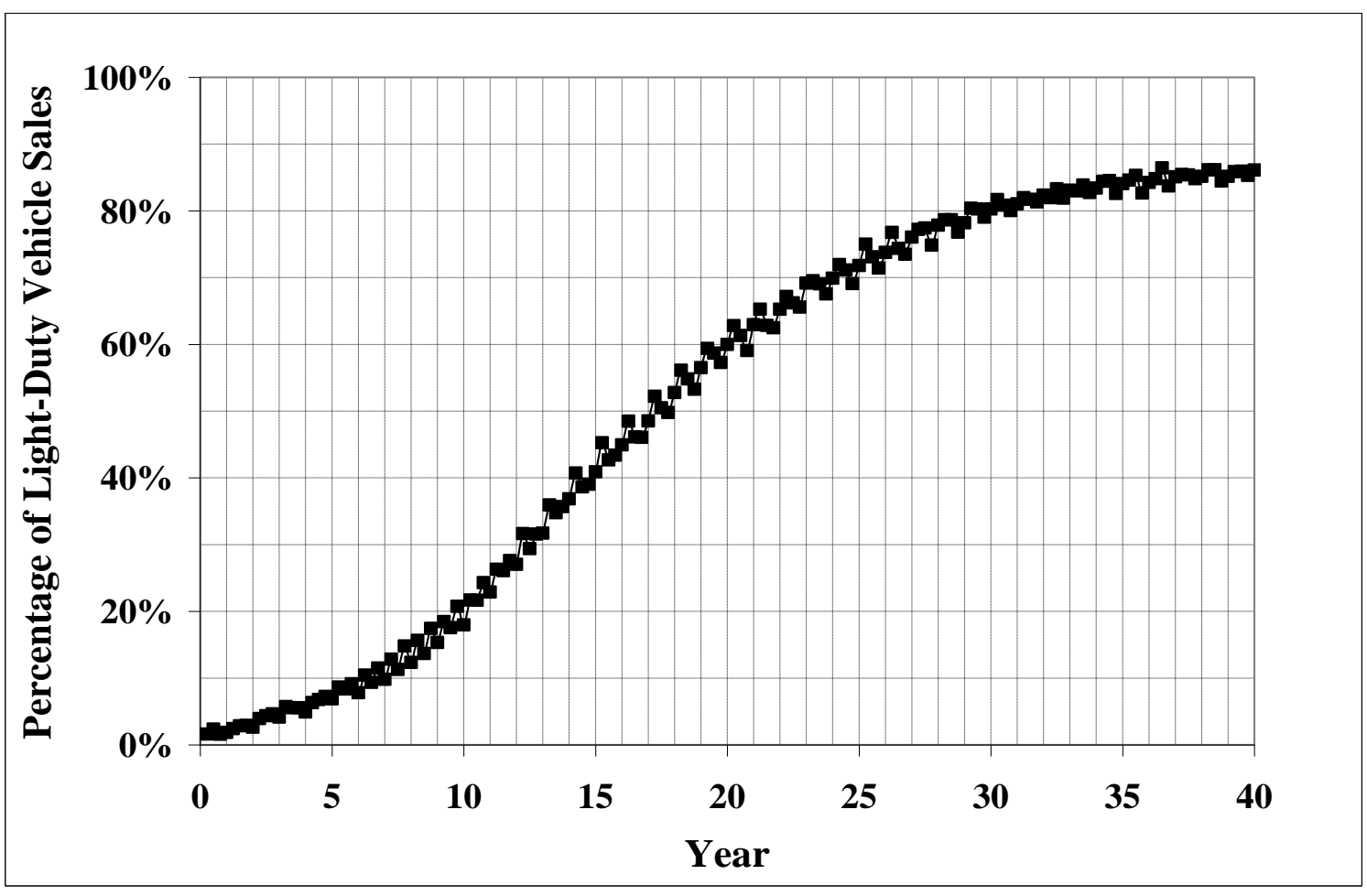

\section{SENSITIVITY TESTING FOR DRIVER BEHAVIOR PARAMETERS}

As discussed in Section 3.2, results of sensitivity analyses for the driver agents show that driver agent behavior can have a significant effect on the rate at which hydrogen vehicles are adopted. The strength of the disadvantage due to limited familiarity has a large initial influence acting to slow sales growth, which is overcome over time due importantly to the bandwagon effect or the impact of drivers who have already bought a hydrogen vehicle on drivers who have not bought one yet. The influence of greenness or driver willingness to pay a premium for an environmentally friendly vehicle is somewhat smaller but still significant.

\section{SENSITIVITY TESTING FOR INVESTOR BEHAVIOR PARAMETERS}

As discussed in Section 3.3, results of the sensitivity analyses for investor agents show that the upper management discount rate can have a large influence on the number of fuel stations built and consequently on hydrogen vehicle sales. The upper management discount rate reflects the attitudes of investors including degree of risk aversion, and the degree of optimism or pessimism about the viability of hydrogen vehicle expansion. In contrast, sensitivity of the model to the staff discount rate used in preparing investment evaluations submitted for consideration by upper management appears to be relatively small, because the staff uses a narrower range of textbook discount rates. Relatively limited effects are also found for sensitivity to the investor's rapidity of learning, method of predicting first year sales at new stations, and method of forming growth expectations. All the latter may have large effects for 
one year, particularly early in the simulation when investor experience is limited, but the unfolding of actual events corrects investor mistakes relatively rapidly. The number of investors has a limited effect because a single investor is already acting much like a pure competitor in view of the threat of entry of other investors and of regulation if monopolistic practices are observed.

\section{EFFECTS OF REALISTIC APPROXIMATIVE DECISIONS}

Section 3.4 asked: What is the effect of realistic, approximative decision making, sometimes called satisficing, in place of traditional, full optimization on the results? Obtaining a strict answer is not feasible because calculating the fully optimized path would be impossibly complicated. However, having perfect information about the growth rate of demand for hydrogen, and about fueling locations with the greatest potential for spurring hydrogen vehicle adoption, would eliminate important complications. An upper bound on these effects can be obtained by re-running the simulation assuming that hydrogen stations are found at every location. The lack of availability of hydrogen would then not be a hindrance to adoption.

The effect of the investor's lack of perfect knowledge about demand in delaying the provision of infrastructure would no longer be operative. Adoption of hydrogen vehicles would still not be instantaneous because drivers would still have to learn about the performance of hydrogen vehicles, which is the driver's contribution to delay in adoption, not the investor's. If we compare the hydrogen vehicle saturation level at a given year, say the $20^{\text {th }}$, in the re-run simulation with that in the original simulation, we obtain an estimate of the maximum possible delay that the investor's satisficing behavior has caused. The results of the comparison reveal that the maximum possible effect is a relatively modest 2 -year delay by the $20^{\text {th }}$ year.

\section{SENSITIVITY TESTING FOR POLICY AND MARKET INFLUENCES}

Part Four reports on sensitivity scenarios for policy and market influences. The market influences studied include changes to the sticker price of hydrogen vehicles, and changes to the price of gasoline. Additional market changes not foreseen at the present time will inevitably occur in the future. The model of this study can be useful beyond providing a prediction of future conditions as seen at the present time. Sensitivity of model results to differences in market conditions indicates how model results will be affected by different market conditions as they emerge in the future, increasing the value of the study as a tool for use beyond the year of the present study. The policy scenarios studied include tax credits for hydrogen vehicle purchase, loan assistance to investors, the effect of possible carbon taxes, and additional seed stations.

Market Developments: Sticker price differences (Section 4.1) have important effects on the adoption of hydrogen vehicles. A decline sticker price disadvantage beginning with a $\$ 14,000$ hydrogen vehicle price disadvantage that declines to $\$ 0$ by year 5 or 10 still allows sales penetrations over $50 \%$ by the $20^{\text {th }}$ year. A non-declining price disadvantage of $\$ 6,500$ precludes a hydrogen take-off. 
Market Developments: Fuel cost savings (Section 4.2) play an important role in the adoption of hydrogen vehicles. Sufficiently low savings will prevent take-off, while very high savings will hasten a take-off. The results are driven by the price of gasoline and suggest that future gasoline prices could be a crucial market consideration determining hydrogen vehicle penetration.

Policies: Permanent tax credits (Section 4.3.1) dramatically hasten sales penetration. Temporary tax credits (Section 4.3.2) that end after 10 years still result in higher sales than in the benchmark case with no tax credits, because so many more hydrogen vehicles are purchased earlier and, operating through the bandwagon and familiarity effects, continue to affect vehicle choice after the expiration of the tax credits.

Policies: Carbon taxes (Section 4.4) have limited effects. An additional 15 stations available at the beginning of the simulation has a perceptible, though not major, but alternative locations of the seed stations have little impact on sales penetration.

\section{MODEL VALIDATION}

As discussed in Part Five, research was conducted on adoption of other durable goods innovations to see if the adoption path predicted for hydrogen vehicles in this study is similar to those for other innovations. A comparative study was conducted on the adoption paths of consumer durables products as a whole. Adoption experiences and lessons learned were gathered for specific vehicle innovations including CNG vehicles, penetration of Japanese vehicles in the U.S. market, and hybrid vehicles.

Overall, we judge the validation tests to be favorable to the Agent-based model of this study. The adoption paths for hydrogen vehicles in the simulations of this study have been found to have a typical S-shaped adoption curve similar to the empirical adoption paths calculated for other consumer durables. The S-curve for hydrogen vehicles exhibits a slower rate of adoption than for the average of all consumer durables. This is to be expected because automobiles including hydrogen vehicles have a much longer life and are thus subject to slower turnover than other durable goods. A lesson from the three vehicle case studies (CNG vehicles, Japanese vehicles, and hybrids) is that gain to the consumer from an innovation and, in the case of Japanese imports, government policy can have a powerful influence on the rate of adoption.

\section{BOTTOM LINE ISSUE OF THIS STUDY: ADEQUACY OF PRIVATE SECTOR INFRASTRUCTURE SUPPLY}

In addition to summarizing the study, Part Six takes stock of the implications of the study for the key question (Section 6.9): Will the private sector supply the necessary infrastructure to permit a transition to a hydrogen transportation economy? This study indicates that the private sector transition will provide the necessary infrastructure, provided prerequisite technological and market conditions are met. The effect of technological and market conditions takes on added importance because the model of this study indicates that a transition to hydrogen transportation in the relatively favorable benchmark case will require a number of years. 
This seemingly favorable answer however leads to two follow-up questions. First, is the rate of adoption rapid enough to satisfy the national goal of extricating from dependence on foreign oil? The rapidity of transition depends on how favorable the pre-requisite conditions are. If the price of gasoline is higher than it has been historically or there is a near-term favorable technological breakthrough greatly reducing the cost of producing hydrogen vehicles, drivers will have substantial incentives to switch to hydrogen vehicles, acting to speed the adoption process. On the other hand, if conditions are just barely favorable, the result may not be very different in terms of policy from no take-off at all. Adoption may proceed so slowly that it is deemed unsatisfactory from the point of view of reducing foreign dependence.

The results lead to a second follow-up question: If the transition to hydrogen is not deemed satisfactory, what policies are available to speed it up? Tax credits, a carbon tax and government assistance with seed stations have been used to illustrate the effects of policies aimed at speeding up the transition. Government assistance policies in the form of tax credits for the purchase of hydrogen vehicles have been found to be quite potent. A temporary tax credit, extending for the first 10 years of the transition, would provide a very significant boost. The early period of high hydrogen shares of sales with the temporary credits will increase the stock of hydrogen vehicles earlier in the transition. Carbon taxes and government assistance in building seed stations have less effect.

\section{FUTURE WORK}

As discussed in Section 6.10, this study has applied an agent-based approach to modeling hydrogen infrastructure supply, using real world decision processes that do not assume unrealistic optimization. Given the resource limitations of the study, help was given by our industry cooperators in choosing which of the many facets of decision-making to concentrate on. A large number of possibilities exist for studying other approximative decisions that drivers and investors may be concerned with beyond those considered here.

Our results have been presented in such a way that they can be adapted to future conditions. While reliably predicting events and policy concerns 10 or 15 years in the future is at best difficult, the model of this study provides a way to analyze effects of a wide range of future possibilities. It is a tool to aid in evaluation of policies that will arise in the future and that can be adapted to changing conditions in the future. 


\section{PART ONE：INTRODUCTION}

\subsection{Purpose of the Present Project}

This study is the final report of the project, Analysis of the Hydrogen Production and Delivery Infrastructure as a Complex Adaptive System, conducted for the Hydrogen, Fuel Cells and Infrastructure Technologies Program of the Office of Energy Efficiency and Renewable Energy of the U.S. Department of Energy. The project represents a team effort with major contributions by RCF Economic \& Financial Consulting, Inc. and Argonne National Laboratory. In addition, significant cooperation came from Ford Motor Company, BP, Protium Energy Technologies, and John E. Johnston, formerly Planning Executive for ExxonMobil's Corporate Strategic Research Laboratories.

The purpose of the project is to analyze market and policy influences on the construction of infrastructure necessary to support a hydrogen transportation system. The central concern of the study is:

Whether the private sector will supply the infrastructure to permit a transition to hydrogen consistent with national goals and, if not, what policy actions would be effective.

\subsection{Approach of this Project}

The methodology used in the project is Agent-based Modeling (ABM), which models the interactions of individualized actors in an economic system. Agent-based modeling permits the introduction of great variety in the analysis of interactions among the many different actors in an economic system. It allows for realistic approximative decisions that depart from perfect optimization approaches often used that assume the agent has complete knowledge and can costlessly predict complex outcomes. The actors in the system - the agents - have varying degrees of knowledge, which is generally imperfect. The agents can learn from their mistakes. The model projects events forward in time. For hydrogen vehicles, the model permits projections of the degree of saturation that will be reached each period, as well as the ultimate market saturation and the length of time required to achieve said saturation.

The two types of agents in the model are vehicle drivers and investors who supply infrastructure. Vehicle drivers take several considerations into account when deciding whether to buy a hydrogen vehicle. Among these are the number and location of stations where hydrogen fuel is available, the sticker price difference between hydrogen and non-hydrogen vehicles, the difference in fuel costs, beliefs about how well a hydrogen vehicle operates, and preference for greenness. Driver agents differ because of spatial differences in their trips as well as differences in other characteristics, all of which occur in a spatial context. If a driver agent identifies positive net utility from buying a hydrogen vehicle then that agent adopts hydrogen, switching from a non-hydrogen vehicle to a hydrogen vehicle. 
The driver agents' purchases of hydrogen fuel result from buying hydrogen vehicles and are observed by investor agents. The investor agents compare actual sales of hydrogen with what they expected and revise their fuel station expansion plans up or down, depending on whether the outcome was more or less favorable than expected. Based on this information, the number and location of stations to build in the next period is decided. This process is repeated each time period. More hydrogen fuel stations appear each period, reinforcing the demand for hydrogen vehicles. However, growth of station availability could stagnate, depending on the choices of the driver agents. The modeling approach of this study models this process, leading to projections of the time path of growth of the hydrogen vehicle economy.

The geographical focus of the study is Los Angeles, viewed as an area likely to feature early adoption of hydrogen vehicles. The empirical platform is based on Los Angeles' geography and driver behavior.

\subsection{Relation of this Project to Other Applied Agent-based Modeling Work}

\subsubsection{Range of Applications}

Although a rarity as late as 1970, ABM has become a common tool and today encompasses a wide variety of applications in ecology, business, economics, manufacturing, social sciences, financial markets, energy markets, pedestrian and vehicular traffic patterns, military command and control systems, and marketing. This study itself builds on work begun at Ford Motor Company.

\subsubsection{Institutes Devoted to Agent-based Modeling Applications}

The Santa Fe Institute, founded in 1984, is an independent research institution which has pioneered the study of complex adaptive systems. It has spun off or inspired other institutes around the world, including the Center for the Study of Complex Systems at the University of Michigan and the Computational Science and Engineering group at the University of California at Davis. While its focus has been on scientific applications, a commercial spin-off, the Santa Fe Institute Business Network, was established in 1992 to promote applications in the business world.

Other institutions engaged in agent-based modeling include:

- Arizona State University: Center for Social Dynamics \& Complexity (CSDC). Focus is on social dynamics of innovation and evolution, cohesion, cooperation and conflict, socioecology, and social allometry.

- Arizona State University: Center for the Study of Institutional Diversity (CSID). Mission is to help decision-makers better understand how different types of institutions perform within different social-ecological systems. 
- Brookings Institution: Center on Social and Economic Dynamics. Applies the study of complexity to public policy, mainly through computation modeling and simulation. Its director, Senior Fellow Joshua Epstein is one of the early leaders in the field.

- Carnegie Mellon University: Center for Computational Analysis of Social and Organizational Systems (CASOS).

- George Mason University: Social Complexity Center. A key project is MASON (Multi-Agent Simulator of Networks and Neighborhoods).

- Max Planck Institute: International Max Planck Research School on Earth System Modeling (IMPRS-ESM). Among other activities, models hydrogen infrastructure.

- Northwestern University: Center for Connected Learning and Computer-Based Modeling. Develops computer-based modeling and simulation packages, such as NetLogo.

- University of Maryland: Center for Complexity in Business. Applies complex systems research to business problems.

- University of Michigan: Center for the Study of Complex Systems. Focus on the general area of nonlinear, dynamic, and adaptive systems. The Center co-hosts an annual UM-Santa Fe Institute Workshop.

- University of Valladolid: Social Systems Engineering Center (INSISOC). Uses $\mathrm{ABM}$ to model complex social systems in the areas of market institutions, financial markets, experimental economics, etc.

- University of Illinois Champagne-Urbana: Center for Complex Systems Research.

\subsubsection{Industry Applications}

\subsubsection{Argonne's Electricity Model}

Energy systems have been increasingly privatized and deregulated, shifting control from a single decision maker (i.e., a local regulated utility) to an open market with many participants. In this new configuration many decision makers, each with a different set of objectives, base their decisions on a number of methods. Conventional simulation techniques used for energy systems analysis are based on a single decision maker seeking to maximize (or minimize) a particular objective. Conventional equilibrium analyses techniques assume that systems gravitate to an equilibrium point where all participants reach a common ground. Neither of these techniques can capture transitory fluctuations driven by system evolution nor identify inflection 
points, phase transitions, or critical conditions under which systems diverge from the past in totally new and unanticipated ways.

To address these issues, Argonne's Center for Energy, Environmental, \& Economic Systems Analysis (CEEESA) developed the Electricity Market Complex Adaptive System (EMCAS) model, in which the diverse participants in the electricity market are represented as agents. All agents can have their own sets of objectives, decision-making rules, and behavioral patterns. Further, agents can draw on an array of historical information (e.g., past power prices) and projected data to support their unique decision processes. Unlike conventional electric system models, the EMCAS agent-based modeling techniques do not postulate a single decision maker with a single objective for the entire system. Rather, agents follow individual objectives and apply individual decision rules.

In its first application, CEEESA staff members used EMCAS to simulate the Illinois and Midwest power markets. This work was performed for the Illinois Commerce Commission, which sought advice on whether the existing transmission system could support a competitive market. At the beginning of 2005, the software became commercially available, and current clients include consulting companies, research institutes, power companies, transmission companies, and regulatory offices in South Korea, Portugal, Croatia, and France. Argonne is currently adapting the tool for the U.S. Department of Energy to study nuclear power prospects in various countries as well as energy-water related issues in the western United States.

\subsubsection{Others}

Procter \& Gamble's (P\&G) virtual laboratory is an innovative computational agent-based model of consumer markets. This capability represents a milestone at the forefront of agentbased consumer market modeling technology in terms of its detail, breadth of coverage, and the large number of agents considered. Some of these advances have resulted in a joint patent application by Argonne National Laboratory and P\&G. ${ }^{1}$ The capability was developed by Argonne, in conjunction with $\mathrm{P} \& \mathrm{G}$, using the Repast ABM toolkit. Argonne and P\&G successfully calibrated, verified, and validated the resulting model using several independent, real world data sets for multiple consumer product categories with over sixty comparison tests per data set. $\mathrm{P} \& \mathrm{G}$ has successfully applied the capability to several challenging business problems where it has directly influenced managerial decision making and produced substantial cost savings.

\subsection{Outline of Report}

The remainder of this report describes the hydrogen transition model that has been developed. A description of the sections in this report is provided below.

\footnotetext{
${ }^{1}$ J. I. Hahn and M. J. North, "Methods of Creating and Using a Virtual Consumer Packaged Goods Marketplace," U.S. Patent Application 11/973053, published April 10, 2008.
} 
Part Two describes the model. Section 2.1 provides an overview of the driver and investor modules and their interactions. Section 2.2 presents the utility function that determines whether a driver agent purchases a hydrogen vehicle. It also explains how the driver agent chooses the hydrogen station at which to re-fuel. Section 2.3 describes the hydrogen production methods available to the investor, which consist of either distributed steam methane reforming (SMR) at each fueling station or centralized production with large-scale SMR using pipeline or truck delivery to dispensing stations. It then describes how investor agents decide on the number of stations to build and where to locate them. Finally, it describes how investor agents evaluate profitability and how corporate staff and corporate upper management behavior are modeled.

Part Three first presents the results of the benchmark case against which other scenarios are compared, and reports on sensitivity of the results to changes of a number of key parameters. In Section 3.1, the parameter values of the benchmark case are presented, along with benchmark results for penetration over time of hydrogen vehicle sales, the cumulative stock of hydrogen vehicles, and station penetration. Section 3.2 reports on the sensitivity of the results to values of major driver agent parameters including the disadvantage due to unfamiliarity with hydrogen vehicles, the bandwagon effect, and preference for greenness. Section 3.3 reports on the sensitivity to major investor agent parameters, including discount rates as affected by differences between corporate upper and lower management, the rapidity of learning, expectations of growth, and the method of estimating first-year demand at potential new station locations.

Part Four reports on sensitivity of results to market influences and various policies. Section 4.1 reports results on the sticker price difference between hydrogen and non-hydrogen vehicles, Section 4.2 on tax credits, Section 4.3 on the difference between hydrogen and nonhydrogen fueling costs, Section 4.4 on carbon taxes, and Section 4.5 on seed stations. Section 4.6 reports the maximum possible effect that the investor agent's approximative behavior rather than full optimization could have on the speed of hydrogen vehicle adoption.

Part Five is concerned with validating the model developed in this study through comparison with other innovations. Section 5.1 compares the adoption path of hydrogen vehicles generated by the individual behavior of the over 7,000 driver agents of the model to the adoption path of a typical consumer durable estimated from market data. Section 5.2 compares the results of the hydrogen model with three other recent vehicle innovations - the compressed natural gas vehicle, Japanese vehicles in the United States, and recent hybrids. Section 5.3 draws overall conclusions from the validation analyses.

Part Six presents a summary of the study and conclusions.

Appendix A contains technical details on the driver module. Appendix B contains technical details on the investor module. Appendix $C$ presents an analysis of sources of future declines in the cost of producing hydrogen vehicles. 


\section{PART TWO: THE MODEL}

The study uses an agent-based model that simulates the interactions of drivers of hydrogen vehicles and investors in hydrogen fueling infrastructure. The purpose of the model is not to provide a single forecast but to provide a tool for assessing the potential impact of a variety of agent-based behavioral characteristics and policy scenarios on the growth of hydrogen vehicle sales and infrastructure. The Agent-based Modeling (ABM) system developed for the study contains 130 parameters which consist of 92 cost parameters from DOE's H2A model ${ }^{2}, 17$ driver behavior parameters, 10 investor behavior parameters, and 11 price and policy variables. The model was developed jointly between RCF Economic \& Financial Consulting, Inc. and Argonne National Laboratory.

Section 2.1 provides an overview of the model, including an introduction to the model agents, a description of the geographic model area, and a discussion of the model simulation method. Section 2.2 gives details regarding the driver agents, including a description of the driver agent population, a description of the components of the driver utility function, and a discussion of driver agent refueling. Section 2.3 provides details regarding investor agents, including a discussion of hydrogen fuel production technologies, the hydrogen fuel station siting process, a description of the investor agent's financial evaluation procedures, and the number of investors.

\subsection{Overview of Model}

This section provides an overview of the main components of the model. The agents used in the model are introduced in section 2.1.1. The geographic area and household densities included in the model area are described in Section 2.1.2. A description of the decision steps involved in the model is presented in Section 2.1.3.

\subsubsection{Introduction of Players}

The model contains two types of agents, driver agents and investor agents.

Driver agents are vehicle drivers living and working in the model area. They live and work in different locations, and make trips throughout the model area over the duration of a simulation. Drivers differ in their proclivities to buy hydrogen vehicles and in their proximity to hydrogen stations. The adoption path of hydrogen vehicles will depend on how driver agents react to hydrogen fuel stations supplied by investor agents.

\footnotetext{
${ }^{2}$ U.S. Department of Energy, "Future (2025) Natural Gas Steam Reformer (SMR) at Forecourt 1500 kg/day," Department of Energy Hydrogen Program, May 27, 2008. http://www.hydrogen.energy.gov/h2a_prod_studies.html (accessed February 17, 2009). All cost figures in the present report have been updated to 2009 dollars.
} 
Investor agents supply the hydrogen infrastructure necessary for refueling hydrogen vehicles purchased by the driver agents. Investor agents cannot foresee hydrogen fuel sales with certainty. Realistically, investors must resort to simplifications and approximations. These are a central feature of the model in the present study, providing a contrast to many traditional economic theories that assume perfect foresight and an unrealistically great ability to compute solutions. The simplifications and approximations take a variety of forms. They include backof-the-envelope calculations and rules of thumb. An investor agent is subject to over- or underoptimistic biases. An investor learns from experience and may change in degree of optimism or pessimism from one period to the next. Decisions are influenced by broader corporate goals of upper management, such as near-term earnings performance that affects share values of the company regardless of the long-term promise of an investment. The terms "satisficing" and "bounded rationality" are sometimes used to describe these types of influences on decisions departing from the assumption of perfect maximization. ${ }^{3}$

\subsubsection{Description of Model Area}

The model area is a 100-by-50-mile rectangular area centered on the Los Angeles metropolitan area. The region is divided into 5,000 square cells. Expressway and highway routes used in the model, chosen on the basis of traffic volumes and population densities, are shown in green in Figure 2-1.

Figure 2-1: Model Grid Structure for Los Angeles Metropolitan Area

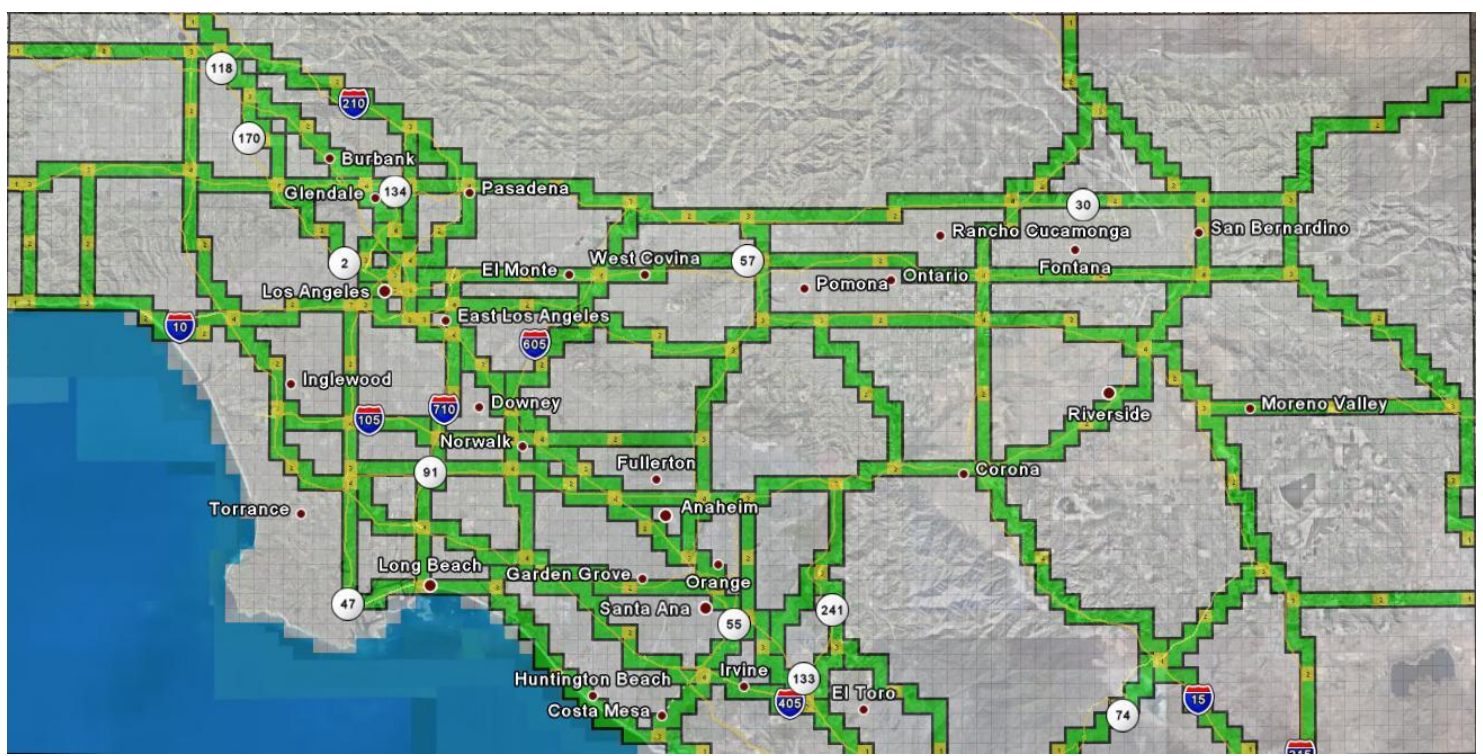

Source: Developed by RCF and Argonne National Laboratory

\footnotetext{
${ }^{3}$ Herbert Simon, “A Behavioral Model of Rational Choice,” Quarterly Journal of Economics, 69 (1955): 99-118; Thomas C. Schelling, Micromotives and Macrobehavior (New York: Norton, 1978); more recently, H. Levy, M. Levy, and S. Solomon Microscopic Simulations of Financial Markets (New York: Academic Press, 2000); Sendhil Mullainathan, "A Memory-Based Model of Bounded Rationality," Quarterly Journal of Economics 117 (Aug., 2002): 735-774; Daniel Kahneman, "Maps of Bounded Rationality: Psychology for Behavioral Economics," American Economic Review 93 (2003): 1449-1475; Ernst Fehr and Jean-Robert Tyran, "Limited Rationality and Strategic Interaction: The Impact of the Strategic Environment on Nominal Inertia," Econometrica 76 (2008): 353-394.
} 
Geographic variation in household density within the model area is shown in Figure 2-2.

Figure 2-2: Households per Square Mile

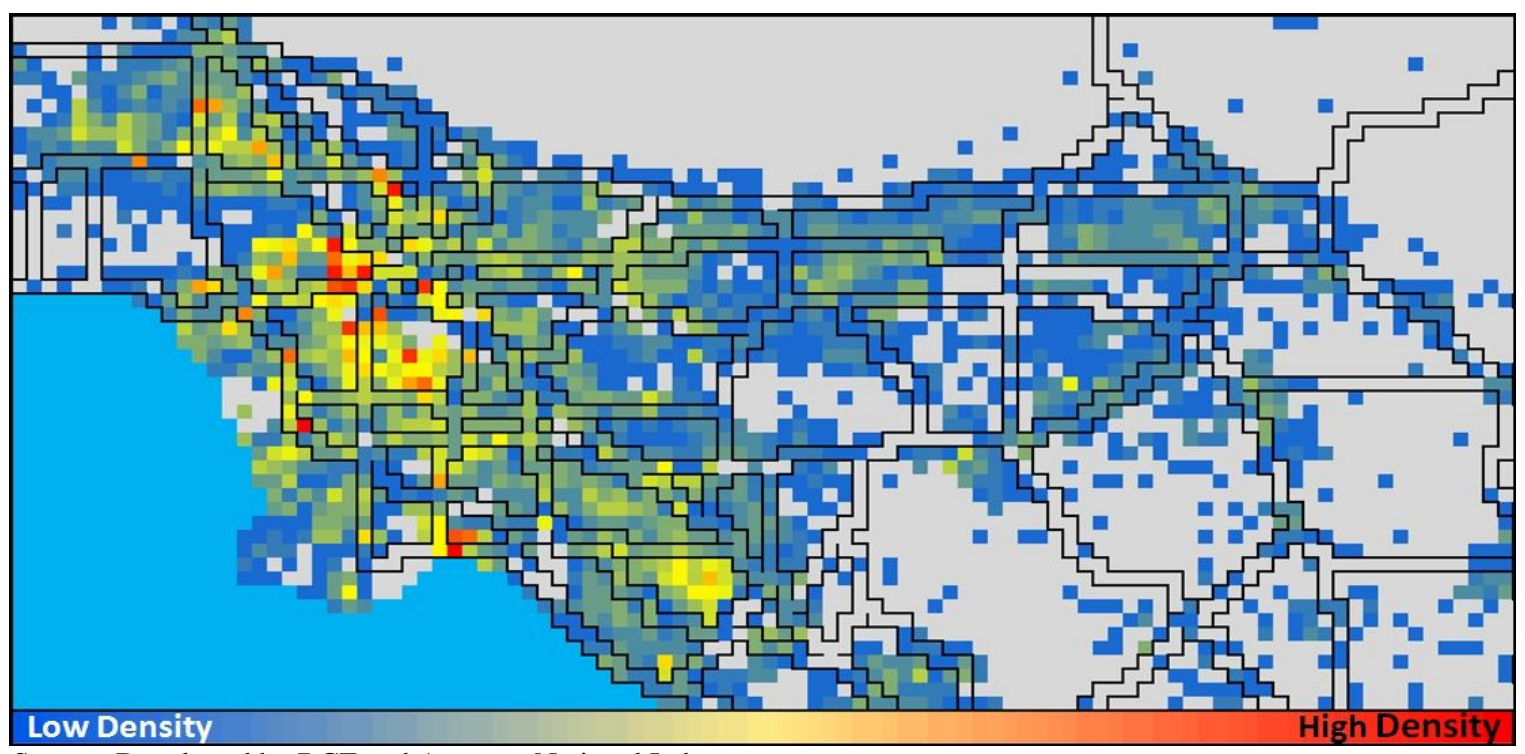

Source: Developed by RCF and Argonne National Laboratory

\subsubsection{Model Simulation Steps}

Figure 2-3 provides an overview of the decision steps in the model. Investors decide whether or not to build hydrogen fueling stations at the beginning of each year. Driver agents make decisions regarding whether or not to purchase hydrogen vehicles each quarter within each year. At the beginning of a simulation run, driver agents own only non-hydrogen vehicles. Driver agents observe the few hydrogen fueling stations which are sited as seed stations as part of the model. Driver agents then decide whether to replace their non-hydrogen vehicles with hydrogen-powered vehicles depending on their individual differences and on the location of stations where they can buy hydrogen fuel. Those hydrogen vehicles are then fueled throughout the simulation year. Investor agents observe the fueling behavior of driver agents, revise their expectations regarding the strength of demand based on the sales they observe, and then decide where and how many new fuel stations to build in the next simulation year. Driver agents then view the stations that have been added and once again make decisions about purchasing hydrogen vehicles. The process repeats for each year of the simulation. 
Figure 2-3: Simulation Steps in the Agent-based Model

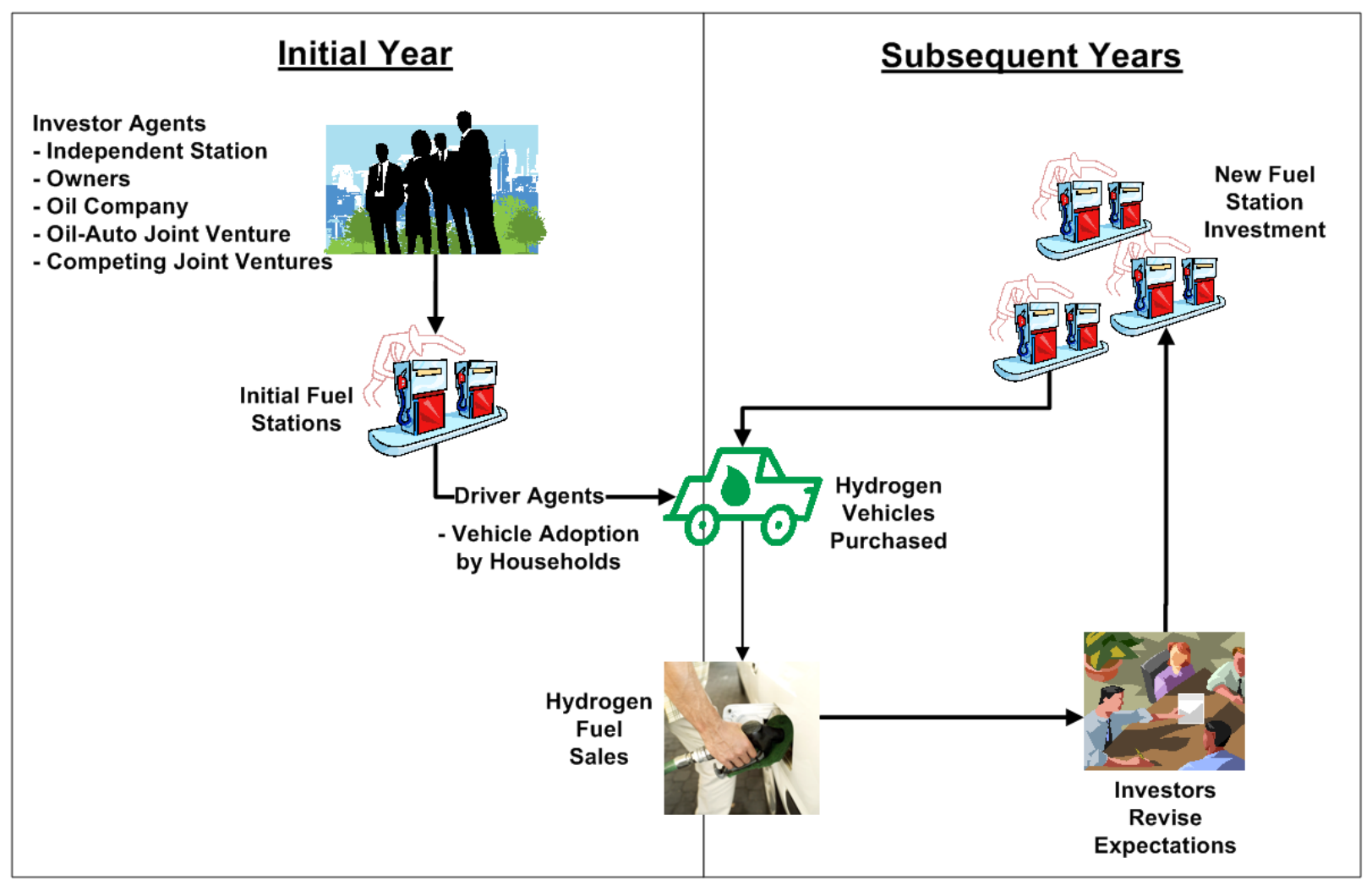

\subsection{Driver Agents}

\subsubsection{Driver Population}

Driver agents simulate the behavior of drivers in the model area, which is centered on the Los Angeles metropolitan area. The model contains approximately 7 thousand drivers, each representing 1,000 vehicles in order to approximate 7 million vehicles in the model area. Each driver agent travels on commuting and non-commuting routes determined by where the agent lives and works. Whether to purchase a hydrogen vehicle is influenced by the location of hydrogen stations in relation to these routes. Driver agents differ from one another by income (high, middle or low), travel behavior (routes and number of miles driven), taste for greenness, and susceptibility to being influenced by other drivers' decisions to buy hydrogen vehicles (bandwagon effect). High-income, middle-income, and low-income driver agents have been assigned to residential and employment locations based on demographic data for the Los Angeles area. For further details on the driver population, see Section A.1 of Appendix A, "Driver Agent Fleet Composition."

Driver agents make two types of decisions. First, when the time arrives to replace an existing vehicle, they must decide whether to purchase another non-hydrogen vehicle or to purchase a hydrogen vehicle, as discussed in Section 2.2.2. Second, they make repeated 
refueling decisions, which depend on where they live, where they work, and the choice of routes between those sites, as discussed in Section 2.2.3.

\subsubsection{Vehicle Purchasing and the Driver Utility Function}

When the pre-determined quarter arrives that the driver's vehicle is of an age to be replaced, the driver agent decides whether to purchase a hydrogen vehicle based on the driver agent's utility function, which specifies the excess of the utility provided by a hydrogen vehicle over a non-hydrogen vehicle. If the utility gained from purchasing a hydrogen vehicle is greater than the utility gained from purchasing a non-hydrogen vehicle, then the driver agent decides to purchase a hydrogen vehicle. The driver utility function contains seven driver behavior parameters, as described in the following sections. The driver agent utility function is presented in mathematical form in Section A.2 of Appendix A, "Driver Utility Function."

\subsubsection{Sticker Price Difference}

The sticker price difference is the cost of a hydrogen vehicle minus that of a comparable non-hydrogen vehicle taking into account any tax credits available for the purchase of hydrogen vehicles. For additional information see Appendix A, Section A.2.1, "Sticker Price Difference."

\subsubsection{Fuel Cost Advantage}

The fuel cost advantage is the present value of any savings in fuel costs from driving a hydrogen vehicle instead of a non-hydrogen vehicle. The fuel cost advantage depends on the prices of hydrogen and non-hydrogen fuel, fuel efficiencies of the two types of vehicles, and miles driven by the driver agents. For additional information see Appendix A, Section A.2.2, "Fuel Cost Advantage."

\subsubsection{Disadvantage Due to Limited Familiarity}

Driver familiarity is modeled using the disadvantage due to limited familiarity parameter which reflects a driver agent's hesitation to purchase a hydrogen vehicle due to a lack of knowledge about it. How will the vehicle handle? What kind of fuel mileage does it really get? Is it safe? Can good service be found for it? The disadvantage due to limited familiarity is the amount of money that the average buyer would need to be paid to buy a hydrogen vehicle, given no knowledge about it. In the beginning of a simulation, hydrogen vehicles suffer a large, initial disadvantage because driver agents are unfamiliar with them. At the outset, because the disadvantage due to limited familiarity is significant, only driver agents for whom other considerations are equally or more positive will purchase hydrogen vehicles. As time goes on drivers learn about the hydrogen vehicles, based importantly on observing others using it. This increases their confidence in the new vehicle. As the simulation continues, the familiarity disadvantage for hydrogen vehicles declines from its initial magnitude until it reaches zero, at 
which point a driver is as familiar with a hydrogen vehicle as with a non-hydrogen vehicle. The rate at which familiarity changes is a result of the bandwagon effect, as described below. For additional information see Appendix A, Section A.2.3, "Disadvantage Due to Limited Familiarity and Bandwagon Coefficient."

\subsubsection{Bandwagon Effect}

The bandwagon effect occurs when a potential buyer's beliefs about the performance of a new product are influenced by those who have already purchased the product. This effect has been widely observed in the adoption of new consumer durables. In the model, the extent to which a driver agent is influenced by other driver agent's adoption behavior is characterized by the bandwagon effect coefficient. Drivers with higher bandwagon coefficients are more inclined to imitate others. For additional information see Appendix A, Section A.2.3, "Disadvantage Due to Limited Familiarity and Bandwagon Coefficient."

\subsubsection{Greenness}

The greenness parameter represents the additional amount of money a buyer is willing to pay to have an environmentally friendly vehicle. Each driver agent has an individual level of preference for greenness. Most people prefer a greener product at least slightly, while some people are willing to pay significantly more for it. For additional information see Appendix A, Section A.2.4, "Greenness."

\subsubsection{Inconvenience}

Inconvenience represents the effect of the scarcity of hydrogen fuel on the decisions made by driver agents regarding whether or not to purchase hydrogen vehicles. In the early stages, drivers of hydrogen vehicles need to plan ahead to insure that they can reach a hydrogen fuel station when they need to refuel. In the model, drivers determine (a) whether it is possible to make a desired trip in a hydrogen vehicle (i.e. if the trip would take them to a location where it is not possible to find any hydrogen fuel), (b) whether a special side trip to purchase hydrogen will be needed to avoid running out of fuel, and (c), in the case where the trip can be taken, which hydrogen fuel stations will be used for refueling. Driver agents assign a dollar value to not being able to make a trip and an additional dollar value proportional to the length of a foregone trip. For additional information see Appendix A, Section A.2.5, "Inconvenience."

\subsubsection{Worry}

In addition to inconvenience, a driver can suffer worry associated with hydrogen refueling. Worry occurs when the fuel level drops below the optimal-to-refuel point and the driver is not sure of the location of the next fueling station. For example, if the want-to-buy point is when the tank is $20 \%$ full and the desperate-to-buy point is when it is $5 \%$ full, then 
refueling after depleting more than $80 \%$ of the tank causes worry. For additional information see Appendix A, Section A.2.6, "Worry."

\subsubsection{Vehicle Refueling}

Refueling behavior influences the driver utility function by increasing or decreasing the inconvenience and worry parameters of the driver utility function. Calculating worry and inconvenience requires knowing where agents travel (travel behavior), and how they prefer to refuel (refueling behavior). The driver agent's trip route is important in determining refueling behavior, as described in Figure 2-4. The figure indicates how refueling prospects differ between work and non-work trips, and illustrates the evaluation of refueling in each quarter.

Driver agents evaluate when and where to refuel based on three potential fueling conditions: willing-to-refuel level; want-to-refuel level; and desperate-to-refuel level. Whenever driver agents stop to refuel, they top off their fuel tanks so that the fuel purchased is equal to the maximum tank capacity minus current fuel level. The outcome of the refueling decision process will influence whether driver agents decide to purchase hydrogen vehicles, and will also affect hydrogen fuel sales. The outcome may change from period to period as more hydrogen fueling stations are sited during a simulation. For an in depth description of driver agent trip routes and the refueling decision process, see Section A.3 of Appendix A, "Refueling." 
Figure 2-4: Trip Route and Refueling

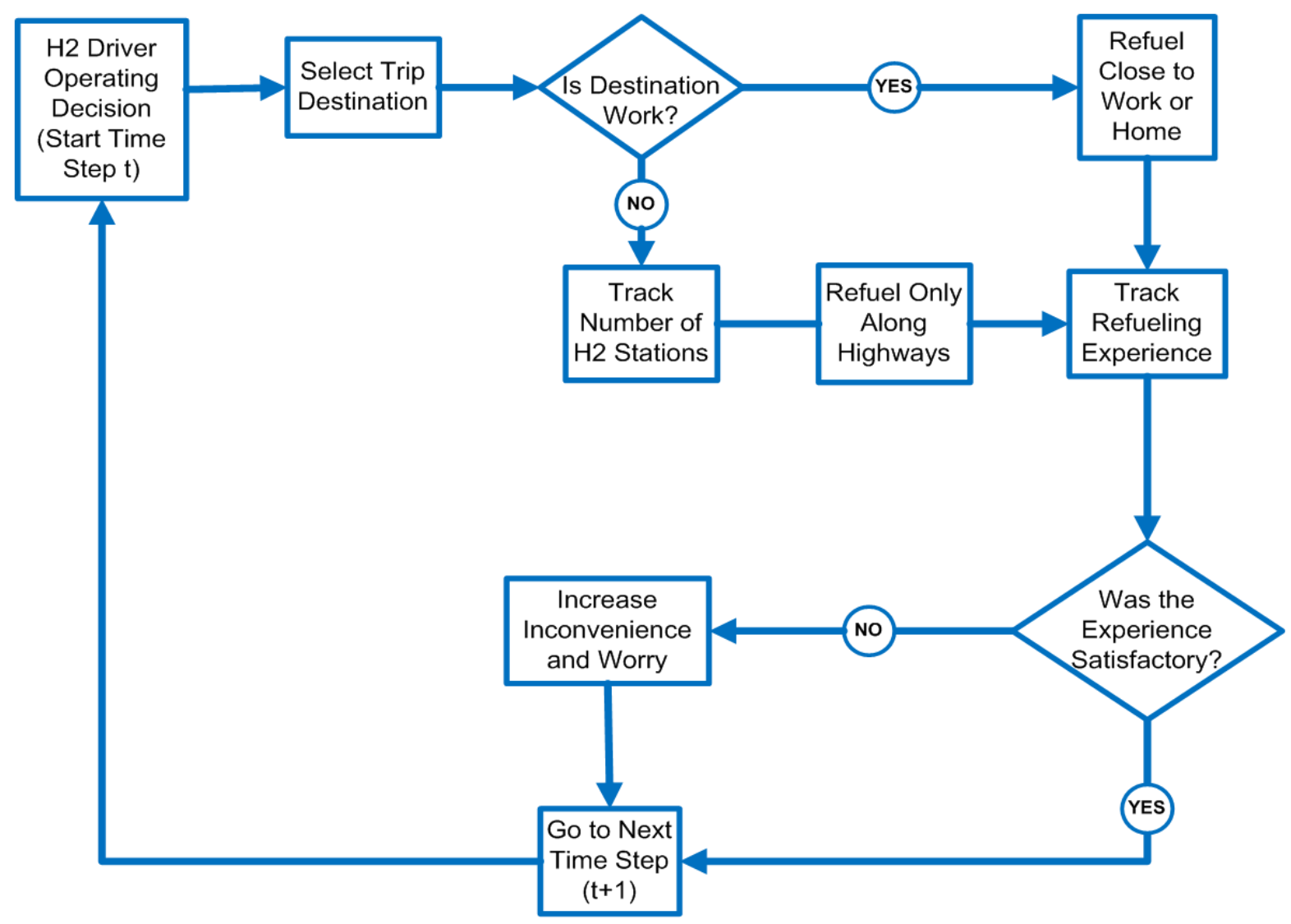

\subsection{Investor Agents}

Investor agents supply the hydrogen infrastructure necessary for refueling hydrogen vehicles. The investor agent must decide whether to invest in hydrogen fueling infrastructure and, if so, whether to engage in distributed or centralized production. The investor uses a net present value approach. The plan must undergo review and be approved by the firm's upper management. The decision for investor agents to invest in hydrogen infrastructure is complex. Investor agents cannot foresee hydrogen fuel sales with certainty. Realistically investors must resort to simplifications and approximations. Here, an overview of the investor agent's behavior is given. For additional information see Appendix B, "Investor Module."

Section 2.3.1 deals with the investor's choice of hydrogen fuel production technology. 2.3.2 Section 2.3.2 describes the relation between hydrogen production technology and the price charged for hydrogen fuel. Section 2.3.3 describes the hydrogen fuel station siting process. Section 2.3.4 describes corporate level financial evaluation. Section 2.3.5 discusses the number of investors. 


\subsubsection{Hydrogen Fuel Production Technologies}

The major hydrogen production technologies considered in this study are distributed and centralized stream methane reforming. Steam methane reforming is used because it appears to be the most likely hydrogen production technology for the model area centered on the Los Angeles metropolitan area. H2A models indicate that SMR is less expensive than either electrolysis or coal gasification. It is unlikely that sufficient volumes of biomass would be available to produce all the hydrogen needed in the latter years of the simulation via biomass gasification. ${ }^{4}$

Steam methane reforming (SMR) consists of heating methane to $700^{\circ}-1,100^{\circ} \mathrm{C}$ which separates it into carbon monoxide and hydrogen. ${ }^{5}$ With distributed SMR production, small reforming units are located at each refueling site. With centralized SMR production, a large reformer serves many refueling sites by pipeline or truck delivery.

The investor faces a choice between building distributed SMR stations, and building centralized plants along with a pipeline infrastructure for delivery of fuel. To make the choice between the two technologies, the investor compares the levelized cost of producing hydrogen using the centralized technology with the levelized cost using distributed stations. The shift to centralized technology, once made, is never undone.

\subsubsection{Distributed Production}

Distributed production is characterized by location of production and dispensing infrastructure at the same site. Distributed steam methane reformers (SMR) use natural gas to produce hydrogen fuel with limited storage on-site. While there are a number of possible sizes of distributed reformers, analysis with DOE's H2A cost model suggests that a 1,500-kg/day reformer with an effective capacity of $85.2 \%$ is the most cost-effective of the sizes in the array of available sizes. The full capital cost of a 1,500-kg/day SMR facility is $\$ 4.8$ million in 2009

\footnotetext{
${ }^{4}$ Examination of the land in a 50-mile radius around the city of Los Angeles reveals only 515,000 usable acres for biomass production: U.S. Department of Agriculture and the National Agricultural Statistics, 2007 Census of Agriculture - County Data - California, Volume 1, "Table 8: Farms, land in Farms, Value of Land and Buildings, and Land Use: 2007 and 2002," available at http://www.agcensus.usda.gov/Publications/2007/Full_Report/Volume_1,_Chapter_2_

County_Level/California/index.asp (accessed March 29, 2010). 7.6 million hydrogen vehicles travelling 12,150 miles per year with a fuel efficiency of 19.9 grams of hydrogen per mile would require biomass production levels of roughly 47 tons per acre of the available acreage, well above the range of possible production levels for switchgrass and poplar reported in Robin L. Graham, Erik Lichtenberg, Vernon O. Roningen, Hossein Shapouri, and Marie E. Walsh, The Economics of Biomass Production in the United States, Oak Ridge National Laboratory, 1995, "Table 1: Potential Biomass Crops, Suitable Acreages, and Average Yields," available at http://bioenergy.ornl.gov/papers/bioam95/graham3.html (accessed March 29, 2010). The biomass-to-hydrogen conversion rate was taken from the Department of Energy's H2A model: U.S. Department of Energy, "Advanced (2010-2020) Hydrogen from Biomass via Gasification and Catalytic Steam Reforming," Department of Energy Hydrogen Program, January 4, 2005, http://www.hydrogen.energy.gov/h2a_prod_studies.html (accessed December 3, 2007).

${ }^{5}$ U.S. Department of Energy, "Hydrogen Production, Natural Gas Reforming," http://www1.eere.energy.gov/hydrogenandfuelcells/production/natural_gas.html, accessed February 2010.
} 
dollars. ${ }^{6}$ The smaller 100-kg/day SMR facility’s capital cost is \$593 thousand, also in 2009 dollars. $^{7}$

Figure 2-5 shows a comparison of the average cost of producing hydrogen using several $100-\mathrm{kg} /$ day stations or one $1,500-\mathrm{kg}$ /day station. The chopped cost curve refers to $100-\mathrm{kg} / \mathrm{day}$ stations, and the smooth curve refers to one 1,500-kg/day station. As the number of hydrogen vehicles increases, the average cost of producing hydrogen first declines due to increased capacity utilization. When the existing $100-\mathrm{kg} /$ day stations reach capacity, a new station needs to be added to meet additional demand as shown by the spikes in the average cost curve. Low initial capacity utilization associated with new stations leads to discrete jumps in the average cost. With 400 vehicles to serve, a 1,500-kg/day station becomes more cost-effective, and its advantage grows with additional vehicles.

The following conclusions can be drawn:

- The lowest cost that can be realized with $100-\mathrm{kg} /$ day stations is $\$ 9.21$ per $\mathrm{kg}$, whereas the lowest cost that can be realized with a $1,500-\mathrm{kg} /$ day station is $\$ 3.16$ per $\mathrm{kg}$.

- Larger fuel stations become the least costly alternative at relatively low levels of demand. A $1,500 \mathrm{~kg} /$ day station can serve 1,995 vehicles. A $100-\mathrm{kg}$ /day station is sufficient to serve 133 drivers [100 kg/day times $85.2 \%$ capacity utilization divided by $(12,150$ miles / 365 days) times 52 miles $/ \mathrm{kg}$ ]. Therefore the first three $100-\mathrm{kg} /$ day stations can serve 399 vehicles; to serve the $400^{\text {th }}$ vehicle, a fourth $100-\mathrm{kg} /$ day station would have to be established. From Figure 2-5, even if there are only 400 vehicles to be served it is less expensive to build the bigger plant and operate it initially at low capacity rather than build four $100-\mathrm{kg} /$ day plants, one at a time.

In view of these results, this study assumes that investors considering distributed production in the model area will use $1,500-\mathrm{kg} /$ day stations.

\footnotetext{
${ }^{6}$ U.S. Department of Energy, "Future (2025) Natural Gas Steam Reformer (SMR) at Forecourt $1500 \mathrm{~kg} /$ day," Department of Energy Hydrogen Program, May 27, 2008. http://www.hydrogen.energy.gov/h2a_prod_studies.html (accessed February 17, 2009).

${ }^{7}$ U.S. Department of Energy, "Forecourt Hydrogen Production," "h2a_forecourt_smr_100kgperday_current_final.xls," Department of Energy Hydrogen Program, October 14, 2004. http://www.hydrogen.energy.gov/h2a_prod_studies.html (accessed December 2005).
} 
Figure 2-5: Comparison of Average Cost of Producing Hydrogen using a 1,500 kg/day SMR Station vs. 100-kg/day SMR Stations

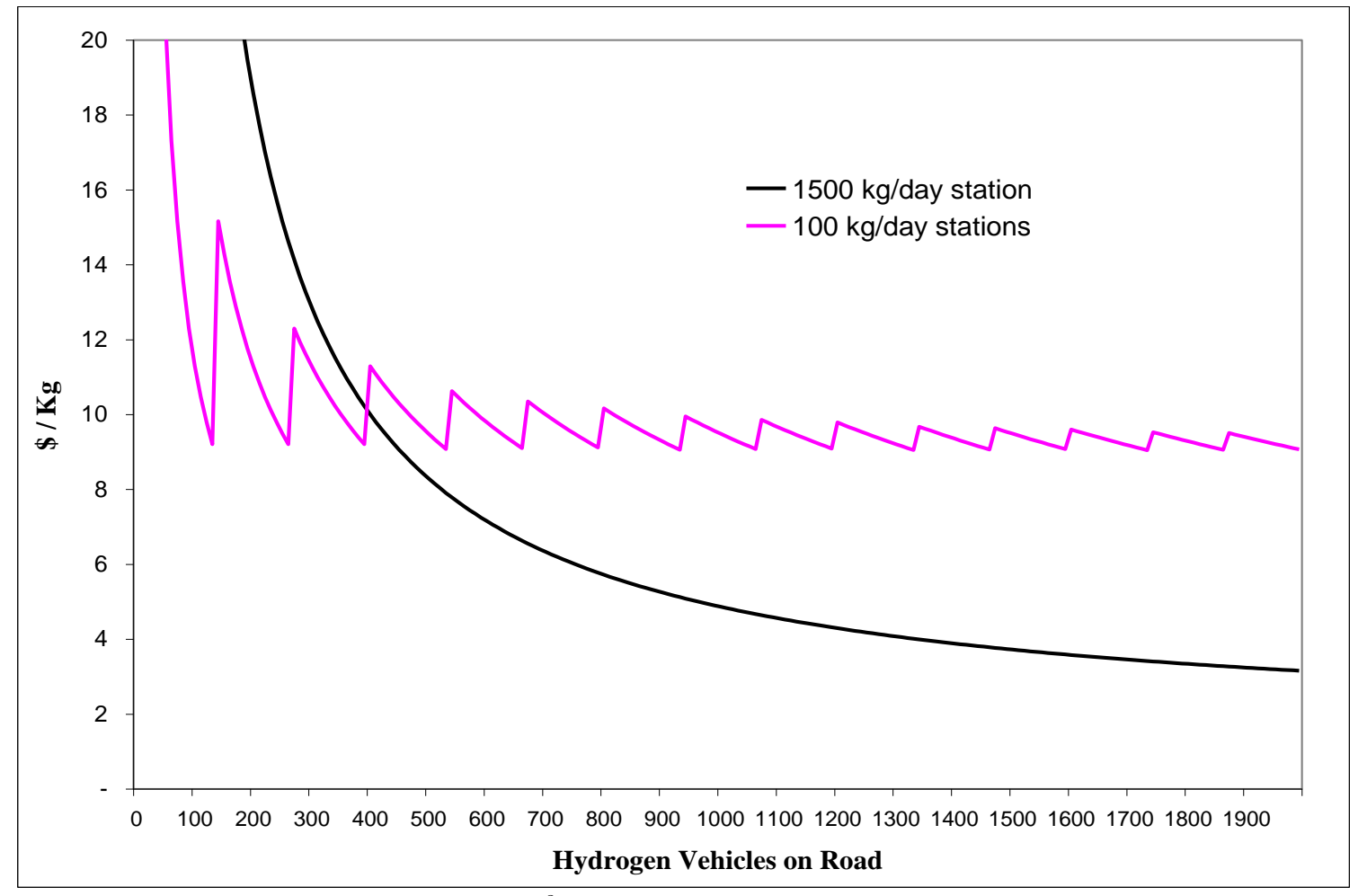

Source: Calculations made with H2A models. ${ }^{8}$ Costs are expressed in 2009 dollars.

\subsubsection{Centralized Production}

Centralized SMR production facilities are large plants capable of producing hydrogen at a lower cost per $\mathrm{kg}$ than $1,500-\mathrm{kg} /$ day on-site reformers. However, centralized plants rely on a pipeline or truck delivery system which moves the hydrogen from the plant to fueling forecourts, which also has to be located by the investor. In view of the cost of this added distribution infrastructure, a large volume of sales must be made to bring average total cost of production plus delivery to a level comparable to the cost of distributed production. From H2A, centralized production plants have a nameplate capacity of about $380,000 \mathrm{~kg} / \mathrm{day}$, and the associated forecourts have a nameplate capacity of $1,500 \mathrm{~kg} / \mathrm{day}$, with effective capacity of $85.2 \%$, the same as distributed fueling stations.

Using H2A cost numbers, a centralized plant requires $\$ 275$ million in capital costs spread over 4 years plus $\$ 10$ million in recurring annual costs during operation. The accompanying

\footnotetext{
${ }^{8}$ U.S. Department of Energy, "Future Forecourt Hydrogen Production from Natural Gas (100 kg per day)," October 14, 2004, and "Future Forecourt Hydrogen Production from Natural Gas (1,500 kg per day)," October 14, 2004, available at http://www.hydrogen.energy.gov/h2a_prod_studies.html. (Accessed December 2005.) Default assumptions. Costs have been converted to 2009 dollars.
} 
delivery and dispensing infrastructure requires $\$ 13$ billion in capital costs ${ }^{9}$ and provides a transmission pipeline, two urban trunk lines and service pipelines to the fueling stations, geologic storage, compressors and dispensing stations. Truck distribution was found to be more expensive than pipeline distribution. Not considered here are problems of securing rights-of-way for new pipeline in urban areas and problems of traffic congestion and gas pressures beyond contemporary standards for truck transportation.

The cost per kilogram of centralized hydrogen production is high if it is introduced in early years of the hydrogen transition when there is not yet sufficient volume to cover its fixed costs, as shown in Panel (1) of Figure 2-6. The levelized cost necessary to recover fixed costs over the life of the project declines as the year of introduction of centralized production is delayed. Centralized production is begun in the year when volume has become sufficient for its levelized cost to fall below the cost of distributed production. In the illustrative example presented here, the cost of distributed production is $\$ 3.50$ per $\mathrm{kg}$. As shown in Panel (2) the levelized cost of centralized production falls to $\$ 3.50$ per $\mathrm{kg}$ by the seventh year, which is the year of switchover from distributed to centralized production. Panel (3) shows that as the rate of adoption of hydrogen vehicles increases, an earlier switchover to centralized production would occur due to the increased fuel demand in early years. Panel (4) shows the effect that higher prices of distributed production would have in speeding up entry of centralized production, such as might be brought about by a carbon tax on distributed production. Since carbon capture and sequestration is impractical with distributed production, its hydrogen would be taxed as much as gasoline, if not slightly more. Carbon capture and sequestration are possible with centralized production, and any carbon tax would be substantially lower on hydrogen provided in such a manner than on hydrogen produced at distributed stations or on gasoline.

\footnotetext{
${ }^{9}$ U.S. Department of Energy, "Future Central Hydrogen Production from Natural Gas with CO2 Sequestration version 2.1.1," May 27, 2008, http://www.hydrogen.energy.gov/h2a_prod_studies.html. (Accessed August 2009). Default assumptions. Costs have been converted to 2009 dollars.
} 
Figure 2-6: Factors Affecting Entry of Centralized Production
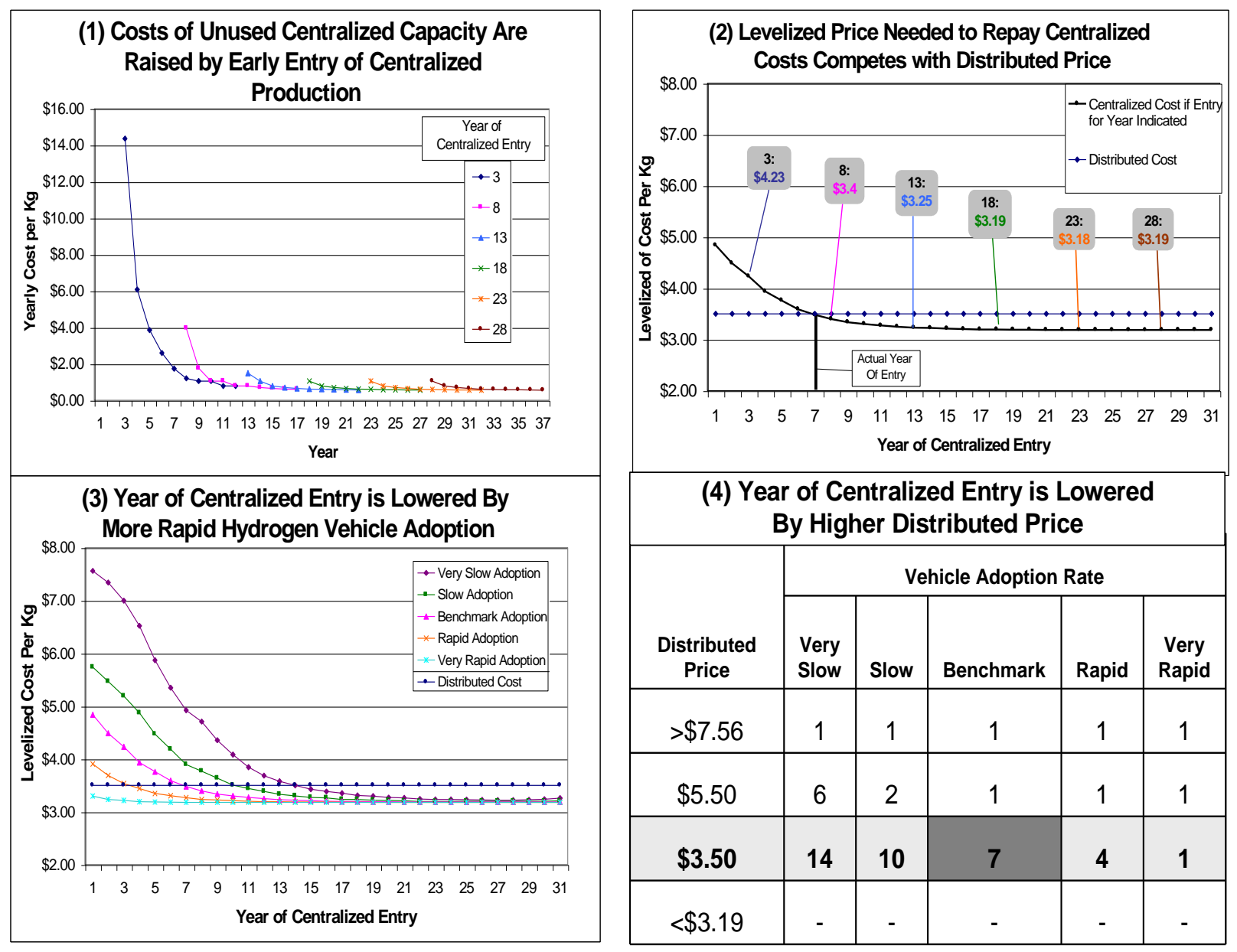

\subsubsection{Price Charged for Hydrogen Fuel}

The investor charges a price for fuel that is equal to the average cost of producing hydrogen. It is assumed that this behavior is brought about by threat of entry by new suppliers or of regulation if monopoly prices are charged, Section B.1 of Appendix B, "Price Charged for Hydrogen Fuel," provides the mathematical formula for average cost used to calculate the price of hydrogen fuel in the model.

\subsubsection{Station Siting}

The investor makes decisions about siting stations at the beginning of each simulation year, starting at the second year. In the first year of a simulation, only seed stations exist. At the beginning of the second year, and of each subsequent year, the investor creates a station siting plan for the year and has the opportunity to site as many stations as desired at each of the possible fueling station locations. 
Establishing a new station can affect future demand at other locations. This happens when a station is established at a location where no station existed previously and is able to attract some of the drivers who would otherwise refuel at nearby locations. If the investor does decide to add another station, the previous estimates of likely sales at all the locations near this station are reduced by the expected diversion of sales from these locations to the new station.

Section 2.3.3.1 describes the possible station locations within the model area. Section 2.3.3.2 describes the steps in the station siting decision. Further details and equations used in the station siting procedure are provided in Section B.2 of Appendix B, "Station Siting."

\subsubsection{Possible Station Locations in Model Area}

The model area is divided into 5,000 1x1-mile cells. While there are 2,500 cells where driver agents may reside, the investor agent is restricted to siting stations in 156 cells located at major highway intersections and at the midpoints of highway segments. These highway intersections are indicated by the yellow dots in Figure 2-7. Each of these cells may have as many stations as the investor chooses to site there.

Figure 2-7: Map of Potential Station Locations

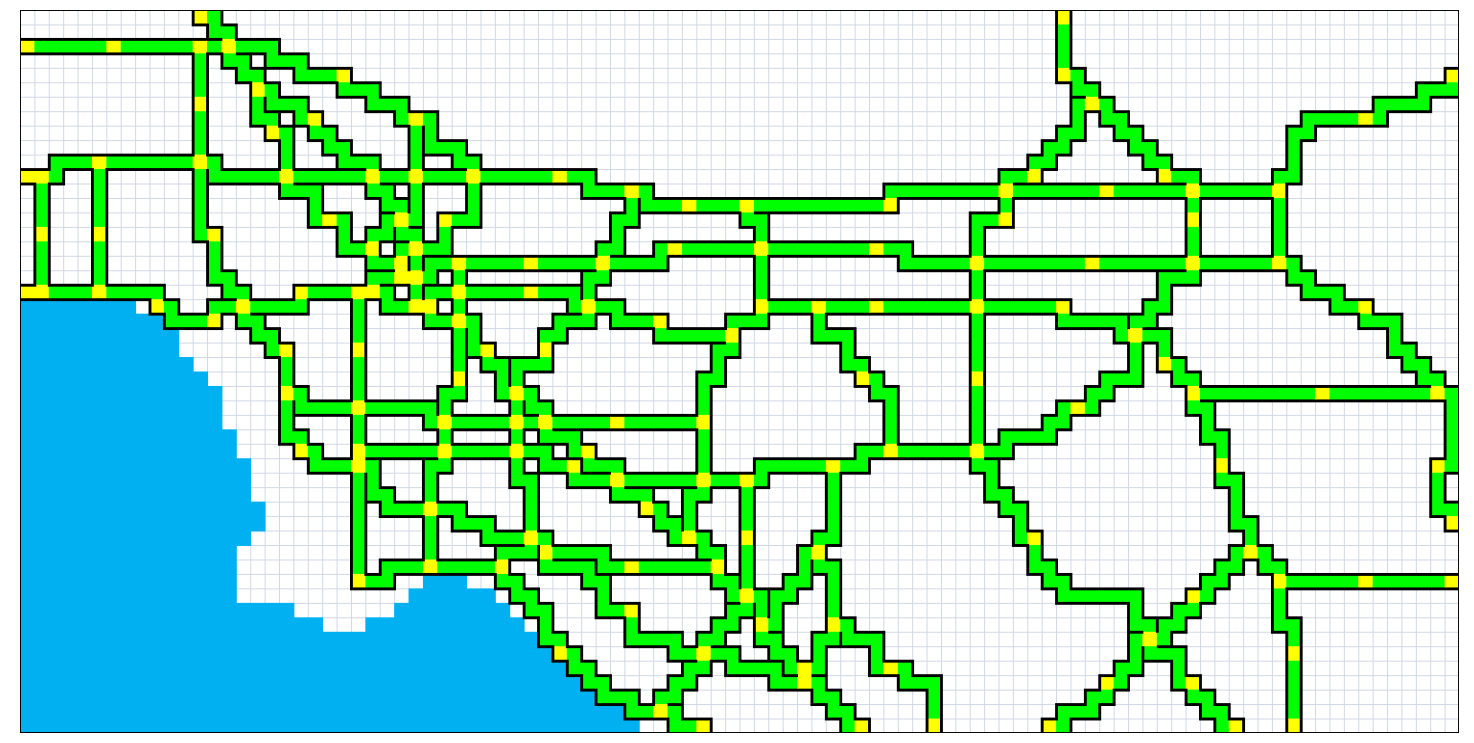

\subsubsection{Station Siting Steps}

In the first year of the simulation, it is assumed that the only stations are seed stations. Investor agents make station siting decisions from the second year onward. An overview of the process is shown in Figure 2-8. 


\section{Figure 2-8: Overview of Investor Station Siting Process}

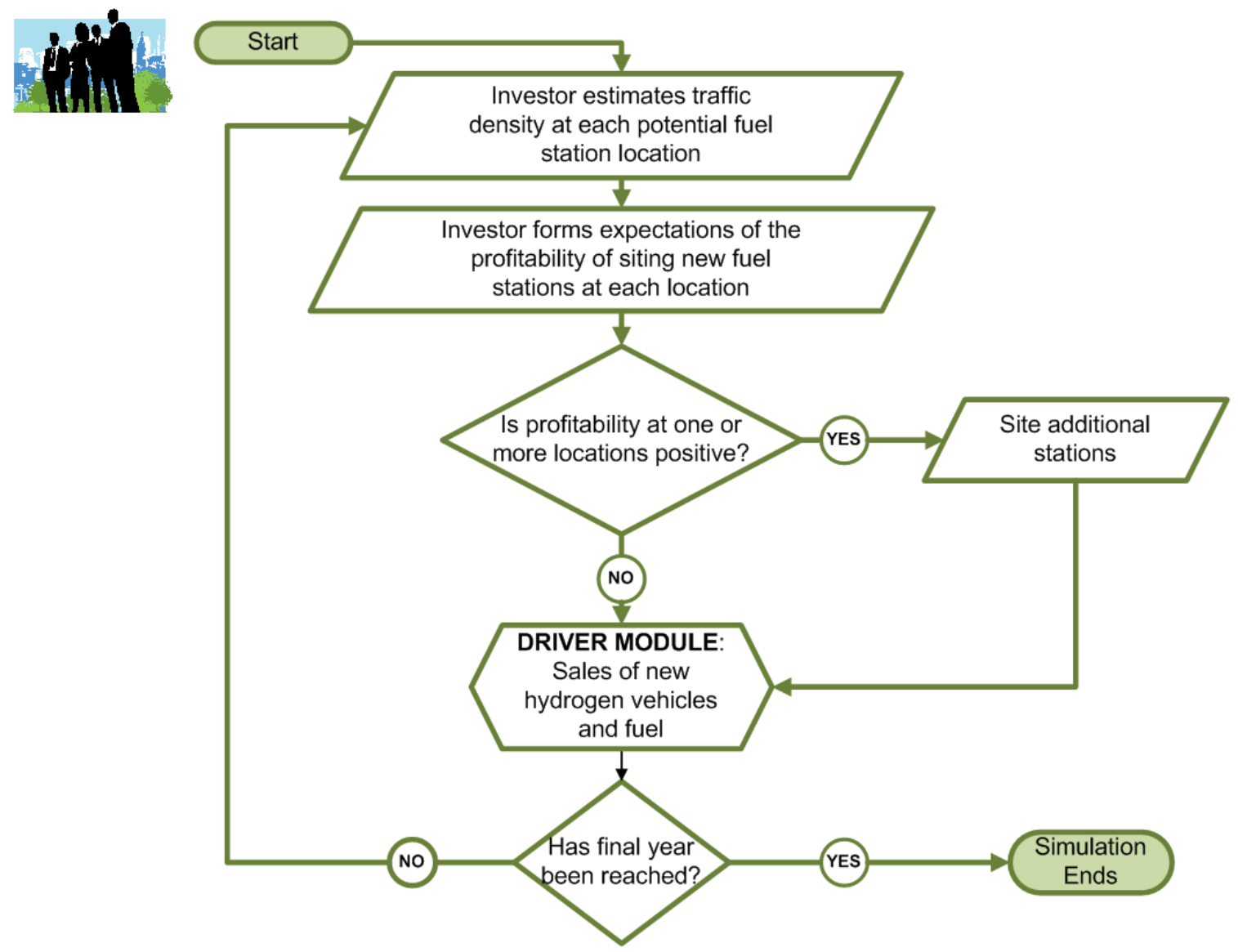

The investor takes the following steps to decide whether to add another station to the existing set of stations:

1. Estimate base sales for each possible location using observed sales for locations with existing stations and using a regression of sales on traffic counts to estimate what sales would be if a station were added at a location where none exists, allowing for diversion of sales from existing stations if a new station is added. See Appendix B, Section B.2.1.1, "Unadjusted Sales at a Location" and Section B.2.1.2, "Adjustments for Sales to Stations Planned but Not Yet Operational," for additional detailed information.

2. Estimate likely future sales at each possible location using a logistic growth function. See Appendix B, Section B.2.1.3, "Estimation of the Growth Parameter," and Section B.2.1.4, "Estimating Future Sales at a Location Using a Logistic Growth Function," for details.

3. Using the estimate of likely future sales at each location, calculate the net present value (NPV) of a new station at each location. See Appendix B, Section B.2.2.1, "Net Present Value (NPV) Calculations," for details. 
4. Rank locations according to the increase in NPV in Step 3. See Appendix B, Section B.2.2.2, "Ranking of Locations," for details.

5. For a proposed new station at the highest-ranked location in the city, make the following NPV calculations using the formulas in Appendix B, Section B.2.2.1, "Net Present Value (NPV) Calculations.”

- Default NPV: Calculate the NPV of the investor's existing set of stations without the proposed new station.

- NPV with the proposed station: Calculate the NPV of the investor's set of stations if the proposed station is sited in the current year.

- NPV with waiting: Calculate the NPV of the station set under the assumption that the proposed station is sited not in the current year but in the following year.

6. Compare the NPV with the proposed station to the default NPV and to the NPV with waiting. See Appendix B, Section B.2.2.3, "Net Present Value (NPV) Rule for Station Siting," for details.

- If the NPV with the proposed station exceeds both the default NPV and the NPV of waiting, then it is profitable to site the station in the current year. The investor sites the proposed station, and repeats Step 5 to see if any additional stations should be sited at the same location in the current year.

- If the NPV with the proposed station is less than either the default NPV or the NPV with waiting then the investor decides not to site the proposed station.

7. Propose a new station at the next best location, and loop back to Step 5.

8. If there is no next best location because a new station has been proposed and rejected at all 156 locations, then the station siting plan is complete for the current year.

\subsubsection{Financial Evaluation of the Investment Plan}

Financial evaluation of plans for undertaking infrastructure investments occurs at two levels: evaluation by division staff and final decisions by upper management.

\subsubsection{Staff Evaluation}

The initial evaluation is conducted by corporate division staff, following textbook principles along the lines of the NPV calculations described above. When the evaluation is 
completed, the assessment is sent to upper management where investment decisions will be made.

\subsubsection{Upper Management Evaluation}

Corporate executives make use of staff evaluations of potential investments but do not regularly follow them exactly. Upper management may exhibit extremes of risk aversion or risk tolerance. Using a wider range of discount rates than the division staff do, upper management can accept or reverse division staff recommendations.

Business experience is replete with highly successful investments based on shrewd and/or lucky estimates that far outstripped the rest of the market, as well as those of the opposite kind resulting in large losses. This study investigates the possible role of these kinds of decisions in influencing the provision of hydrogen infrastructure.

Typically, the division staff forwards potential investments that pass minimum financial requirements to upper management. Upper management then takes additional considerations into account that are outside the scope of the division staff, such as overall company goals, and shareholder and lender perceptions. Upper management often has access to separate departments outside the division staff that will assist them in their analysis, with titles such as Strategic Planning and Investor Relations.

Figure 2-9 illustrates the structure of corporate decision-making. Multiple parties are often involved in project investment decision making. These include: 1) the division staff, 2) shareholders, 3) lending institutions, and 4) upper management. Figure 2-9 suggests that each party has a role with separate objectives. The division is likely to seek funding for any profitable projects that come to its attention. Upper management evaluates the projects proposed by division staff. Upper management also communicates with the shareholders and is aware of the available company resources, information on which division staff may not have direct knowledge. 


\section{Figure 2-9: Role of Upper Management in Corporate Decision-Making}

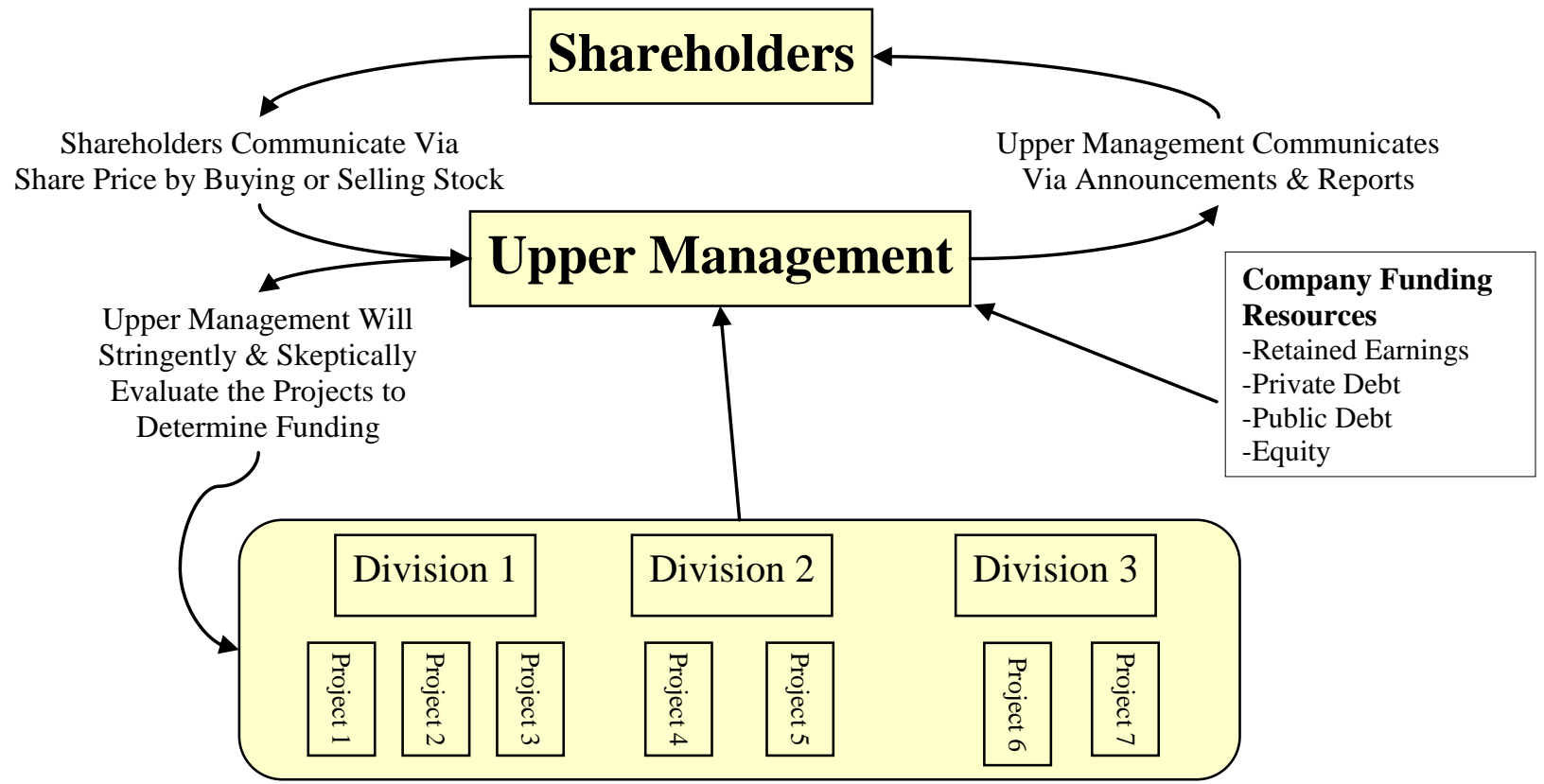

Most companies have limited funding available for new projects, resulting in some profitable projects not being selected by a company. Other projects may be highly profitable but small and short-lived. Still others may have lower profitability but be large and sustainable, with the potential to provide cash for other projects in the future. Depending on the company's goals, upper management may find the larger, less profitable project to be a better fit for the company. Upper management is typically sensitive to the funding providers' opinions of the company. If the company takes on a large project that its primary lender views as risky, the company may find its debt costs rising the following year. Management wants to be confident that the company is investing in projects that align with its shareholders' interests and long-term goals.

Faced with these challenges, upper management chooses projects for inclusion in the investment portfolio, giving attention to such indicators as return on investment, profitability, and growth. A variety of financial metrics can be used to evaluate a project. This study focuses on the commonly used metrics of discount rate, projected growth rate, and planning horizon. By performing sensitivity analyses on these variables, the model can evaluate the effect of upper management on the rate of vehicle adoption and whether ultimate adoption is affected. Because the individual company decision process can vary even within an industry, different cases need to be considered.

Responses by upper management may include:

1. Adjusting the discount rate to reflect the specific perceived risk level of a hydrogen investment.

2. Adjusting the level of optimism or pessimism to reflect personal views about a new market. 
3. Adjusting the rapidity of learning to reflect views about a new market.

4. Adjusting the planning horizon used to reflect concerns about short-term shareholder opinion.

5. Adjusting capital availability to reflect a desire or need to keep the corporation's leverage level below a particular point.

Each of these responses is considered below:

1. Discount rate. Some upper management groups are conservative and others are more risk tolerant. The discount rate used for an investor's profit calculation represents the profit level, or rate of return, required by the investor for the project to be attractive. In the division staff scenario, rates of return are assumed that are reasonable and likely. However, what if the investor has an upper management that is highly risk-tolerant or risk-averse? In the highly risktolerant case upper management would pursue a project without being compensated adequately for risk; this would correspond to use of a low discount rate. The opposite is true in the riskaverse case: an investor would require an unusually high return for the risk level, corresponding to a high discount rate. To illustrate the potential effects of an upper management intercession of this type, additional scenarios would need to be investigated in which an investor uses more extreme discount rates than used in the division staff scenarios.

2. Optimism or pessimism. The upper management of a company may find that it disagrees with the current beliefs of its division staff. Without any substantive market data, an investor selects an initial growth rate believed to be the growth rate of hydrogen fuel sales. This rate is adjusted over time as the investor learns. Upper management may disagree with the division staff's initial growth projections and exhibit greater optimism or pessimism than a purely financial view of the data would suggest. Optimism or pessimism at the division staff level can be represented by a high or low value for the initial growth rate applicable to expected hydrogen sales.

3. Rapidity of learning. Should the upper management disagree with its staff, it is likely that even if conflicting data were to appear, upper management may still be skeptical of the results. For this situation, the growth weights are altered in the learning calculation, as described in Section B.2.1.3 of Appendix B, "Estimation of the Growth Parameter," to shift the basis of upper management's current beliefs toward either its previous beliefs or its latest observations. If upper management places greater weight on the previous period's information than on that of the current period, this has the effect of creating a "stubborn" investor, reflecting the possibility of upper management relying on its first assessment about the market for a somewhat longer period of time. By slowing the rapidity of learning the case can be simulated in which upper management disagrees with the market data coming in and is slower to react to actual results. This may also reflect considerations of upper management's view of longer-term trends in the specific business, the economy, or the policy environment that are not accounted for in the current market response. 
4. Planning horizon. Often upper management feels pressure to invest in projects that will reward the shareholders with returns more quickly than others. This can cause the upper management of some corporations to over-value short-term profits. Despite the longevity of the hydrogen infrastructure, it is possible that upper management will look at a shorter time horizon to make sure the shareholders receive a quick return on investment. In these cases upper management is interested in knowing if the investment can pay for itself in a certain timeframe ignoring the cost of capital. If the project restricts capital for too long, upper management may be hesitant to invest.

5. Restrict capital. Capital budgeting is an important component of upper management's decision-making responsibilities. Some companies will have greater ability to fund a large investment in hydrogen than will others. Those companies with large existing investments may find resistance from corporate lenders and shareholders to providing them with additional inexpensive liquidity. For the right profit level, capital can usually be found for even the most leveraged company. However in the early stages of an unproven market, capital may be restricted for companies with existing high levels of leverage.

\subsubsection{Number of Investors}

Most of the simulations reported in this study have been for a single investor agent. If a single investor acted as a monopolist to substantially raise the price of hydrogen, the number of investors might have more important effect in acting to bid down the price of hydrogen. However, as noted above in Section 2.3.2, "Price Charged for Hydrogen Fuel," threats of potential competition and of regulation are assumed to keep the price of hydrogen close to its average cost of production.

The methodological complications for the multiple investor case are described in Section B.3, "Number of Investors," in Appendix B. Results of a sensitivity study showing that the number of investors has little impact on the sales of hydrogen vehicles are presented in the text below in Section 3.3.6, "Number of Investors." 


\section{PART THREE: SENSITIVITY TO MODEL PARAMETERS}

In order to understand the effects of driver and investor agents on the rapidity of adoption of hydrogen vehicles, sensitivity analyses were conducted on selected parameters used in the model. As discussed in Part Two, the model contains 130 parameters which consist of 92 cost parameters from DOE's H2A model ${ }^{10}, 17$ driver behavior parameters, 10 investor behavior parameters, and 11 price and policy variables.

The sensitivity analyses were conducted in relation to a benchmark case. The purpose of this study is to examine hydrogen vehicle growth and the provision of hydrogen infrastructure once hydrogen vehicles become competitive in the marketplace. The benchmark case provides an example of a set of prices for vehicles, as well as fuels for hydrogen and non-hydrogen vehicles that would result in cost competitiveness and allow a take-off. It is to be emphasized that this study does not attempt to predict the year when the required cost competitiveness will be achieved.

The results presented in this section are for the following three parameters pertaining to driver agent behavior: driver familiarity with hydrogen vehicles, the bandwagon effect or the impact of drivers who have already bought a hydrogen vehicle on drivers who have not bought one yet, and taste for greenness or driver willingness to pay a premium for an environmentally friendly vehicle.

Results are also presented for six parameters pertaining to investor behavior: staff discount rate, upper management discount rate, rapidity of learning, expectation of growth, demand estimation method, and number of investors. Effects are explored of the use of approximative decision making by investors on whether the same penetration is ultimately reached as with exact optimization and how the rapidity of adoption is affected.

The benchmark case is described in Section 3.1. Sensitivity scenarios for driver parameters are presented in Section 3.2. Sensitivity scenarios for investor parameters are presented in Section 3.3. Effects of approximative decision-making are examined in Section 3.4.

\subsection{Benchmark Case}

The benchmark case represents a 40 year scenario where hydrogen vehicles and fuel become competitive with traditional vehicles. Section 3.1.1 presents values for the major driver and investor agent parameters used in the benchmark case. Section 3.1.2 shows the results of the benchmark scenario for hydrogen vehicles sales market penetration. Section 3.1.3 shows the results for the market penetration of the stock of hydrogen vehicles. Section 3.1.4 presents the growth of the number of stations under the benchmark case. Section 3.1.5 provides an overview

\footnotetext{
${ }^{10}$ U.S. Department of Energy, “Future (2025) Natural Gas Steam Reformer (SMR) at Forecourt 1500 kg/day,” Department of Energy Hydrogen Program, May 27, 2008. http://www.hydrogen.energy.gov/h2a_prod_studies.html (accessed February 17, 2009). All cost figures in the present report have been updated to 2009 dollars.
} 
of the distribution of fuel stations within the model area at selected years. Section 3.1.6 presents estimates of investor agent cash flows.

\subsubsection{Parameter Values for the Benchmark Case}

Values for the main driver agent and investor agent parameters used in the benchmark scenario are shown in Table 3-1. Among the driver agent parameters, the disadvantage due to limited familiarity is the additional amount a driver without any knowledge of the hydrogen vehicle would have to be paid to buy the vehicle. The parameter for the bandwagon effect is a coefficient of the proportion of drivers who have already adopted hydrogen vehicles. Greenness central tendency is the premium the median driver is willing to pay for an environmentally friendly vehicle. Greenness dispersion is a measure of how the degree of preference for greenness varies among the population of drivers.

The benchmark values of the investor agent parameters are taken from DOE's H2A model. ${ }^{11}$ The fueling station capital cost is based on a $1,500-\mathrm{kg} /$ day steam methane reforming station. Fixed operations and maintenance (O\&M) costs are incurred annually and do not vary with the volume of hydrogen produced. The salvage value is the excess of terminal-period asset value of a station over decommissioning costs. The investor discount rate is the interest rate at which future income and costs are discounted. The hydrogen selling price equals the average cost of hydrogen production as described above in Section 2.3.2, "Price Received for Hydrogen Fuel." The fuel station operating capacity is the average annual daily hydrogen production level, allowing for maintenance down time and statistically anticipated outages.

${ }^{11}$ Ibid. 


\subsubsection{Hydrogen Vehicle Sales Penetration}

Results for the benchmark case regarding the penetration of hydrogen vehicle sales are presented in Figure 3-1. Hydrogen vehicle sales as a percent of all light-duty vehicle sales are shown for the first 40 years. Hydrogen vehicle sales reach $60 \%$ of all sales by year 20 , and increase to $86 \%$ by year 40 . The figure suggests that the results of this study are consistent with the general pattern of an S-shaped adoption path typically found for new product innovations. This consistency is examined in Part Five of this report on validation. In order to highlight the period of time likely to be of most concern in policy, scenario results up to the $20^{\text {th }}$ year are presented in the remainder of this report.

Figure 3-1: Hydrogen Vehicle Sales Penetration - Benchmark Case

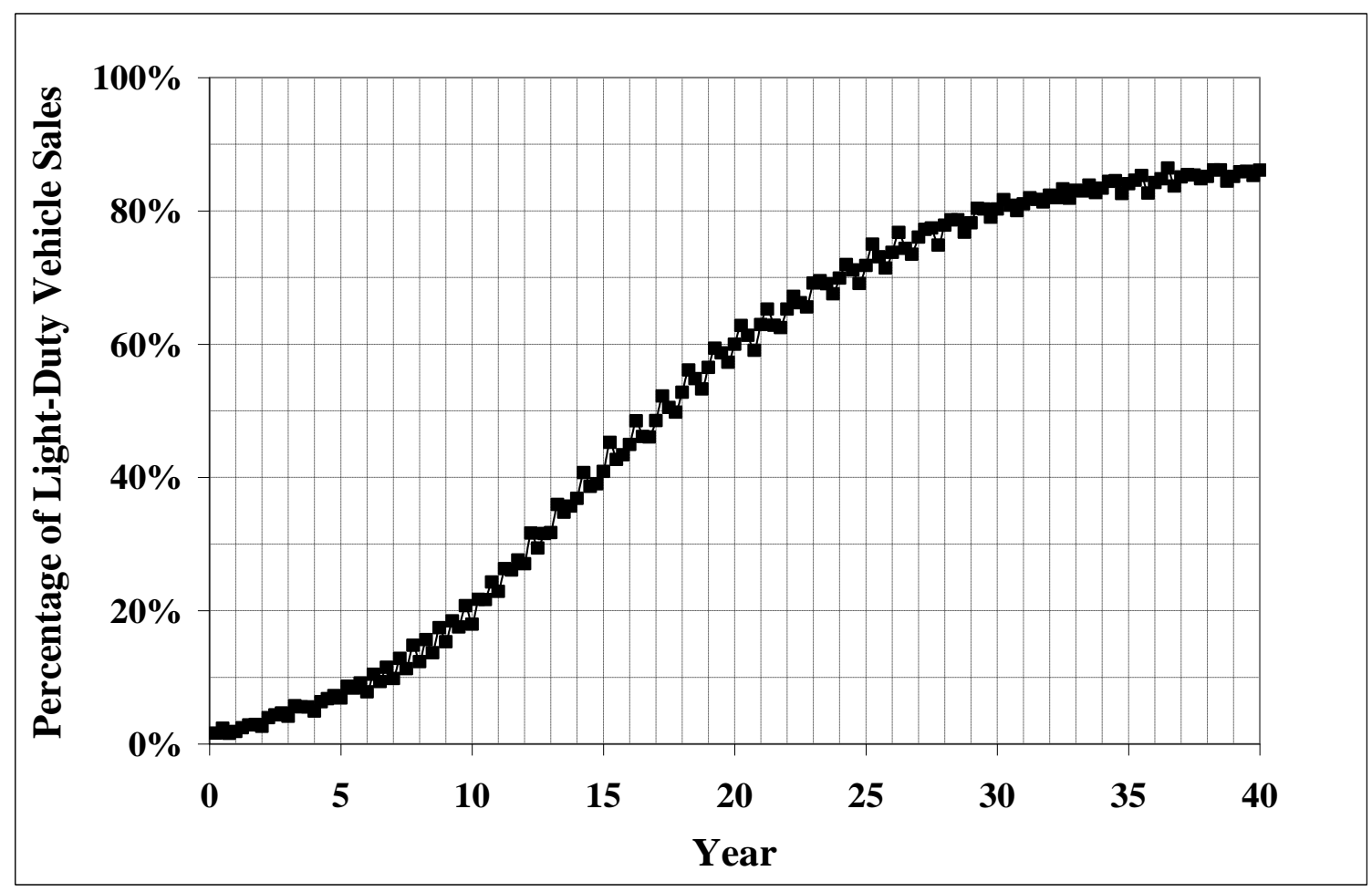




\subsubsection{Hydrogen Vehicle Stock Penetration}

In Figure 3-2, the stock of hydrogen vehicles as a percentage of the total stock of lightduty vehicles is shown for the first 40 years using the benchmark case. The stock penetration is lower than the sales penetration at any given time, as a vehicle lasts for many years and only a fraction of the total vehicle stock is replaced in any one year. For instance, the stock penetration is $25 \%$ by the $20^{\text {th }}$ year, whereas sales penetration is $60 \%$. By the $40^{\text {th }}$ year, the stock penetration is $77 \%$, while the sales penetration is $86 \%$.

Figure 3-2: Stock of Hydrogen Vehicles as Percent of Total Light-Duty Vehicles Benchmark Case

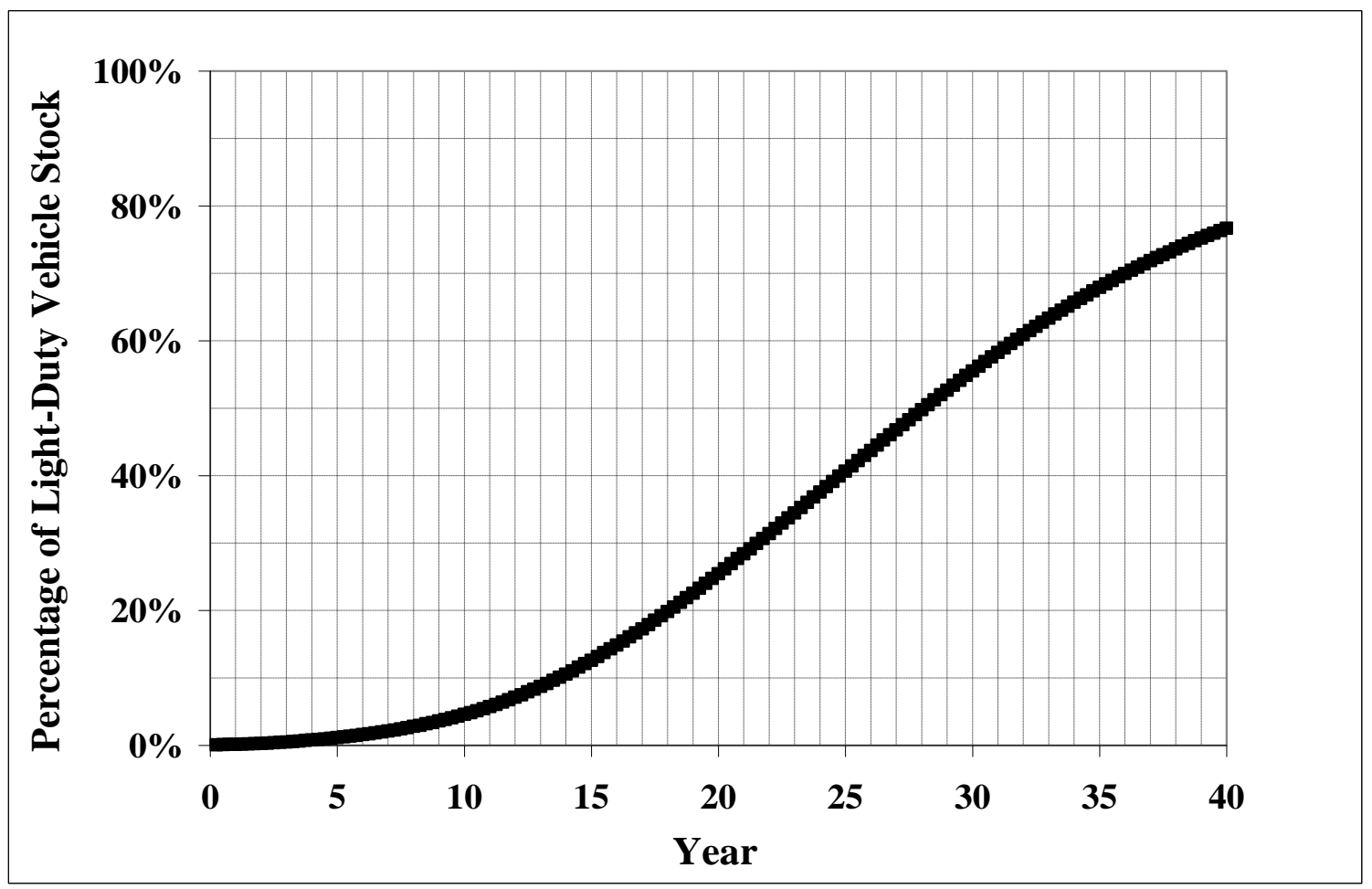




\subsubsection{Hydrogen Fuel Station Penetration}

Figure 3-3 shows the growth in the number of hydrogen fuel stations for the benchmark case. From an initial number of 15 seed stations, 250 stations are established by year 7 , and 600 stations by the $11^{\text {th }}$ year. At 20 years, 1,750 stations have been established, and by the $40^{\text {th }}$ year, some 3,650 stations are in existence.

Figure 3-3: Number of Hydrogen Fuel Stations - Benchmark Case

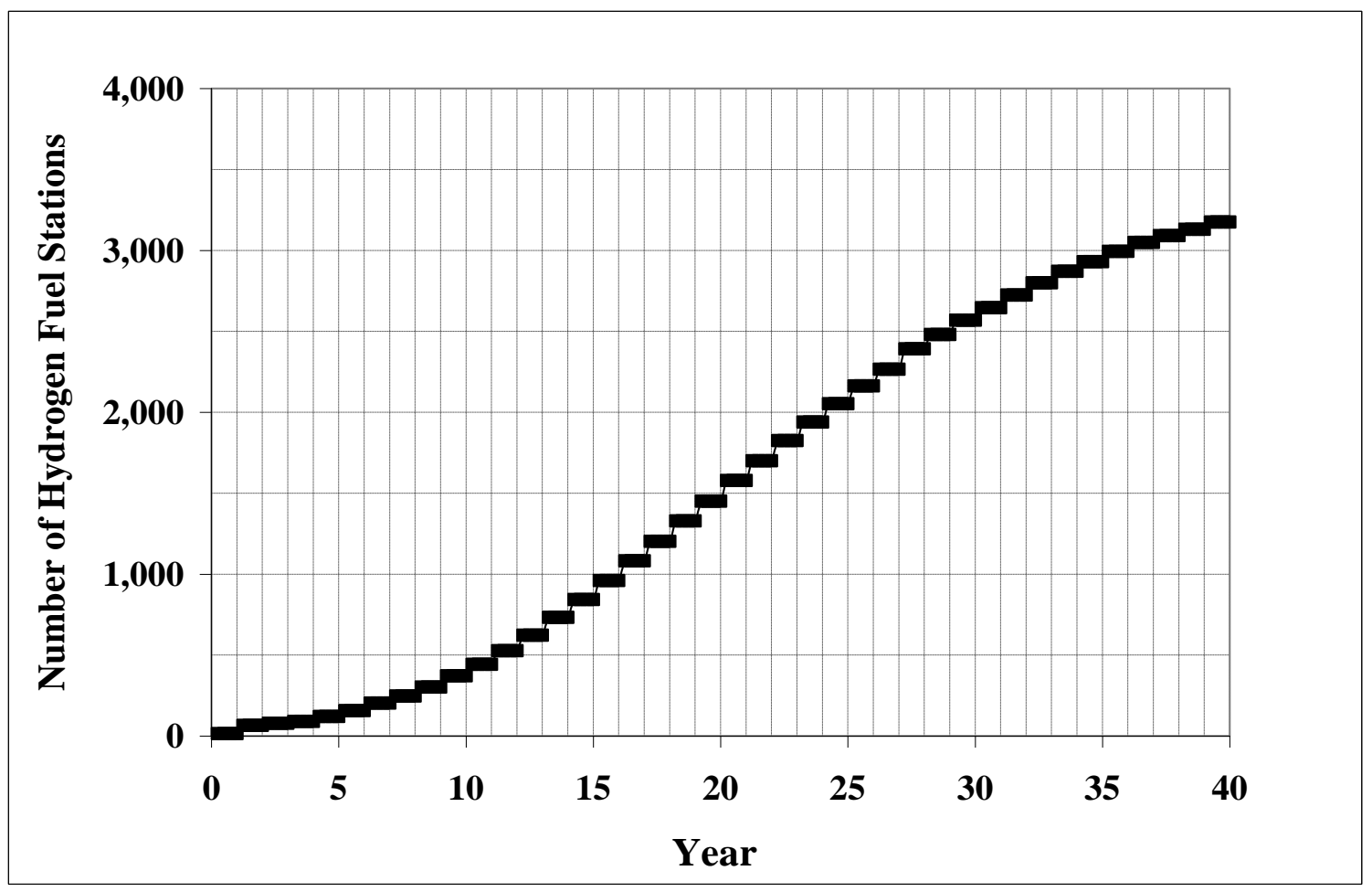




\subsubsection{Location of Fuel Stations}

Figure 3-4 illustrates how the model chooses the location of stations over time. The illustrations shown are for years $5,10,20$, and 40 .

Figure 3-4: Illustration of Hydrogen Fuel Station Growth
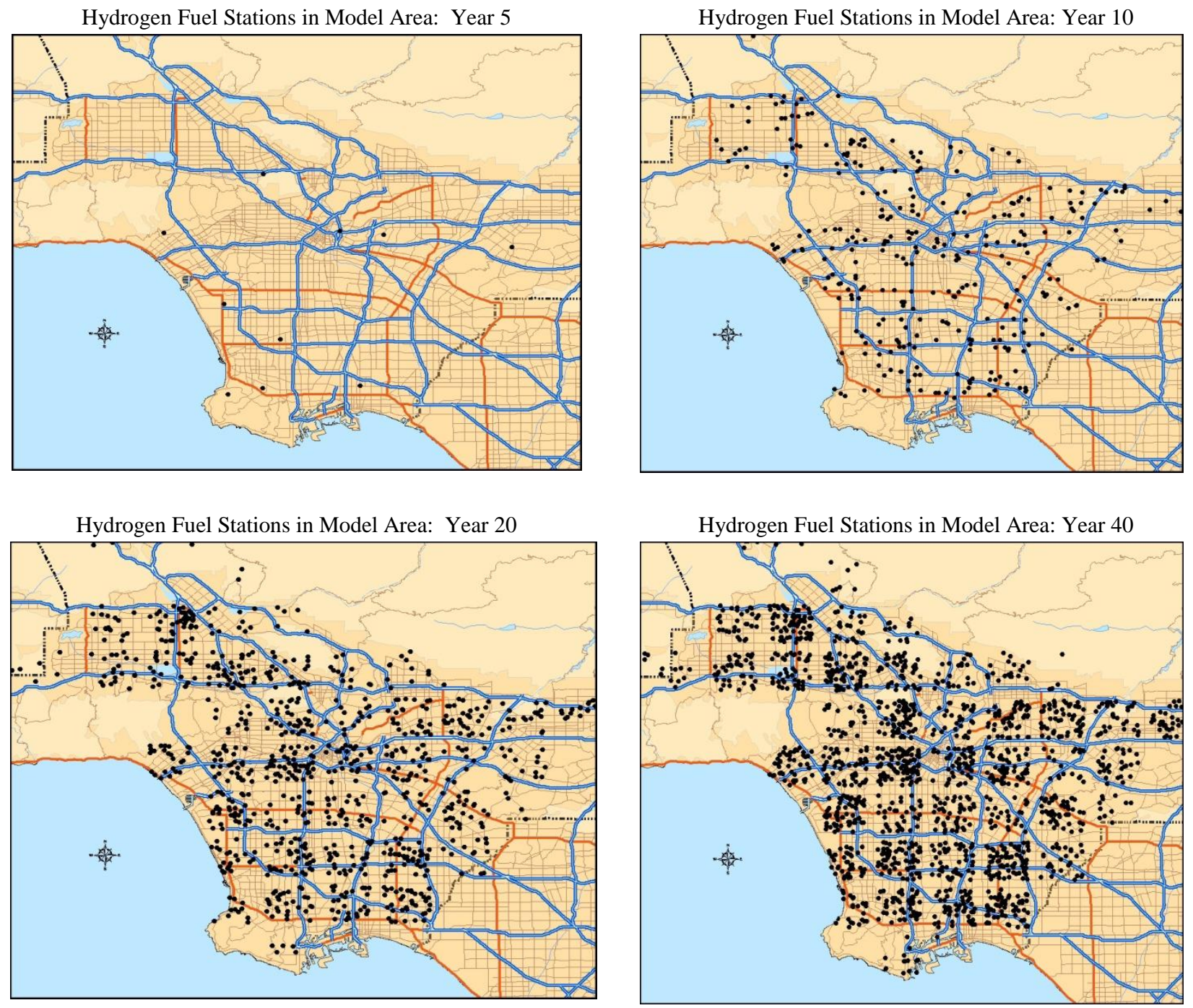

Note: The model area is a rectangular 100 mile x 50 mile area centered on Los Angeles, California. Station locations may represent multiple stations.

\subsubsection{Investor Agent Cumulative Cash Flows}

Many financial measurements for investors can be calculated. As an example, Figure 3-5 shows cumulative cash flows for the investor during the first twenty years. The green line shows the undiscounted cash flows. The line reaches its lowest point in year 16, which shows that for 
the first 16 years, any profits from the existing stations would be exceeded by capital outlays required for the new stations that the investor decides to site. An implication is that the investor in this benchmark scenario would require net cash infusions during the first 16 years.

The blue line presents the discounted cash flow using a $10 \%$ annual discount rate. In this scenario, 30 years are required before the project earns a positive net return.

\section{Figure 3-5: Investor Portfolio Valuation under the Benchmark Scenario}

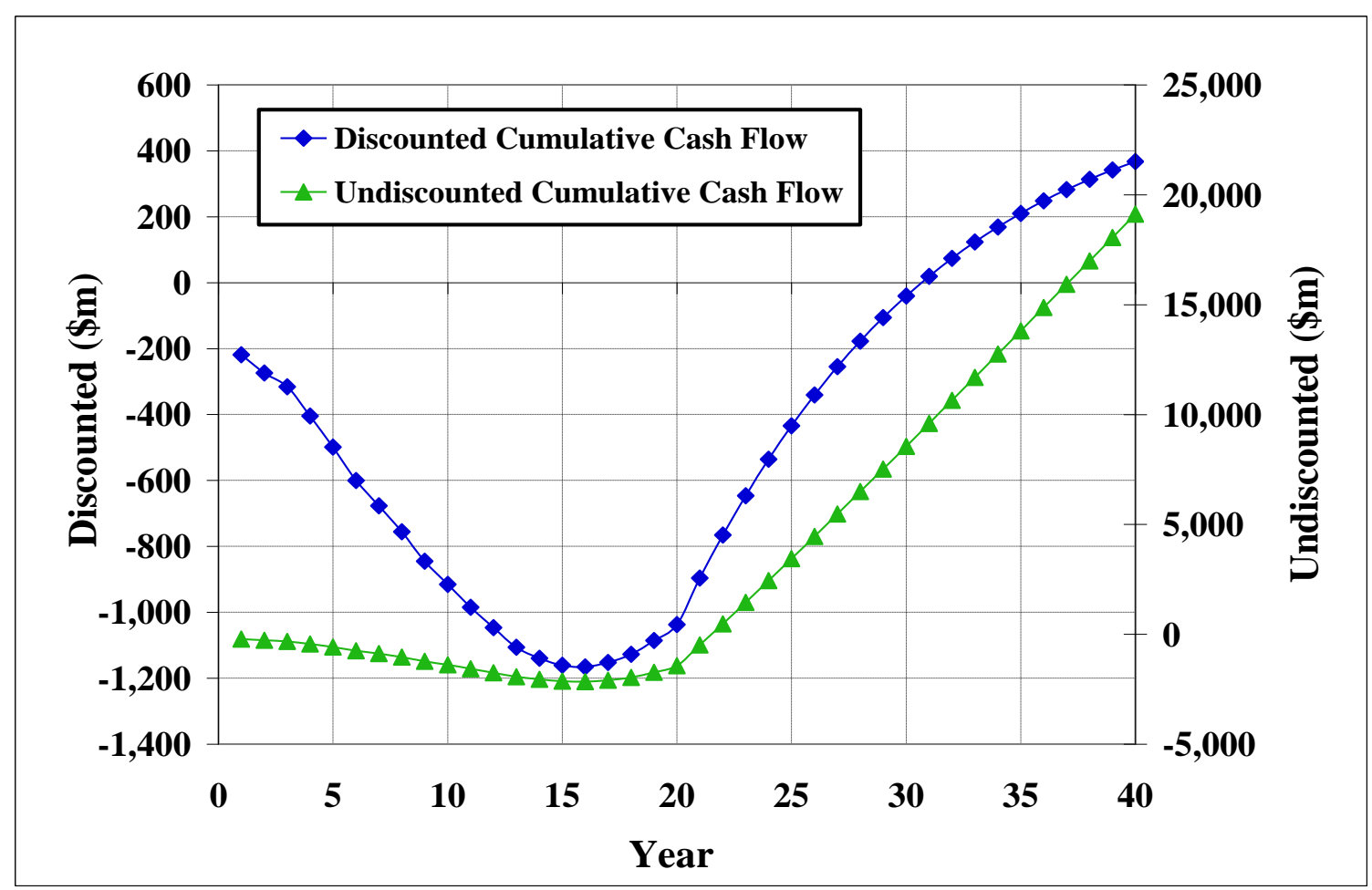

In 2009 dollars.

\subsection{Driver Sensitivity Scenarios}

This section presents the results of sensitivity scenarios for three major driver behavior parameters. Section 3.2.1 examines sensitivity to driver familiarity with a hydrogen vehicle. Section 3.2.2 presents sensitivity to the bandwagon effect. Section 3.2.3 gives sensitivity results for a driver's taste for greenness. Section 3.2.4 summarizes the results of the driver sensitivity scenarios.

\subsubsection{Driver Familiarity}

At the beginning of a simulation, driver agents are unfamiliar with hydrogen vehicle technology. This unfamiliarity depresses the amount they are willing to pay for a hydrogen vehicle. The magnitude of this value, measured in dollars, is the disadvantage due to limited 
familiarity. Stated alternatively, the disadvantage due to limited familiarity is the amount of money that the average buyer would need to be paid to buy a hydrogen vehicle, given no knowledge about it. The value of the disadvantage due to limited familiarity used in the benchmark case is $\$ 12,000$. This amount is roughly the difference between the manufacturer's suggested retail price for the average light-duty vehicle (approximately $\$ 23,000$ ) and the least costly light-duty vehicle (approximately $\$ 11,000){ }^{12}$ In the sensitivity analyses, the difference between the average vehicle price and the average price of small vehicles such as the Chevrolet Aveo and the Honda Fit, is closer to $\$ 8,000$, which is the lower bound. The average price of a light-duty vehicle, $\$ 23,000$, is used as the upper bound.

As shown in Figure 3-6, sales penetration grows as driver familiarity increases, reaching $79 \%$ by the $20^{\text {th }}$ year, compared to $60 \%$ in the benchmark scenario. In the scenario where driver agents are less familiar with hydrogen vehicles, adoption is substantially slowed, with sales penetration reaching only $24 \%$ in the $20^{\text {th }}$ year.

Figure 3-6: The Effect of Disadvantage Due to Limited Familiarity on Hydrogen Vehicle Sales Growth

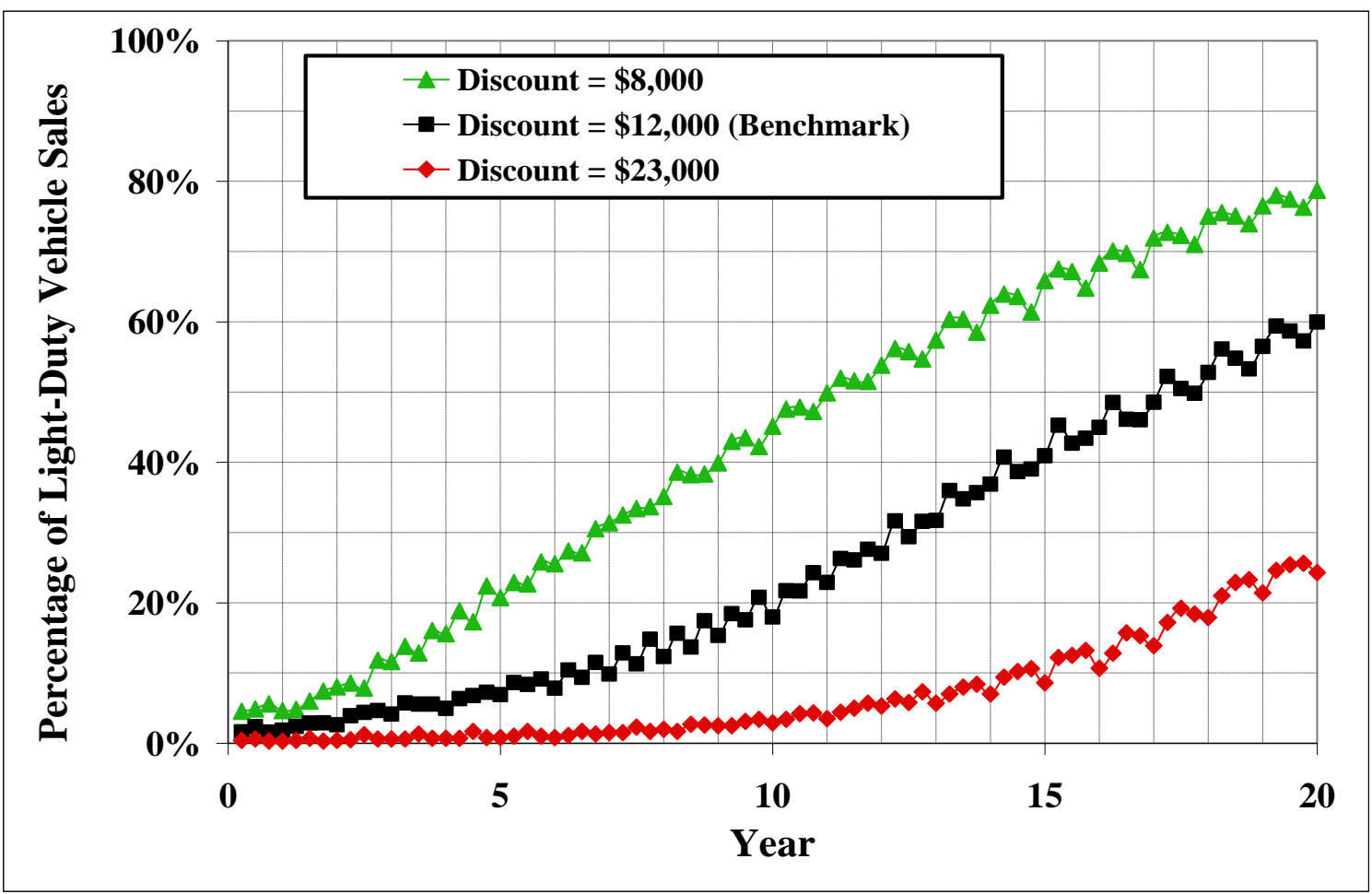

\begin{tabular}{|l|c|c|c|c|}
\hline \multirow{2}{*}{$\begin{array}{l}\text { Disadvantage Due to Limited } \\
\text { Familiarity }\end{array}$} & \multicolumn{4}{|c|}{ Hydrogen Vehicle Sales Penetration } \\
\cline { 2 - 5 } & $\mathbf{5 ~ y r}$ & $\mathbf{1 0} \mathbf{~ y r}$ & $\mathbf{1 5} \mathbf{~ y r}$ & $\mathbf{2 0} \mathbf{~ y r}$ \\
\hline$\$ 8,000$ (Agents have more familiarity) & $20 \%$ & $45 \%$ & $66 \%$ & $79 \%$ \\
\hline$\$ 12,000$ (Benchmark) & $7 \%$ & $18 \%$ & $41 \%$ & $60 \%$ \\
\hline$\$ 23,000$ (Agents have less familiarity) & $1 \%$ & $3 \%$ & $9 \%$ & $24 \%$ \\
\hline
\end{tabular}

\footnotetext{
${ }^{12}$ Ward's Automotive Yearbook, 2009.
} 


\subsubsection{Bandwagon Effect}

The bandwagon effect parameter influences the hydrogen vehicle adoption rate by affecting the driver's familiarity with hydrogen vehicles. A driver agent's disadvantage due to unfamiliarity declines as the opportunity to observe the new technology in operation increases. This effect has been observed universally in the adoption of new consumer durables and is a major consideration in the behavior of the driver agents in this model.

For the scenario analyses, the strength of the bandwagon effect is varied using a central tendency value. Each driver has a value for the strength of the bandwagon effect, which is calibrated using a log normal distribution. The distribution of the population's bandwagon strengths has a central tendency value associated with it. When the central tendency value is increased, the bandwagon effect becomes stronger for all drivers. When it is decreased, the bandwagon effect becomes weaker for all drivers. In the benchmark case, the central tendency value is 0.1 , which means that the median driver's familiarity will increase by $1 \%$ for every $10 \%$ of other drivers who already own hydrogen vehicles.

A dispersion value, which controls the number of drivers at the high and low ends of the distribution, is also included. The benchmark dispersion value is 2.2. This choice of benchmark is calibrated to match the bandwagon effect of a selection of consumer durable goods to which the adoption of hydrogen vehicles might be compared. The high and low magnitudes of the bandwagon effect are calibrated to be similar to the adoption rates of air conditioning and color television, which are products representative of high and low levels of bandwagon effect. ${ }^{13}$

As shown in Figure 3-7, hydrogen sales penetration grows more rapidly in the scenario with the strong bandwagon effect, as drivers grow more familiar with the new technology more rapidly. In addition, the effect is much stronger in early years than in later ones. After 10 years, the slower-than-benchmark bandwagon effect scenario results in sales penetration of $10 \%$, while the faster-than-benchmark scenario results in sales penetration of 63\%, compared to a benchmark of $18 \%$. After 20 years, sales penetration reaches $94 \%$ in the faster-than-benchmark scenario, but only $27 \%$ in the slower-than-benchmark scenario.

\footnotetext{
${ }^{13}$ Frank M. Bass, “A New Product Growth Model for Consumer Durables,” Management Science, 15 (1969): $215-227$ [ Reprinted in Management Science 50, No. 12 Supplement (2004): 1825-1832.]; Frank M. Bass, Trichy V. Krishnan, and Dipak C. Jain, "Why the Bass Model Fits without Decision Variables," Marketing Science 13 (1994): 203-223; and Farrena Sultan, John U. Farley, and Donald R. Lehmann, “A Meta-Analysis of Applications of Diffusion Models," Journal of Marketing Research 27 (1990): 70-77.
} 
Figure 3-7: Effect of Bandwagon Strength on Hydrogen Vehicle Sales Growth

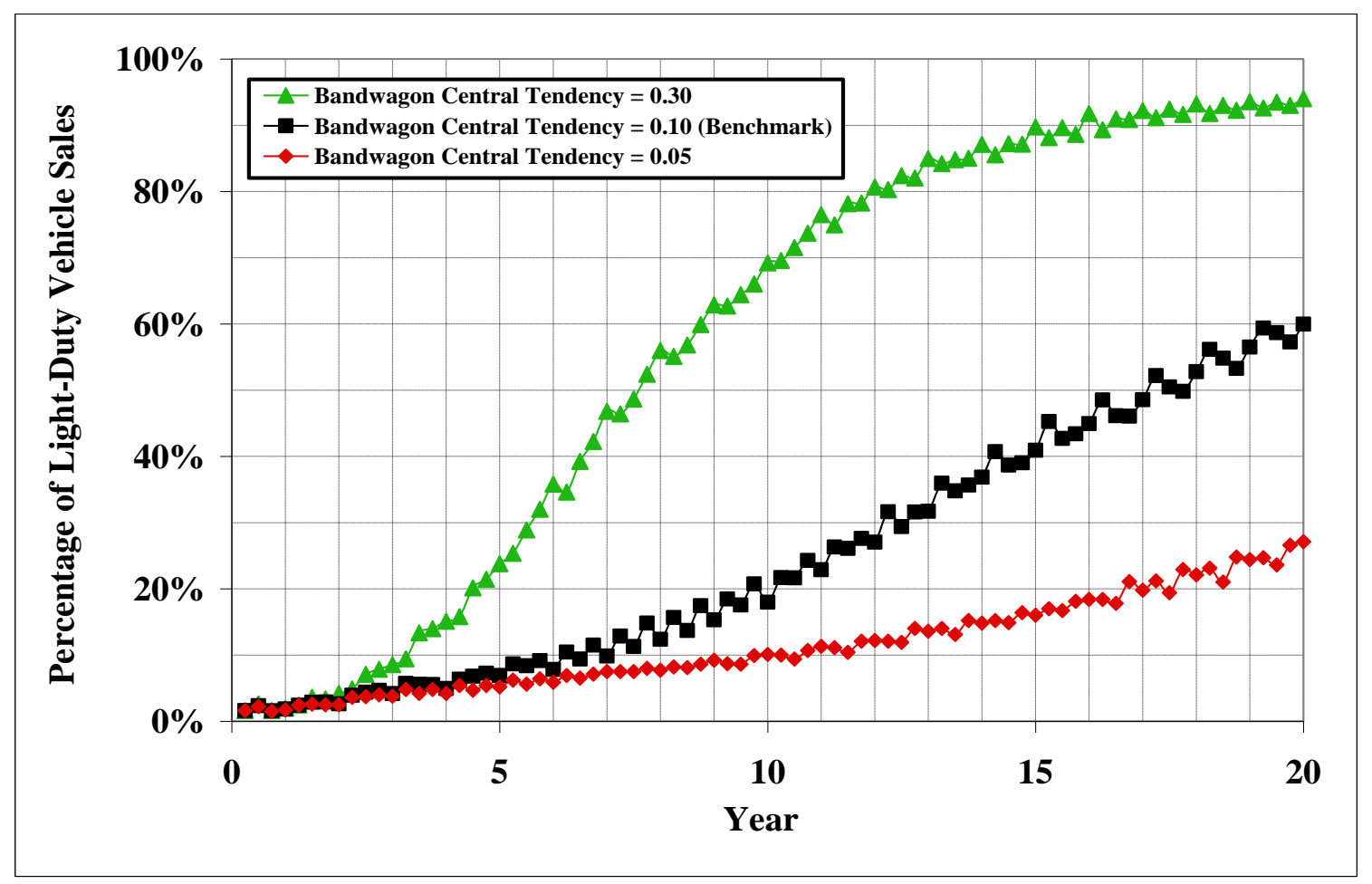

\begin{tabular}{|l|c|c|c|c|}
\hline \multirow{2}{*}{ Bandwagon Central Tendency } & \multicolumn{4}{|c|}{ Hydrogen Vehicle Sales Penetration } \\
\cline { 2 - 5 } & $\mathbf{5} \mathbf{~ y r}$ & $\mathbf{1 0} \mathbf{~ y r}$ & $\mathbf{1 5} \mathbf{~ y r}$ & $\mathbf{2 0} \mathbf{~ y r}$ \\
\hline 0.30 & $24 \%$ & $63 \%$ & $92 \%$ & $94 \%$ \\
\hline 0.10 (Benchmark) & $7 \%$ & $18 \%$ & $41 \%$ & $60 \%$ \\
\hline 0.05 & $5 \%$ & $10 \%$ & $16 \%$ & $27 \%$ \\
\hline
\end{tabular}

\subsubsection{Greenness}

Each driver has a taste for greenness, which is represented by the additional amount of money the driver would be willing to pay for the perceived environmental benefits of a hydrogen vehicle. Similar to the bandwagon effect, the greenness values are log-normally distributed with a central tendency and dispersions that measure the distribution of the taste for greenness in the driver agent population. The minimum level of greenness is $\$ 0$. Most drivers cluster at similar, low values, with a minority of drivers having very high values. Scenarios were conducted on both dispersion and central tendency.

The dispersion measure describes how diverse the drivers are. The larger the dispersion, the more drivers have extreme tastes for greenness. If the central tendency value of greenness is $\$ 250$ and the dispersion measure is 10 , as in the benchmark, then $68.3 \%$ of agents will have greenness levels between $\$ 25$ and $\$ 2,500$. If the dispersion measure is $6,68.3 \%$ of agents will have greenness levels between $\$ 42$ and $\$ 1,500$. 
The choices of a central tendency value of $\$ 250$ and a dispersion measure of 10 to define the benchmark greenness distribution are based on evidence of willingness to pay for a green vehicle observed among hybrid buyers and reported in stated-preference surveys. ${ }^{14}$ The high value of the central tendency represents a $150 \%$ increase above the benchmark level, while the low value is chosen to represent no median greenness effect. Because hybrid buyers provide an imperfect example of greenness - they are also influenced by fuel savings, tax credits, and the limited variety of hybrid vehicle models - and because people may not act exactly the way they respond in stated preference surveys, there is uncertainty about the actual influence of greenness on driver purchasing decisions. The sensitivity estimates attempt to reflect that uncertainty.

Results are shown in Figure 3-8 for sensitivity to greenness central tendency. If the central tendency is $\$ 375$ as opposed to the benchmark case of $\$ 250$, penetration by the $20^{\text {th }}$ year is $69 \%$ as compared to $60 \%$ in the benchmark case. If the central tendency is a low $\$ 1$, sales penetration by the $20^{\text {th }}$ year is only $17 \%$.

\footnotetext{
${ }^{14}$ Information on hybrid vehicles is taken from Matthew E. Kahn, "Do Greens Drive Hummers or Hybrids? Environmental Ideology as a Determinant of Consumer Choice," Journal of Environmental Economics and Management 54 (2007): 129-145; and Ward's Automotive Yearbook, 2008. Stated preference sources are R. Graham, Comparing the Benefits and Impacts of HEV Options (Palo Alto, Calif. EPRI, 2001), D. J. Santini and A. D. Vyas, Suggestions for a New Vehicle Choice Model Simulating Advance Vehicles Introduction Decisions (AVID): Structure and Coefficients, Center for Transportation Analysis, Argonne National Laboratory, 2005; and Melanie Tompkins, David Bunch, Danilo Santini, Mark Bradley, Anant Vyas, and David Poyer, "Determinants of Alternative Fuel Vehicle Choice in the Continental United States," Transportation Research Record: Journal of the Transportation Research Board 1641 (1998): 130-138. The benchmark central tendency and dispersion used in the model are mean values calculated from data in these reports.
} 
Figure 3-8: Effect of Greenness Central Tendency on Hydrogen Vehicle Sales Growth

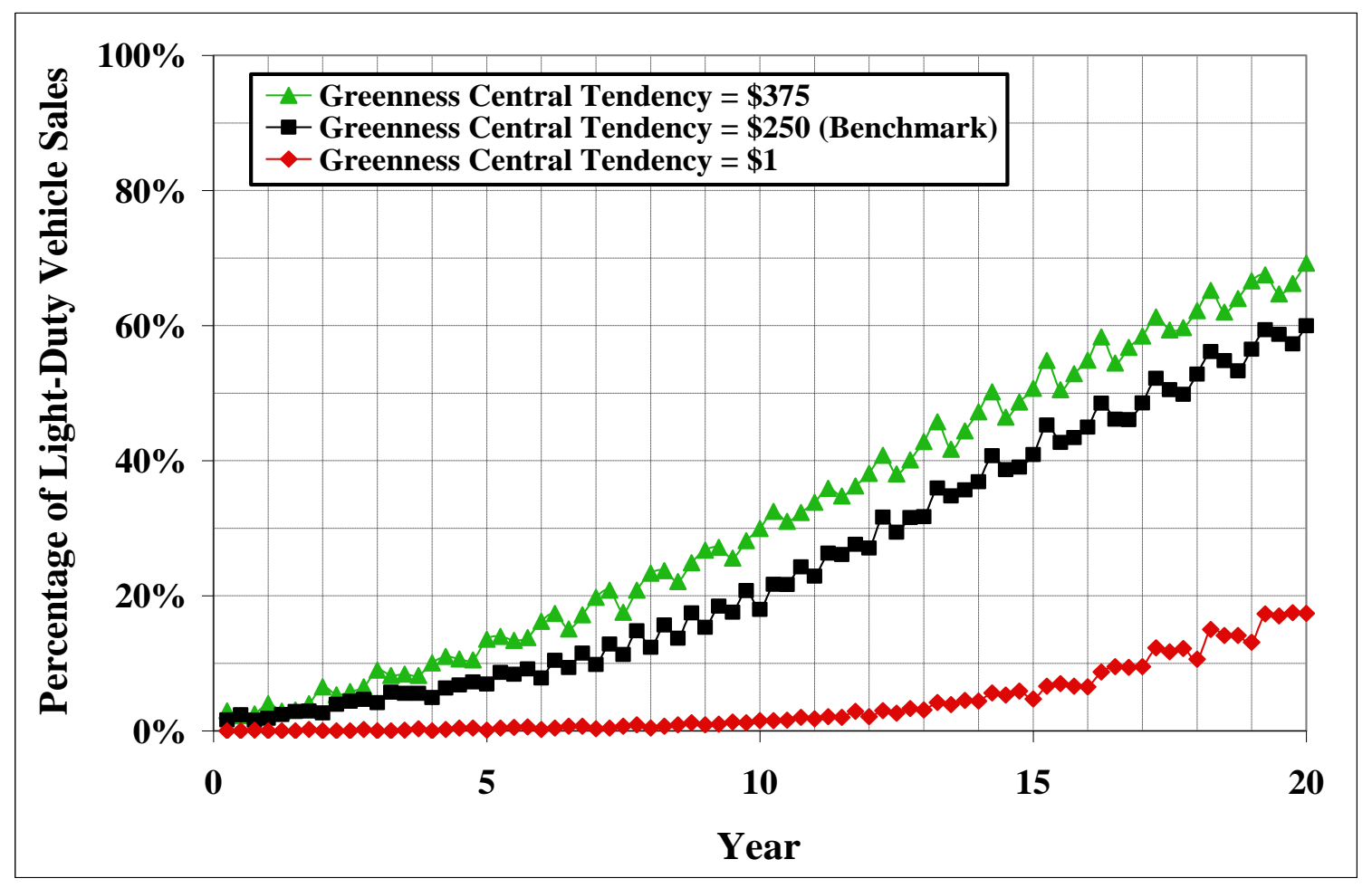

\begin{tabular}{|l|c|c|c|c|}
\hline \multirow{2}{*}{ Greenness Central Tendency } & \multicolumn{4}{|c|}{ Hydrogen Vehicle Sales Penetration } \\
\cline { 2 - 5 } & $\mathbf{5 ~ y r}$ & $\mathbf{1 0} \mathbf{~ y r}$ & $\mathbf{1 5} \mathbf{~ y r}$ & $\mathbf{2 0}$ yr \\
\hline$\$ 375$ & $14 \%$ & $30 \%$ & $51 \%$ & $69 \%$ \\
\hline$\$ 250$ (Benchmark) & $7 \%$ & $18 \%$ & $41 \%$ & $60 \%$ \\
\hline$\$ 1$ & $0 \%$ & $2 \%$ & $5 \%$ & $17 \%$ \\
\hline
\end{tabular}


Results are shown in Figure 3-9 for sensitivity to greenness dispersion. The range considered is from a high dispersion value of 20 and a low value of 2 , representing a larger number of drivers with strong and weak tastes for greenness and a very small number of each, respectively. In the high dispersion scenario, sales penetration by the $20^{\text {th }}$ year is $71 \%, 11$ percentage points higher than in the benchmark scenario. In the low dispersion scenario, sales penetration by the $20^{\text {th }}$ year reaches only $21 \%, 39$ percentage points lower than in the benchmark.

Figure 3-9: Effect of the Dispersion of Greenness on Hydrogen Vehicle Sales Growth

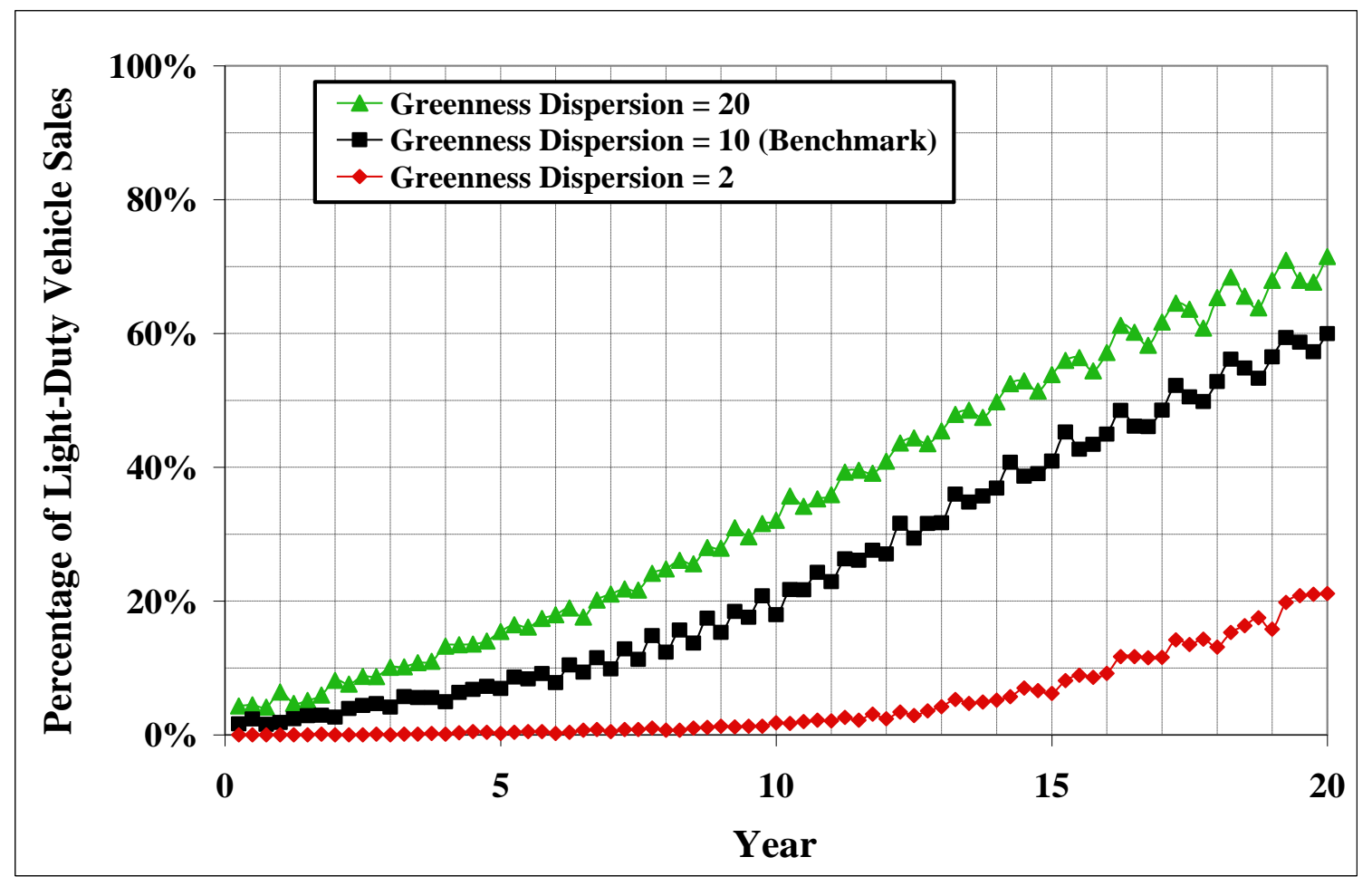

\begin{tabular}{|l|c|c|c|c|}
\hline \multirow{2}{*}{ Greenness Dispersion Value } & \multicolumn{4}{|c|}{ Hydrogen Vehicle Sales Penetration } \\
\cline { 2 - 5 } & $\mathbf{5} \mathbf{~ y r}$ & $\mathbf{1 0} \mathbf{~ y r}$ & $\mathbf{1 5} \mathbf{~ y r}$ & $\mathbf{2 0} \mathbf{~ y r}$ \\
\hline 20 & $15 \%$ & $32 \%$ & $54 \%$ & $71 \%$ \\
\hline 10 (Benchmark) & $7 \%$ & $18 \%$ & $41 \%$ & $60 \%$ \\
\hline 2 & $0 \%$ & $2 \%$ & $6 \%$ & $21 \%$ \\
\hline
\end{tabular}

\subsubsection{Conclusions on Model Sensitivity to Driver Behavior}

As can be seen in the scenarios reported in this section, assumptions about driver agent behavior have a significant effect on the results of the model. The strength of driver familiarity has a large influence on hydrogen vehicle sales growth. A change in the disadvantage due to 
limited familiarity creates an early change in sales that compounds over time. The level of driver agent familiarity can substantially accelerate or delay the rate of hydrogen vehicle adoption, even if hydrogen vehicles still dominate the market in the long-run. While the literature has much to say on how to estimate the disadvantage due to limited familiarity, there are justifications for a number of different values. The influence of the bandwagon effect on hydrogen vehicle sales serves to counteract the lack of familiarity with the passage of time. The influence of greenness on vehicle choice is somewhat smaller but still significant.

\subsection{Investor Sensitivity Scenarios}

This section presents sensitivity scenarios for major investor behavior parameters. Section 3.3.1 examines sensitivity to the staff discount rate, and Section 3.3.2 examines sensitivity to the upper management discount rate. Section 3.3.3 reports sensitivity to the rapidity of learning. Sections 3.3.4 through 3.3.6 examine sensitivity to three facets of the sophistication of the investor agent's calculations underlying profitability assessments: how hydrogen demand is estimated for the first period of a new station, how expectations of the growth of hydrogen sales are formed, and the number of investors. Section 3.3.7 summarizes the results of the investor sensitivity scenarios.

\subsubsection{Investor Discount Rate - Staff}

The discount rate used by investor agents has a direct effect on the price that drivers will pay for hydrogen. Different assumptions regarding the discount rate imply different required rates of return on capital investments, and consequently affect the production cost of hydrogen and the number of refueling stations sited. In the case of a large investor with a planning staff, the staff evaluation uses a relatively narrow range of discount rates applied using textbook project evaluation methods in an effort to evaluate alternative degrees of project risk. Upper management may apply a wider range of discount rates, as discussed in Section 3.3.2, "Investor Discount Rate - Upper Management."

For the benchmark case, a staff discount rate of $10 \%$ is used. ${ }^{15}$ Sensitivity scenarios are presented using a higher discount rate of $17 \%$ and a lower discount rate of $7 \%$. Results of the lower discount rate scenario show that hydrogen vehicle sales penetration occurs slightly more rapidly with the lower discount rate than in the benchmark case. By the $20^{\text {th }}$ year, sales penetration in the lower discount rate scenario reaches $62 \%$ compared to $60 \%$ in the benchmark case, as shown in Figure 3-10. In the higher discount rate scenario, adoption of hydrogen vehicles is slower, leading to sales penetration of $54 \%$ by the $20^{\text {th }}$ year of the simulation.

\footnotetext{
15 "DOE H2A Standard Economic Assumptions," DOE Hydrogen Annual Review Program: DOE H2A Analysis, http://www.hydrogen.energy.gov/h2a_analysis.html (accessed August 26, 2009).
} 


\section{Figure 3-10: Effect of the Investor's Staff Discount Rate on Hydrogen Vehicle Sales Growth}

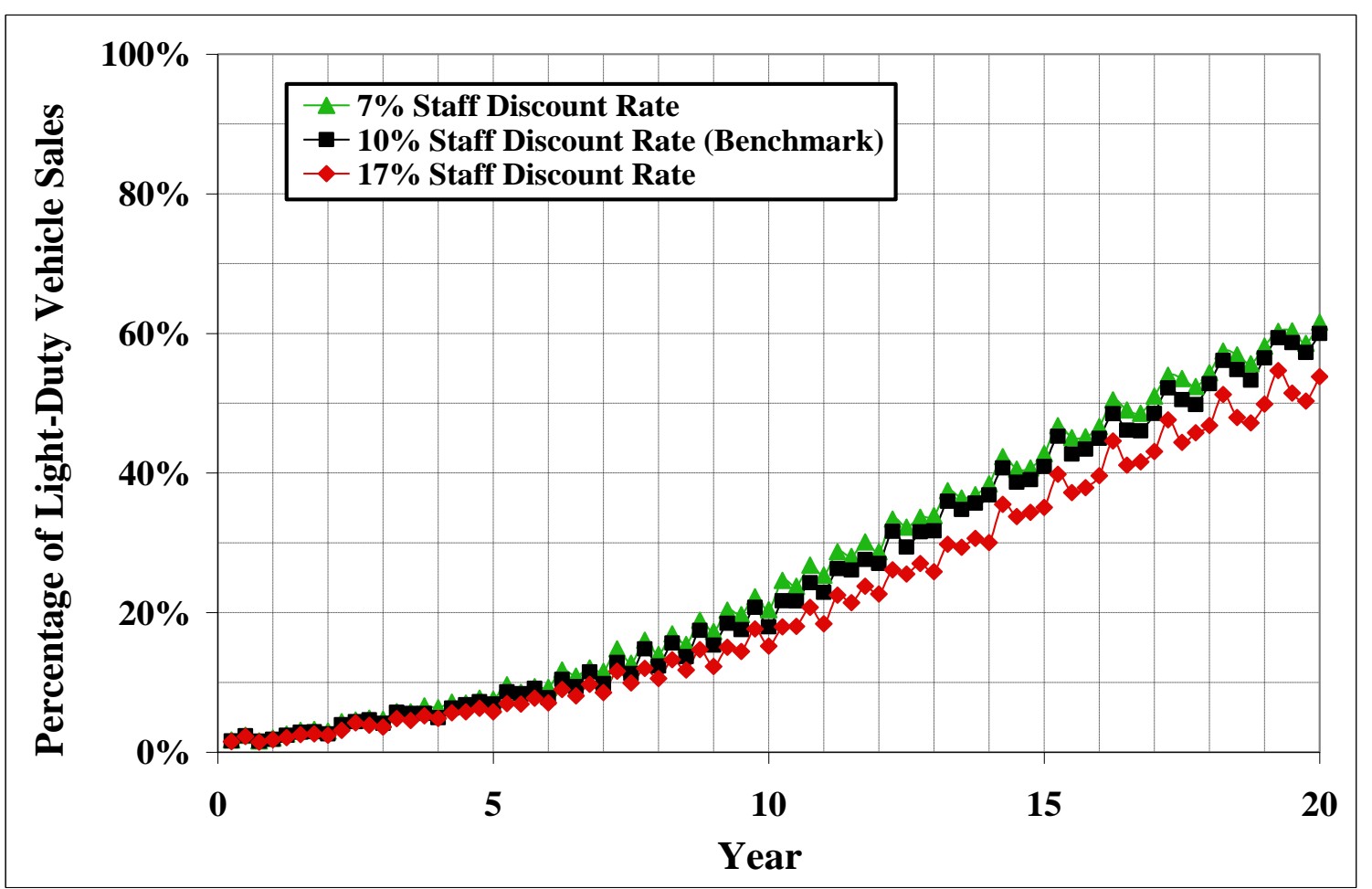

\begin{tabular}{|c|c|c|c|c|}
\hline \multirow{2}{*}{ Staff Discount Rate } & \multicolumn{4}{|c|}{ Hydrogen Vehicle Sales Penetration } \\
\cline { 2 - 5 } & $\mathbf{5} \mathbf{~ y r}$ & $\mathbf{1 0} \mathbf{~ y r}$ & $\mathbf{1 5} \mathbf{~ y r}$ & $\mathbf{2 0} \mathbf{~ y r}$ \\
\hline $7 \%$ & $8 \%$ & $20 \%$ & $43 \%$ & $62 \%$ \\
\hline $10 \%$ (Benchmark) & $7 \%$ & $18 \%$ & $41 \%$ & $60 \%$ \\
\hline $17 \%$ & $6 \%$ & $15 \%$ & $35 \%$ & $54 \%$ \\
\hline
\end{tabular}

\subsubsection{Investor Discount Rate - Upper Management}

Some upper management groups are conservative, and others are more risk tolerant. The discount rate used for an investor's profit calculation reflects the rate of return required by the investor for a project to be attractive. Discount rates consistent with a range of ordinary business decisions are used in the staff scenario. Scenarios are also examined in which an investor is highly risk-tolerant or highly risk-averse. In the highly risk-tolerant case, an investor agent would pursue a project without being compensated adequately for its risk. This is simulated using a discount rate of $0 \%$. In the extremely risk-averse case, an investor agent would require an unusually high return for the risk level. Three risk-averse scenarios were tested, using discount rates of $35 \%, 50 \%$, and $100 \%$.

Results are shown in Figure 3-11 for the sensitivity of the effect of upper management risk tolerance. Using an upper-management discount rate of $35 \%$ leads to a 20 -year sales penetration of $33 \%$, while a discount rate of $50 \%$ leads to 20 -year sales penetration of $11 \%$. Low 
risk tolerance by an investor, using a discount rate of $100 \%$, leads to a sales penetration of only $2 \%$. High risk tolerance by an investor will accelerate hydrogen vehicle sales penetration. Using a discount rate of $0 \%$ generates a 20 -year hydrogen vehicle sales penetration of $73 \%$.

\section{Figure 3-11: Effect of the Investor's Upper Management Discount Rate} on Hydrogen Vehicle Sales Growth

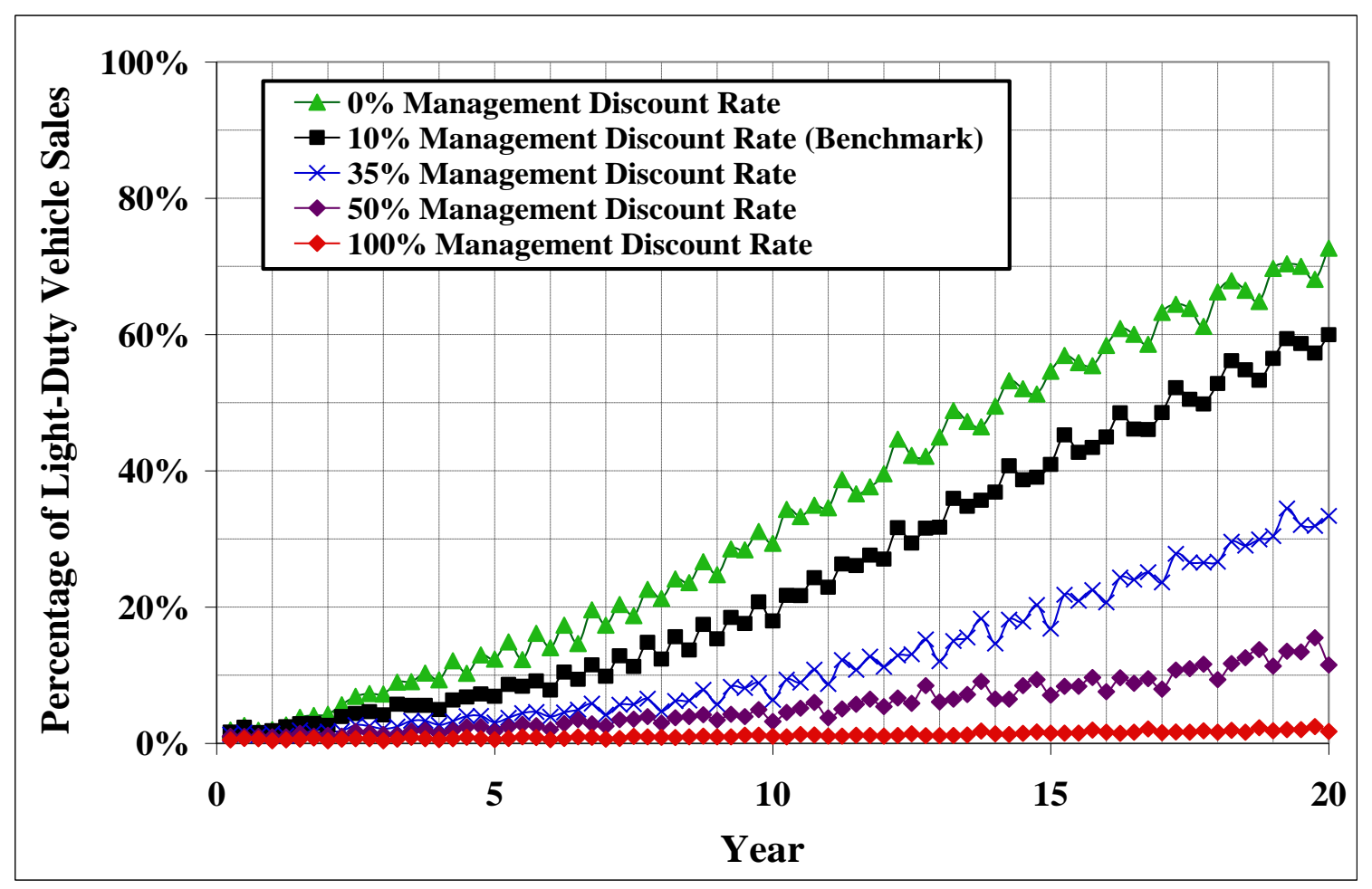

\begin{tabular}{|c|c|c|c|c|}
\hline \multirow{2}{*}{ Management Discount Rate } & \multicolumn{4}{|c|}{ Hydrogen Vehicle Sales Penetration } \\
\cline { 2 - 5 } & $\mathbf{5} \mathbf{~ y r}$ & $\mathbf{1 0} \mathbf{~ y r}$ & $\mathbf{1 5} \mathbf{~ y r}$ & $\mathbf{2 0} \mathbf{~ y r}$ \\
\hline $0 \%$ & $12 \%$ & $29 \%$ & $55 \%$ & $73 \%$ \\
\hline $10 \%$ (Benchmark) & $7 \%$ & $18 \%$ & $41 \%$ & $60 \%$ \\
\hline $35 \%$ & $3 \%$ & $6 \%$ & $17 \%$ & $33 \%$ \\
\hline $50 \%$ & $2 \%$ & $3 \%$ & $7 \%$ & $11 \%$ \\
\hline $100 \%$ & $1 \%$ & $1 \%$ & $2 \%$ & $2 \%$ \\
\hline
\end{tabular}

\subsubsection{Rapidity of Learning}

One of the dimensions of the sophistication of the investor's planning is how quickly experience changes beliefs. The investor has an initial belief about the rate of hydrogen sales growth that is subject to change as new evidence becomes available. Rapidity of learning is modeled by choosing a Bayesian weight $w$ that averages the influence of past observations and a newly added observation. See Section B.2.1.3, "Estimation of Growth Parameter, $\mathrm{G}_{\mathrm{t}}$." of Appendix $\mathrm{B}$ for additional information. An investor is said to be learning more rapidly if the most recent estimate of growth is weighted more heavily. 
To show the sensitivity of results to differences in rapidity of learning, the investor was assigned several alternative uses of prior information. In the benchmark case, the investor places equal weights on the previous estimate of growth and the most recent observation of growth, or $w=0.5$. Values of $w$ of 0.1 and 0.2 reflect slow learning. A value of 1.0 for $w$ indicates that the investor uses only the most recent growth information. Results for alternative values of $w$ are shown in Figure 3-12. All in all, adoption of hydrogen vehicles is not particularly sensitive to these alternative specifications of learning.

Figure 3-12: Effect of Rapidity of Learning on Hydrogen Vehicle Sales Growth

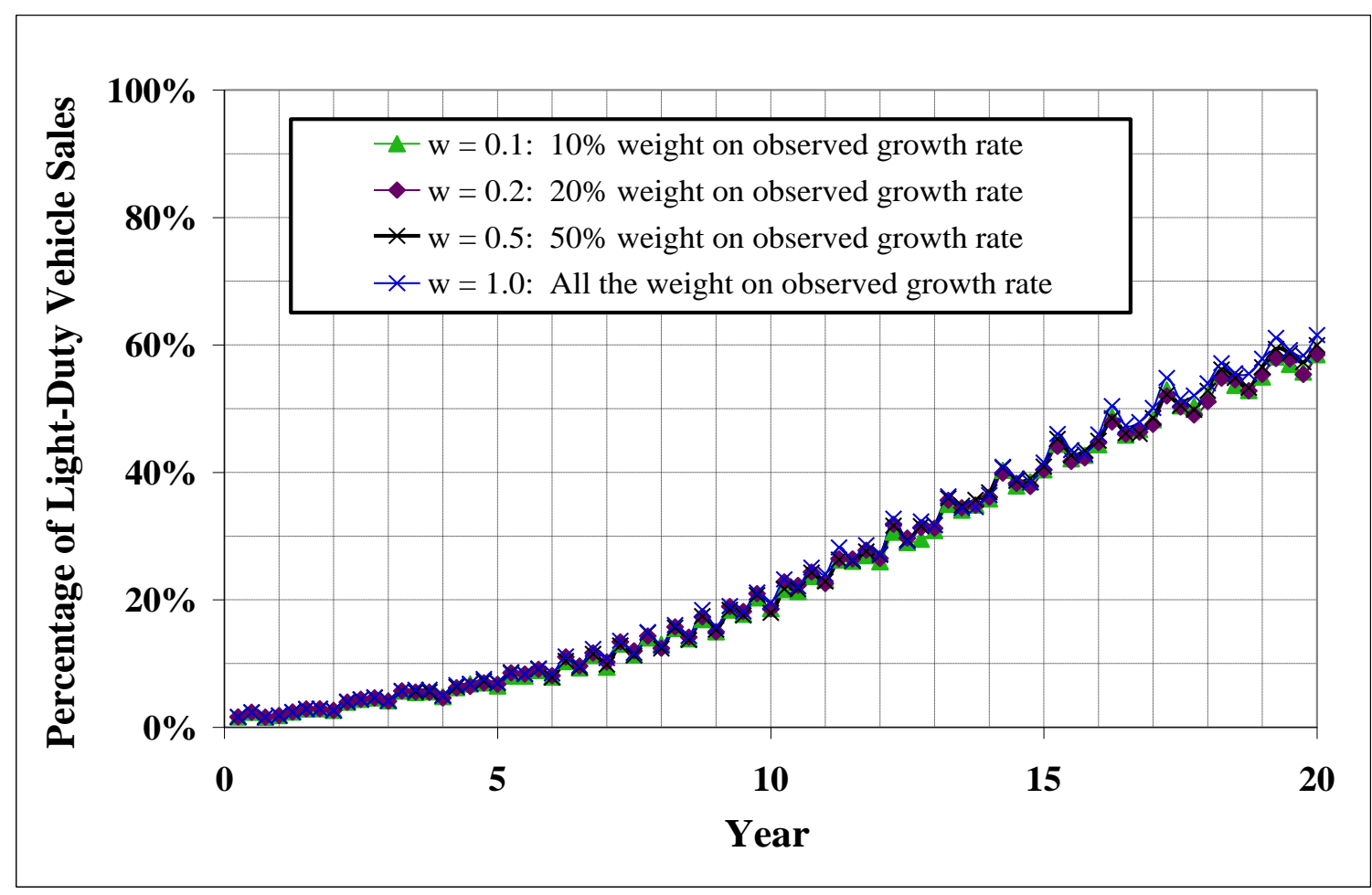

\begin{tabular}{|l|c|c|c|c|}
\hline \multirow{2}{*}{ Rapidity of Learning Parameter } & \multicolumn{4}{|c|}{ Hydrogen Vehicle Sales Penetration } \\
\cline { 2 - 5 } & $\mathbf{5 ~ y r}$ & $\mathbf{1 0} \mathbf{~ y r}$ & $\mathbf{1 5} \mathbf{~ y r}$ & $\mathbf{2 0} \mathbf{~ y r}$ \\
\hline 0.1 & $8 \%$ & $19 \%$ & $40 \%$ & $59 \%$ \\
\hline 0.2 & $9 \%$ & $19 \%$ & $40 \%$ & $59 \%$ \\
\hline 0.5 (Benchmark) & $7 \%$ & $18 \%$ & $41 \%$ & $60 \%$ \\
\hline 1.0 & $8 \%$ & $20 \%$ & $42 \%$ & $58 \%$ \\
\hline
\end{tabular}

\subsubsection{First Year Demand Estimation at Potential Station Locations}

The impact of the method an investor uses to estimate the demand for hydrogen fuel at potential station locations was studied, i.e., at locations where no station currently exists but 
where a station could be sited. In the model, the investor has the ability to observe the traffic going by locations to estimate future hydrogen demands. Two alternative methods of observing traffic were simulated, an "HPV Only" strategy and an "All Traffic" strategy. In the "HPV Only" strategy, the investor counts only the number of hydrogen vehicles going past a given location. In the "All Traffic" strategy, the investor counts all drivers going past a particular location. See Section B.2.1.1, "Unadjusted Sales at a Location," of Appendix B for additional information.

While there are slight differences, Figure 3-13 shows that the method of estimating first year demand at potential station locations using traffic counts has relatively little impact on the growth of hydrogen vehicle sales.

\section{Figure 3-13: Effect of Method of Estimating First Year Demand at Potential New Station Locations on Hydrogen Vehicle Sales Growth}

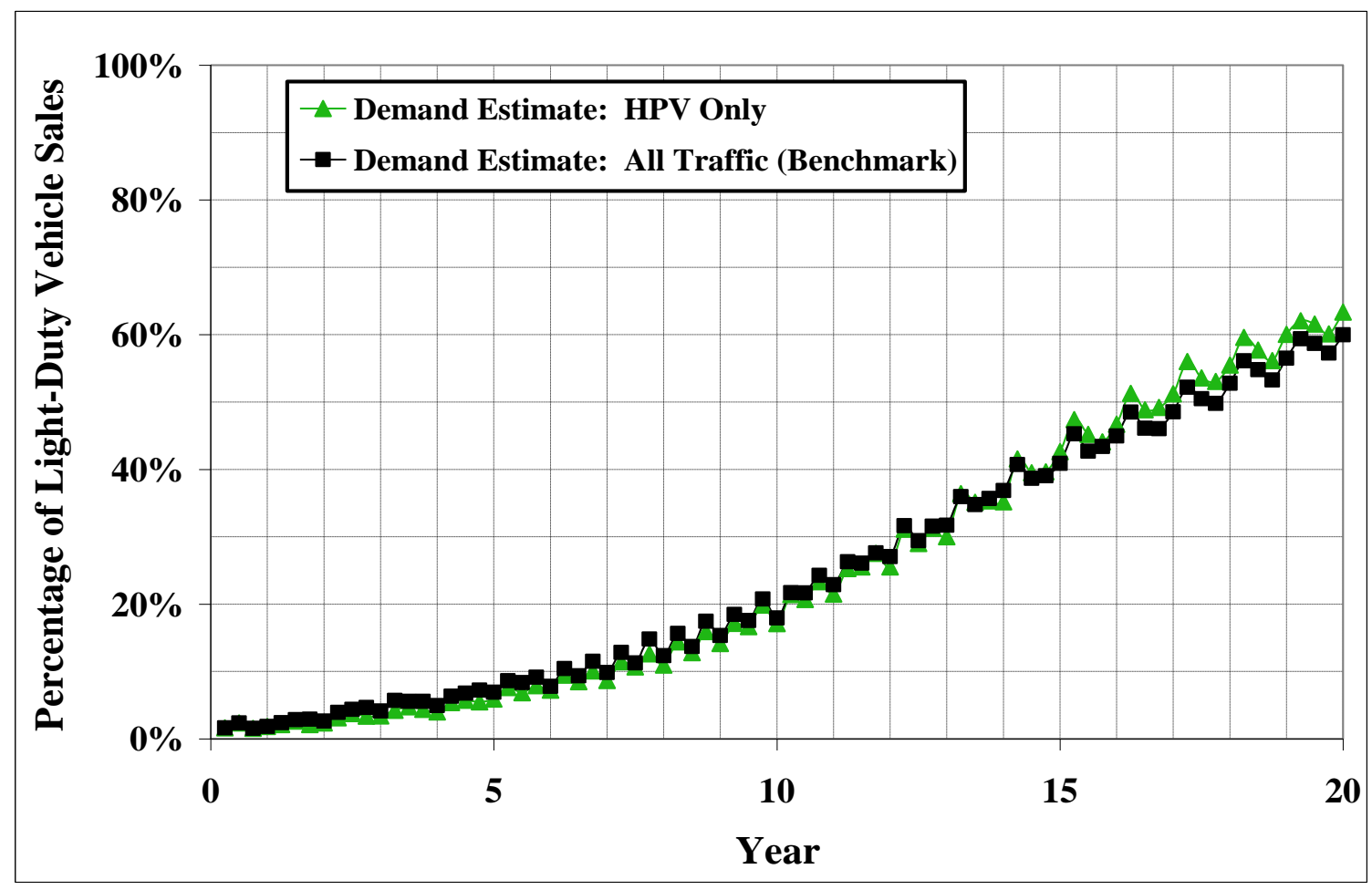

\begin{tabular}{|l|c|c|c|c|}
\hline First Year Demand Estimation & \multicolumn{4}{|c|}{ Hydrogen Vehicle Sales Penetration } \\
\cline { 2 - 5 } $\begin{array}{l}\text { Method at Potential New Station } \\
\text { Locations }\end{array}$ & $\mathbf{5 ~ y r}$ & $\mathbf{1 0 ~ y r}$ & $\mathbf{1 5} \mathbf{~ y r}$ & $\mathbf{2 0} \mathbf{~ y r}$ \\
\hline All Traffic (Benchmark) & $7 \%$ & $18 \%$ & $41 \%$ & $60 \%$ \\
\hline HPV Only & $6 \%$ & $14 \%$ & $43 \%$ & $63 \%$ \\
\hline
\end{tabular}




\subsubsection{Expectation of Growth}

Another calculation characterizing the sophistication of the investor's planning pertains to how the investor forms the expectation of hydrogen sales growth. To study sensitivity, two approaches have been used. In the first approach, the investor makes a projection each year of sales in the upcoming year based on the most recent year's growth and assumes that the new level of sales will prevail in all future years. Expected sales are ratcheted up each year based on expected one year growth, but no allowance is made for the fact that the whole future growth path will be affected. The investor thus does not allow for the fact that growth will continue in the future. In the second approach, the investor uses a logistic growth method. The same hydrogen sales expectation for the next year is used as in the first approach, but a logistic growth function is used to forecast subsequent hydrogen sales. This process is also repeated each year. The logistic model of growth expectation is used in the benchmark case. The results presented in Figure 3-14 show that the method chosen does not have much effect on adoption. Sections B.2.1.4, "Estimating Future Sales Using a Logistic Growth Function," and B.2.1.5, "Estimating Future Sales Using a Simpler Approach," of Appendix B describe these procedures.

\section{Figure 3-14: Effect of How Growth Expectations Are Modeled on Hydrogen Vehicle Sales Growth}

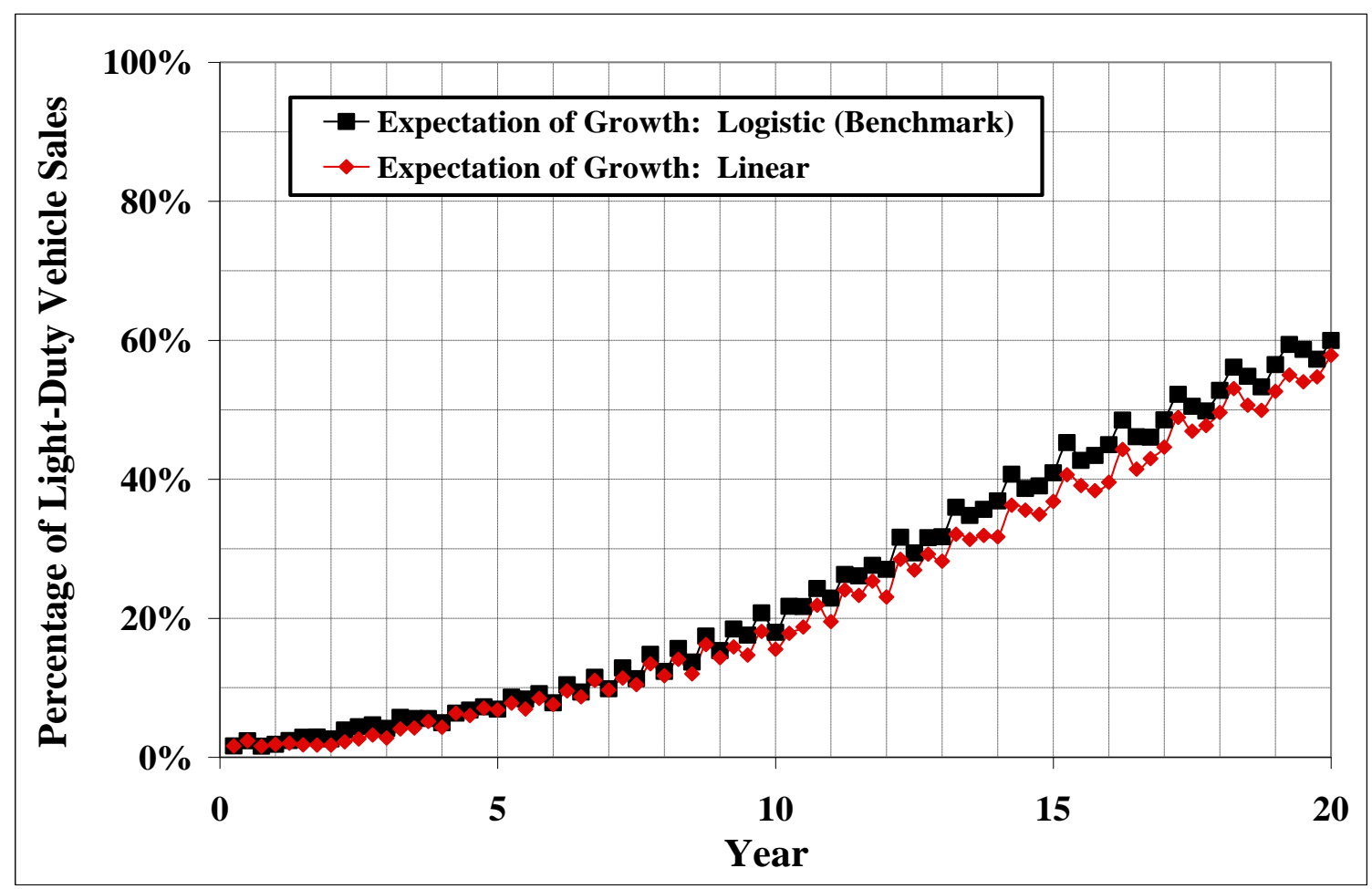

\begin{tabular}{|l|c|c|c|c|}
\hline \multirow{2}{*}{ Expectation of Growth } & \multicolumn{4}{|c|}{ Hydrogen Vehicle Sales Penetration } \\
\cline { 2 - 5 } & $\mathbf{5} \mathbf{~ y r}$ & $\mathbf{1 0} \mathbf{~ y r}$ & $\mathbf{1 5} \mathbf{~ y r}$ & $\mathbf{2 0} \mathbf{~ y r}$ \\
\hline Logistic (Benchmark) & $7 \%$ & $18 \%$ & $41 \%$ & $60 \%$ \\
\hline Linear & $7 \%$ & $16 \%$ & $39 \%$ & $58 \%$ \\
\hline
\end{tabular}




\subsubsection{Number of Investors}

To evaluate the influence of the number of investors on hydrogen vehicle adoption, scenarios with 2 and 10 investors were run in addition to the single investor scenario of the benchmark case. As shown in Figure 3-15, the number of investors in a simulation has relatively little effect on hydrogen vehicle sales penetration. A key to understanding this result is that each investor, even a single investor, prices hydrogen at average cost, responding to potential competition from other investors and to the threat of regulation if higher prices are charged, implying that additional investors do not add price competition to an already competitive market, as discussed earlier in Section 2.3.2, "Price Charged for Hydrogen Fuel."

This result does not however mean that investors act independently of one another. They are still competing with each other for sales available at any location. With multiple investors, an individual investor first evaluates the profitability of potential new station locations as if no other investors were present. Next, for locations that pass the profitability tests, the investor locates a station with probability equal to one over the number of investors, assuming other investors will also be building station. Using a random number generator, this procedure yields on average one new station located at each profitable location, although depending on randomness occasionally no station or more than one station might be sited there. See Section B.3, "Number of Investors," of Appendix B. 
Figure 3-15: Effect of Multiple Investor Agents on Hydrogen Vehicle Sales Growth

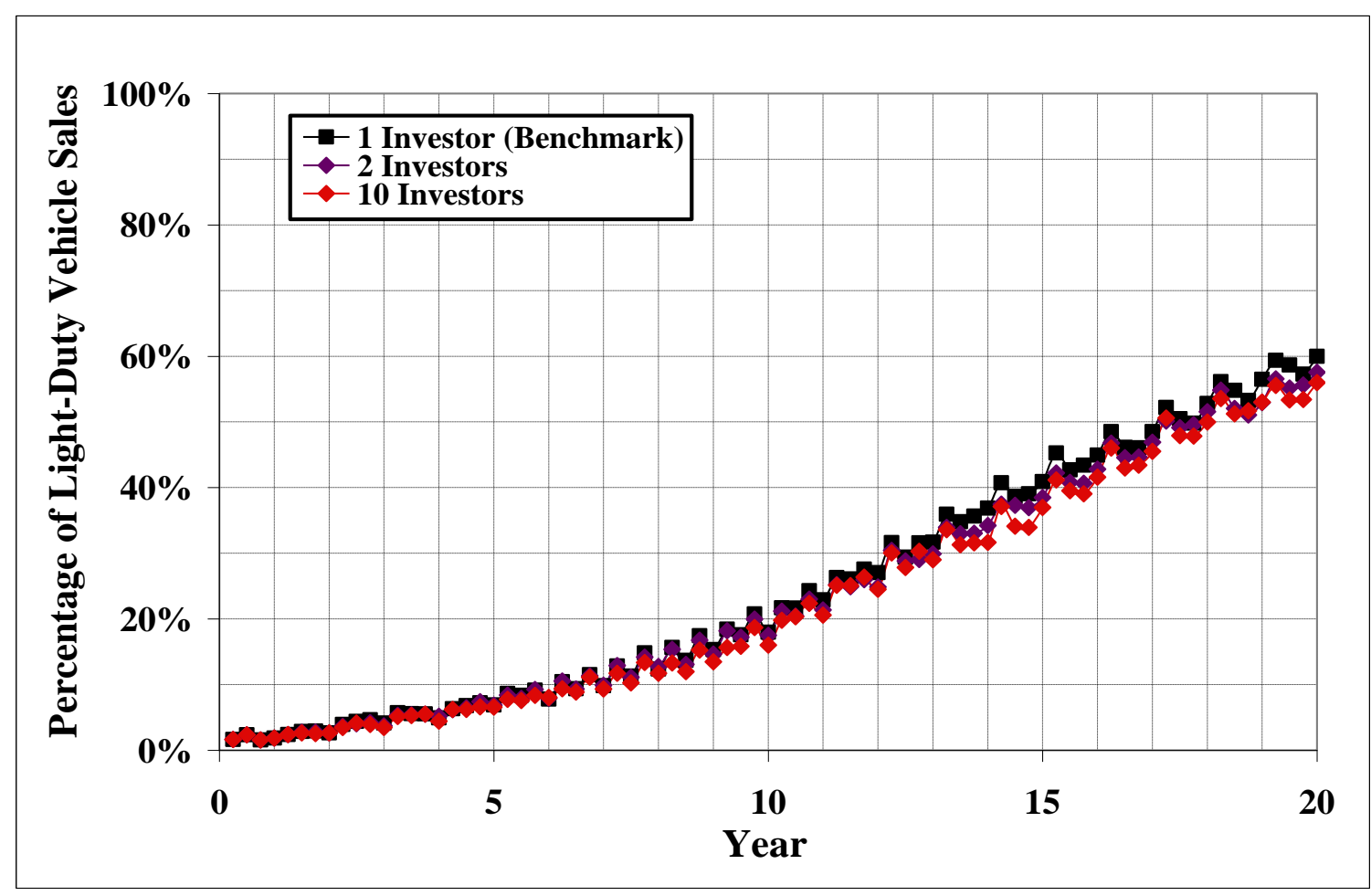

\begin{tabular}{|l|c|c|c|c|}
\hline \multirow{2}{*}{$\begin{array}{l}\text { Number of Investor } \\
\text { Agents }\end{array}$} & \multicolumn{4}{|c|}{ Hydrogen Vehicle Sales Penetration } \\
\cline { 2 - 5 } & $\mathbf{5} \mathbf{~ y r}$ & $\mathbf{1 0} \mathbf{~ y r}$ & $\mathbf{1 5} \mathbf{~ y r}$ & $\mathbf{2 0} \mathbf{~ y r}$ \\
\hline 1 (Benchmark) & $7 \%$ & $18 \%$ & $41 \%$ & $60 \%$ \\
\hline 2 & $7 \%$ & $18 \%$ & $38 \%$ & $56 \%$ \\
\hline 10 & $7 \%$ & $16 \%$ & $37 \%$ & $58 \%$ \\
\hline
\end{tabular}

\subsubsection{Conclusions on Model Sensitivity to Investor Behavior}

The upper management discount rate can have a large influence on the number of fuel stations built and consequently on hydrogen vehicle sales. In contrast, sensitivity of the model to the staff discount rate appears to be relatively small due to the narrower range used by the staff, reflecting textbook values. The same is true for sensitivity to the investor's rapidity of learning, method of forming growth expectations, and method a predicting first year sales at new stations were also small. All the latter may have large effects for one year, particularly early in the simulation when investor experience is limited, but the unfolding of actual events corrects investor mistakes relatively rapidly. The number of investors likewise has a limited effect, because a single investor is already acting much like of pure competitor in view of the threat of entry of other competitors and of regulation if monopolistic practices are observed. 


\subsection{Use of Realistic Approximative Decisions}

What is the effect of realistic, approximative decision making, sometimes called satisficing, in place of traditional, full optimization on the results? Obtaining an answer to this question faces the difficulty that derivation of the time path of full optimization is far too complicated to be able to estimate. While it is not possible to obtain an exact answer, a sensitivity analysis was performed to simulate an upper bound on the penetration that would result from an investor siting hydrogen fueling stations using perfect information. Having perfect information would imply that an investor could completely resolve two chief uncertainties, the growth rate of demand for hydrogen, and identification of fueling locations with the greatest potential for spurring hydrogen vehicle adoption. This upper bound is simulated by a hydrogen vehicle adoption path achieved in the case of an Unlimited Supply at Each Location, as it is not feasible for an investor to push the rate of adoption any higher than by providing hydrogen fueling opportunities comparable in availability to that of gasoline. The actual adoption path generated by an investor with perfect information would be below this adoption path, but it is impossible to construct the perfect-information adoption path. This maximum possible path gives an upper bound that can be compared with actual adoption paths generated with various types of approximative behavior.

The results of the effect of the investor's approximative behavior are shown in Figure 316, which shows penetration achieved for the stock of hydrogen vehicles at a given year (as opposed to sales penetration used for the other sensitivity comparisons). In the benchmark case, each investor agent follows a rule-of-thumb algorithm, and a stock penetration of $25 \%$ is reached by the $20^{\text {th }}$ year. In the unlimited fueling availability case, the upper bound of stock penetration by the $20^{\text {th }}$ year is $33 \%$. At the $20^{\text {th }}$ year, the actual stock penetration of $25 \%$ would be reached no earlier than the $18^{\text {th }}$ year, indicating that the delay at the $20^{\text {th }}$ year due to satisficing behavior is at most 2 years. 
Figure 3-16: The Effect of Realistic Approximative Behavior on Hydrogen Vehicle Stock Penetration Rate

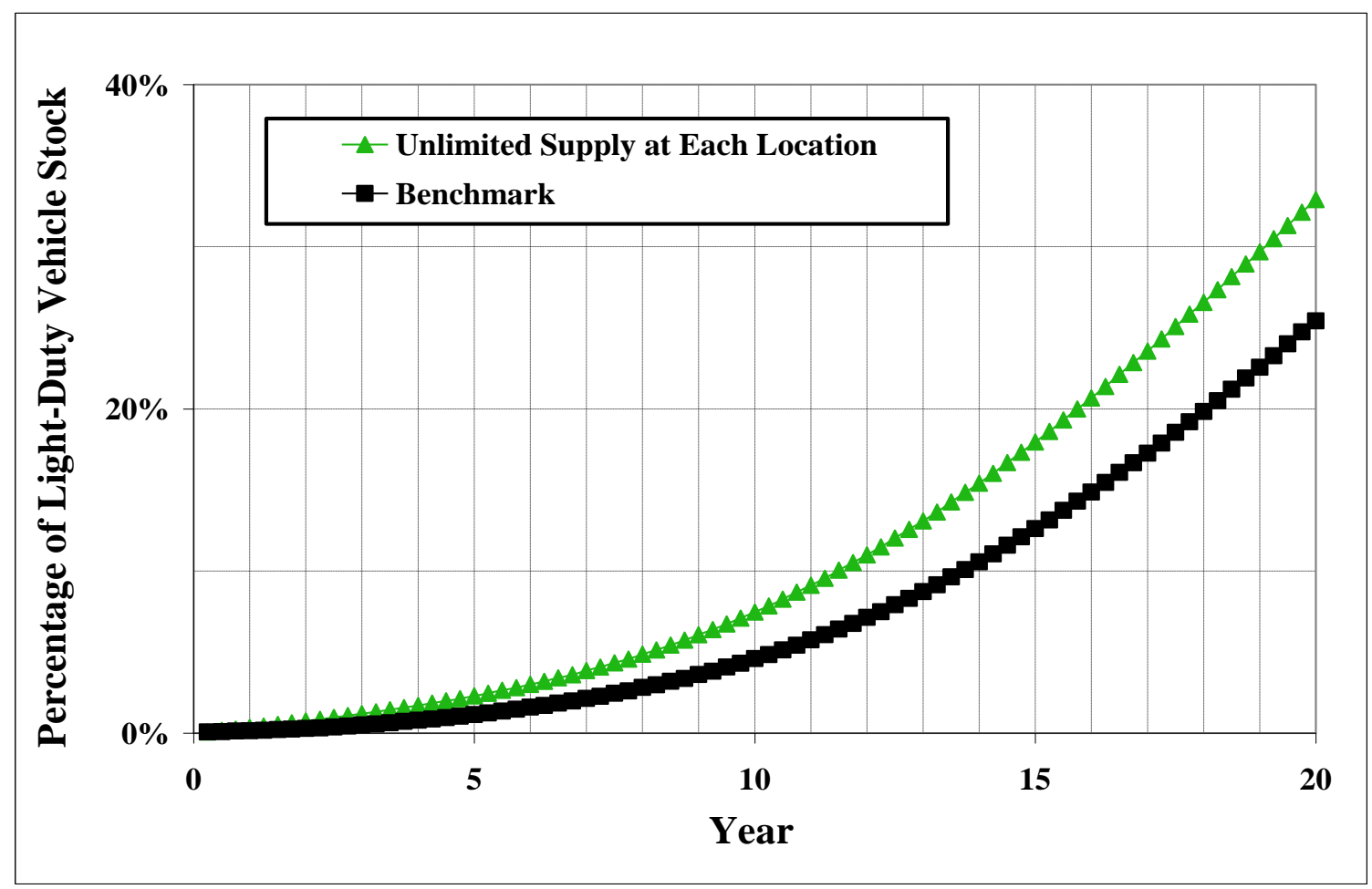

\begin{tabular}{|l|c|c|c|c|}
\hline \multirow{2}{*}{$\begin{array}{l}\text { Upper Bound on the Effect of } \\
\text { Approximative Behavior }\end{array}$} & \multicolumn{4}{|c|}{ Hydrogen Vehicle Share of Stock } \\
\cline { 2 - 5 } & $\mathbf{5} \mathbf{~ y r}$ & $\mathbf{1 0} \mathbf{~ y r}$ & $\mathbf{1 5} \mathbf{~ y r}$ & $\mathbf{2 0} \mathbf{~ y r}$ \\
\hline Unlimited Fueling Supply Case & $2 \%$ & $7 \%$ & $18 \%$ & $33 \%$ \\
\hline Benchmark & $1 \%$ & $5 \%$ & $13 \%$ & $25 \%$ \\
\hline
\end{tabular}




\section{PART FOUR: SENSITIVITY TO MARKET AND POLICY INFLUENCES}

This Part of the report presents model results intended to show the main uses of the study. These are estimating the effects of market developments that could importantly affect the adoption of hydrogen vehicles, and policy initiatives that could influence adoption.

The market developments considered here pertain to two chief ways that markets can affect profitability of adoption, namely, through purchase prices of vehicles and through prices of the fuels used by the vehicles. Section 4.1 is concerned with the difference between the price of a new hydrogen vehicle and a new non-hydrogen vehicle, called sticker price difference. A constant difference and a declining difference over time are considered. Section 4.2 is concerned with differences in operating costs between hydrogen and non-hydrogen vehicles.

The policies considered are of 3 kinds. Section 4.3 presents estimates of the effects of tax credits for the purchase of hydrogen vehicles. Section 4.4 presents estimates of effects of carbon taxes. Section 4.5 presents estimates of the effects of the number of initial hydrogen seed stations, which might be financed wholly or partly by government entities.

\subsection{Market Developments: Sticker Price Difference}

\subsubsection{Constant Sticker Price Difference}

In the benchmark scenario, it is assumed that at some point hydrogen vehicles will be competitive with non-hydrogen vehicles, although the model makes no prediction of the date that competitiveness will be reached. For the two vehicles to be on exactly equal terms, the sum of the sticker price difference and the present value of operating costs would be zero. It is reasonable, however, to assume that some advantage to hydrogen vehicles would be needed in order for there to be a gain to drivers from switching away from the type of vehicle they are already driving. In the benchmark case in this study, the hydrogen and non-hydrogen vehicle have the same purchase price, with hydrogen fuel cost savings giving the hydrogen vehicle an edge.

As shown in Figure 4-1, a sticker price difference of $\$ 2,000$ in favor of the hydrogen vehicle, sales penetration reaches $92 \%$ by the $20^{\text {th }}$ year compared to the benchmark penetration rate of $60 \%$ with equal vehicle sticker prices. A sticker price difference of $\$ 6,500$ in favor of a non-hydrogen vehicle results in only $6 \%$ hydrogen vehicle sales penetration by the $20^{\text {th }}$ year. 
Figure 4-1: Effect of Sticker Price on Hydrogen Vehicle Sales Growth

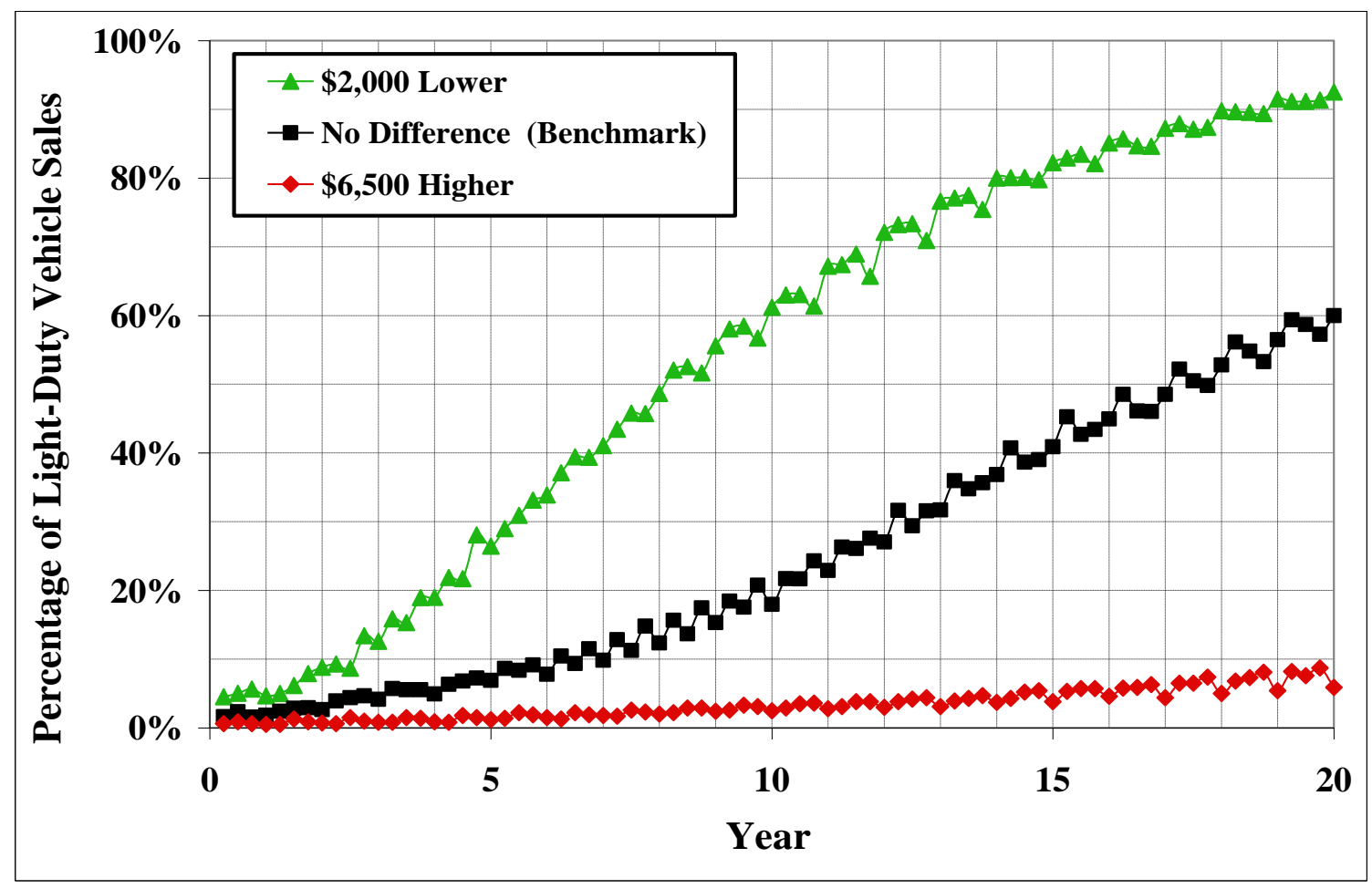

\begin{tabular}{|l|c|c|c|c|}
\hline \multirow{2}{*}{$\begin{array}{l}\text { Sticker Price of } \\
\text { Hydrogen Vehicle }\end{array}$} & \multicolumn{4}{|c|}{ Hydrogen Vehicle Sales Penetration } \\
\cline { 2 - 5 } & $\mathbf{5} \mathbf{~ y r}$ & $\mathbf{1 0} \mathbf{~ y r}$ & $\mathbf{1 5} \mathbf{~ y r}$ & $\mathbf{2 0} \mathbf{~ y r}$ \\
\hline \$2,000 Lower & $26 \%$ & $61 \%$ & $82 \%$ & $92 \%$ \\
\hline $\begin{array}{l}\text { No Difference } \\
\text { (Benchmark) }\end{array}$ & $7 \%$ & $18 \%$ & $41 \%$ & $60 \%$ \\
\hline \$6,500 Higher & $1 \%$ & $3 \%$ & $4 \%$ & $6 \%$ \\
\hline
\end{tabular}

\subsubsection{Declining Sticker Price Difference}

For hydrogen vehicles to sell at the same price as non-hydrogen vehicles, fuel cell costs will need to fall substantially. Given that hydrogen vehicles require about 80 to $100 \mathrm{~kW}$ of power, a PEM fuel cell cost of $\$ 1,000 / \mathrm{kW}$, gives a fuel cell cost of $\$ 100,000$ per vehicle. ${ }^{16}$ Costs of other components raise the total cost of a hydrogen vehicle further, giving a cost several times that needed to be viable in a mass market. At present, such products do not exist much beyond the prototype stage. A $2009 \mathrm{DOE}$ report has emphasized that the cost of a hydrogen fuel cell is expected to decline significantly in the future. ${ }^{2}$ Three factors have been recognized as contributing to future declines: 1) economies of scale that progressively lower production costs as production volume increases; 2) learning by doing in manufacturing which lowers costs as more experience with a new product is gained, and 3) technological advancements that increase

\footnotetext{
${ }^{16}$ National Academy of Engineering, The Hydrogen Economy: Opportunities, Costs, Barriers, and R\&D Needs (Washington, D.C.: National Research Council, 2004), pp. 4, 98, 119.
} 
durability and reliability and reduce the cost of major components. These major components including polymer electrolyte membranes, catalyst electrodes, the fuel cell stack, the fuel cell processor, the power conditioner, and air supply systems. Appendix $\mathrm{C}$ reviews estimates of the potential for contributions of these factors.

Based on Appendix C, scenarios of decline in the sticker price difference between hydrogen and non-hydrogen vehicles were chosen in which, after an unspecified number of years, the difference in sticker price becomes low enough to attract a significant number of buyers of hydrogen vehicles. In the scenarios, further declines occur as the three factors mentioned in the preceding paragraph continue to operate.

Results of the declining sticker price scenarios are presented in Figure 4-2 below. In the benchmark case, sales penetration reaches $60 \%$ by the 20th year of the simulation. In the 5 year case, the sticker price difference declines at a constant rate from a $\$ 14,000$ to $\$ 0$ over the first five years of the simulation. After five years, the hydrogen vehicle and the non-hydrogen vehicle have the same sticker price for the remainder of the simulation. In the 10 year case, the same sticker price difference declines at a constant rate over ten years instead of five years. In the 20 year case, there is a decline in sticker price difference from $\$ 14,000$ to $\$ 4,000$ over a 20 year period. As shown in the figure, there is a moderate response for the 5 year and 10 year declining sticker price difference scenarios, reaching 58\% and 52\% sales penetration, respectively. For the 20 year case, the effect is strong resulting in only $10 \%$ sales penetration by the 20th year of the simulation. 
Figure 4-2: Effect of Declining Sticker Price Difference on Hydrogen Vehicle Sales Growth

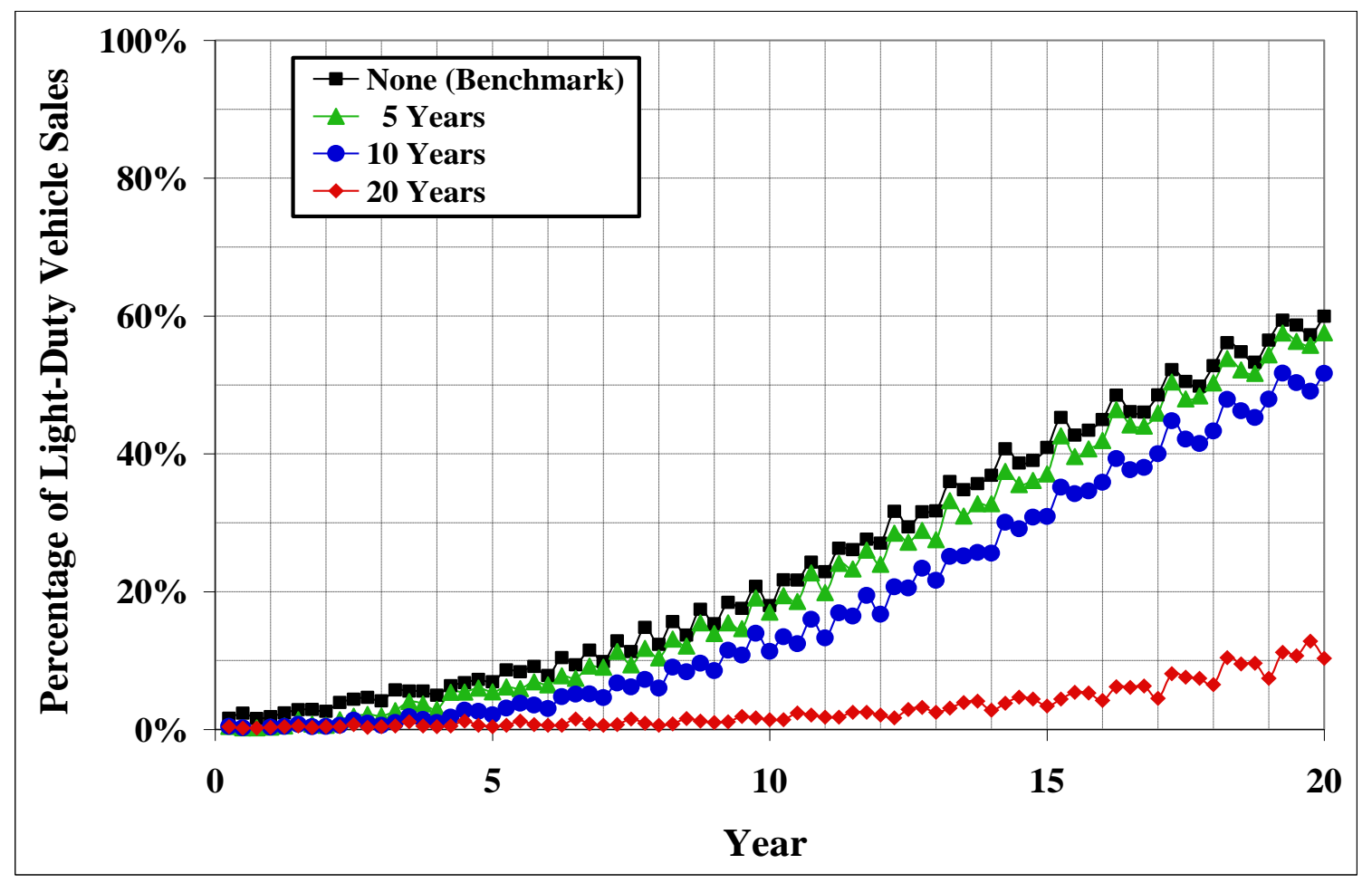

\begin{tabular}{|l|c|c|c|c|}
\hline \multirow{2}{*}{$\begin{array}{l}\text { Years to Reach Same Price } \\
\text { as Non-Hydrogen Vehicle }\end{array}$} & \multicolumn{4}{|c|}{ Hydrogen Vehicle Sales Penetration } \\
\cline { 2 - 5 } & $\mathbf{5 ~ y r}$ & $\mathbf{1 0} \mathbf{~ y r}$ & $\mathbf{1 5} \mathbf{~ y r}$ & $\mathbf{2 0} \mathbf{~ y r}$ \\
\hline None (Benchmark) & $7 \%$ & $18 \%$ & $41 \%$ & $60 \%$ \\
\hline 5 Years & $5 \%$ & $17 \%$ & $37 \%$ & $58 \%$ \\
\hline 10 Years & $2 \%$ & $11 \%$ & $31 \%$ & $52 \%$ \\
\hline 20 Years & $0 \%$ & $1 \%$ & $3 \%$ & $10 \%$ \\
\hline
\end{tabular}

${ }^{a}$ Decline to $\$ 4,000$ disadvantage

\subsection{Market Developments: Fuel Prices}

In the benchmark scenario, driver agents can save 9.8 cents per mile on fuel by driving a hydrogen vehicle instead of a non-hydrogen vehicle. In calculating this amount, the benchmark gasoline price is based on the EIA Annual Energy Outlook 2010 reference case. ${ }^{17}$ The savings

\footnotetext{
${ }^{17}$ Energy Information Administration, http://www.eia.doe.gov/oiaf/aeo/aeoref_tab.html, Table 3, Energy Prices by Sector and Source. Gasoline price for an assumed initial showroom year of 2018 is $\$ 3.91$ per gallon, giving a mid-year price in the adoption process for use in the simulation of \$4.85 in 2025, using EIA's projected 2.7\% annual gasoline price increase (2009 prices).
} 
per mile are calculated using a hydrogen price equal to $\mathrm{H} 2 \mathrm{~A}$ hydrogen production $\operatorname{cost}^{18}$ and fuel efficiency estimates for non-hydrogen and hydrogen vehicles. ${ }^{19}$

The present value of the fuel savings comes to $\$ 3,383$ over the life of the vehicle for the average driver, who drives 12,150 miles a year. In the benchmark case, the sticker prices of the hydrogen and non-hydrogen vehicle are equal. The fuel savings make the hydrogen vehicle a good enough financial investment to lead to $60 \%$ penetration by the $20^{\text {th }}$ year. Any combination of sticker prices and fuel savings that leads to a $\$ 3,383$ gain from switching to hydrogen will lead to the same results as in the base case.

Results for two scenarios in addition to the benchmark case are presented: one in which fuel prices are such that drivers save a high 20.7 cents per mile by driving a hydrogen vehicle, and one in which they save a low 0.5 cents per mile. The gain per mile made possible in the high savings case translates into a present value of approximately $\$ 7,174$ for the average driver agent. The low savings per mile translates into a present value of only $\$ 183$.

\footnotetext{
${ }^{18} \$ 3.63$ per kg (2009 prices). U.S. Department of Energy, "Future (2025) Natural Gas Steam Reformer (SMR) at Forecourt 1,500 kg/day,” Department of Energy Hydrogen Program, May 27, 2008. http://www.hydrogen.energy.gov/h2a_prod_studies.html (accessed February 17, 2009).

${ }^{19} 29$ mpg and 52 miles per kg, Norman Brinkman, Michael Wang, Trudy Weber, and Thomas Darlington, "Wells-to-Wheels Analysis of Advanced Fuel/Vehicle Systems - A North American Study of Energy Use, Greenhouse Gas Emissions, and Criteria Pollutant Emissions," Argonne National Laboratory, 2005, p. 89, Table 3-3.
} 
Figure 4-3: Effect of Fuel Cost Savings on Hydrogen Vehicle Sales Growth

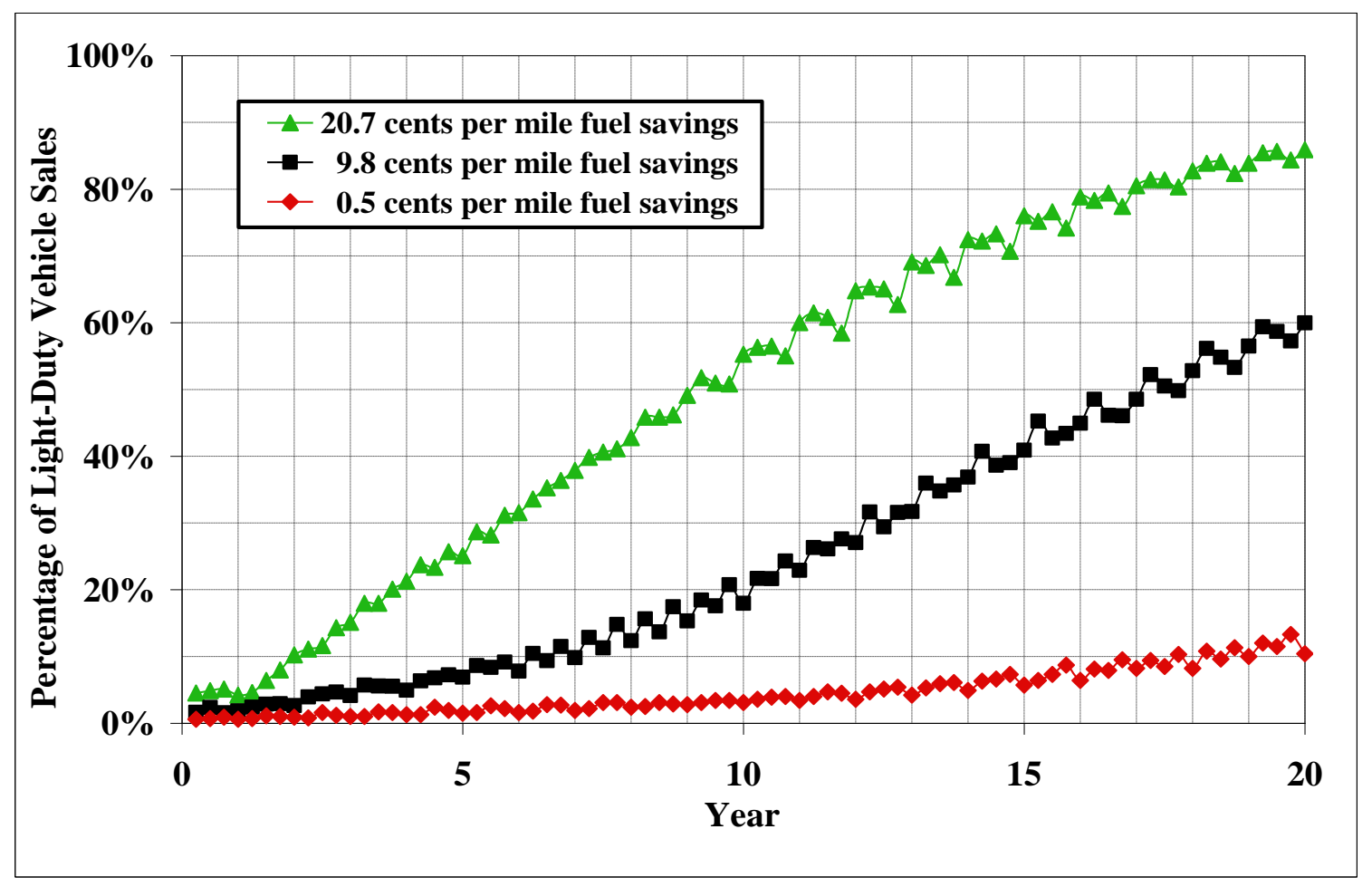

\begin{tabular}{|l|c|c|c|c|}
\hline \multirow{2}{*}{ Per Mile Fuel Savings } & \multicolumn{4}{|c|}{ Hydrogen Vehicle Sales Penetration } \\
\cline { 2 - 5 } & $\mathbf{5 y r}$ & $\mathbf{1 0 y r}$ & $\mathbf{1 5 y r}$ & $\mathbf{2 0 y r}$ \\
\hline 20.7 cents per mile & $25 \%$ & $55 \%$ & $76 \%$ & $86 \%$ \\
\hline $\begin{array}{l}9.8 \text { cents per mile } \\
\text { (Benchmark) }\end{array}$ & $7 \%$ & $18 \%$ & $41 \%$ & $60 \%$ \\
\hline 0.5 cents per mile & $2 \%$ & $3 \%$ & $6 \%$ & $10 \%$ \\
\hline
\end{tabular}

Results for the fuel cost cases are shown in Figure 4-3. As compared to the $60 \%$ penetration by the $20^{\text {th }}$ years in the base case, $86 \%$ penetration is reached by the $20^{\text {th }}$ year in the high-savings scenario and only $10 \%$ in the low-savings scenario.

\subsection{Policies: Tax Credits for Hydrogen Vehicle Purchase}

To turn now from effects of market developments to effects of policies, a tax credit toward a vehicle purchase works in the same way as a drop in sticker price, since drivers who buy the vehicle can subtract the tax credit from their income tax and get a dollar for dollar savings. A precedent can be found in tax credits that have been offered for the purchase of hybrid electric vehicles. 


\subsubsection{Permanent Tax Credit}

The benchmark scenario in Figure 4-4 is again shown as the lower line. Also shown is the result for a scenario in which a $\$ 2,500$ tax credit is offered for purchasing a hydrogen vehicle. The effectiveness of the tax credit is reflected in the result that by the $20^{\text {th }}$ year, $88 \%$ of all light-duty vehicles sold are powered by hydrogen, as compared with $60 \%$ in the benchmark case. Results for a higher tax credit of $\$ 6,000$ are also shown, in which the hydrogen sales share reaches $99 \%$ in the $20^{\text {th }}$ year.

Figure 4-4: Effect of Permanent Tax Credits on Hydrogen Vehicle Sales Penetration

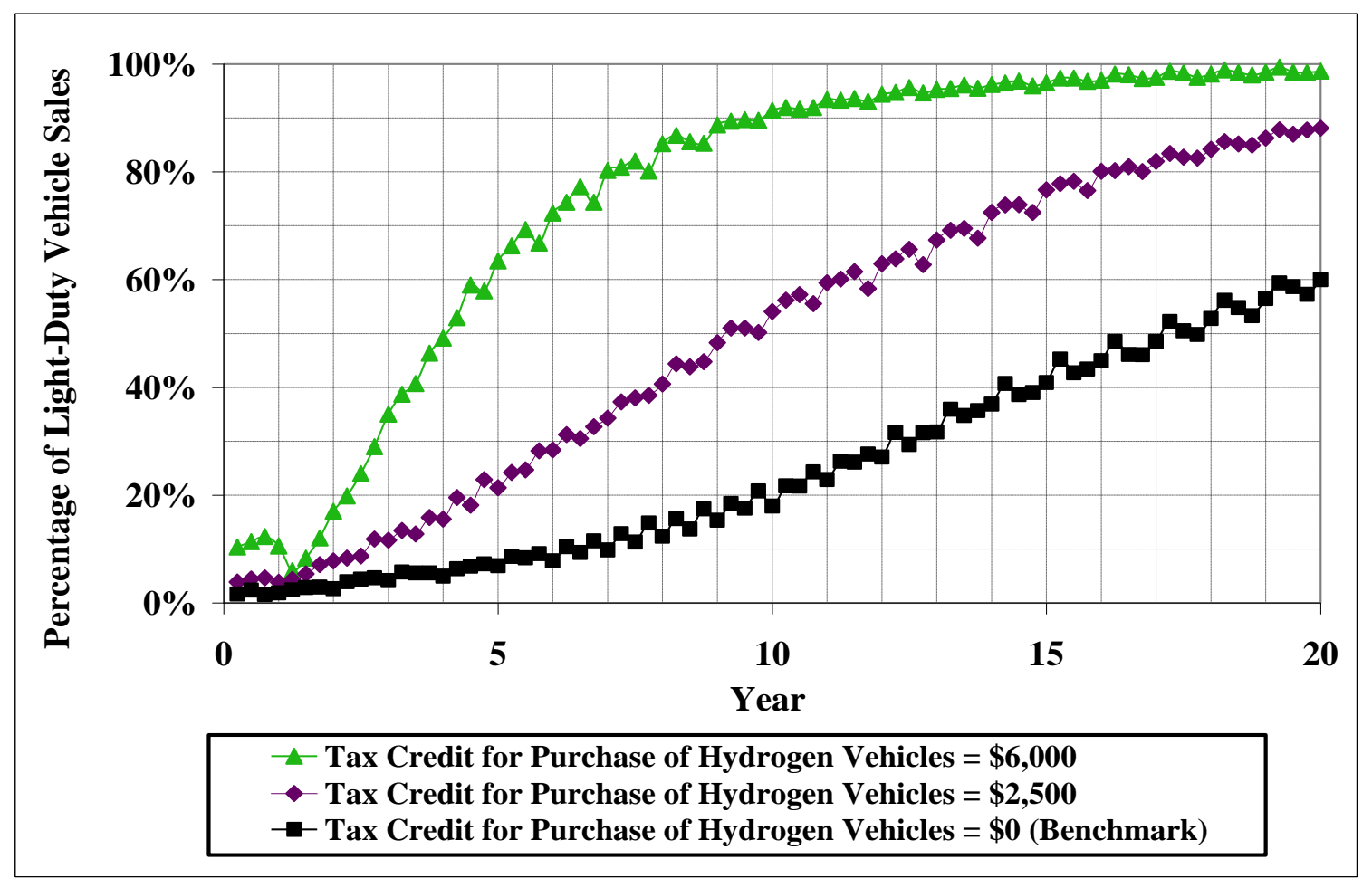

\begin{tabular}{|l|c|c|c|c|}
\hline \multirow{2}{*}{ Permanent Tax Credit } & \multicolumn{4}{|c|}{ Hydrogen Vehicle Sales Penetration } \\
\cline { 2 - 5 } & $\mathbf{5} \mathbf{y r}$ & $\mathbf{1 0} \mathbf{~ y r}$ & $\mathbf{1 5} \mathbf{~ y r}$ & $\mathbf{2 0} \mathbf{~ y r}$ \\
\hline \$6,000 Tax Credit & $63 \%$ & $91 \%$ & $97 \%$ & $99 \%$ \\
\hline \$2,500 Tax Credit & $21 \%$ & $54 \%$ & $77 \%$ & $88 \%$ \\
\hline \$0 Tax Credit (Benchmark) & $7 \%$ & $18 \%$ & $41 \%$ & $60 \%$ \\
\hline
\end{tabular}

\subsubsection{Temporary Tax Credit}

Figure 4-5 below shows the consequence of eliminating a vehicle tax credit after 10 years. While the drop in the percent of sales once the tax credit is terminated may appear to be large, hydrogen sales penetration continues to climb after termination of the credit, reaching $69 \%$ of sales after 20 years with the $\$ 2,500$ credit and $79 \%$ with the $\$ 6,000$ credit. The temporary tax 
credit hastens the growth of the hydrogen vehicle stock, which in turn hastens driver agents' familiarity with the vehicle through the bandwagon effect and contributes to accelerated growth throughout the simulation. Relative effects on the stock of hydrogen vehicles are even more noticeable. Without a tax credit, the hydrogen vehicle stock would make up about $5 \%$ of the total vehicle stock after 10 years, as was shown in Figure 3-2. The tax credits raise the stock at 10 years to $13 \%$ and $29 \%$, respectively, which in turn raise the level of the hydrogen sales penetration above the no-credit benchmark case in the remaining years.

Figure 4-5: Effect of Temporary Tax Credits on Hydrogen Vehicle Sales Penetration

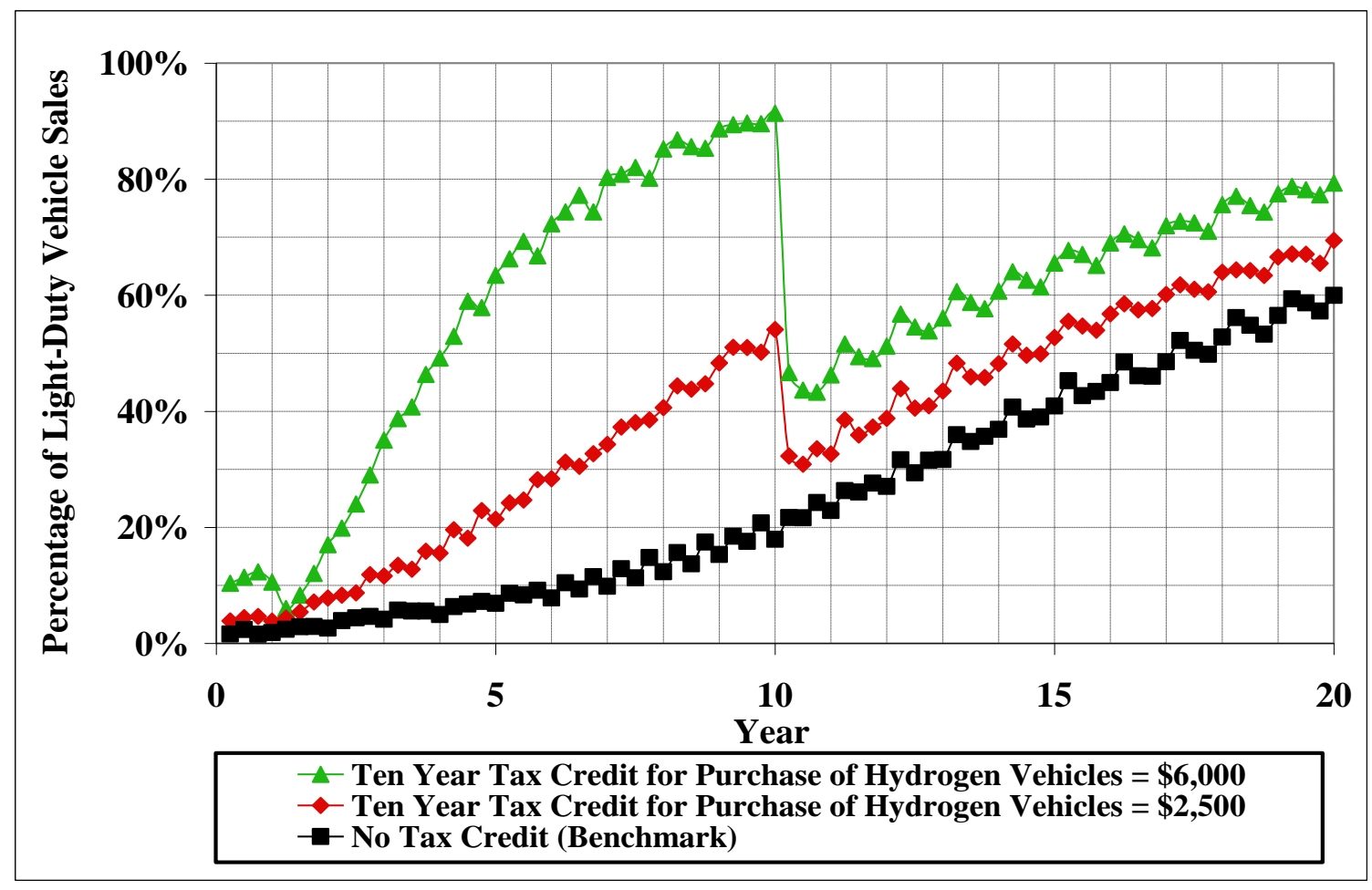

\begin{tabular}{|l|c|c|c|c|}
\hline \multirow{2}{*}{$\begin{array}{l}\text { Temporary Tax Credit } \\
\text { Terminated after 10 years }\end{array}$} & \multicolumn{4}{|c|}{ Hydrogen Vehicle Sales Penetration } \\
\cline { 2 - 5 } & $\mathbf{5} \mathbf{~ y r}$ & $\mathbf{1 0} \mathbf{~ y r}$ & $\mathbf{1 5} \mathbf{~ y r}$ & $\mathbf{2 0} \mathbf{~ y r}$ \\
\hline \$6,000 Tax Credit & $63 \%$ & $91 \%$ & $66 \%$ & $79 \%$ \\
\hline \$2,500 Tax Credit & $21 \%$ & $54 \%$ & $53 \%$ & $69 \%$ \\
\hline \$0 Tax Credit (Benchmark) & $7 \%$ & $18 \%$ & $41 \%$ & $60 \%$ \\
\hline
\end{tabular}




\subsection{Policies: Carbon Taxes}

Two carbon tax levels have been investigated: $\$ 38$ and $\$ 116$ per metric ton of $\mathrm{CO}_{2}$, calculated with the Greenhouse Gases, Regulated Emissions, and Energy Use in Transportation (GREET) Model. ${ }^{20}$ These compare with $\$ 85$ per metric ton estimated by the Stern Report as the social (i.e., total) cost of carbon, and $\$ 110$ per metric ton estimated as the requirement to have an impact on large-scale power generation from renewables. ${ }^{21}$ The smaller tax of $\$ 38$ per metric ton corresponds to a tax of 33 cents per gallon of gasoline and 44 cents per $\mathrm{kg}$ of hydrogen produced at distributed SMR stations. The larger tax of $\$ 116$ per metric ton corresponds to a tax of $\$ 1.01$ per gallon of gasoline and $\$ 1.34$ per $\mathrm{kg}$ of hydrogen produced at distributed stations. With the H2A model's assumption of $90 \%$ effective carbon capture and sequestration at centralized production facilities, the $\$ 38$ and $\$ 116$ taxes translate into 6 cent and 18 cents per $\mathrm{kg}$ taxes, respectively, on centrally produced hydrogen.

As noted in Part Two, centrally produced hydrogen is more expensive at the pump than is distributed production, and hence will not be profitable without a tax that has a greater effect on distributed costs. As shown in Figure 4-6 below, the lower carbon tax of $\$ 38$ per metric ton is not large enough to noticeably affect sales penetration compared to the benchmark case of no tax. The larger tax of $\$ 116$ per metric ton, which makes centrally produced hydrogen profitable in the very first year, results in modestly higher levels of hydrogen vehicle sales penetration.

\footnotetext{
${ }^{20}$ Argonne National Laboratory, "The Greenhouse Gases, Regulated Emissions, and Energy Use in Transportation (GREET) Model," "http://www.transportation.anl.gov/modeling_simulation/GREET/ index.html, December 2009.

${ }^{21}$ David J. C. MacKay, Sustainable Energy: Without the Hot Air (Cambridge: UIT Cambridge Press, 2009), p. 224, Figure 29.2.
} 
Figure 4-6: Effect of Carbon Taxes on Hydrogen Vehicle Sales Penetration

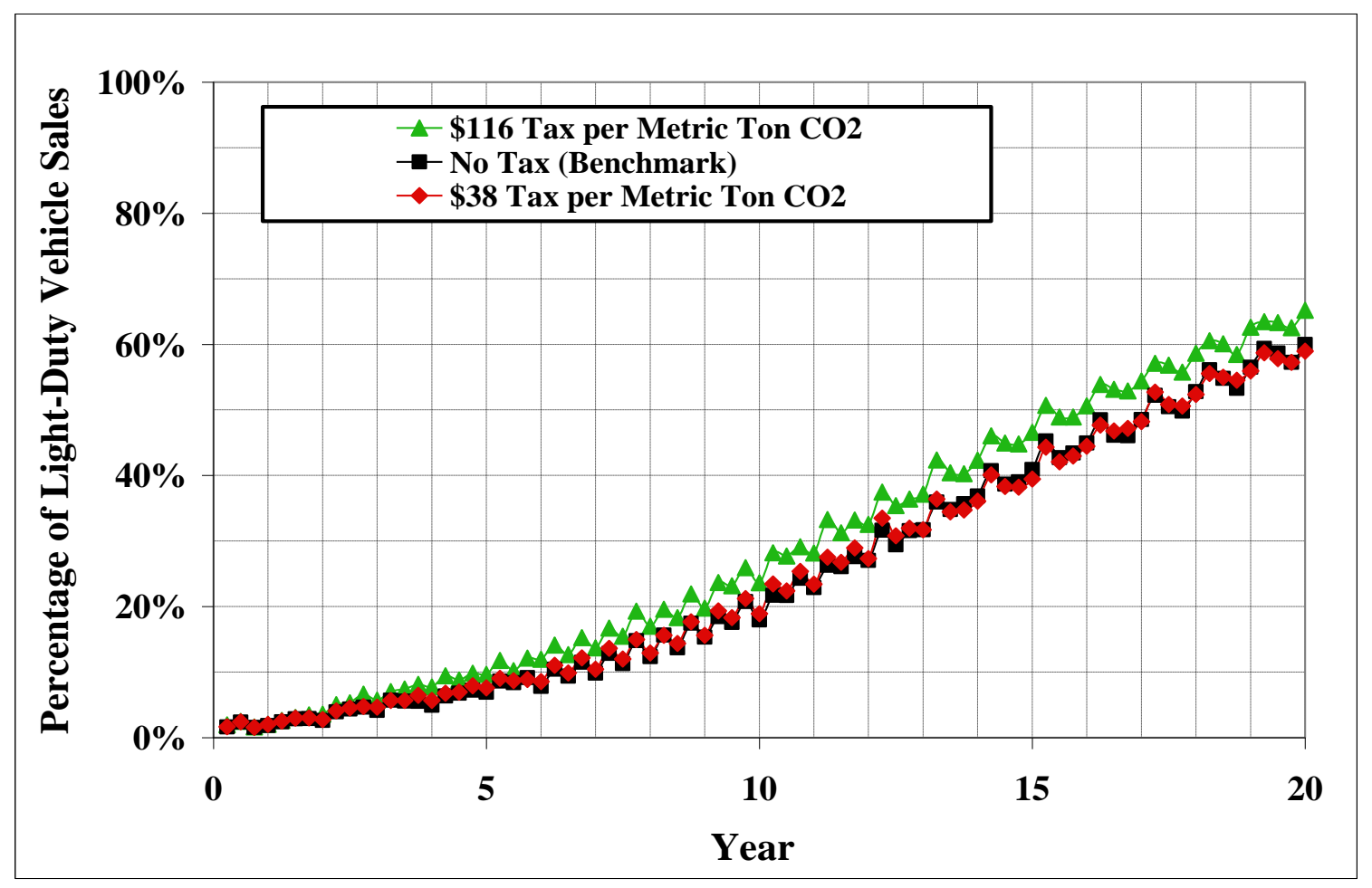

\begin{tabular}{|l|c|c|c|c|}
\hline \multirow{2}{*}{ Carbon Tax } & \multicolumn{4}{|c|}{ Hydrogen Vehicle Sales Penetration } \\
\cline { 2 - 5 } & $\mathbf{5} \mathbf{y r}$ & $\mathbf{1 0} \mathbf{~ y r}$ & $\mathbf{1 5} \mathbf{~ y r}$ & $\mathbf{2 0} \mathbf{~ y r}$ \\
\hline \$116 Tax per Metric Ton $\mathrm{CO}_{2}$ & $9 \%$ & $24 \%$ & $46 \%$ & $64 \%$ \\
\hline No Tax (Benchmark) & $7 \%$ & $18 \%$ & $41 \%$ & $60 \%$ \\
\hline \$3 Tax per Metric Ton $\mathrm{CO}_{2}$ & $8 \%$ & $19 \%$ & $39 \%$ & $59 \%$ \\
\hline
\end{tabular}

\subsection{Policies: Seed Stations}

Seed stations, established through policy assistance, assure drivers within range of those stations of a supply of hydrogen fuel and may tip their vehicle purchase decisions in favor of a hydrogen vehicle in early periods before hydrogen becomes more widely available. The benchmark case includes 15 seed stations, which correspond to current locations of hydrogen stations in the Los Angeles area. The existing stations are smaller than the standard 1,500 kg/day stations used for later periods and are not all accessible to the public. Nevertheless, in the absence of better data, these stations are included in the initial conditions of the model for two reasons. First, they represent a guess as to where new commercially viable stations may be sited through public-private partnerships. Second, although smaller than the subsequently located private stations, the effect of these seed stations on early adoption of hydrogen vehicles is likely to be about the same as larger stations later since there will only be a few potential adopters of hydrogen vehicles early on and station capacity would not materially affect drivers' utility calculations. In any event, as described below, the location of the seed stations does not seem to make a large difference to the adoption path. 
Sensitivity of the model to the introduction of 15 additional stations (totaling 30 seed stations) is tested. In one case, these additional 15 stations are placed in what the model deems to be the most profitable 15 locations for stations in early years (i.e., the first 15 locations where the investor would want to locate a station). In the other case, these 15 stations are placed where the model deems it least profitable (i.e., the last 15 locations at which the investor sites a station). The results are shown in Figure 4-7 below. For comparison, a scenario is also included in which refueling is ubiquitous, i.e., no matter where a driver would like to refuel, more than enough stations are available.

Both of these scenarios result in sales penetration rates that are very close to the benchmark after 20 years, and the locations of seed stations have a smaller effect on adoption than the number of seed stations. The case where the additional seed stations are placed in the least profitable locations (the last 15 locations to get stations otherwise), the 20-year sales penetration is $63 \%$, slightly higher than the case in which the seed stations are placed in more profitable locations (the first 15 locations to get stations otherwise), 59\%, and the benchmark of $60 \%$. This small effect may be due to driver agents being highly mobile and able to substitute one location for another easily, or more simply, due to the outcome that regular stations sprout soon enough to make it immaterial whether, at any location, a seed station existed or not at the beginning of the simulation. The magnitude of the effect of seed station locations also may be influenced by the strength of the inconvenience effect.

Siting additional seed stations at the least profitable locations does spur marginally higher adoption, as placing stations where the market would otherwise hesitate to place them leads to some drivers buying hydrogen vehicles in cases where otherwise they may not have due to being underserved. The siting of initial seed stations has a more pronounced effect on the stock of hydrogen vehicles because the additional stations spur adoption in early years. 
Figure 4-7: Effect of Seed Stations on Hydrogen Vehicle Sales Penetration

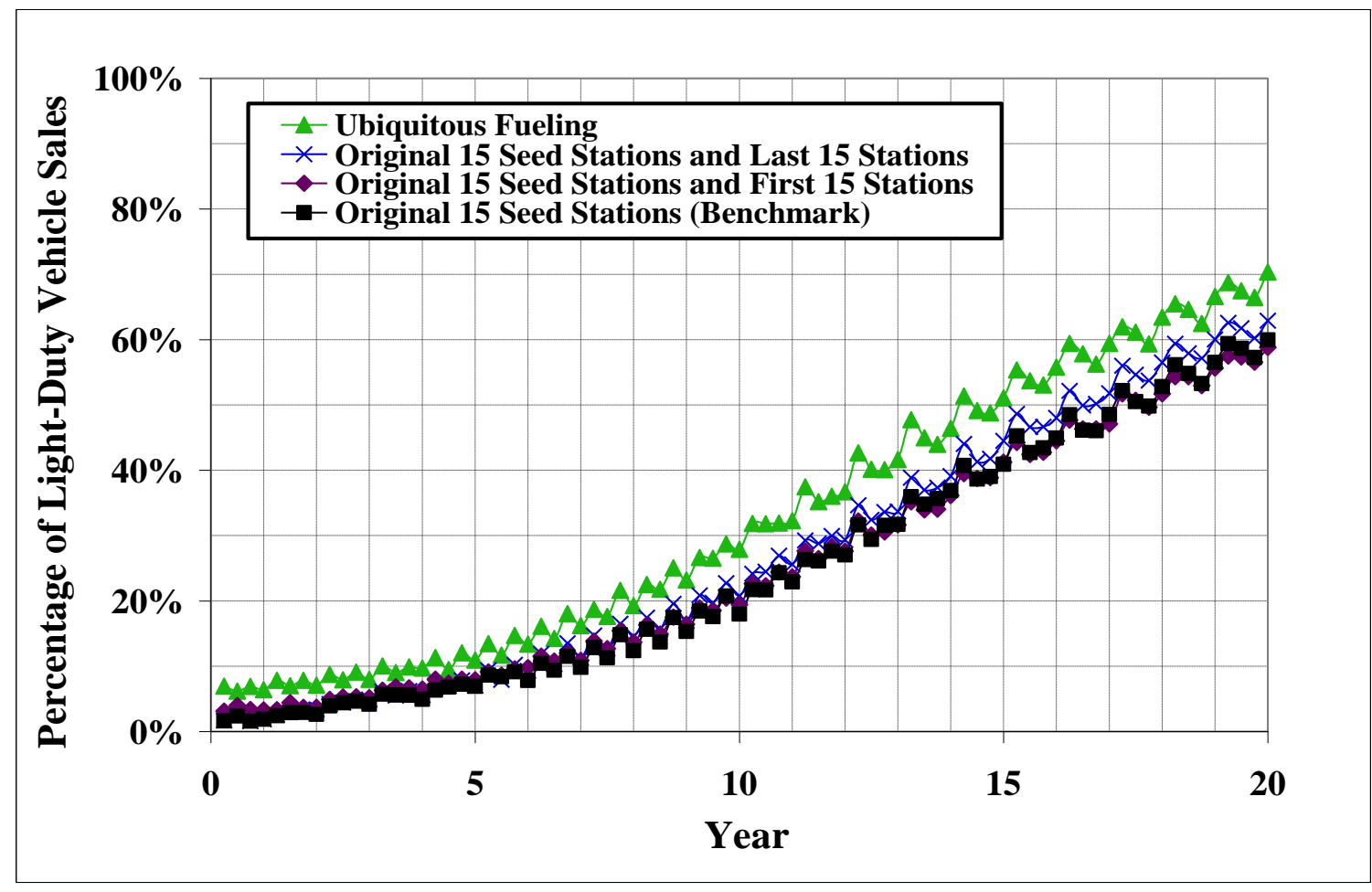

\begin{tabular}{|l|c|c|c|c|}
\hline \multirow{2}{*}{ Seed Stations } & \multicolumn{4}{|c|}{ Hydrogen Vehicle Sales Penetration } \\
\cline { 2 - 5 } & $\mathbf{5} \mathbf{y r}$ & $\mathbf{1 0} \mathbf{~ y r}$ & $\mathbf{1 5} \mathbf{~ y r}$ & $\mathbf{2 0} \mathbf{~ y r}$ \\
\hline Ubiquitous Fueling & $11 \%$ & $28 \%$ & $51 \%$ & $70 \%$ \\
\hline $\begin{array}{l}\text { Original 15 Seed Stations and } \\
\text { Last 15 Stations }\end{array}$ & $7 \%$ & $21 \%$ & $44 \%$ & $63 \%$ \\
\hline $\begin{array}{l}\text { Original 15 Seed Stations and } \\
\text { First 15 Stations }\end{array}$ & $8 \%$ & $19 \%$ & $41 \%$ & $59 \%$ \\
\hline $\begin{array}{l}\text { Original 15 Seed Stations } \\
\text { (Benchmark) }\end{array}$ & $7 \%$ & $18 \%$ & $41 \%$ & $60 \%$ \\
\hline
\end{tabular}

\begin{tabular}{|l|c|c|c|c|}
\hline \multirow{2}{*}{ Seed Stations } & \multicolumn{4}{|c|}{ Total Vehicle Stock Penetration } \\
\cline { 2 - 5 } & $\mathbf{5} \mathbf{~ y r}$ & $\mathbf{1 0} \mathbf{~ y r}$ & $\mathbf{1 5} \mathbf{~ y r}$ & $\mathbf{2 0} \mathbf{~ y r}$ \\
\hline Ubiquitous Fueling & $3 \%$ & $9 \%$ & $21 \%$ & $38 \%$ \\
\hline $\begin{array}{l}\text { Original 15 Seed Stations and } \\
\text { Last 15 Stations }\end{array}$ & $2 \%$ & $7 \%$ & $17 \%$ & $33 \%$ \\
\hline $\begin{array}{l}\text { Original 15 Seed Stations and } \\
\text { First 15 Stations }\end{array}$ & $2 \%$ & $7 \%$ & $17 \%$ & $32 \%$ \\
\hline $\begin{array}{l}\text { Original 15 Seed Stations } \\
\text { (Benchmark) }\end{array}$ & $1 \%$ & $6 \%$ & $16 \%$ & $30 \%$ \\
\hline
\end{tabular}




\subsection{Conclusions}

Equal prices of hydrogen and non-hydrogen vehicles, as in the benchmark case, allows a $60 \%$ sales penetration by the $20^{\text {th }}$ year because of fuel savings with hydrogen vehicles. Among alternative sticker price difference scenarios, beginning with a $\$ 14,000$ hydrogen vehicle price disadvantage that declines to 0 disadvantage by either 5 or 10 years still allows sales penetration to reach over $50 \%$ by the $20^{\text {th }}$ year. A non-declining price disadvantage of $\$ 6,500$ precludes a hydrogen take-off.

Permanent tax credits of $\$ 2,500$ and $\$ 6,000$ dramatically hasten sales penetration. Tax credits that end after 10 years lead to a drop in new sales penetration when the credits expire, but the $20^{\text {th }}$-year sales penetration is still higher than in the benchmark case with no tax credits. This is because so many more hydrogen vehicles are purchased earlier and, operating through the bandwagon and familiarity effects, continue to affect vehicle choice after the expiration of the tax credits.

Fuel cost savings, as influenced by the prices hydrogen and non-hydrogen fuels such as gasoline, play an important role in the adoption of hydrogen vehicles. Sufficiently low savings will prevent take-off, while very high savings have an effect similar to the smaller tax credit.

Carbon taxes have limited effects. A low carbon tax of $\$ 38$ per metric ton of $\mathrm{CO}_{2}$ translates into taxes of 44 cents per $\mathrm{kg}$ of hydrogen and 33 cents per gallon of gasoline. It favors hydrogen relative to gasoline because of hydrogen's fuel efficiency advantage, which makes the rise in costs of a hydrogen vehicle less than the rise in cost of a gasoline-powered vehicle. The tax falls more on distributed than centralized hydrogen production because carbon emissions per $\mathrm{kg}$ from distributed production are assumed to be less than for centralized production. A high carbon tax of $\$ 116$ per metric ton of $\mathrm{CO}_{2}$ results in taxes of $\$ 1.34$ per $\mathrm{kg}$ of hydrogen at distributed stations and \$1.01 per gallon of gasoline. Centralized production, bearing lesser tax, becomes profitable in the first year of simulation. The hydrogen it produces is taxed at only $\$ 0.18$ per $\mathrm{kg}$, giving hydrogen a greater advantage over gasoline. Consequently, the higher carbon tax generates somewhat higher $20^{\text {th }}$-year hydrogen sales penetration than the base case.

An additional 15 stations available at the beginning of the simulation has a perceptible, though not major effect in increasing the $20^{\text {th }}$-year stock of hydrogen vehicles. Alternative locations of the seed stations have little impact on $20^{\text {th }}$-year sales penetration. 


\section{PART FIVE: VALIDATION}

A model that projects how events could unfold far in the future under alternative conditions must find its validation in parallels between its results and other similar phenomena that have occurred in the past. This chapter reports the results of an investigation of the validity of the hydrogen model by comparing its results with experiences of other innovations.

Section 5.1 tests the benchmark adoption path of the hydrogen model against adoption paths of consumer durables reported in the literature. Section 5.2 compares the projections of the hydrogen model with the experiences of three other automotive innovations: compressed natural gas (CNG) vehicles, Japanese vehicles adopted in the United States, and other hybrid vehicles. Section 5.3 summarizes the results of the validation exercises.

\subsection{Relation of Adoption Paths of this Study to Previously Estimated Adoption Paths}

Much of the previous literature on adoption of new products involves use of data on the total number of adopters in each time period. One of the most enduring diffusion models to come out of this literature is the Bass Model, which uses three parameters - an innovation factor, an imitation factor, and a potential market size - to create an adoption path with a logistic pattern. $^{22}$ The Bass Model allows for both innovators and imitators in the population of innovation adopters. The timing of an innovator's adoption decision is not influenced by the number of people who have already bought the product. Imitators are, however, influenced by the number of previous adopters, learning in a sense from those who have already bought. These features of the Bass Model are in the driver module in the form of the bandwagon effect (Section 2.2.2.4, "Bandwagon Effect"), and the taste for greenness among some drivers (Section 2.2.2.5, "Greenness"), whereby the early hydrogen vehicle purchases of innovators with a high taste for greenness provide examples and information for subsequent adopters through the bandwagon effect. Extensively in the existing literature, Bass Model parameters have been estimated through statistical regression analysis for many consumer durables, using data on total purchases in a time period.

The present study on the other hand has used a completely different approach, based on the thousands of individual driver agents in the model. The validation exercise builds an adoption path for hydrogen vehicles from the ground up, modeling the choices of several thousand individuals rather than using market-wide totals. The test is whether this approach reproduces patterns found in other studies. It does, in fact, generate a logistic-shaped adoption path.

\footnotetext{
${ }^{22}$ Frank M. Bass, “A New Product Growth Model for Consumer Durables,” Management Science 15 (1969): 215-227. Reprinted in Management Science 50, No. 12 Supplement (2004): 1825-1832.
} 


\subsubsection{The Logistic Function and the Comparison of Adoption Paths}

Because it takes time for consumers to adopt innovative new products, much literature has been devoted to studying the adoption rates of these products. The adoption of a new technology or innovation, when plotted in a cumulative graph, has been observed to follow a logistic, or S-shaped pattern. ${ }^{23}$ This phenomenon is observed repeatedly because word of mouth, or personal observation, must spread about any worthwhile innovation before everyone who might find it useful actually adopts it. The adoption rate begins slowly at first, when there are only a few initial adopters who are either willing to take chances on the new product or simply quick to inform themselves about it. Then, as initial adopters share their knowledge with nonadopters, the rate of adoption grows substantially until the adopters outnumber the non-adopters. At that point adoption begins to slow because fewer non-adopters remain to switch behaviors and adopt. This pattern has been observed with a variety of new innovations, from hybrid seed $\operatorname{corn}^{24}$ to the telegraph and the telephone. The S-shaped adoption path is an observation that occurs with successful innovations in which the news spread by the initial adopters is good news. Unsuccessful innovations will instead see a shift downward which will lead to discontinuance of the product.

During the development of the hydrogen model the observation of S-shaped adoption paths was used as a validation method. It was found that the agents, both drivers and investors, in responding to their individual criteria, yielded a market adoption path that had the elongated $\mathrm{S}$-shape. That the model produces this pattern is the most basic level of validation, since it provides the indication that the complex system of interactions between agents that has been built produces intuitive results that match real world behavior in at least one major respect.

It is, of course, important to note that there is more than one set of agent behaviors that would produce an S-shaped adoption path, and not all of those sets may be realistic or sensible. During the course of model development, sensitivity tests were carried out in which some model structures that produce $\mathrm{S}$-shaped adoption paths broke down under various conditions. This produced more specific insights into the proper model structure, as reported for many of the parameter and policy variable variations in Parts Three and Four.

While model results have a logistic growth path in common with past product adoptions, adoption paths can still vary greatly. A wide variety of adoption rates are observed for previous innovations, and little information is available on which to base judgments about what speed of adoption to expect for hydrogen vehicles. Even if the technology is successful, thought needs to be given to the similarities and differences between hydrogen technology and the types of technologies that have seen rapid or slow adoption. Care should be exercised when comparing adoption data for a diverse set of products. For example, consider targeting an adoption rate of " $60 \%$ of households" as an indicator of successful adoption. This metric could be misleading in some cases, since the potential market for some technologies may not include all households. If, for example, during the first decade of a product's introduction it is only affordable for, say, half

\footnotetext{
${ }^{23}$ Everett M. Rogers, Diffusion of Innovations (New York: Free Press, 2003), Chapter 7, "Innovativeness and Adopter Categories: The S-Shaped Curve of Adoption and Normality," pp. 272-275.

${ }^{24}$ Zvi Griliches, "Hybrid Corn: An Exploration in the Economics of Technological Change,” Econometrica 25 (1957): $501-522$.
} 
of all households, and most of that group has adopted by the end of the decade, then adoption might be considered largely complete, with the later widening of the product's affordability being considered a separate phenomenon. This and other matters of interpretation make the analysis and comparison of adoption paths highly subjective. In order to eliminate as much subjectivity as possible, this report makes extensive use of the product diffusion modeling literature.

\subsubsection{Comparison of Hydrogen Vehicles with Consumer Durables as a Whole}

Over the years the Bass Model has been used to analyze many consumer durables and industrial products with a wide variety of adoption paths. A meta-analysis of 213 innovations has synthesized Bass Model applications into a set of adoption paths for various categories of products. $^{25}$ That analysis reports an adoption curve for consumer durables as a whole that is defined by a Bass curve with an innovation parameter of 0.03 and an imitation parameter of 0.38 , controlling for characteristics of the original study, the type of innovation, and where the innovation occurred-Europe or the United States. Consequently, the parameter magnitudes of 0.03 and 0.38 represent underlying structural tendencies of innovations. However, these estimates remain composites across many applications of the Bass Model, and certain product characteristics - such as whether sales data were from Great Britain or the United States and whether the innovation analyzed was an industrial product or consumer durable-were found to affect the magnitudes of the innovation and imitation parameters. The adoption path for consumer durables as a whole in the United States was found to be a Bass curve with an innovation parameter of 0.007 and an imitation parameter of 0.295 . Figure 5-1 shows this adoption curve.

\footnotetext{
${ }^{25}$ Fareena Sultan, John U. Farley and Donald R. Lehmann, “A Meta Analysis of Diffusion Models,” Journal of Marketing Research 27 (1990): 70-77.
} 
Figure 5-1: Historical Adoption Path for Consumer Durables as a Whole

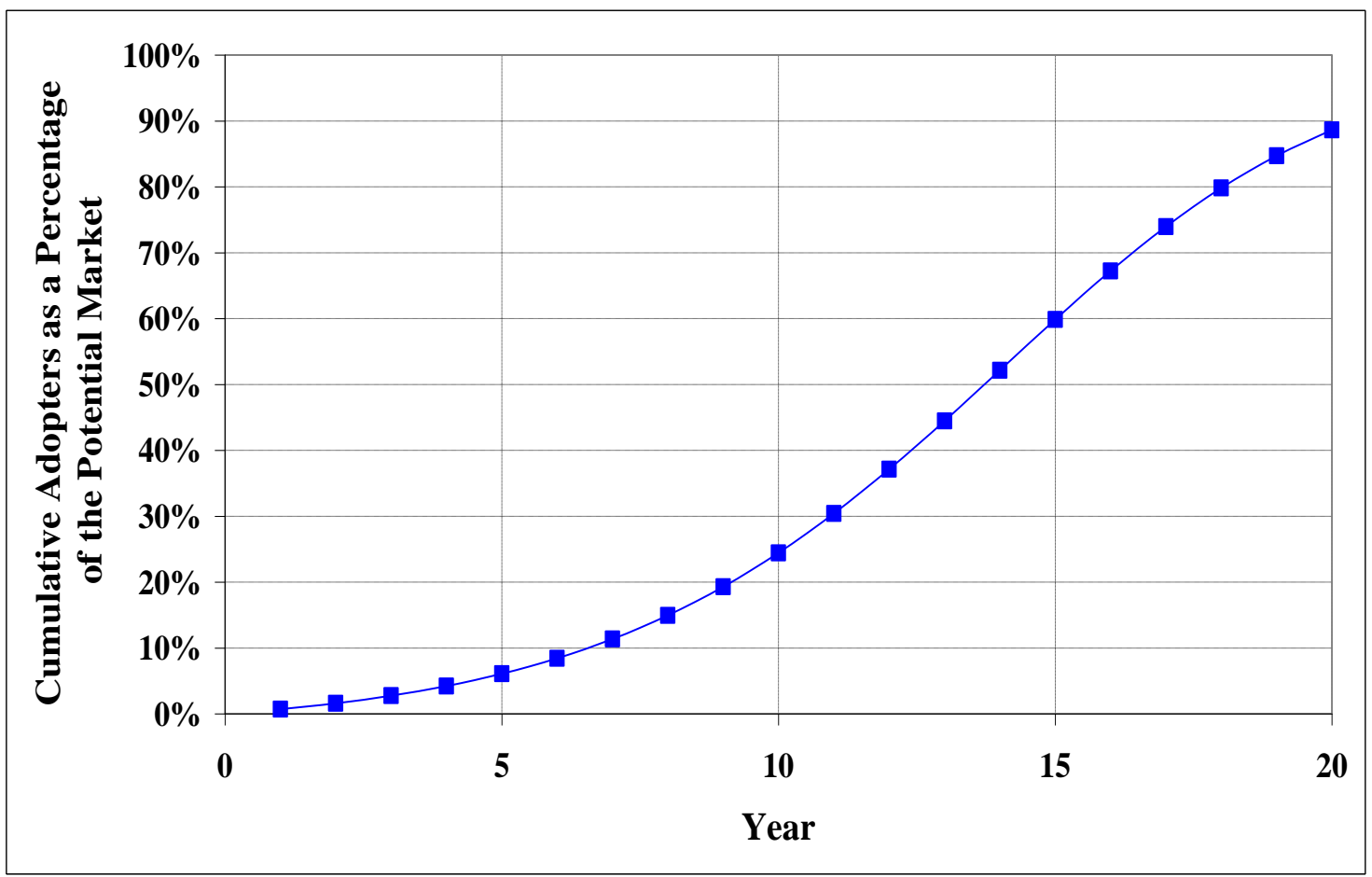

Figure 5-1 bears comparison with the adoption path of hydrogen vehicles in the benchmark run for stock penetration (Figure 3-2). While the hydrogen vehicle adoption path in Figure 3-2 follows the classic S-shaped pattern, it is actually a slowed-down version of the typical path shown in Figure 5-1. This is to be expected. Figure 5-1 refers to replacement of consumer durables which are considerably less expensive and less durable and face fewer uncertainties than hydrogen vehicles. The following forces are likely to slow down the adoption of hydrogen vehicles relative to common consumer durables.

1. Predecessor product. Most past consumer durables subjected to analysis by product diffusion modelers did not have a significant comparable predecessor, giving consumers more incentive to adopt the new product at any time as opposed to waiting for a predecessor product they already own to age. Even if hydrogen vehicles do provide a clear benefit to them, most consumers will wait for their non-hydrogen vehicle to age before they replace it. Meanwhile, because the air conditioner and the black-and-white TV - two products from the consumer durables - were not replacing a close alternative, consumers did not have the same incentive to wait.

2. Network effects. While some of the products in the consumer durables group faced network hurdles, such as black-and-white and color TV, many other products did not, such as window air conditioners, clothes dryers, and dishwashers. Additionally, not all network effects are as significant as the one facing hydrogen vehicles, i.e., consumers are not likely to adopt hydrogen vehicles unless they are assured of convenient access to hydrogen fuel, and the investors will be reluctant to invest in hydrogen fueling infrastructure unless they expect demand to increase. The network 
effect for color TV, for example, involved the appearance of broadcasting in color, an event that was less gradual than the appearance of fuel stations, and color broadcasting, which could be received by black-and-white sets, grew for many years before any significant number of people began to adopt, meaning that by the time adoption took off the hurdle was largely already cleared.

3. Drastic improvement over past products. Hydrogen vehicles will perform largely the same functions as non-hydrogen vehicles do today, whereas many past innovations in consumer durables performed completely new functions that were of an unknown but certainly large value to consumers. This lack of novel application is likely to dampen the enthusiasm of drivers to adopt hydrogen relative to many previous new products.

\subsection{Adoption Experience under Other Vehicle Information}

\subsubsection{Compressed Natural Gas Vehicles}

\subsubsection{Review of Experience}

Interest in compressed natural gas (CNG) vehicles arose in the early 1980s from the steep rise in oil prices following the Iranian Revolution and the beginning of the Iran-Iraq War in 1979 and 1980. The public benefits of energy security enhancements from reduced oil imports and environmental benefits from reduced automotive emissions combined with private incentives from lower natural gas prices relative to oil to offer promise for the introduction of this alternative fuel vehicle. Additionally, the regulation of natural gas prices appeared to offer greater price stability than with oil.

During this period, and as early as the 1970s in some countries, natural gas vehicles saw increased adoption worldwide, especially prominently in Argentina and New Zealand where combinations of recent natural gas strikes, government support (tax allowances for consumers and suppliers but not direct fuel subsidies) and foreign exchange problems provided a combination of opportunities and incentives. However, changing economic incentives during the 1990s greatly reduced the competitiveness of CNG vehicles in both Argentina and New Zealand. $^{26}$

Although the CNG vehicle was introduced around the same time in the United States, it did not receive widespread acceptance for a combination of reasons. First, as shown in Figure 52, the large price differential of oil over natural gas in the United States that existed at the beginning of the 1980s had eroded by mid-decade. Deregulation of natural gas that began with the 1978 Natural Gas Policy Act took place in stages from the 1980s to 1993 removing the possibly illusory promise of price stability from natural gas. So the CNG vehicle attempted to enter the U.S. market with no advantage in either fuel price or fuel price stability.

\footnotetext{
${ }^{26}$ J.C. Fraccia, "An Overview of the Argentine NGV Experience," (paper presented at World Bank Workshop on CNG Vehicles, 2000); Garth Harris, "Compressed Natural Gas in New Zealand," (paper presented at World Bank Workshop on CNG Vehicles, 2000).
} 
Figure 5-2: U.S. Natural Gas and Oil Prices (wellhead price of gas in barrel-of-oil equivalents)

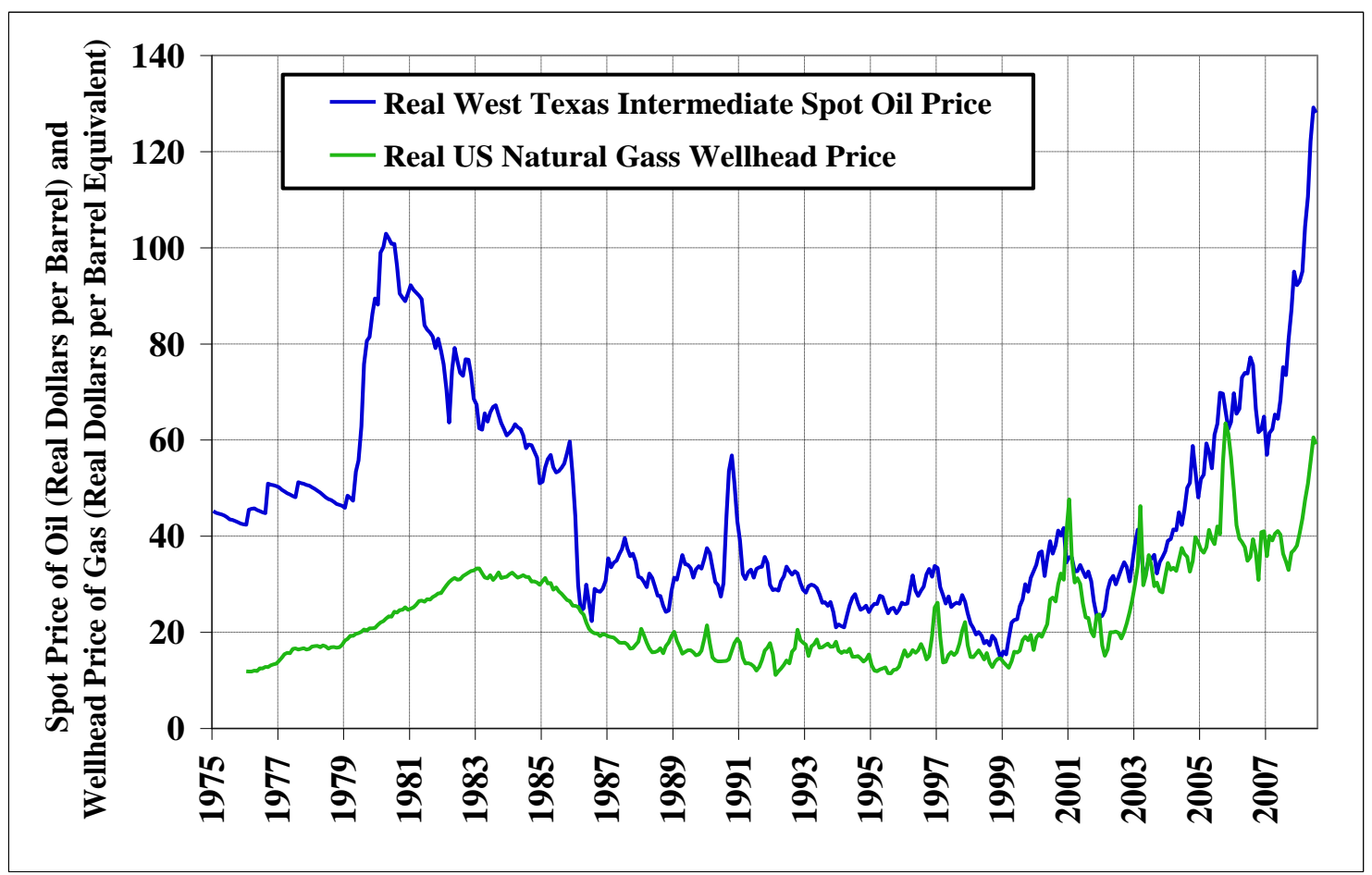

Source: Natural Gas Navigator, accessed at http://tonto.eia.doe.gov/dnav/ng/ng_pri_top.asp; Petroleum Navigator, accessed at http://tonto.eia.doe.gov/dnav/pet/pet_pri_top.asp.

Second, CNG vehicles were often more expensive than conventional vehicles. ${ }^{27}$ As there were no opportunities to buy one from manufacturers, they required a conversion costing between $\$ 1,800$ and $\$ 2,200$ in 1986 (\$2,700 and \$3,200 in 2009 dollars). Conversion costs have increased four- to five-fold after inflation since the 1980s, as regulations have tightened, carbon fiber material has replaced steel for tanks, and fixed costs are being spread across fewer conversions. $^{28}$ Refueling stations, too, were expensive, costing $\$ 225,000$ (\$325,000 in 2009 dollars). Although the American Gas Association promoted the use of CNG vehicles, federal and state support was minimal, and growth was very slow in the United States. During the 1980 s, there were no federal incentives for the purchase of alternative fuel vehicles. ${ }^{29}$ When incentives did appear, federal policy support initially was an income tax deduction, which was considerably less valuable than the tax credit offered beginning in 2007 , by which time the vehicle was widely perceived as having failed to become a mainstream market alternative. During the 1990s, CNG vehicle numbers grew, especially in fleets, peaking at over 120,000 in 2001, but their numbers declined during the first decade of the 2000s, as shown in Figure 5-3.

\footnotetext{
${ }^{27}$ The following account of barriers to wider CNG vehicle adoption in the United States is derived from Peter C. Flynn, "Commercializing an Alternate Vehicle Fuel: Lessons Learned from Natural Gas for Vehicles," Energy Policy 30 (2002): 613-619.

${ }^{28}$ Telephone interview with Richard Kolodzeij, President of Natural Gas Vehicles for America, July 2009.

${ }^{29}$ Michael A. Andrews, "Letter to the Editor," New York Times, June 16, 1989 p. A26, http://www.nytimes.com/1989/06/16/opinion/l-as-alternative-fuel-methanol-is-not-yet-a-cure-all-federal-incentives478289.html (accessed December 31, 2009).
} 
The sharp increase in the number of CNG vehicles beginning in the early 1990s is most likely the result of the Energy Policy Act of 1992, which required the federal government to begin buying alternative fuel vehicles for its fleets in $1993 .^{30}$ There are currently over 100,000 CNG vehicles in the United States, but this stock has never reached six one-hundredths of a percent of the national vehicle stock.

Figure 5-3: U.S. CNG Vehicles on the Road

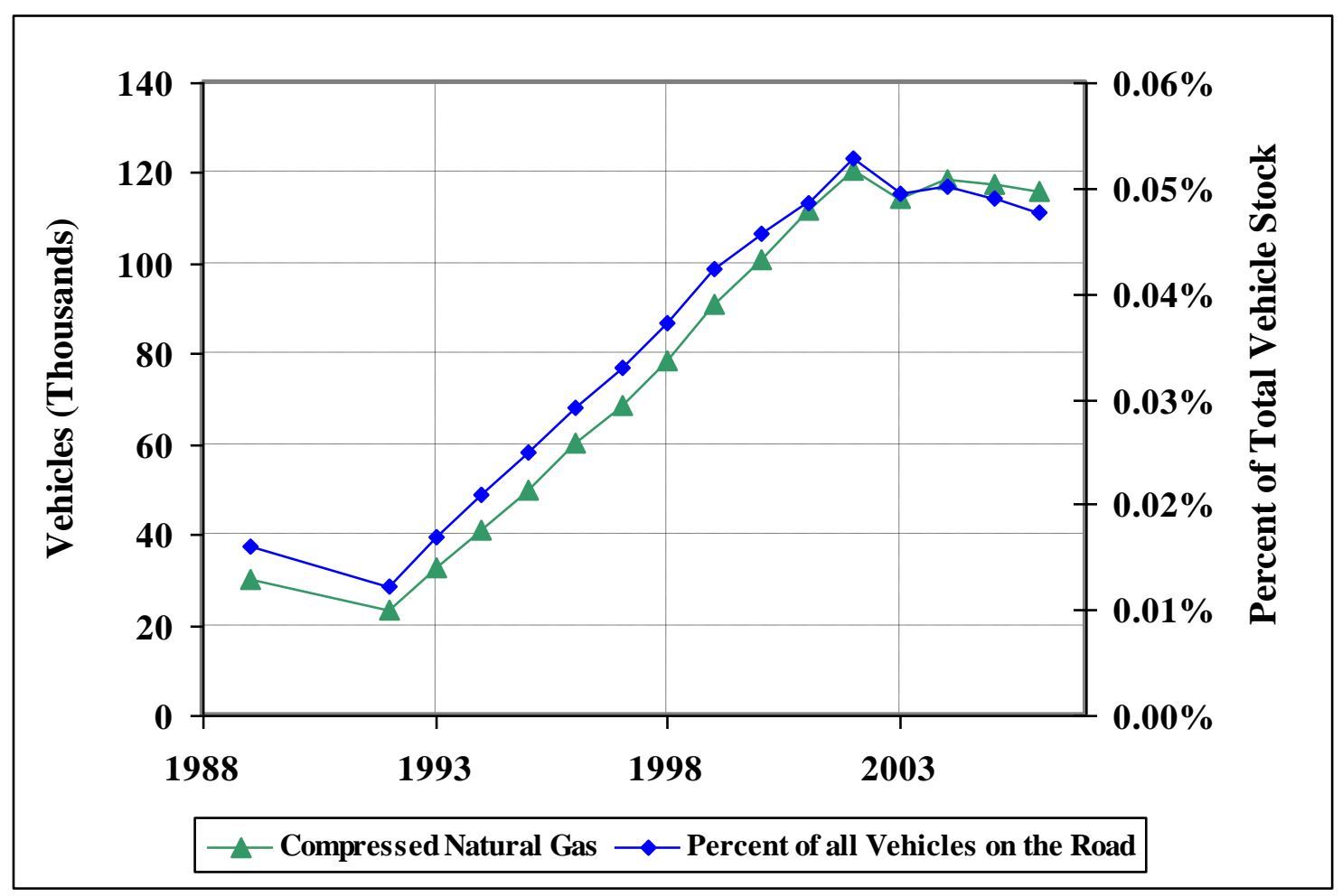

Sources: See Footnote ${ }^{31}$

Third, natural gas fuel stations were not quickly profitable. It was believed that it would take up to five years for an individual station to reach capacity utilization of 100,000 litersequivalent per month. Few stations were on target in reaching utilization and profitability goals, and policy attention to the issue of balance between investor profitability and consumer interests was late in coming. Lack of retained earnings meant that marketing resources were low, and eventually the interest of fuel retailers waned. The refueling infrastructure proved at least as important as the vehicle technology.

\footnotetext{
${ }^{30}$ Brian Anthony Abbanat, "Alternative Fuel Vehicles: The Case of Compressed Natural Gas (CNG) Vehicles in California Households," M.S. Thesis, University of California Davis, 2001, p. 10.

${ }^{31}$ For 1989, Thomas C. Hayes. "Natural Gas Sales Set at Denver AMOCO Sites," New York Times, December 21, 1989, p, D7. http://www.nytimes.com/1989/12/21/business/natural-gas-sales-set-at-denver-amoco-sites.html (accessed December 31, 2009.); for 1992-2003, Energy Information Administration. "Estimated Number of Alternative Vehicle Fuels in Use and Fuel Consumption, 1992-2007." June 2009. http://www.eia.doe.gov/emeu/aer/txt/ptb1005.html (accessed March 10, 2010); Total vehicles on the road: Transportation Energy Data Book 28. (Oak Ridge, Tenn.: Oak Ridge National Laboratory) last updated June 29, 2009. http://cta.ornl.gov/data/Index.shtml (accessed December 31, 2009).
} 
Fourth, CNG was adopted initially more by commercial fleets than individuals. In California in particular this was for two reasons: taxation of private dispensing often was ignored by state authorities, and the capital cost of a public refueling network was widely seen as prohibitive, especially inasmuch as a large proportion of the fleet to be refueled would not use publicly available fueling stations.

\subsubsection{Comparison of CNG Vehicle Experience with the Hydrogen Model of this Study}

In sum, between external market events, the technology itself, and policy support, neither the vehicles nor the supporting fueling infrastructure were particularly profitable as private investments. The proximate market impetus for the CNG vehicle in the United States was a temporary, sharp increase of the oil price over the U.S. natural gas price while the market forces behind hydrogen are the possibility of long-term, permanent increases in the oil price and increasing concerns with carbon emissions. CNG technology in the 1980s and 1990s was more of a fuel substitution in an internal combustion engine than the radical technological change of the hydrogen vehicle. Policy support for adoption of CNG vehicles was scattered and not particularly strong during the early years of its adoption. Finally, the low adoption of non-fleet CNG vehicles lengthened the pay-back period on infrastructure investments in fueling facilities.

In contrast to CNG vehicles, hydrogen vehicles have had considerable policy support through $\mathrm{R} \& \mathrm{D}$, and the modeling here explores further temporary policy support during early market transition. The price of the principal competing transportation fuel, oil, is not expected to decline, and the full cost of operating the hydrogen vehicle - sticker price plus fuel cost - is advantageous relative to that of the competing non-hydrogen vehicle. The modeling of hydrogen fuel stations shows them to be profitable early over a broad range of conditions, and they become sufficiently widely distributed in early simulation periods to allay a good deal of driver anxiety. Altogether, initial similarities between $\mathrm{CNG}$ vehicles and what should be expected from hydrogen vehicles dwindle upon examination.

\subsubsection{The Market Penetration of Japanese Vehicles in the United States}

\subsubsection{Review of Experience}

Before 1968, Japanese imports to the United States accounted for less than 1\% of U.S. retail auto sales. Japanese imports, and domestically produced Japanese models beginning in the mid-1980s, experienced their period of major expansion in the U.S. auto market from 1968 to 1991. Over a span of one year, 1967 to 1968, sales of Japanese imports more than doubled, from $0.8 \%$ to $1.8 \%$ of new car sales. By 1982 , Japanese imports peaked at $22.6 \%$ of the U.S. market. $^{32}$

\footnotetext{
${ }^{32}$ Ward's Automotive Yearbooks (Southfield, Mich.: Ward's Communications, 1968-2008).
} 
Figure 5-4: Growth of the Market Share of Japanese Light-Duty Vehicles in the United States, 1965-2008

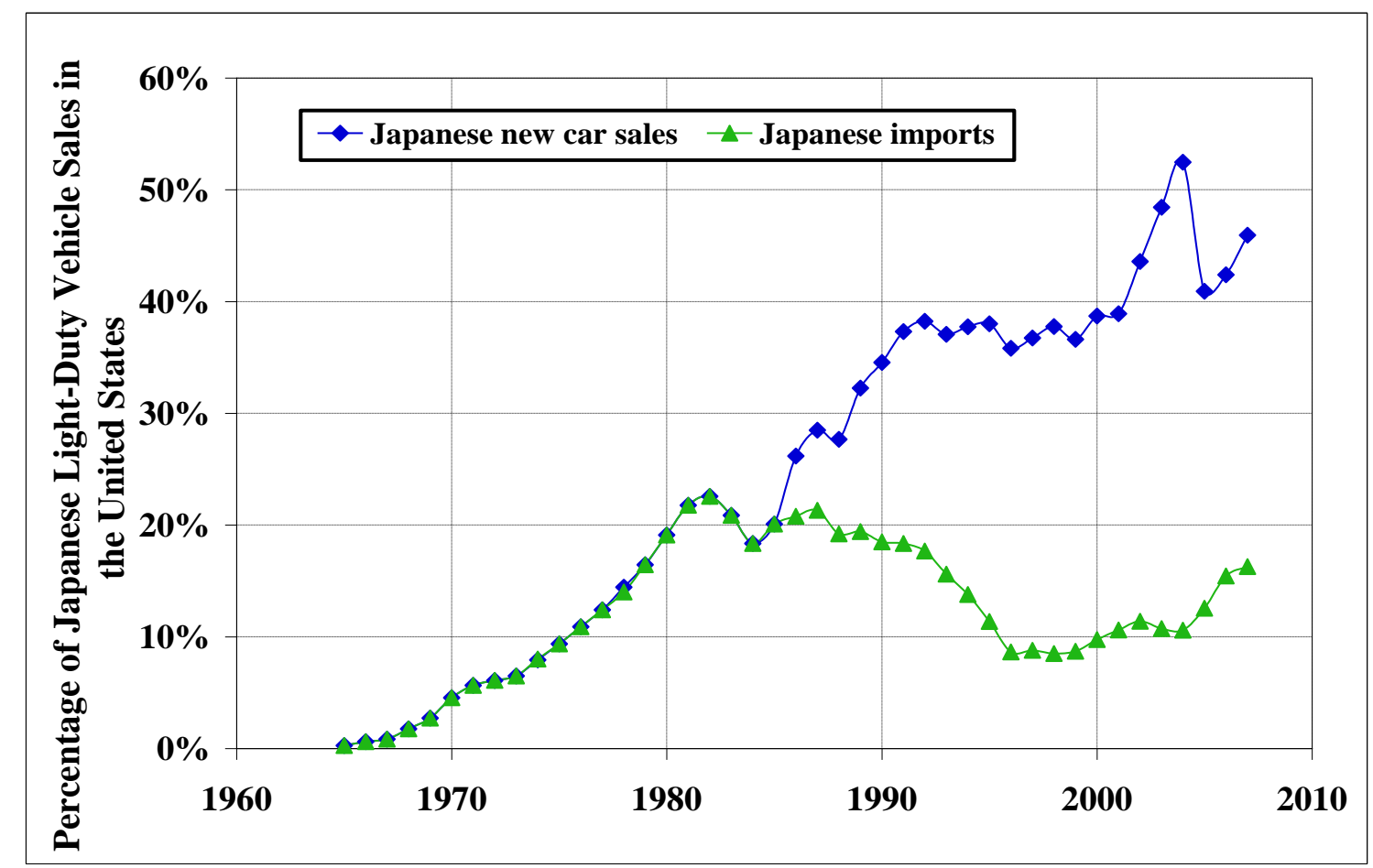

Source: Ward's Automotive Yearbooks, 1968-2008.

With Japanese auto presence skyrocketing, the United States instituted an automobile import quota on Japan in 1981. The Reagan-backed Voluntary Export Restraint (VER) limited Japanese auto imports to 1.68 million a year which, as Figure 5-4 above shows, curtailed the pace of market penetration of Japanese vehicles for several years in the mid-1980s. The cap was periodically raised and reached 2.3 million before it was terminated in $1992 .{ }^{33}$

The VER turned out to be a gift to Japanese auto makers. During the late 1970s and early 1980s, Toyota and Honda produced high quality vehicles and began to cultivate strong U.S. demand. The VER raised prices and lowered sales volumes of Toyotas and Honda in the United States, but did not hurt profits. ${ }^{34}$

In response to increasing U.S. demand for Japanese vehicles and the constraints of the VER, Japanese automakers began to produce in the United States. Honda began manufacturing vehicles in the United States in $1982,{ }^{35}$ and has produced 14 million in the country since then. ${ }^{36}$

\footnotetext{
${ }^{33}$ Steven Berry, James Levinsohn, and Ariel Pakes, "Voluntary Export Restraints on Automobiles: Evaluating a Trade Policy," American Economic Review 89 (1999): 400-430.

${ }^{34}$ Berry et. al., Ibid.

${ }^{35}$ Ward's Automotive Yearbook, 1982.

${ }^{36}$ Ward's Automotive Yearbook, 1982-2008.
} 
Toyota began manufacturing in the United States in $1984,{ }^{37}$ and has produced 15 million domestically. ${ }^{38}$ Nissan, which began manufacturing in the United States in $1983,{ }^{39}$ has produced more than 5 million vehicles. ${ }^{40}$ Mitsubishi, Subaru and Isuzu also have U.S. production plants. ${ }^{41}$ As Figure 5-4 demonstrates, adding the U.S.-produced vehicles to the Japanese imports reveals an overall picture of Japanese growth into the U.S. auto market.

Factoring in this U.S. production, Japanese autos account for almost one-half of newvehicle sales in the U.S. market. The full Japanese market share, including imports and domestically produced autos, peaked in the United States in 1991 at $39.6 \%$ of U.S. light-duty vehicle sales. During the 1990s the Japanese market share dipped, dropping to $34 \%$ of new sales in 1997, probably because of a lengthy period of lower oil prices. In the past decade Japanese sales have climbed again, reaching almost $45 \%$ of new auto sales.

\subsubsection{Comparison of Japanese Import Experience with the Hydrogen Model of this Study}

Japanese vehicle adoption in the United States shows the classic S-shape, where adoption starts slowly, eventually takes off, and then plateaus. This path is common for new product penetration. The speed of market penetration of new Japanese vehicles was less rapid than the benchmark case in the current hydrogen model: a little under $30 \%$ of new sales in the twenty years between 1965 (using that as a rough start date) and 1985, compared with $60 \%$ in the hydrogen model's benchmark simulation. It is possible, however, that the VER period may have set back that market penetration by about 5 years, judging from the shape of the curve in Figure $5-4$.

The comparison here is between two innovations in the automobile market, although the case of the hydrogen vehicle is a more drastic change in technology than was the introduction of Japanese models. While the Japanese vehicles were $30 \%$ to $75 \%$ more fuel-efficient than the U.S. Big Three fleet average, the smaller Japanese vehicles may not have offered comparable features demanded by many American consumers, sheer physical size being prominent among them. The growth of sales penetration by Japanese vehicles in the 1975-85 decade was somewhat slower than the sales penetration projected for hydrogen vehicles during their first decade, possibly because of the imperfect substitutability of the Japanese for the American-made vehicles (the hydrogen and non-hydrogen vehicles are specified as essentially perfect substitutes in features other than fuel efficiency). In the 1985-95 decade, the slower growth of Japanese

\footnotetext{
${ }^{37}$ Ward's Automotive Yearbook, 1984.

${ }^{38}$ Ward's Automotive Yearbooks, 1984-2008.

${ }^{39}$ Ward's Automotive Yearbook, 1983.

${ }^{40}$ Ward's Automotive Yearbooks, 1983-2008.

${ }^{41}$ Ward's Automotive Yearbook, 2008.
} 
sales share compared to the hydrogen model can be accounted for additionally by the converging fuel efficiency of the American vehicles. ${ }^{42}$

\subsubsection{Hybrid Vehicles}

\subsubsection{Review of Experience}

In 2008, 312,000 hybrid vehicles were sold in the United States, $1.94 \%$ of all light-duty vehicles sold, down slightly from 352,000 in 2007, as shown in Figure 5-5. Slightly over half of these were Toyota Priuses. The Honda Insight was introduced in 1999, and the Prius in $2000{ }^{43}$

Figure 5-5: United States Hybrid Vehicle Sales Volume

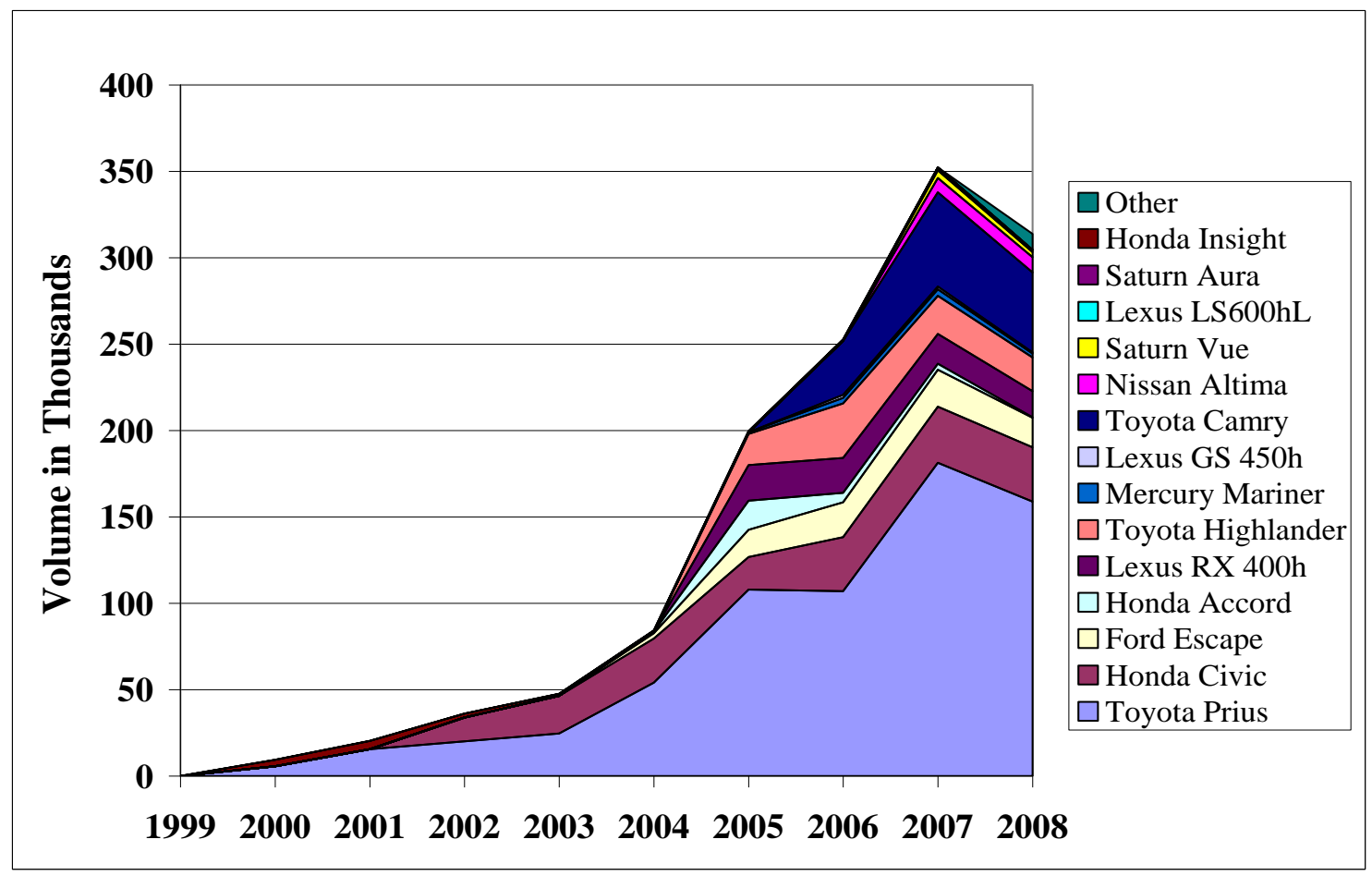

Source: U.S. Department of Energy, Alternative Fuels \& Advanced Vehicles Data Center, HEV Sales by Model accessed July 28, 2009 at http://www.afdc.energy.gov/afdc/data/vehicles.html.

Worldwide, hybrid vehicle sales have taken off sharply since the Prius was introduced in Japan in 1997, with most of the sales coming in North America, as shown in Figure 5-6. The global downturn in the second half of 2008 led to a decline in North American sales, but Prius sales continue to grow worldwide. The annual growth rates have been high, quadrupling

${ }^{42}$ U.S. EPA Office of Transportation and Air Quality, "Light-Duty Automotive Technology and Fuel Economy Trends, 1975 through 2008," U.S. EPA, EPA420-S-08-003, September 2008, http://www.epa.gov/otaq/fetrends.htm (accessed August 5, 2009).

43 U.S. Department of Energy Office of Energy Efficiency and Renewable Energy, "Alternative Fuels \& Advanced Vehicles Data Center, HEV Sales by Model,” U.S. Department of Energy. http://www.afdc.energy.gov/afdc/data/vehicles.html (accessed July 28, 2009). 
between 2003 and 2005. This corresponded to a change in the production method - starting with the 2004 model, Toyota began producing the Prius on a standard mass production assembly line, resulting in one being produced every minute instead of one every 8 to 10 minutes as before. ${ }^{44}$ The use of a standard assembly line has dropped the manufacturing cost significantly, allowing Toyota to deliver a substantially upgraded model, which in turn has generated publicity and popularity. Another major limiting factor in hybrid production is third-party component availability, particularly batteries. Currently, all production of Priuses is in Japan, although plans are in progress to open factories in other countries. ${ }^{45}$

Figure 5-6: Annual Worldwide Prius Sales

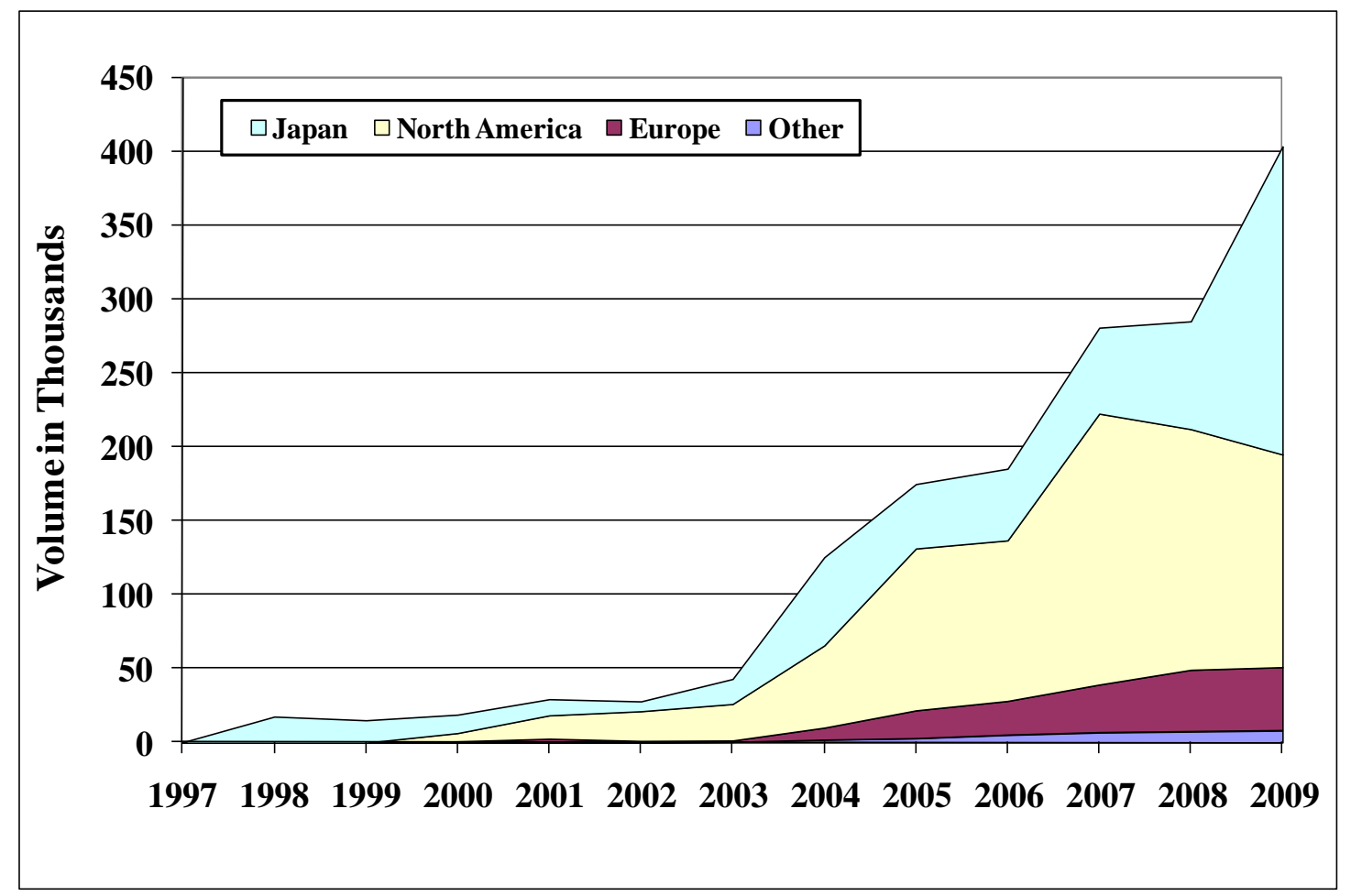

Source: Ward's Automotive Yearbooks, 1997-2008.

The U.S. light duty vehicle market includes at least 20 hybrid vehicles, including sedans, luxury cars, SUVs, and trucks. While sedans are the most popular, Figure 5-7 shows that SUVs such as the Toyota Highlander, the Ford Escape, and the Lexus RX400h are popular as well.

\footnotetext{
${ }^{44}$ Wired News Report, “Toyota Says Hybrids Can Be Cheap,” Wired, October, 2, 2003. http://www.wired.com/cars/energy/news/2003/10/60667 (accessed July 28, 2009).

45 Mike Millikin, "US Sales of Hybrids Down 8.9\% in September," Green Car Congress News, October 3, 2008. http://www.greencarcongress.com/2008/10/us-sales-of-hyb.html (accessed July 28, 2009).
} 
Figure 5-7: Composition of Hybrid Car Sales Volume in the United States in 2008

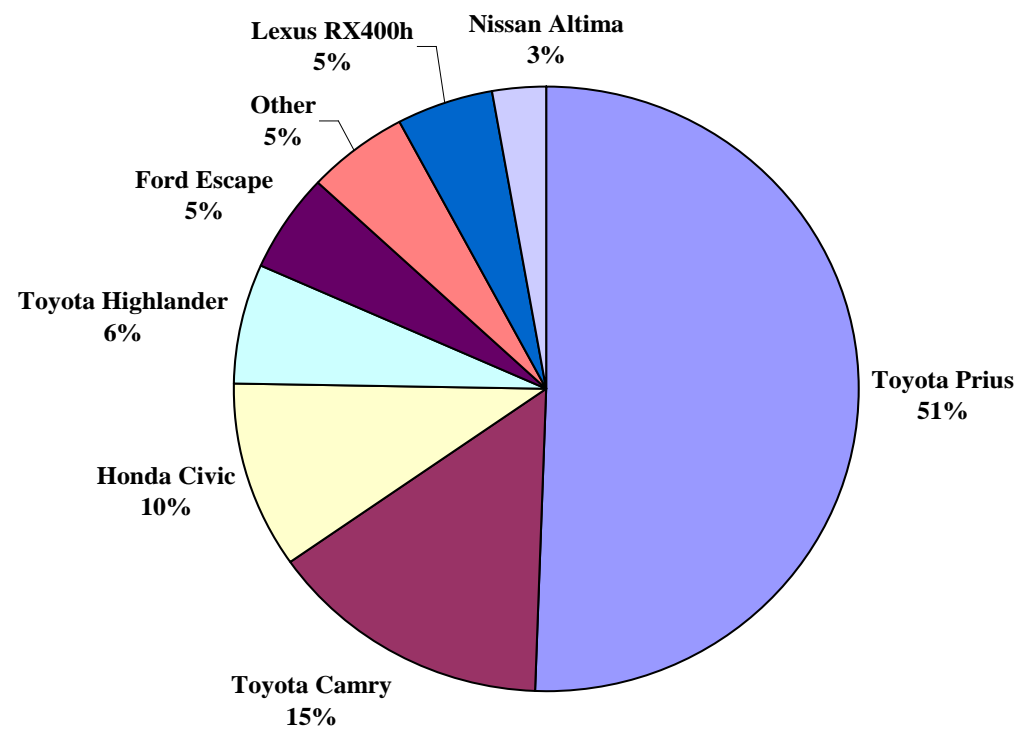

Source: Ward's Automotive Yearbook, 2008.

Hybrid vehicles generally have a higher manufacturer's suggested retail price (MSRP) than comparable conventionally powered vehicles, but make up for that with better fuel mileage. Table 5-1 below shows the mileage and MSRP for various popular hybrid vehicles.

Table 5-1: Selection of Hybrid Vehicles, Prices, and Mileages

\begin{tabular}{|c|c|c|}
\hline Vehicle & MPG (city/hwy) & MSRP \\
\hline Honda Accord Hybrid ${ }^{\mathrm{a}}$ & $29 / 37$ & $\$ 31,540$ \\
\hline Honda Civic Hybrid $^{\text {a }}$ & $50 / 50$ & $\$ 22,400$ \\
\hline Toyota Prius $^{\mathrm{a}}$ & $60 / 51$ & $\$ 22,305$ \\
\hline Toyota Camry Hybrid ${ }^{\mathrm{b}}$ & $40 / 38$ & $\$ 25,653$ \\
\hline Toyota Highlander Limited $4 \mathrm{X} 2^{\mathrm{a}}$ & $33 / 28$ & $\$ 33,595$ \\
\hline Toyota Highlander Limited $4 \mathrm{X} 4^{\mathrm{a}}$ & $31 / 27$ & $\$ 34,995$ \\
\hline Lexus RX 400h FWD ${ }^{\mathrm{b}}$ & $32 / 27$ & $\$ 40,586$ \\
\hline Lexus RX 400h AWD ${ }^{b}$ & $31 / 27$ & $\$ 41,942$ \\
\hline Lexus GS $450 \mathrm{~h}^{\mathrm{b}}$ & $25 / 28$ & $\$ 53,877$ \\
\hline Ford Escape FWD ${ }^{a}$ & $36 / 31$ & $\$ 27,515$ \\
\hline Ford Escape $4 \mathrm{WD}^{\mathrm{a}}$ & $33 / 29$ & $\$ 29,140$ \\
\hline Mercury Mariner AWD ${ }^{a}$ & $33 / 29$ & $\$ 29,840$ \\
\hline
\end{tabular}


A federal tax credit is available to purchasers of hybrid vehicles, varying in magnitude with the size of the vehicle and the cumulative production volume, as shown in Table 5-2. ${ }^{46}$

Table 5-2: Federal Tax Credits as of June 2006

\begin{tabular}{|c|c|}
\hline Vehicle & $\begin{array}{c}\text { Fed. Tax Credit (as } \\
\text { of March 2006) }\end{array}$ \\
\hline Toyota Prius & $\$ 3,150$ \\
\hline Toyota Camry Hybrid & $\$ 2,600$ \\
\hline Toyota Highlander Hybrid & $\$ 2,600$ \\
\hline Ford Escape Hybrid & 47 \\
\hline Lexus RX 400h & $\$ 2600 / \$ 1950$ \\
\hline Honda Civic Hybrid & $\$ 2,200$ \\
\hline Mercury Mariner Hybrid & $\$ 2,100$ \\
\hline Lexus GS 450h & $\$ 1,950$ \\
\hline Honda Insight & $\$ 1,550$ \\
\hline Honda Accord Hybrid & $\$ 1,450$ \\
\hline & $\$ 1350 / \$ 650$ \\
\hline
\end{tabular}

Source: U.S. Internal Revenue Service, "2006 Model Year Hybrid Vehicles,” http://www.irs.gov/newsroom/article/0,,id=176418,00.html (accessed June 2007).

Table 5-3 combines the price and tax credit data above and compares the difference in price to the savings from lowered fuel cost available to hybrid drivers. The price and fuel efficiency of each hybrid vehicle in this table are compared to those of the conventional vehicle closest to the hybrid model.

\footnotetext{
${ }^{46}$ Consumers seeking the federal tax credit may need to buy early since the full credit is only available for a limited time. Taxpayers may claim the full amount of the allowable credit up to the end of the first calendar quarter after the quarter in which the manufacturer records its sale of the $60,000^{\text {th }}$ hybrid or advanced lean-burn technology. For the second and third calendar quarters after the quarter in which the $60,000^{\text {th }}$ vehicle is sold, taxpayers may claim $50 \%$ of the credit. For the fourth and fifth calendar quarters, taxpayers may claim $25 \%$ of the credit. No credit is allowed after the fifth quarter.

${ }^{47}$ \$2,600 for the 4WD and \$1,950 for the FWD; see U.S. Internal Revenue Service (IRS), (2007), "2006 Model Year Hybrid Vehicles," http://www.irs.gov/newsroom/article/0,,id=176418,00.html (accessed June, 2007).

48 The Accord gets $\$ 650$ when not calibrated and $\$ 1,350$ when it is calibrated; see IRS, ibid.
} 
Table 5-3: Hybrid Vehicle Cost Savings

\begin{tabular}{|l|c|c|c|}
\hline $\begin{array}{c}\text { Selection of Hybrid } \\
\text { Vehicles }\end{array}$ & $\begin{array}{c}\text { Vehicle Price } \\
\text { Difference }^{\mathbf{a}}\end{array}$ & $\begin{array}{c}\text { Difference in } \\
\text { Gallons of Gasoline } \\
\text { per 12,000 Miles }\end{array}$ & Savings per Mile $^{\text {a }}$ \\
\hline Accord Hybrid & $\$ 3,690$ & 107.0 & $\$ 0.043$ \\
\hline Civic Hybrid & $\$ 3,590$ & 107.8 & $\$ 0.043$ \\
\hline Prius / Corolla XRS & $\$ 3,985$ & 183.8 & $\$ 0.074$ \\
\hline Camry Hybrid & $\$ 2,318$ & 128.7 & $\$ 0.052$ \\
\hline Highlander Limited & $\$ 2,570$ & 157.6 & $\$ 0.063$ \\
\hline RX 400h AWD & $\$ 3,662$ & 144.3 & $\$ 0.058$ \\
\hline GS 450h & $\$ 1,852$ & 105.3 & $\$ 0.04 .2$ \\
\hline Escape 4WD & $\$ 4,240$ & 112.9 & $\$ 0.046$ \\
\hline Mariner AWD & $\$ 6,095$ & 158.4 & $\$ 0.064$ \\
\hline Average & $\$ \mathbf{3 , 5 5 6}$ & $\mathbf{1 3 4 . 0}$ & $\$ \mathbf{0 . 0 5 4}$ \\
\hline
\end{tabular}

${ }^{\mathrm{a}}$ Ward's Automotive Yearbook, 2006, 2007.

Although hybrid SUVs get substantially lower fuel mileage than hybrid sedans (around $30 \mathrm{mpg}$ ), this represents a relatively large savings when considered in terms of how many gallons of gasoline are used by the average driver driving 12,000 miles per year.

\subsubsection{Comparison of Hybrid Vehicle Experience with the Hydrogen Model of this Study}

Sensitivity analysis to fuel efficiency and sticker price differences allows comparison of the model results for hydrogen vehicle adoption with the market experience of hybrid vehicle adoption. In Los Angeles, the hybrid sales penetration in 2009, which is a tenth-year market penetration, reached an estimated $4.9 \%{ }^{49}$

The 2009 Los Angeles sales penetration is roughly two-thirds the magnitude of the tenthyear sales penetration of hydrogen vehicles in the benchmark simulation of the model. The perfect substitutability between the hydrogen and non-hydrogen vehicles assumed in the model makes the adoption of the hydrogen vehicle more sensitive to fuel efficiency differences than hybrids may be, and as noted, the hybrids' sticker prices are relatively higher. Conducting a hydrogen simulation with a $\$ 3,500$ price disadvantage for hydrogen vehicles, the same as the price differential of hybrids in Table 5-3, and the 5.4 cents per mile fuel efficiency advantage, yields a tenth-year penetration of $4.1 \%$.

The $4.9 \%$ result for observed hybrid sales and the simulated $4.1 \%$ result for hydrogen vehicle sales are of the same general order of magnitude, under the conditions that the price disadvantage and fuel efficiency advantage for a hydrogen vehicle are the same as for a hybrid

\footnotetext{
${ }^{49}$ Bradley Berman, “December 2009 Dashboard: Year-End Tally,” HybridCars.com Market Dashboard, January 20, 2010, http://www.hybridcars.com/hybrid-sales-dashboard/december-2009-dashboard.html (accessed March 2, 2010). Los Angeles market share estimated assuming approximately 750,000 new vehicle sales used in the model, reduced by $21 \%$ to account for the reduction in national sales in 2009 .
} 
vehicle. A hybrid vehicle bears a greater similarity to a gasoline-powered vehicle than a hydrogen vehicle does to a non-hydrogen vehicle. Drivers are more familiar with technology and performance characteristics of hybrid vehicles than they would be with hydrogen vehicles early in the adoption process with hydrogen vehicles. Furthermore, hydrogen vehicles require special fueling stations that are less frequently encountered than conventional fuel stations capable of serving hybrid vehicles. Accordingly a somewhat lower penetration by the tenth year could be expected for hydrogen vehicles.

\subsection{Conclusions on Validation}

As discussed in Part Five, research was conducted on adoption of other durable goods innovations to see if the adoption path predicted for hydrogen vehicles in this study is similar to those for other innovations. A comparative study was conducted on the adoption paths of consumer durables products as a whole. Adoption experiences and lessons learned were gathered for specific vehicle innovations including CNG vehicles, penetration of Japanese vehicles in the U.S. market, and hybrid vehicles.

Overall, we judge the validation tests to be favorable to the Agent-based model of this study. The adoption paths for hydrogen vehicles in the simulations of this study have been found to have a typical S-shaped adoption curve similar to the empirical adoption paths calculated for other consumer durables. The S-curve for hydrogen vehicles exhibits a slower rate of adoption than for the average of all consumer durables. This is to be expected because automobiles including hydrogen vehicles have a much longer life and are thus subject to slower turnover than other durable goods. A lesson from the three vehicle case studies (CNG vehicles, Japanese vehicles, and hybrids) is that gain to the consumer from an innovation and, in the case of Japanese imports, government policy can have a powerful influence on the rate of adoption. 


\section{PART SIX: SUMMARY AND CONCLUSIONS}

The present Part of the study first brings together and summarizes the findings from Part Two describing the agent-based model, Parts Three and Four on numerical results, and Part Five on validation. This Part then turns to the implications of the findings for the central concern of the study:

Whether the private sector will supply the infrastructure to permit a transition to hydrogen consistent with national goals and, if not, what policy actions would be effective.

Finally, future work is discussed, with emphasis on the use of the study as an aid in analyzing policies under changing conditions in the future.

\subsection{The Agent-based Model}

As described in Part Two, the agent-based model (ABM) developed for this study simulates the behavior of more than 7 million Los Angeles drivers using over 7 thousand individual driver agents. The driver and investor modules and their interactions highlight the strengths of the ABM approach in allowing for realistic approximative decisions that depart from perfect optimization. The actors have imperfect knowledge. They can learn from their mistakes. The model projects events forward in time period by period building on outcomes from previous periods. The model permits projections of ultimate market penetration of hydrogen vehicles and the length of time required to achieve the penetration.

In deciding whether to buy a hydrogen vehicle, vehicle driver agents consider the sticker price difference between hydrogen and non-hydrogen vehicles, the difference in fuel costs, beliefs about how well a hydrogen vehicle operates, their preference for greenness, and the availability of hydrogen fuel as determined by the number and location of stations where hydrogen fuel is sold. Investor agents who supply hydrogen infrastructure compare actual sales of hydrogen fuel each period with what they expected and decide on the number and location of stations to build in the next period. If sales are favorable, more hydrogen fuel stations are supplied each period, further reinforcing demand growth as driver agents purchase more hydrogen vehicles. The predictions of number of hydrogen vehicles replicate the $S$-shaped pattern of adoption generally observed for innovations.

\subsection{Benchmark Case}

The benchmark case, chosen as a base from which to examine sensitivity, was described in Section 3.1. The benchmark uses driver and investor behavior parameters, combined with prices of vehicles and fuels for hydrogen and non-hydrogen vehicles that would result in cost competitiveness and allow a hydrogen vehicle take-off. This study does not attempt to predict the year when the required cost competitiveness permitting take-off will be achieved. That will 
depend on progress in reducing costs of producing hydrogen vehicles, on future prices of competitor vehicles, and on future hydrogen and non-hydrogen fuel prices, among other things. These are subject to unpredictable change over the course of the many years involved in the transformation to hydrogen transportation. The present study is designed to ascertain the conditions under which the hydrogen fuel infrastructure necessary for the transition will be supplied once the pre-conditions for a transition are achieved. The results can be used to show how the transformation will be affected as conditions change in the future and also to explore policy alternatives.

In the benchmark case, hydrogen vehicle sales penetration as a percent of all new vehicle sales rises first at an accelerating rate up until approximately year 20, when sales penetration reaches $60 \%$, after which penetration continues to rise but at a declining rate. It reaches $86 \%$ by year 40 after which it is rather flat.

Much of the present study has been devoted to examining the sensitivity of the benchmark case to the numerical parameters used. Of the 130 parameters of the model, selected parameters have been identified as being of particular importance. In view of the difficulty of predicting conditions 40 years in the future and the greater policy relevance of nearer term events, penetration for the first 20 years of transition has been used for the sensitivity comparisons.

\subsection{Sensitivity to Driver Behavior}

Sensitivity to driver parameters was considered in Section 3.2. Of the 17 parameters describing driver behavior, three have been identified as being of special importance: (1) driver familiarity with hydrogen vehicles; (2) the bandwagon effect indicating how greatly undecided drivers are influenced by the favorable experience of drivers who have already bought hydrogen vehicles; and (3) taste for greenness, meaning how much the driver's decision is swayed by the vehicle's environmental friendliness.

\subsubsection{Familiarity with Hydrogen Vehicle Performance}

Driver lack of familiarity with the performance characteristics of hydrogen vehicles has an effect on early sales that has a compound effect on later adoption. Whereas in the benchmark scenario, hydrogen vehicles account for $60 \%$ of sales within the 20 -year period being used for comparison, the range of 20 -year penetration between low and high familiarity is $24 \%$ to $79 \%$.

\subsubsection{Bandwagon Effect}

By the $20^{\text {th }}$ year, the range of sales penetration between low and high bandwagon strength is found to be greater than for familiarity, namely $27 \%$ to $94 \%$. Most of the impact is between the 10th and 15 th years of the transition. 


\subsubsection{Greenness}

Differences in the level and distribution of the taste for greenness affect the number of drivers adopting in the early years, giving a change that is compounded by the bandwagon effect and can have large lasting consequences for sales penetration. The sensitivity is less than that of familiarity or bandwagon effects. For the 20-year comparison period, the greenness penetration range is $17 \%$ to $69 \%$.

\subsection{Sensitivity to Investor Behavior}

Sensitivity to investor parameters was considered in Section 3.4. A major finding is that the rapidity of adoption can be greatly affected by upper management's degree of risk aversion and optimism or pessimism about the hydrogen vehicle. These attitudes are reflected in the discount rate used by upper management. High discount rates equivalent to risk-averse short payback periods could keep sales penetration to the range of only $2 \%$ to $11 \%$ after 20 years, effectively preventing a hydrogen take-off. On the other hand, one or more other companies with more optimistic upper management could come in and start the adoption process.

Many investor practices have more limited impact on the pace of adoption of hydrogen vehicles. There is less sensitivity to the narrower range of discount rates used by the line staff in its evaluations submitted to upper management, because the staff uses less extreme textbook discount rates. Relatively limited effects are also found for the rapidity of the investor's learning (weight on new observations), sophistication of expectations formation (whether future growth will be logistic), and method of estimating first year demand at locations where there is not yet a station (observing either total vehicles or only hydrogen vehicles). All the latter effects may be large for one year, particularly early in the simulation when investor experience is limited, but the unfolding of actual events corrects investor mistakes relatively rapidly. Because a single investor is already acting much like a pure competitor in view of the threat of entry of other investors and of regulation if monopolistic practices are observed, whether there is a single investor or a number of investors has limited impact.

\subsection{Effect of Realistic Approximative Decisions in the Agent-based Model}

Section 3.4 was concerned with whether the use of realistic approximative decision rules, sometimes called satisficing, in place of full optimization, interferes with the ultimate penetration of hydrogen vehicles. Obtaining a strict answer to this question is not feasible, because the calculation of the time path of adoption under perfect information would requires solution of an impossibly complex set of conditions. In order to address the, a test was carried out to obtain an upper bound on the possible effect. Having perfect issue information would imply that an investor could perfectly estimate the growth rate of demand for hydrogen and the fueling locations with the greatest potential for spurring hydrogen vehicle adoption. An upper bound is simulated by a hydrogen vehicle adoption path achieved by running a case with unlimited hydrogen supply at each location. This maximum possible path gives an upper bound that can be compared with actual adoption paths generated with approximative behavior. 
In the benchmark case, where the investor agent uses approximative rules of thumb, a stock penetration of $25 \%$ is reached by year 20 . In the unlimited fueling availability case, $25 \%$ stock penetration is achieved approximately 2 years earlier. This is the maximum effect of the investor's lack of perfect information during the first 20 years.

\subsection{Use of the Model to Examine Market Developments}

Sensitivities to two types of market developments were investigated: 1) prices of hydrogen and non-hydrogen vehicles and 2) operating costs as affected by prices of the fuels used by the vehicles.

\subsubsection{Vehicle Prices}

Scenarios of the effects of sticker price differences between the two types of vehicles demonstrate the vital importance of vehicle prices to the adoption process. These were investigated in Section 4.1. In the benchmark case, the sticker prices of hydrogen and nonhydrogen vehicles are equal. The major incentive to adopt a hydrogen vehicle is its greater fuel efficiency. The market share attained by hydrogen vehicles by the $20^{\text {th }}$ year is then $60 \%$. In a scenario where the hydrogen vehicle has a sticker price that is $\$ 2,000$ less than the non-hydrogen vehicle, the market share attained by the $20^{\text {th }}$ year is a high $92 \%$. On the other hand, in a scenario where the hydrogen vehicle is $\$ 6,500$ more than the non-hydrogen vehicle, market share in the $20^{\text {th }}$ year is reduced to only $6 \%$.

The foregoing vehicle price scenarios assume that the sticker prices remain constant throughout the simulation. Realism can be added by taking account of the fact that the price of a newly innovated product typically continues to fall for some time. To add this realism, additional scenarios of decline in the sticker price difference were investigated in which the cost of hydrogen vehicles declines first to the point where an initial subset of drivers adopts, providing a beginning to the innovation process. The cost of hydrogen vehicles then continues to drop as further adoption proceeds.

The first declining sticker price scenario is that the sticker price differences will decline at a constant percentage rate from a $\$ 14,000$ hydrogen vehicle disadvantage to no sticker price difference, in 5 years. This contrasts with the benchmark case in which the situation of no price difference has already been reached by the start of the simulation and there are no further declines. The second declining sticker price scenario is that the decline is from a $\$ 14,000$ disadvantage to no price difference over 10 years. In both of these scenarios, penetration exceeds $50 \%$ by year 20 and is thus not too different from the benchmark case.

In the final declining price scenario, the decline is from a $\$ 14,000$ sticker price difference to $\$ 4,000$ over 20 years. In this scenario, penetration by year 20 is only $10 \%$. The indication is that attention to the rate of price decline during the innovation process can be important to the rapidity of adoption. 


\subsubsection{Prices of Gasoline and Hydrogen Fuel}

With the prices of gasoline and hydrogen fuel used in the benchmark case, driver agents can save 9.8 cents per mile on fuel by driving a hydrogen vehicle instead of a non-hydrogen vehicle. In Section 4.2, results for two fuel price scenarios in addition to the benchmark case were presented: one in which drivers save 20.7 cents per mile by driving a hydrogen vehicle, and the other in which they save 0.5 cents per mile. As compared to the $60 \%$ penetration by the $20^{\text {th }}$ years in the base case, $86 \%$ penetration is reached by the $20^{\text {th }}$ year in the high-savings scenario, and only $10 \%$ in the low-savings scenario. The results are driven by the price of gasoline and suggest that future gasoline prices could be a crucial market consideration determining hydrogen vehicle penetration.

\subsection{Policies}

Three types of policies have been considered that would affect the rapidity of hydrogen vehicle adoption: 1) tax credits, 2) carbon taxes and 3) government assistance with initial seed stations.

\subsubsection{Tax Credits}

Tax credits for the purchase of a hydrogen vehicle were considered in Section 4.3. The effectiveness of a $\$ 2,500$ tax credit is reflected in the result that by the $20^{\text {th }}$ year, $88 \%$ of all lightduty vehicles sold are powered by hydrogen, as compared with $60 \%$ in the benchmark case. For a higher tax credit of $\$ 6,000$, the hydrogen vehicle sales share is $99 \%$ in the $20^{\text {th }}$ year.

Under a more modest approach, the tax credit would be available only for the first 10 years. Hydrogen sales penetration would then reach $69 \%$ of sales after 20 years with the $\$ 2,500$ credit and $79 \%$ with the $\$ 6,000$ credit.

\subsubsection{Carbon Taxes}

Two carbon tax levels have been investigated: $\$ 38$ and $\$ 116$ per metric ton of $\mathrm{CO}_{2}$. Results were presented in Section 4.4. The tax of $\$ 38$ per metric ton on carbon translates into a tax of 33 cents per gallon on gasoline, 44 cents per $\mathrm{kg}$ on hydrogen produced at distributed SMR stations, and 6 cents per $\mathrm{kg}$ on hydrogen produced at centralized facilities. The tax of $\$ 116$ per metric ton translates into a tax of $\$ 1.01$ per gallon of gasoline, $\$ 1.34$ per $\mathrm{kg}$ of hydrogen at distributed stations, and 18 cents per $\mathrm{kg}$ on centrally produced hydrogen.

The lower carbon tax of $\$ 38$ per metric ton is not large enough to noticeably affect sales penetration compared to the benchmark case of no tax. The larger tax of $\$ 116$ per metric ton makes centrally produced hydrogen profitable in the very first year and results in modestly higher levels of hydrogen vehicle sales penetration. 


\subsubsection{Seed Stations}

Seed stations, established through policy assistance, assure drivers within range of those stations of a supply of hydrogen fuel and may tip their vehicle purchase decisions in favor of a hydrogen vehicle in early periods before hydrogen more widely available. The benchmark case includes 15 seed stations, which correspond to current locations of hydrogen stations in the Los Angeles area.

In Section 4.5, sensitivity to the introduction of 15 additional stations, totaling 30 seed stations, was examined. The additional 15 stations were placed alternatively in the most profitable and least profitable locations. Both scenarios gave sales penetration rates that were very close to the benchmark after 20 years, $63 \%$ and 59\% respectively, as compared to $60 \%$ for the base case without the extra seed stations.

\subsection{Model Validation}

Several validation tests were applied to the model of this study by comparing its results to experiences with other innovations, as reported in Part Five. The model generates empirical patterns of adoption that are similar to those observed for other innovations. Where differences have appeared between the model's results for hydrogen vehicles and innovation patterns for other innovations, they can be explained in terms of different characteristics of the innovations or of the market settings in which the technologies were introduced. These other innovations include a composite of consumer durables in general, CNG vehicles, Japanese vehicles, and gasoline-electric hybrid vehicles.

\subsection{Bottom Line Issue of this Study: Adequacy of Private Sector Infrastructure Supply}

Will the private sector supply the necessary infrastructure to permit a transition to a hydrogen transportation economy? The ABM of this study indicates that the private sector transition will provide the necessary infrastructure, provided prerequisite technological and market conditions are met. The prospect of a satisfactory return on investment will call forth sufficient initial production of hydrogen fuel and the building of dispensing stations to make fuel conveniently available to enough drivers to initiate a hydrogen vehicle sales take-off.

This seemingly favorable answer however leads to two follow-up questions. First, is the rate of adoption rapid enough to satisfy the national goal of extricating from dependence on foreign oil? The rapidity of transition depends on how favorable the pre-requisite conditions are. If the price of gasoline is higher than it has been historically or there is a favorable technological breakthrough greatly reducing the cost of producing hydrogen vehicles, drivers will have large incentives to switch to hydrogen vehicles, acting to speed the adoption process. On the other hand, if conditions are just barely favorable, the result may not be very different in terms of 
policy from no take-off at all. Adoption may proceed so slowly that it is deemed unsatisfactory from the point of view of reducing foreign dependence.

Examples of the importance of prerequisite technological and market conditions have been given. In the benchmark case with savings of 9.8 cents per mile in favor of the hydrogen vehicle, 20-year sales penetration is $60 \%$; but with a 20.7 cents per mile savings due to a higher price of gasoline than assumed in the benchmark, the 20 -year penetration is $86 \%$. Fuel cost savings remaining as low as 0.5 cents per mile can effectively stall the transition. The price of a hydrogen vehicle relative to a non-hydrogen vehicle has an equally powerful influence. If the hydrogen vehicle's price were $\$ 2,000$ lower than the non-hydrogen vehicle's price instead of equal as in the benchmark case, sales penetration would reach $92 \%$ percent in 20 years. If the cost of the hydrogen vehicle is $\$ 6,500$ higher than the non-hydrogen vehicle, penetration will be only $6 \%$ after 20 years.

The pronounced effect of technological and market conditions takes on added importance because the results indicate that a transition to hydrogen in the relatively favorable benchmark case will require many years. If the cost of producing hydrogen vehicles falls rapidly and farther than in the benchmark case, adoption will be speeded. If the price of gasoline climbs greatly, adoption will be speeded. The opposite conditions will slow the transition.

The results lead to a second follow-up question: If the transition to hydrogen is deemed unsatisfactory, what policies are available to speed it up? Tax credits, a carbon tax and government assistance with seed stations have been used to illustrate the effects of policies aimed at speeding up the transition. As examples, government assistance policies in the form of tax credits for the purchase of hydrogen vehicles are quite potent. Permanent tax credits of $\$ 2,500$ to $\$ 6,000$ per vehicle could effectively complete the transition within 20 years. Even a temporary tax credit, extending for the first 10 years of the transition, would provide a significant fillip. By the 10th year, the last year of the temporary credit, credits of these magnitudes would help the hydrogen sales penetrations reach $54 \%$ to $91 \%$, and even though the shares of sales drop precipitously when the tax credits are terminated, by the 20th year, hydrogen sales penetration still reaches $69 \%$ to $79 \%$. The early period of high hydrogen shares of sales with the temporary credits will increase the stock of hydrogen vehicles earlier in the transition. Carbon taxes and government assistance in building seed stations have less effect.

\subsection{Future Work}

This study has applied an agent-based approach to modeling hydrogen infrastructure supply, using real world decision processes that do not assume unrealistic optimization. It is an early agent-based modeling study applied to the problem. Given the resource limitations of the study, help was given by industry cooperators in choosing which of the many facets of decisionmaking to concentrate on. A large number of possibilities exist for studying other approximative decisions that drivers and investors may be concerned with beyond those considered here. 
Our results have been presented in such a way that they can be adapted to future conditions. While reliably predicting events and policy concerns 10 or 15 years in the future is at best difficult, the model of this study provides a way to analyze effects of a wide range of future possibilities. It is a tool to aid in evaluation of policies that will arise in the future and that can be adapted to changing conditions in the future. 


\section{APPENDIX A: DRIVER MODULE}

\section{A.1 Driver Agent Fleet Composition}

\section{A.2 Driver Utility Function, $U_{j t}^{R}$}

A.2.1 Sticker Price Difference, $P_{t}^{S}$

A.2.2 Fuel Cost Advantage, $P_{j t}^{V}$

A.2.3 Disadvantage Due to Limited Familiarity and Bandwagon Coefficient, $P_{j t}^{F}$ and $\mathbf{q}_{\mathbf{j}}$

A.2.4 Greenness, $T_{j}$

A.2.5 Inconvenience, $\mathrm{I}_{\mathrm{jt}}$

A.2.6 Worry, $W_{j t}$

\section{A.3 Refueling}

\section{A.3.1 Trip Routes}

A.3.2 Refueling Decision

A.3.3 How Much Hydrogen Fuel to Buy 


\section{A.1 Driver Agent Vehicle Fleet Composition}

Table A-1 below provides the age distribution of the total stock of vehicles owned by driver agents by income type. In the beginning of a simulation, the overwhelming majority of the total stock of vehicles owned by drivers is non-hydrogen powered. During each period during the simulation, driver agents replace some of the non-hydrogen vehicles in their fleet with hydrogen vehicles. This replacement increases the fraction of hydrogen vehicles in driver agents' fleets over time. The age mix of the total stock of vehicles is assumed to remain unaffected. The initial row of Table A-1 pertains to new cars and shows that each year 111 new vehicles are purchased per 1,000 high income drivers, and 55 new vehicles are purchased per 1,000 middle income drivers. Low income drivers do not buy new vehicles. They rely on a used car market to obtain vehicles discarded by the high-income drivers.

Of the total vehicles purchased each year by driver agents, some are hydrogen vehicles and some are non-hydrogen vehicles. Overall, 5.52\% of the total vehicle stock is turned over each year. 
Table A-1: Number of Vehicles Owned per Thousand Low, Middle, and High Income Drivers, by Age of Vehicle

\begin{tabular}{|c|c|c|c|}
\hline Age of Vehicle & Low Income & Middle Income & High Income \\
\hline 0 & 0 & 55 & 111 \\
\hline 1 & 2 & 55 & 109 \\
\hline 2 & 4 & 55 & 107 \\
\hline 3 & 7 & 55 & 104 \\
\hline 4 & 12 & 55 & 99 \\
\hline 5 & 18 & 55 & 93 \\
\hline 6 & 26 & 55 & 85 \\
\hline 7 & 34 & 53 & 73 \\
\hline 8 & 43 & 51 & 60 \\
\hline 9 & 51 & 49 & 47 \\
\hline 10 & 58 & 47 & 36 \\
\hline 11 & 63 & 44 & 26 \\
\hline 12 & 65 & 42 & 18 \\
\hline 13 & 65 & 39 & 12 \\
\hline 14 & 64 & 36 & 8 \\
\hline 15 & 61 & 33 & 5 \\
\hline 16 & 57 & 30 & 3 \\
\hline 17 & 53 & 28 & 2 \\
\hline 18 & 48 & 25 & 1 \\
\hline 19 & 43 & 22 & 1 \\
\hline 20 & 39 & 20 & 0 \\
\hline 21 & 34 & 17 & 0 \\
\hline 22 & 30 & 15 & 0 \\
\hline 23 & 26 & 13 & 0 \\
\hline 24 & 22 & 11 & 0 \\
\hline 25 & 19 & 10 & 0 \\
\hline 26 & 16 & 8 & 0 \\
\hline 27 & 13 & 7 & 0 \\
\hline 28 & 11 & 6 & 0 \\
\hline 29 & 9 & 5 & 0 \\
\hline 30 & 7 & 4 & 0 \\
\hline All & 1,000 & 1,000 & 1,000 \\
\hline \multicolumn{4}{|c|}{$\begin{array}{l}\text { Source: The distributions were chosen to match the distribution in Stacy Davis et al., } \\
\text { "Transportation Energy Data Book," ORNL-6981 (Ed. 27-2008), Table } 3.10 \text { for } 1990 \text { model yea } \\
\text { cars. }\end{array}$} \\
\hline
\end{tabular}




\section{A.2 Driver Utility Function, $U_{j t}^{R}$}

Drivers measure the net utility of hydrogen vehicles, $U_{j t}^{R}$, as the utility of a hydrogen vehicle minus the utility of a non-hydrogen vehicle using the following equation:

$$
U_{j t}^{R}=P_{t}^{S}+P_{j t}^{V}-P_{j t}^{F}+T_{j}-I_{j t}-W_{j t}
$$

where:

$P_{t}^{S}=$ the difference in price paid, or sticker price difference between hydrogen and nonhydrogen vehicles

$P_{j t}^{V}=$ the fuel cost advantage of hydrogen vehicles over non-hydrogen vehicles;

$P_{j t}^{F}=$ agent $\mathrm{j}$ 's disadvantage due to limited familiarity with hydrogen vehicles

$\mathrm{T}_{\mathrm{j}}=$ utility from a hydrogen minus that from a non-hydrogen vehicle and other things being equal, or agent j's taste for the hydrogen vehicle, resulting in this case from a preference for green vehicles;

$\mathrm{I}_{\mathrm{jt}}$ = fueling inconvenience associated with owning a hydrogen vehicle;

$\mathrm{W}_{\mathrm{jt}}=$ worry factor associated with finding a hydrogen refueling station.

The units of each of the utility terms are dollars. When the time comes for the driver agent to purchase a new vehicle, the utility function is used to decide whether it will be a hydrogen or non-hydrogen vehicle. Each of the terms in the driver utility function equation above is discussed below.

\section{A.2.1 Sticker Price Difference, $P_{t}^{S}$}

The sticker price difference is the cost of a hydrogen vehicle minus that of a nonhydrogen vehicle.

$$
P_{t}^{S}=H_{t}^{f}-G_{t}^{f}
$$

where;

$H_{t}^{f}=$ the average sticker price of a hydrogen-powered light-duty vehicle.

$G_{t}^{f}=$ the average sticker price of a non-hydrogen-powered light-duty vehicle; 
Numerical values of sticker price differences used in this study are presented in Section 4.1 of the main body of the report.

\section{A.2.2 Fuel Cost Advantage, $P_{j t}^{V}$}

$P_{j t}^{V}$, the fuel cost advantage of hydrogen vehicles over non-hydrogen vehicles, enters the utility function as a discounted sum of the savings on fuel costs, calculated as follows:

$$
P_{j t}^{V}=d_{j} *\left(g^{v} e^{g}-h^{v} e^{h}\right) * \frac{1-[1+(r / 4)]^{-4 L}}{r / 4}
$$

where:

$$
\begin{aligned}
& P_{j t}^{V}=\text { fuel cost advantage; } \\
& \mathrm{d}_{\mathrm{j}}=\text { number of miles each agent } \mathrm{j} \text { drives each quarter; } \\
& \mathrm{g}^{\mathrm{v}}=\text { cost per gallon of gasoline; } \\
& \mathrm{h}^{\mathrm{v}}=\text { cost per kilogram of hydrogen; } \\
& \mathrm{e}^{\mathrm{g}}=\text { fuel efficiency of non-hydrogen vehicles, in gallons per mile; } \\
& \mathrm{e}^{\mathrm{h}}=\text { fuel efficiency of hydrogen vehicles, in kg per mile; } \\
& \mathrm{r}=\text { driver annual discount rate; } \\
& \mathrm{L}=\text { driver time horizon for evaluating fuel savings. }
\end{aligned}
$$

The discount rate is divided by four and the time horizon is multiplied by four to account for the fact that the driver model operates in time intervals of quarters, not years.

The cost per unit of fuel multiplied by the units per mile yields a cost per mile of using the fuel. The cost per mile of using non-hydrogen minus that of hydrogen is multiplied by the number of miles driver agent $\mathrm{j}$ drives each period, to give quarterly fuel savings, which is then multiplied by the capitalization factor to give the present value of fuel savings.

Additional information regarding the influence of the fuel cost advantage is presented in Section 4.2 of the main body of the report which provides results of a sensitivity study of this parameter. 


\section{A.2.3 Disadvantage Due to Limited Familiarity and Bandwagon Coefficient, $P_{j t}^{F}$ and $\mathbf{q}_{\mathbf{j}}$}

The disadvantage due to limited familiarity is calculated using a familiarity premium equation. The familiarity premium, $P_{j t}^{F}$, measures the dollar value of driver agent j's familiarity with hydrogen vehicles at time $t$. The rate at which the familiarity premium declines is calculated using the bandwagon coefficient, $q_{j}$.

Drivers with higher bandwagon coefficients are more inclined to imitate others. In each period, each driver agent's bandwagon coefficient is multiplied by the proportion of hydrogen vehicles on the road in the previous period, and that product is subtracted from the current value of the familiarity disadvantage, yielding a smaller disadvantage each period, which is unique to each driver. When the familiarity disadvantage reaches zero for a driver, it cannot decrease further and the bandwagon effect has had its maximum impact.

The familiarity premium required of agent $\mathrm{j}$ at time $\mathrm{t}, P_{j t}^{F}$, is given by:

$$
P_{j t}^{F}=\beta^{F}\left[1-\min \left(\sum_{i=0}^{t-1} q_{j}\left(N_{i} / M\right), 1\right)\right]
$$

where:

$\beta^{\mathrm{F}}=$ the value of full familiarity, i.e., the amount a driver who is completely unfamiliar with a hydrogen vehicle would have to be paid to be willing to purchase the vehicle;

$\mathrm{N}_{\mathrm{i}}$ = the total number of hydrogen vehicles in the model area in period $\mathrm{i}$;

$\mathrm{M}=$ the stock of vehicles in the model area, so that $\mathrm{N}_{\mathrm{i}} / \mathrm{M}$ is the proportion of driver agents who already own hydrogen vehicles;

$\mathrm{q}_{\mathrm{j}}=$ the bandwagon coefficient, a multiplier that converts a given level of adoption to an amount of familiarity gained by agent $\mathrm{j}$;

$\beta^{\mathrm{F}}$ is the initial familiarity premium which driver agents require if they are to choose a hydrogen vehicle over a non-hydrogen vehicle. This initial familiarity premium is common to all drivers. Thereafter, in each period it decreases by the fraction of the vehicle stock in Los Angeles that is hydrogen fueled, multiplied by the agent-specific scaling factor $\mathrm{q}_{\mathrm{j}}$, the bandwagon coefficient.

The bandwagon coefficient is distributed log-normally among the driver agents with the mean and variance parameters of the distribution chosen such that the adoption path of the 
hydrogen vehicles approximates the consumer goods Bass curve from the literature. ${ }^{50}$ Once it reaches $\$ 0$, the familiarity premium does not decline any more.

Additional information regarding the influence of the disadvantage due to limited familiarity and the bandwagon effect is presented in Sections 3.2.1 and 3.2.2 of the main body of the report, which provide results of sensitivity studies of these parameters.

\section{A.2.4 Greenness, $T_{j}$}

Each driver has a taste for greenness, and each driver agent is assigned a value from a taste distribution. In the benchmark case, greenness values are distributed log normally among drivers with a median of $\$ 250$. Similar to the bandwagon effect, a log normal distribution implies that the minimum level of greenness is $\$ 0$. Most drivers cluster at similar, low values, with a minority of drivers having very high values. The minimum is $\$ 0$ taste for greenness, assuming that a vehicle with no pollution would at worst have no positive effect on a person's purchase decision.

In the utility function, $\mathrm{T}_{\mathrm{j}}$ is agent $\mathrm{j}$ 's intrinsic taste for the hydrogen vehicle resulting from a preference for a green vehicle. $T_{j}$ is also measured in dollars and is added to the driver's utility, so that if agent $\mathrm{j}$ is otherwise indifferent between hydrogen and non-hydrogen vehicles but is willing to pay $\$ 100$ for the environmental benefits of a hydrogen vehicle, $T_{j}$ equals 100 .

Additional information regarding the influence of greenness is presented in Section 3.2.3 of the main body of the report which provides results of a sensitivity study of this parameter.

\section{A.2.5 Inconvenience, $\mathrm{I}_{\mathrm{jt}}$}

Driver agent $\mathrm{j}$ 's inconvenience in period $t$ is measured in dollars and is given by the following equation:

$$
I_{j t}=\left(I_{j t}^{n}+I_{j t}^{s}+I_{j t}^{e}+I_{j t}^{g}+I_{j t}^{w}\right) * V
$$

where:

$\mathrm{I}_{\mathrm{jt}}=$ total inconvenience experienced by the driver;

$I_{j t}^{n}=$ inconvenience from not being able to make a trip with a hydrogen vehicle;

\footnotetext{
${ }^{50}$ The benchmark values used is from the average imitation and innovation parameters from 213 applications in 15 separate articles summarized in Frank M. Bass, Trichy V. Krishnan, and Dipak C. Jain, "Why the Bass Model Fits without Decision Variables," Marketing Science 13 (1994), Table 2, p. 214; The high and low values are taken from estimates of imitation and innovation in the diffusion of color television, clothes driers, and room air conditioners, with color television diffusion representing low bandwagoning and with clothes dryer diffusion representing high bandwagoning. Fareena Sultan, John U. Farley, and Donald R. Lehmann, "A Meta-Analysis of Applications of Diffusion Models," Journal of Marketing Research 27 (1990), Table 2, p. 75.
} 
$I_{j t}^{s}=$ inconvenience from having to make a special trip to buy hydrogen;

$I_{j t}^{e}=$ inconvenience from having to buy hydrogen earlier than desired;

$I_{j t}^{g}=$ inconvenience from finding a hydrogen station supply exhausted and having to travel to another;

$I_{j t}^{w}=$ inconvenience from finding a hydrogen station supply exhausted and waiting for more supply;

$\mathrm{V}=$ the present value multiplier that allows the driver to take into account expected inconvenience over the entire life of the vehicle.

Each of these inconvenience terms is the total inconvenience incurred over the course of the quarter from all of the times each of these events occurs. They are all measured in dollars. driver.

The following paragraphs present in detail the various sources of inconvenience to the

Not being able to make a trip. When an agent cannot make a trip with a hydrogen vehicle, a base inconvenience cost is incurred for the loss of that trip as well as additional inconvenience based on its length. The term $I_{j t}^{n}$ is the sum of all these occurrences in a given quarter:

$$
I_{j t}^{n}=\sum_{a=1}^{T}\left(i^{n f}+i^{n v} d_{a}^{n}\right)
$$

where $\mathrm{i}^{\mathrm{nf}}$ is the base inconvenience cost associated with not being able to make a trip with a hydrogen car, $\mathrm{i}^{\mathrm{nv}}$ is the inconvenience cost incurred per mile of the trip the agent could not take, and $d_{a}^{n}$ is the length, in miles, of the a th trip the driver agent must give up this quarter. $\mathrm{T}$ represents the total number of trips the driver owning a hydrogen vehicle would have to forgo this quarter.

Having to make a special trip. As with forgone trips, each special trip an agent must make causes him to incur a base inconvenience cost and additional inconvenience costs based on the trip's length. The term $I_{j t}^{s}$ is the sum of all these occurrences in a given quarter:

$$
I_{j t}^{s}=\sum_{a=1}^{T}\left(i^{s f}+i^{s v} d_{a}^{s}\right)
$$

where $\mathrm{i}^{\mathrm{sf}}$ is the base inconvenience cost associated with needing to make a special trip, $\mathrm{i}^{\mathrm{sv}}$ is the inconvenience cost incurred per mile of that trip, and $d_{a}^{s}$ is the length, in miles, of the a ${ }^{\text {th }}$ special 
trip the driver agent must make this quarter. T represents the total number of special trips the driver owning a hydrogen vehicle would have to make this quarter.

Having to refuel earlier than desired. Each time an agent has to buy fuel earlier than desired because of a scarcity of hydrogen fueling sites, a cost per mile is incurred based on how much later, in miles, refueling would have been wanted. The term $\mathrm{I}_{\mathrm{jt}}^{\mathrm{e}}$ is the sum of all these occurrences in a given quarter:

$$
I_{j t}^{e}=\sum_{a=1}^{T}\left(i^{e v} d_{a}^{e}\right)
$$

where $\mathrm{i}^{\mathrm{ev}}$ is the inconvenience cost incurred per mile, and $d_{a}^{e}$ is the distance, in miles, to the point the driver would have preferred to refuel at on the $\mathrm{a}^{\text {th }}$ occurrence of an early refueling. $\mathrm{T}$ represents the total number of times the driver needs to refuel early in a quarter.

Finding a station over capacity. Each time an agent finds a station at overcapacity, a one-time inconvenience cost is incurred. The term $I_{j t}^{g}$ is the sum of all these occurrences in a given quarter:

$$
I_{j t}^{g}=\sum_{a=1}^{T} i^{o p}\left[\frac{\text { Total Sales in Cell }}{\text { Capacityof Cell }}-1\right]
$$

where $\mathrm{i}^{\mathrm{gf}}$ is the inconvenience cost associated waiting in a queue, $i^{o p}$ reflects the inconvenience cost of refueling at a station that is $100 \%$ over-capacity, and T represents the total number of times that happens to this agent this quarter.

Present value term. The present value term $\mathrm{V}$ multiplied by this quarter's inconvenience cost gives the full discounted cost of inconvenience over the driver time horizon. The present value term is given by the following equation:

$$
V=\frac{1-[1+(r / 4)]^{-4 L}}{r / 4}
$$

where:

$r=$ the annual discount rate;

$\mathrm{L}=$ driver time horizon.

\section{A.2.6 Worry, $W_{j t}$}

Worry is accumulated each time a driver refuels when the tank is between the "want-tobuy" and "desperate-to-buy" points. For example, if the want-to-buy point is when the tank is 
$20 \%$ full and the desperate-to-buy point is when it is $5 \%$ full, then refueling after depleting more than $80 \%$ of the tank causes worry. A driver will never make a trip that depletes more than $95 \%$ of the tank. Worry increases nonlinearly in distance from the optimal-to-refuel point. equation:

Driver agent $\mathrm{j}$ 's worry in quarter $\mathrm{t}$ is measured in dollars and is given by the following

$$
W_{j t}=V * w^{*} \sum_{a=1}^{T}\left(\left(1+\frac{f_{\alpha}}{h}\right)\right)^{-1}
$$

where:

$\mathrm{V}=$ The present value multiplier that allows the driver to take into account how much worry is expected over the entire life of the vehicle. This is the same as the multiplier for inconvenience.

$\mathrm{w}=$ The most a driver can worry, measured in dollars. Worry reaches this level when the amount of fuel in the tank reaches the desperate-to-buy level;

$\mathrm{f}=$ The amount of fuel left in the tank above the desperate-to-buy level, measured in hundred-thousandths of a tank of fuel;

$\mathrm{h}=$ The amount of fuel left in the tank above the desperate-to-buy level at which worry reaches one-half its maximum, measured in hundred-thousandths of a tank of fuel; this parameter allows the user to choose the rate at which worry grows;

$\mathrm{T}=$ The total number of times the driver agent gets worried this quarter, which is basically the total number of times the driver actually makes a trip and refuels after the fuel tank has passed the "want-to-buy" point.

\section{A.3 Refueling}

To carry out the above calculations of worry and inconvenience requires knowing 1) where agents travel (travel behavior) and 2) how they prefer to refuel (refueling behavior). In general, driver agents will incur less inconvenience and worry as the number of hydrogen stations increases, especially along the travel route of the driver.

Section A.3.1 presents an explanation of trip routes taken by driver agents. Discussions regarding how driver agents make decisions about refueling are presented in Sections A.3.2, and A.3.3.

\section{A.3.1 Trip Routes}

Each driver agent travels on a certain number of commuting and non-commuting routes each quarter. The commuting trips are between home and work locations. Non-commuting trips 
are between home and non-work locations such as regional attractions, shopping malls, and so on. Depending on the home location, there are 20 possible trip routes outside of a work commute that a driver can take. From this individual set of trips for a driver, 20 trips are randomly selected with replacement each quarter. Consequently, it is possible that in one quarter a driver would happen to be assigned relatively longer non-commute trips from the set of possible trips, and in another quarter would be assigned relatively shorter trips. This gives rise to variation in the driving distance of drivers to reflect a similar stochastic element in real world driving behavior.

For the purpose of simulation, all the trips are intertwined in a larger trip called a megatrip. The megatrip is what the drivers undertake each quarter of a simulation. Since the length of a megatrip need not necessarily approximate the annual driving range of 12,000 miles, a multiplier is applied to actual length of the megatrip to scale it up. This multiplier is calculated only in the first year of simulation and equals 12,000/actual length of the megatrip. The multiplier assigned during this first period stays with the driver agent for the entire run of the model. So when the driver is designated the trips in the first year and the trips total 6,000 miles, the multiplier will be 2, and the total miles driven will be 12,000. The next year, if the driver receives trips assigned that add to 7,000 miles, total miles driven will be 14,000 the following year.

\section{A.3.2 Refueling Decision}

All drivers have the following three salient markers on their fuel gauge, though the precise level of these markers may differ from driver to driver.

- Willing-to-buy level;

- Want-to-buy level;

- Desperate-to-buy level.

In the model, a driver agent loses fuel at a varying rate depending on the cells (highway or local, diagonal or straight road) being traversed, and must eventually refuel. The driver would prefer to buy fuel as close to the want-to-buy level as possible but no sooner than the willing-tobuy level. If the driver is unable to buy fuel and indeed hits the want-to-buy marker on the fuel gauge, inconvenience begins to register. Thus, hitting the want-to-buy level on the fuel gauge is an inconvenience event. If the driver is still not able to buy fuel even after hitting the want-tobuy level, worry would also start accumulating. Worry will be accumulated between the wantto-buy level and the desperate-to-buy level.

The case of a driver not being able to refuel is not permitted in the model. It is assumed that all drivers are assumed to possess a GPS device that gives them locations of each hydrogen fuel station. If they would not be able to refuel on the way, they would first consider topping-off their tanks by making special trips to the nearest hydrogen fuel station, and would then undertake their regular trips. When the drivers have to do this, they incur a penalty to reflect the time and money cost of such a special refueling trip. If the nearest hydrogen fuel station is so far away that the driver would lose enough fuel on the way back to again make the planned trip unfeasible 
then the driver foregoes the planned trip and incurs a penalty to reflect the value of the foregone trip.

Since each agent represents some 1,000 vehicles, even if not all these vehicles are hydrogen vehicles, the choice of which hydrogen fuel station from which to purchase fuel has a significant effect on a hydrogen fuel station's total sales. This fact, coupled with the limited selection of trips each agent can make, means that it is not unlikely that a single hydrogen fuel station might receive a large proportion of the driver's purchases to the exclusion of other hydrogen fuel stations in the immediate vicinity. Drivers traveling the same routes, even from the same starting point, will spread out their purchases over all the hydrogen fuel stations in the vicinity. This concern is taken into account in two ways. Since there can be many hydrogen fuel stations in a single cell, a purchase made at a given cell is divided evenly among all hydrogen fuel stations in that cell. Secondly, if there are other cells containing hydrogen fuel stations within an exogenous input driving distance of that cell, then the purchase is first divided evenly among all such cells, then within each cell, among the hydrogen fuel stations in that cell.

\section{A.3.3 How Much Hydrogen Fuel to Buy}

Whenever driver agents stop to refuel, they top off their tanks so that the fuel purchased is equal to the maximum tank capacity minus current fuel level. If all the vehicles in a driver agent's fleet were driven the same number of miles, this would be sufficient. However, it is assumed that newer vehicles are driven more than older vehicles, so a weighting factor that takes into account the ages of the hydrogen vehicles in the driver agent's fleet is used to determine the purchase of hydrogen.

When a driver agent stops at a hydrogen fuel station to refuel, only that weighted proportion, which could be zero, of the total purchase is credited to the hydrogen fuel stations from which the purchase has been made. 


\section{APPENDIX B： INVESTOR MODULE}

\section{B.1 Price Charged for Hydrogen Fuel}

\section{B.2 Station Siting}

B.2.1 Forecasting Expected Hydrogen Fuel Sales

B.2.1.1 Unadjusted Sales at a Location, $D_{j, t-1}^{*}$

B.2.1.2 Adjustments for Sales to Stations Planned but Not Yet Operational, $D_{j, t-1}^{* *}$

B.2.1.3 Estimation of the Growth Parameter, $G_{t}$

B.2.1.4 Estimating Future Sales Using a Logistic Growth Function, $D_{j, t+s-1}$

B.2.1.5 Estimating Future Sales Using a Simpler Approach

B.2.2 Effect of a New Station on Profitability of Entire Set of Stations

B.2.2.1 Net Present Value (NPV) Calculations

B.2.2.2 Ranking of Locations

B.2.2.3 Net Present Value (NPV) Rule for Station Siting

\section{B.3 Number of Investors}

B.3.1 Single Investor

B.3.2 More than One Investor

\section{B.4 Options beyond Runs in this Study}

B.4.1 Using Current Capacity Utilization to Rank Locations

B.4.2 Allowing the Investor to Be a Loss Leader in Siting Stations

B.4.3 Introducing a Capital Budget Constraint in the Investor's Decision-Making 


\section{B.1 Price Charged for Hydrogen Fuel}

The price charged for hydrogen fuel is set to equal the average cost of producing hydrogen, derived from H2A, plus any tax. The price charged by the investor for hydrogen fuel, $P$, is then given by:

$$
P=U+E+\frac{A+r C}{\alpha H}
$$

where:

$$
\begin{aligned}
& U=\text { per kilogram variable cost of hydrogen; } \\
& E=\quad \text { per kilogram tax on hydrogen fuel; } \\
& A=\quad \begin{array}{l}
\text { annual maintenance costs inclusive of any depreciation and interest payment on } \\
\text { borrowed funds; }
\end{array} \\
& C=\quad \text { equity's share of capital costs; } \\
& r=\quad \text { rate of return on equity; } \\
& H=\quad \text { effective capacity of the station in } \mathrm{kg} / \mathrm{year}^{51} ; \text { and } \\
& \alpha=\text { expected capacity utilization of the plant. }
\end{aligned}
$$

Table 3-1 of the study provides the price of hydrogen fuel used in the benchmark run of the model.

\section{B.2 Station Siting}

\section{B.2.1 Forecasting Expected Hydrogen Fuel Sales}

In order to decide whether to invest in another fueling station, the investor makes a forecast of future sales at each location in the city. This forecast is made by employing a logistic growth function. The logistic growth function requires knowing the most recently completed year's sales (base sales), the sales corresponding to the entire target population adopting the innovation (saturation sales), the rate of growth parameter.

The investor estimates base sales in two steps. First, as explained in Section B.2.1.1 below, "Unadjusted Sales at a location, $D_{j, t-1}^{*}$," the most recently completed year's sales at the location are observed using the data supplied by the driver module run for the previous year. In

${ }^{51}$ Dispensing forecourts of centralized plants and distributed stations have the same nameplate capacity of $1,500 \mathrm{~kg} / \mathrm{day}$. 
the second step, the investor adjusts the most recently completed year's sales at this location by the diversion of sales, if any, to newly planned stations near the location under consideration. This adjustment process is described in Section B.2.1.2 below, "Adjustments for Sales to Stations Planned but Not Yet Operational, $D_{j, t-1}^{* *}$." When the adjustment is made, the investor has an estimate of this location's base sales which can be used to forecast future sales at that location.

Saturation sales are based on the assumption that by the time sales reach the maximum possible level at any location, there would be at least one fueling station at all possible station locations. For this reason, the saturation level of hydrogen sales is obtained in a pre-run of the simulation in which all the vehicles are hydrogen and all the locations have fueling stations.

The growth parameter is developed using a Bayesian learning algorithm. Section B.2.1.3 below, "Estimation of the Growth Parameter, $\mathrm{G}_{\mathrm{t}}$," provides additional details.

Estimates of fuel sales are developed applying the logistic growth function as described in Section B.2.1.4 below, "Estimating Current and Future Year Sales at a Location Using a Logistic Growth Function, $D_{j, t+s-1}$."

\section{B.2.1.1 Unadjusted Sales at a Location, $D_{j, t-1}^{*}$}

The investor is able to observe directly the most recently completed year's hydrogen sales at the locations where a fueling station existed during the previous year. For such locations, the estimate of the most recently completed year's sales are the fuel sales that were observed in the previous year, i.e.,

$$
D_{j, t-1}^{*}=S_{j, t-1}
$$

where

$$
\begin{aligned}
D_{j, t-1}^{*}= & \text { the investor's estimate of base sales at each location } j \text { that had at least one } \\
& \text { fueling station in the most recently completed year; } \\
S_{j, t-1}= & \text { the realized sales at location } j \text { in the most recently completed year. }
\end{aligned}
$$

Fuel sales at the locations where no station existed in the previous year are zero by definition, but the investor must estimate of how much fuel may be expected to be sold at these locations, if stations were to be sited there. These estimates are made using a regression that relates fuel sales in a location to the vehicle traffic passing through the location and to competition from nearby fueling stations. The regression is:

$$
\frac{S_{i, t-1}}{V_{i, t-1}}=a_{0}+\sum_{n=1}^{N} a_{n} C_{n, t-1}^{i}+\varepsilon_{i}
$$


where:

$$
\begin{aligned}
S_{i, t-1}= & \text { fuel sales in grid cell } i \text { in the year } t-1 ; \\
V_{i, t-1}= & \text { vehicle traffic passing through location } i \text { in the year } t-1 ; \\
a_{0}= & \text { constant term; } \\
C_{n, t-1}^{i}= & \text { the count of locations in the } n^{\text {th }} \text { ring around location } i \text { which had at least one } \\
& \text { station in the last period; the investor counts the number of cells with a fuel } \\
& \text { station in each of several rings around the candidate location; the number of rings } \\
& \text { (up to } 3 \text { ) and their radii are exogenous input parameters; if the investor chooses to } \\
& \text { ignore the surrounding rings in the regression estimation (i.e., choosing } N=0 \text { ), } \\
& \text { then only the average sales/traffic ratio is used to predict base sales volume; } \\
a_{n}= & \text { regression coefficient; } \\
\varepsilon_{i}= & \text { error term. }
\end{aligned}
$$

Denoting the estimated coefficients by $\hat{a}_{0}, \hat{a}_{1}$, and $\hat{a}_{n}$, the investor estimates base sales for locations without any station in the previous period as:

$$
D_{j, t-1}^{*}=V_{j, t-1}\left[\hat{a}_{0}+\sum_{n=1}^{N} \hat{a}_{n} C_{n, t-1}^{j}\right] .
$$

Putting the previous two equations together, and using $\mathrm{K}_{\mathrm{j}, \mathrm{t}-1}$ to denote the number of stations that existed in location $j$ in the most recently completed year, the investor's estimate of the previous year's sales in location $j$ is:

$$
D_{j, t-1}^{*}=\left\{\begin{array}{cl}
S_{l, t-1} & \text { if } K_{j, t-1}>0 \\
V_{j, t-1}\left[\hat{a}_{0}+\sum_{n=1}^{N} \hat{a}_{n} C_{n, t-1}^{j}\right] & \text { if } K_{j, t-1}=0
\end{array}\right\} \text { for } j=1 \text { to } L .
$$

The regression in equation (B.3) was based on observing all vehicle traffic. As a variant considered in the sensitivity analysis in Section 3.3.4 of the main body of the report, "First Year Demand Estimation at Potential Station Locations," the investor could focus on hydrogen vehicle traffic only, not simply all vehicle traffic. Using this method entails a redefinition of $\mathrm{V}_{\mathrm{i}, \mathrm{t}-\mathrm{i}}$ in Equation (B.3) to refer to hydrogen vehicle traffic only. 


\section{B.2.1.2 Adjustments for Sales to Stations Planned But Not Yet Operational, $D_{j, t-1}^{* *}$}

The estimate of the most recently completed year's sales in Equation (B.5) gives base sales before the investor has decided to site any new stations. When a first station is established at a location that previously did not have one, that station is able to attract some of the fuel sales that would have taken place otherwise at nearby locations. The estimates of fuel sales in the nearby locations must be adjusted to allow for this diversion effect. The adjustment is:

$$
D_{j, t-1}^{* *}=D_{j, t-1}^{*}+\sum_{n=1}^{N} \sum_{l=1}^{L} I_{l \in \Omega_{j}^{n}}^{1} I_{K_{l, t-1}=0}^{2} \hat{a}_{n}
$$

where

$$
\begin{aligned}
D_{j, t-1}^{* *}= & \text { the adjusted expected base sales at location } j, \text { taking into consideration any } \\
& \text { diversion effect of planned stations; } \\
D_{j, t-1}^{*}= & \text { the unadjusted estimate of the most recently completed year's sales. }
\end{aligned}
$$

To define "nearby," the investor considers $N$ surrounding rings, leading the first summation in Equation (B.6) to be over $n=1$ to $N$. The estimated diversion effect of a location newly populated with a fuel station is $\hat{a}_{n}$. This estimate is obtained from the regression defined in Equation (B.3). For each ring, the investor iterates over all the locations, obtaining a negative effect specific to that ring for each location that meets two criteria:

- The location must lie in the one of the surrounding rings of the location $j$. Using $\Omega_{j}^{n}$ to denote the $n^{\text {th }}$ ring around the location $j$, this condition is captured by the first indicator function, $I_{l \in \Omega_{j}^{n}}^{1}$;

- The location must be getting its first station under the station siting plan of the current year. This condition is captured by the second indicator function, $I_{K_{l, t-1}=0}^{2}$.

Given that each planned station can potentially cause a diversion of sales, the adjustment needs to be calculated for each potential new station evaluated.

\section{B.2.1.3 Estimation of the Growth Parameter, $G_{t}$}

The investor's estimate of the rate of growth of sales at each station is this year's minus last year's area-wide sales. In the benchmark case from which sensitivity is explored, the investor's $G_{t}$ is $30 \%$ for the first and second years. Beginning with the third year, the investor applies Bayesian inference in connection with the observed rate of growth in sales between the 
preceding two years to update the previous estimate $G_{t}$. The new estimate is a weighted average of the previous growth estimate, or "prior," and the observed growth rate. The weights reflect the rapidity with which the investor learns from experience. The larger the weight on the most recent observation, the faster is learning. The equation for $G_{t}$ is:

$$
G_{t}=\left\{\begin{array}{cc}
G_{0} & \text { if } t \leq 2 \\
(1-w) G_{t-1}+w G_{t, l}^{o b s} & \text { if } t>2
\end{array}\right\}
$$

where

$$
\begin{gathered}
G_{t-1}=\quad \begin{array}{l}
\text { the most recently completed year's estimate of growth, also known } \\
\text { as the prior; }
\end{array} \\
w=\text { Bayesian weight on the most recent observation; } \\
G_{t, l}^{o b s=} \quad \text { the average of observed growth rates in the past, i.e., } \\
G_{t}^{o b s}=\frac{1}{t-2} \sum_{\tau=2}^{t-1} \frac{S_{\tau}-S_{\tau-1}}{S_{\tau-1}\left(1-\frac{S_{\tau-1}}{\bar{D}}\right)} \\
\bar{D}=\text { the maximum sales potential of the model area; and, } \\
S_{\tau}=\text { hydrogen sales in period } \tau .
\end{gathered}
$$

\section{B.2.1.4 Estimating Future Sales Using a Logistic Growth Function, $D_{j, t+s-1}$}

Having obtained adjusted base sales and the estimated growth parameter, the investor uses a logistic growth function assuming that the upper bound on sales is the vehicle stock of the region:

$$
D_{j, t+s-1}=\frac{v_{j} D_{j, t-1}^{* *} \bar{D} \exp \left(s G_{t}\right)}{v_{j} \bar{D}+D_{j, t-1}^{* *}\left[\exp \left(s G_{t}\right)-1\right]} \text { for } s=1 \text { to } T_{P}
$$

where

$$
\begin{aligned}
& D_{j, t-1}^{* *}=\text { adjusted base sales at location } j \\
& \bar{D} \quad=\text { model area hydrogen sales if all vehicles used hydrogen; } \\
& v_{j} \quad=\text { the sales share of location } j \text { in } \bar{D}
\end{aligned}
$$




$$
\begin{aligned}
T_{P} \quad= & \text { planning horizon of the investor. Investor estimates sales } \\
& \text { over the next } T_{p} \text { years. }
\end{aligned}
$$

An illustration of the sales forecast made by investors is shown in Figure B-1. Initially sales grow slowly, driven by early adopters who are relatively few in number. As information about performance increases as abetted by observing successful experience of those who have adopted, more drivers adopt. The process feeds on itself, further speeding up adoption, until there are fewer non-adopters remaining. With fewer drivers remaining to be convinced, the growth in percentage of all drivers adopting in any year slows down.

\section{Figure B-1：Logistic Growth Function}

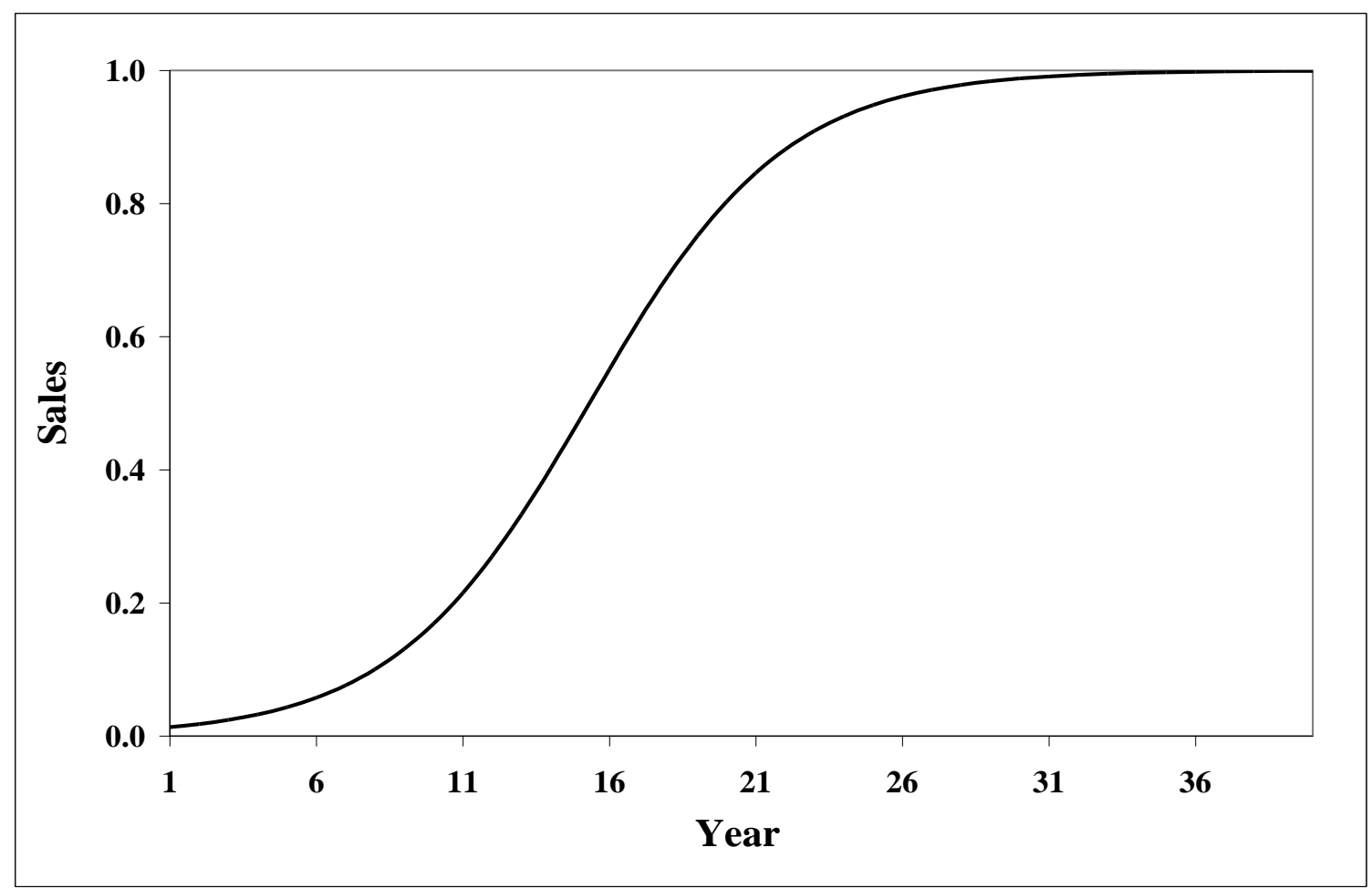

\section{B.2.1.5 Estimating Future Sales Using a Simpler Approach}

An alternative to assuming the investor uses a logistic forecast of sales is to assume the investor forecasts sales to grow for one period only and then stabilize. This case is considered in Section 3.3.5 of the main body of the report, "Expectation of Growth," exploring sensitivity of growth of hydrogen sales to investor method of forecasting sales. In this case, the estimate of growth is:

$$
g_{t}^{o b s}=\frac{S_{t-1}-S_{t-2}}{S_{t-2}} \text {. }
$$


Equation (B.9) in Section B.2.1.4 "Estimating Future Sales Using Logistic Growth Function, $D_{j, t+s-1}$," is replaced by:

$$
D_{j, t+s-1}=D_{j, t-1}^{* *}\left(1+g_{t}\right) \text { for } s=1 \text { to } T_{P}
$$

\section{B.2.2 Effect of a New Station on Profitability of Entire Set of Stations}

Beyond being concerned with the profits from sales at a new station, the investor is concerned with the profitability of the entire set of stations at all locations as determined by how the addition of a new station at one of those locations will affect the profitability of all stations at all locations.

\section{B.2.2.1 Net Present Value (NPV) Calculations}

To accurately reflect profitability, net present value (NPV) calculations are needed taking account of cash inflows and outflows. Cash inflows come from revenues realized from the sale of hydrogen. Cash outflows include capital outlays in establishing new stations and periodically replacing major components such as compressor systems, annual maintenance and other recurring expenditures including feedstock, plus over-capacity penalties incurred when sales at a station exceed the regular capacity of the station, e.g., when customers are supplied using hydrogen trucked-in from other fueling stations or industrial facilities.

To estimate the impact of an additional station on the NPV of the set of stations, the investor first calculates the value of the set of stations without the additional station (i.e., the default value), and then the value of the set of stations with the proposed station. Finally, the

value of waiting is calculated, i.e., the value of the set of stations if another year were to pass before building a station.

The default NPV is calculated as follows:

$$
\begin{aligned}
& N P V^{0}=\sum_{s=1}^{T_{P}}\left[(1+r)^{-s}\left\{\sum_{l=1}^{L} \pi_{l, t+s-1}-K_{l} A\right\}\right] \\
& \text { where } \\
& \pi_{l, t+s-1}=K_{l}\left[(P-U) \min \left(\frac{D_{l, t+s-1}}{K_{l}}, H\right)+(P-V) \max \left(\frac{D_{l, t+s-1}}{K_{l}}-H, 0\right)\right]
\end{aligned}
$$

where

$$
D_{l, t+s-1}=\text { Investor's estimate of sales at location } l \text { in future year } t+s-1 \text {. This estimate is }
$$
obtained in Equation (B.9) or alternatively (B.11) above; 
$T_{P}=$ planning horizon of the investor. Investor estimates sales and profits over the next $T_{p}$ years;

$A=$ annual maintenance costs inclusive of any debt service charges;

$K_{l}=$ number of stations owned by the investor at location $l$ (if at any location, $K_{l}=0$, i.e., the investor does not own any stations at the location, then profits are zero at that location);

$U=$ per-unit variable cost facing the investor;

$P \quad=$ price per $\mathrm{kg}$ of hydrogen;

$H=$ capacity of a plant in $\mathrm{kg} / \mathrm{day}$;

$V=$ variable cost of the plant over the range exceeding its capacity (i.e., regular variable cost $U$ plus the penalty). In this model, stations do not face a hard capacity constraint. If demand exceeds capacity $H$, the excess demand is met by purchasing and trucking in hydrogen from other un-modeled producers of hydrogen such as industrial users. $V$ is the purchase price plus delivery cost paid for each kilogram of excess demand.

Having calculated the default NPV, the investor calculates the potential NPV of the set of stations with the proposed new station at location $j^{*}$ :

$$
N P V_{j^{*}}^{1}=-C+\sum_{s=1}^{T_{p}}\left[(1+r)^{-s}\left\{\sum_{l=1}^{L} \pi_{l, t+s-1}-\left(K_{l}+I_{l=j^{*}}\right) A\right\}\right]
$$

where

$$
\pi_{l, t+s-1}=\left(K_{l}+I_{l=j^{*}}\right)\left[(P-U) \min \left(\frac{D_{l, t+s-1}}{K_{l}+I_{l=j^{*}}}, H\right)+(P-V) \max \left(\frac{D_{l, t+s-1}}{K_{l}+I_{l=j^{*}}}-H, 0\right) \min \left(1, K_{l}\right)\right]
$$

The additional terms in this NPV equation are: $\mathrm{C}$, the equity share of the cost of a new station, and an indicator function $I_{l=j^{*}}$ which takes the value 1 if $l=j^{*}$ and 0 otherwise. This indicator function is used to increase the number of stations at the candidate location by 1 . Overcapacity penalties are ignored if the investor agent is siting its very first station at a location. This condition is captured by use of $\min \left(1, K_{l}^{i}\right)$ in the NPV equation.

Finally, the investor calculates the value of the set of stations under the assumption that the station is built not this year but the next year. This step prevents the investor from unnecessarily carrying excess capacity. 


$$
\begin{aligned}
& N P V_{j^{*}}^{2}=-\frac{C}{1+r}+\sum_{s=1}^{T_{P}}\left[(1+r)^{-s}\left\{\sum_{l=1}^{L} \pi_{l, t+s-1}-\left(K_{l}+I_{l=j^{*}}\right) A\right\}\right] \\
& \text { where } \\
& \pi_{l, t+s-1}=\left(K_{l}+I_{l=j^{*}} I_{s>1}\right)\left[(P-U) \min \left(\frac{D_{l, t+s-1}}{K_{l}+I_{l=j^{*}} I_{s>1}}, H\right)+(P-V) \max \left(\frac{D_{l, t+s-1}}{K_{l}+I_{l=j^{*}} I_{s>1}}-H, 0\right) \min \left(1, K_{l}\right)\right]
\end{aligned}
$$

The additional term in the equation above is the indicator function $I_{s>1}$ which is 1 if $\mathrm{s}>1$ and 0 otherwise. This indicator function allows the investor to estimate the effect of siting the station at this location not in the current year but the next year.

\section{B.2.2.2 Ranking of Locations}

In order to select a candidate station, the investor needs to rank all the locations in order of their profitability with a new station. Ideally, the investor should reorder the locations every time a decision is made to add a new station, in case locating a new station at one location affects the profitability of existing stations at other locations. However, in a case of approximative behavior considered here, the investor ranks the locations only once a year. At the beginning of each year, the investor calculates the increase in the NPV of the set of stations by adding one more station. This additional station is alternatively placed at each of the possible locations. The resulting NPV, when compared to NPVs obtained by placing stations at other locations, determines the rank of that location:

$$
\operatorname{Rank}\left(j^{*}\right)=\sum_{l=1}^{N} \boldsymbol{I}_{N P V_{j^{*}}} \geq N P V_{l}
$$

In this equation, $N$ is the total number of locations where fuel stations can be sited, and $N P V_{i}$ is the NPV of the investor's portfolio with an additional station at location $i$. $I_{N P V_{j^{*}} \geq N P V_{l}}$ is an indicator function that has a value of 1 if $N P V_{J^{*}} \geq N P V_{l}$, and is 0 otherwise.

\section{B.2.2.3 Net Present Value (NPV) Rule for Station Siting}

Once the ranking of locations is completed, the investor applies an NPV rule for siting new stations to each location, in order of the location's ranking. A new station is added if

1. The investor can increase the value of the set of stations by siting another station,

$$
N P V_{j^{*}}^{1}>N P V^{0}
$$


2. The increase in the value of the investor's set of station by siting the station in this year is greater than the increase expected by waiting another year to site the station,

$$
N P V_{j^{*}}^{1}>N P V_{j^{*}}^{2}
$$

This rule is applied for the first proposed station at the most highly ranked location, then if that station is evaluated as profitable, for a second station at the same location, and so on until a proposed station at that location is found to be not profitable to build this year. Then the same sets of calculations are applied to a new station at the second-ranked location, and so on across all 156 locations.

\section{B.3 Number of Investors}

The model's simulations have been executed primarily with a single investor agent, although the model can simulate the actions of multiple investors.

\section{B.3.1 Single Investor}

The case of the single investor described so far models a large corporation making decisions about providing hydrogen infrastructure. Any market power that might be possessed by a single investor is assumed to be of second-order magnitude and fleeting. The single investor competes against fuel producers who supply fuel for non-hydrogen vehicles that compete against hydrogen vehicles. Additionally, the potential entry of other large investors, should the hydrogen price stray too high, would also constrain the single investor's hydrogen price. If these threats of potential competition are not sufficient, rate-of-return regulation might occur, whose purpose is to ensure competitive-like behavior.

\section{B.3.2 More than One Investor}

This case was described in Section 3.3.6 of the main body of the report, "Number of Investors." An investor first evaluates projects as if no other investors exist and, second, sites stations at profitable locations taking into account the actions of other investors. Each investor believes that all investors will act in a similar fashion, placing a station at each profitable location with probability equal to one over the number of investors.

\section{B.4 Options beyond Runs in this Study}

This appendix has described the methods used in the simulations presented in the study. The model can be extended to encompass many other situations. Some of these situations are described below. 


\section{B.4.1 Using Current Capacity Utilization to Rank Locations}

Section B.2.2.2, "Ranking of Locations," described how the investor agent ranks locations. The rank of a location determines the order in which an investor agent will consider siting the next station at various locations. It is also possible for the investor agent to use a simpler rule for ranking locations in which locations are ranked simply in the order of expected capacity utilization taking into account the proposed station. If the investor were to use this method, Equation (B.15) above would be replaced by the following equation:

$$
\operatorname{Rank}(j)=\sum_{l=1}^{N} \boldsymbol{I}\left(\frac{D_{l, t}}{1+K_{l, t-1}} \geq \frac{D_{j, t}}{1+K_{j, t-1}}\right)
$$

In this equation $N$ is the total number of possible locations in the model area. $D_{i, t}$ is estimated fuel sales at location $i$ in the current period as estimated in Section B.2.1.4 "Estimating Future Sales Using the Logistic Growth Function," using Equation (B.9), and $K_{i, t-1}$ is the number of stations at location $i$, where $i=l, j$ in the most recently completed year. The indicator function $I()$ takes the value of 1 if $\frac{D_{l, t}}{1+K_{l, t-1}} \geq \frac{D_{j, t}}{1+K_{j, t-1}}$, and 0 otherwise.

\section{B.4.2 Allowing the Investor to Be a Loss Leader in Siting Stations}

Section B.2.2.3, "Net Present Value (NPV) Rule for Station Siting," described the NPV decision rule of the investor. Following this rule the investor would wait another year if delaying the station by an additional year would add even more to the value of the portfolio of the stations owned by the investor. However, if the investor is operating in a competitive market such that a delay in station siting can lead to a loss of the market to a competitor, then the investor may site the station in the current period even if the value of portfolio could be increased by waiting an additional year. Such behavior is a form of loss leadership since the investor is incurring losses to capture a larger share of the market before a competitor has an opportunity to do the same.

\section{B.4.3 Introducing a Capital Budget Constraint in the Investor's Decision-Making}

Section B.2.2.3, "Net Present Value (NPV) Rule for Station Siting," described the NPV decision rule of the investor. Under this rule the investor can continue to site stations as long as they are expected to be profitable. However, it is possible that there is a limit on the number of stations the investor can site in a given year due to a budget constraint imposed on these expenditures. Accordingly, the investor considers siting a new station only if the remaining budget is sufficient to finance it. The remaining capital budget of the investor should be sufficient to site another station, i.e.,

$$
K \leq \frac{B}{C}-1
$$


where $K$ is the number of stations sited by the investor in the current year so far, $B$ is the total capital budget for the year, and $C$ is the capital cost of siting one station. 


\section{APPENDIX C: FACTORS AFFECTING FUTURE COSTS OF PRODUCING HYDROGEN VEHICLES}

C.1 Introduction

C.2 Hydrogen Vehicle Sticker Price

C.3 Technological Advances

C.4 Learning by Doing Estimates for HPVs

C.5 Returns to Scale and Scale Elasticities for HPVs

C.6 Summary 


\section{C.1 Introduction}

This appendix considers the sources of decline in cost of producing hydrogen vehicles that could enable them to enter the market place on a mass basis. Cost declines from three sources are considered:

- Technological advances in the production of HPVs

- Learning by doing in the manufacturing of HPVs

- Returns to scale in the production of HPVs

The following three sections review the literature with regard to these sources of price decrease. This appendix ends with a summary.

\section{C.2 Hydrogen Vehicle Sticker Price}

Sticker price difference is the purchase price of an HPV minus that of a non-hydrogen vehicle. Several projections of the price of an HPV relative to that of a non-hydrogen vehicle have been made. For example, the International Energy Association in 2005 estimated that in 2030, an HPV will cost between $\$ 2,500$ and $\$ 7,625$ more than a non-hydrogen vehicle. ${ }^{52}$ RCF and Argonne staffs reviewed other studies which collectively provide a range of estimated values for future prices of HPVs relative to those of non-hydrogen vehicles. ${ }^{53,54,55,56}$ Price difference estimates vary from several thousand dollars less, to several thousand dollars more for an HPV compared to a non-hydrogen vehicle. The time horizon usually extends to 2015 , but also reaches as far as 2025 .

The main factor accounting for the difference in price of an HPV compared to price for a non-hydrogen vehicle is the cost of the fuel cell. In turn, fuel cell cost estimates depend on the state of technology at a particular time.

The agent-based model's benchmark price of an HPV of equality with the price of a nonhydrogen vehicle was selected using price and cost estimates found in the literature as a starting point, and then applying the collective wisdom of RCF and Argonne staff to project a reasonable estimate of the price difference looking out 30 to 40 years in the future, not 5, 10, or 20 years out which some of the studies in the literature reference. As analyzed in this report, high and low

\footnotetext{
52 International Energy Association, "Prospects for Hydrogen and Fuel Cells," 2005, http://www.iea.org/textbase/nppdf/free/2005/hydrogen2005.pdf, p. 101, Table 3.5.

${ }^{53}$ Stephen Eaves and James Eaves, “A Cost Comparison of Fuel-Cell and Battery Electric Vehicles,” Journal of Power Sources 130 (2004), pp. 208-212.

${ }^{54}$ Sam Hawkins and Nick Hughes, “Technological Characteristics of Hydrogen Fuel Cell Vehicles," UKSHEC Social Science Working Paper No. 22 (London: Policy Studies Institute, 2006), especially pp. 7, 13.

${ }^{55}$ Joan M. Ogden, Robert H. Williams and Eric D. Larson, "Toward a Hydrogen-Based Transportation System," final draft (Princeton University Center for Energy and Environmental Studies, May 8, 2001).

${ }^{56}$ Haruki Tsuchiya and Osamu Kobayashi, “Mass Production Cost of PEM Fuel Cell by Learning Curve,” International Journal of Hydrogen Energy 29 (2004), pp. 985-990.
} 
scenarios also were simulated, with the high case $\$ 6,500$ more, and the low case $\$ 4,000$ less than the non-hydrogen vehicle cost.

\section{C.3 Technological Advances}

The price of an HPV is dependent on many factors, most important of which are costs of manufacturing the glider, the electronic motor, the hydrogen storage system, and the fuel cell. The most expensive of these components is the hydrogen fuel cell, and the main driver in the expected price decline of hydrogen vehicles will be the corresponding decrease in fuel cell cost. In the literature, fuel cells are often priced in dollars per kilowatt. Fuel cells for HPVs will have a capacity between 70 and 100 kilowatts, with 80 kilowatts being the size assumed in this study. Thus, an $80-\mathrm{kW}$ fuel cell with a per-kilowatt cost of $\$ 50$ will cost $\$ 4,000$. Other important components are the electric motor, control electronics, the hydrogen storage system, and the glider which consists of the body and interior of the vehicle. While it is possible that glider cost will be less for an HPV than for a non-hydrogen vehicle due to the removal of some of the complexity associated with combustion engines in non-hydrogen vehicles, we assume conservatively that glider cost is the same for hydrogen and non-hydrogen vehicles. ${ }^{57}$

Major avenues of progress in fuel cell technology involve three interrelated areasdurability, reliability, and cost. Cost reduction of individual components has proceeded over the past twenty years, and should continue, stemming from reductions in the costs of components: 1) polymer electrolyte membrane, also known as proton exchange membrane, or PEM; 2) catalyst electrodes (i.e., membrane electrode assemblies, or MEA); 3) the fuel cell stack; 4) the fuel cell processor; 5) the power conditioner; and, 6) air supply systems. ${ }^{58}$

\footnotetext{
${ }^{57}$ David L. Greene, Paul N. Leiby, and David Bowman, Integrated Analysis of Market Transformation Scenarios with HyTrans (Oak Ridge, Tenn.: Oak Ridge National Laboratory, June 2007), p. 13.

${ }^{58}$ Department of Energy, “DOE Hydrogen Program: 2008 Progress Report - Fuel Cells,” November, 2008, accessed September 1, 2009 at http://www.hydrogen.energy.gov/annual_progress08_fuelcells.html.
} 


\section{Figure C-1: Stack Cost Component Distribution}

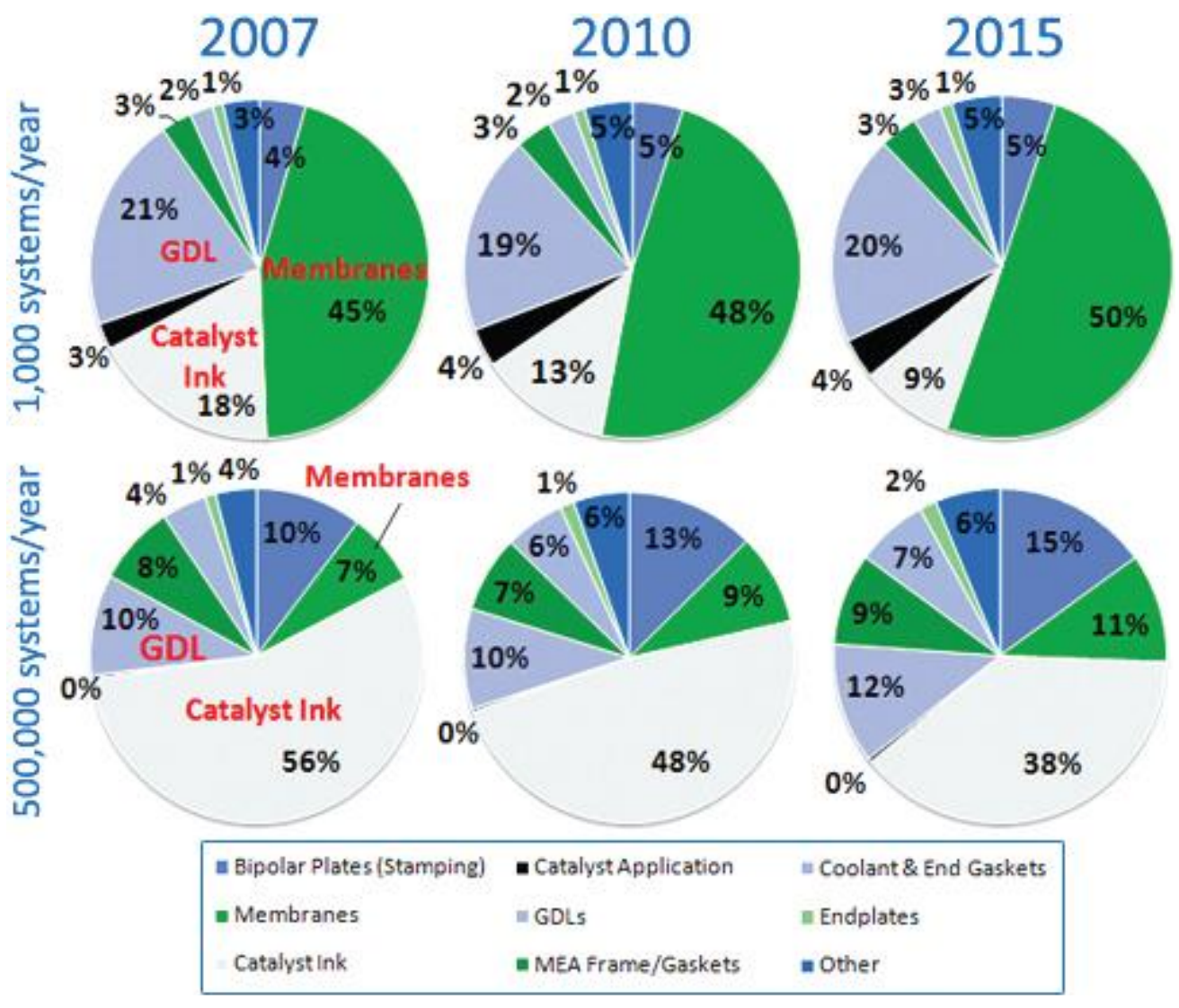

Source: Brian James, "Mass Production Cost Estimation for Direct $\mathrm{H}_{2}$ PEM Fuel Cell System for Automotive Applications," DOE Hydrogen Annual Review Program: FY2008 Annual Progress Report, p.800, accessed September 2, 2009, at http://www.hydrogen.energy.gov/pdfs/progress08/v a 2 james.pdf.

As shown in Figure C-1, the membrane, the catalyst ink, the gas diffusion layer, and the bipolar plates are the most expensive components in PEM fuel cells. The membrane commonly used is DuPont's Nafion 117, but intense research is being conducted to develop cheaper membranes. For instance, the Asahi Chemical Company and the Asahi Glass Company have put forward a pair of potential alternatives, Aciplex and Flemion. ${ }^{59}$ Also, experiments with nonhydrated membranes, in which liquids other than water are used, are promising. This would allow the membrane to work at temperatures above $100{ }^{\circ} \mathrm{C}$, and thus be more efficient. Further, lowering the need for platinum in the catalyst has been the subject of much research. Toward this end, thinner platinum sheets, non-hydrated membrane methods, and carbon or nickel nanotube-based gas diffusion layers are being developed. While there is not yet a membrane that

\footnotetext{
${ }^{59}$ Michael A. Hicknew, Hossein Ghassemi, Yu Seung Kim, Brian R. Einsla, and James E. McGrath, "Alternative Polymer Systems for Proton Exchange Membranes (PEMs),” Chemical Reviews, Vol. 104, No. 10, (2004), p. 4591.
} 
matches the DuPont product, there is a significant push for increased efficiency and lower costs in this area. ${ }^{60,61}$

The cost of fuel cells could be reduced further by substituting the graphite plates with plates of cheaper composite materials, notably metal-carbon-polymer plates. ${ }^{62,63}$ Durability issues are being studied intensely as well. This is a topic that is especially important for fuel cells intended for use in motor vehicles, because such systems see great variation in conditions such as temperature and humidity which cause stress on components. Significant improvements have been made in this area through the introduction of new catalysts, improved catalyst support materials, optimized electro-catalyst layer structures, enhanced flow field design, and significant improvements in fuel cell stack and system controls. ${ }^{64,65}$ Also, system design has received some attention, with some progress through the heat-flow-based technique called pinch technology. ${ }^{66}$ Many advances have come through better understanding of unit cell component failures, design optimization, and operating strategies. ${ }^{67}$ Better models of system components such as the stack, gas humidifier, pressure swing absorber, membrane reactor, fuel cell processor, and membrane gas separator have been introduced recently or are in progress, all of which further contribute to the development of cheaper and more efficient components. ${ }^{68}$

The Department of Energy regularly reviews the cost and technological progress of hydrogen storage and of fuel cells. In these and other reports in the literature, the cost per kilowatt is reported under an assumption that fuel cells are produced at a high volume, for instance of at least 500,000 units per year (typical automobile manufacturing volume is between 75,000 and 500,000 vehicles per factory per year).

Table C-1 reports recent cost declines. High-volume cost estimates are relevant because the gains from economies to scale are substantial, as will be seen below in Section C.5. Over time, technological advances have brought the estimated cost down substantially.

These advances include reduction in the amount of platinum needed in constructing the fuel cell. The Department of Energy has had as a stated goal that the price of fuel cells be $\$ 45$

\footnotetext{
${ }^{60}$ Kamaruzzaman Sopian and Wan Ramli Wan Daud, "Challenges and Future Developments in Proton Exchange Membrane Fuel Cells,” Renewable Energy Vol.31, Issue 5, (2006), pp. 719-727.

${ }^{61}$ Sunita Satyapal, "Hydrogen Program Overview, 2009 DOE Hydrogen Annual Review and Vehicle Technologies Program," Annual Merit Review and Peer Evaluation Meeting, May 18, 2009, accessed 7/30/2009 at http://www.hydrogen.energy.gov/pdfs/review09/program_overview_2009_amr.pdf.

${ }^{62}$ Jinfeng Wu, Xiao Zi Yuan, Jonathan J. Martin, Haijiang Wang, Jiujun Zhang, Jun Shen, Shaohong Wu, and Walter Merida, “A Review of PEM Fuel Cell Durability: Degradation Mechanisms and Mitigation Strategies," Journal of Power Sources, Vol.184, Issue 1 (15 September 2008), pp. 104-119.

${ }^{63}$ Sopian and Wan Daud, "Challenges and Future Developments in Proton Exchange Membrane Fuel Cells."

${ }^{64}$ Wu et al., "A Review of PEM Fuel Cell Durability: Degradation Mechanisms and Mitigation Strategies.”

${ }^{65}$ Jürgen Stumper and Charles Stone, "Recent Advances in Fuel Cell Technology at Ballard,” Journal of Power Sources, Vol. 176, Issue 2 (1 February 2008), pp. 468-476.

${ }^{66}$ C. Wallmark and P. Alvfors, "Design of Stationary PEFC System Configurations to Meet Heat and Power Demands," Journal of Power Sources, Vol. 106, Issues 1-2 (April 2002), pp. 83-92.

${ }^{67}$ Stumper and Stone, "Recent Advances in Fuel Cell Technology at Ballard."

${ }^{68}$ Sopian and Wan Daud, "Challenges and Future Developments in Proton Exchange Membrane Fuel Cells."
} 
per $\mathrm{kW}$ by 2010 and $\$ 30$ per $\mathrm{kW}$ by 2015 , assuming annual HPV production volume of $500,000 .^{69}$

Table C-1: Costs of Fuel Cell System, Assuming 500,000 Vehicles Produced Annually $(2015$ goal is $\$ 30 / \mathbf{k W})$

\begin{tabular}{|c|c|c|c|c|}
\hline Year & 2002 & 2006 & 2007 & 2008 \\
\hline $\begin{array}{l}\text { Cost of Fuel } \\
\text { Cell System }\end{array}$ & $\$ 275 / \mathrm{kW}$ & $\$ 108 / \mathrm{kW}$ & $\$ 94 / \mathrm{kW}$ & $\$ 73 / \mathrm{kW}$ \\
\hline
\end{tabular}

Source: Satyapal, "Hydrogen Program Overview, 2009 DOE Hydrogen Annual Review and Vehicle Technologies Program," p. 5.

For comparison, sticker price parity between HPV and non-hydrogen vehicles is reached roughly when the cost of an $80-\mathrm{kW}$ fuel cell approaches $\$ 40$ per $\mathrm{kW}$.

One estimate puts the cost of an HPV at approximately $\$ 29,147$, with a cost break-out by individual components as follows: (1) fuel cell, \$23,033; (2) 3.2-kg storage tank, \$2,288; and, (3) drive train, $\$ 3,826 .^{70}$ The ultimate price of the HPV thus depends mostly on the cost of the fuel cell. The components which add the most to that cost are the platinum catalysts and bipolar plates between cells. The bipolar plates are made largely of machined graphite sheets. Some severely reduced cost estimates include assumptions of major technological leaps in the future, such as elimination of bipolar plates and gaskets, or uses of a carbon-polymer composite fuel cell which can be molded for mass-manufacturing. ${ }^{71}$

The full magnitude of cost reductions in the future will depend as well on technological progress reducing the cost of manufacturing hydrogen fuel cells, through learning by doing in manufacturing, as factories become more adept at the production of fuel cells, and on the size of production runs of fuel cells being large enough to capture economies of scale.

\section{C.4 Learning by Doing Estimates for HPVs}

Learning by doing refers to cost declines as a consequence of performing tasks many times. Learning by doing is often measured by a progress ratio. This number is the ratio of the cost of production after cumulative production doubles, to the initial cost. A 1984 paper refers to an often-cited finding of an average industry progress ratio equal to $80 \%$ based on a 1947 analysis of progress ratios of 118 World War II airframe models. ${ }^{72}$ If a manufactured product has a progress ratio of $80 \%$ and the production cost is $\$ 100$ to make the first 100 units, when cumulative production reaches 200 units, the second batch of 100 units will have cost $\$ 80$.

\footnotetext{
${ }^{69}$ Satyapal, “Hydrogen Program Overview, 2009 DOE Hydrogen Program and Vehicle Technologies Program,” p. 5.

${ }^{70}$ Stephen Eaves and James Eaves, “A Cost Comparison of Fuel-Cell and Battery Electric Vehicles,” Journal of Power Sources 130 (2004), pp. 208-212.

${ }^{71}$ Hawkins and Hughes, “Technological Characteristics of Hydrogen Fuel Cell Vehicles,” p. 7.

72 John M. Dutton, Annie Thomas, and John E. Butler, “The History of Progress Functions as a Managerial Technology," The Business History Review Vol. 58, No. 2 (Summer 1984), p. 222.
} 
Formally, for some product, if $\operatorname{Cost}(\mathrm{t})$ is cost at time $\mathrm{t}, \mathrm{d}(\mathrm{t})$ is the number of doublings of cumulative output of the product at time $t$, and $a$ is the percent reduction in cost for each doubling of cumulative output (i.e., 1 -a is the progress ratio), then we have $\operatorname{Cost}(t)=\operatorname{Cost}(0)(1$ a) ${ }^{\mathrm{d}}$.

Table C-2 below gives estimates of progress ratios for various products. Progress ratio estimates for hydrogen vehicles exist. Separate estimates of progress ratios for fuel cells have been given. Japanese scientists Haruki Tsuchiya and Osamu Kobayashi reported a progress ratio of photovoltaic cost of 82\% from 1979 to 1999 in Japan, while Princeton University scientists Joan Ogden, Robert Williams and Eric Larson estimated a progress ratio for the same product of $83 \% .^{73,74}$ Beyond estimating progress ratios, Tsuchiya and Kobayashi give estimates of eventual fuel cell stack costs between $\$ 15$ per $\mathrm{kW}$ and $\$ 145$ per $\mathrm{kW}$ in 2020 , with a middle scenario estimate of $\$ 38$ per $\mathrm{kW}$ or $\$ 3,800$ for a 100 -kilowatt fuel cell system in $2020 .^{75}$

Table C-2: Progress Ratios for Various Products

\begin{tabular}{|l|c|c|c|c|c|}
\hline \multicolumn{1}{|c|}{ Technology } & Period & $\begin{array}{c}\text { Year 1 } \\
\text { Production }\end{array}$ & $\begin{array}{c}\text { Cumulative } \\
\text { Production }\end{array}$ & Cost Index & $\begin{array}{c}\text { Progress } \\
\text { Ratio }\end{array}$ \\
\hline Ford Model T Auto & $1909-1923$ & 15,741 & $8,028,992$ & 0.290 & $87 \%$ \\
\hline Integrated Circuits & $1962-1968$ & 4 million units & 828 million units & 0.047 & $67 \%$ \\
\hline CFC Substitutes & $1988-1999$ & 100,000 tons & $3,871,000$ tons & 0.690 & $93 \%$ \\
\hline Scrubbers & $1987-1995$ & $65.8 \mathrm{GW}$ & $84.3 \mathrm{GW}$ & 0.941 & $89 \%$ \\
\hline Photovoltaic Cells & $1971-2000$ & $0.1 \mathrm{MW}$ & $1,451.4 \mathrm{MW}$ & 0.042 & $72 \%$ \\
\hline Magnetic Ballasts & $1977-1993$ & 29.4 million & 629.3 million & 0.897 & $97 \%$ \\
\hline Electronic Ballasts & $1986-2001$ & 431,000 & 350 million units & 0.277 & $88 \%$ \\
\hline Refrigerators & $1980-1998$ & 5.1 million & 126.3 million & 0.556 & $88 \%$ \\
\hline Freezers & $1980-1998$ & 1.8 million & 26.1 million & 0.374 & $78 \%$ \\
\hline Clothes Washers & $1980-1998$ & 4.4 million & 104.7 million & 0.536 & $87 \%$ \\
\hline $\begin{array}{l}\text { Electronic Clothes } \\
\text { Dryer }\end{array}$ & $1980-1998$ & 2.5 million & 61.0 million & 0.557 & $88 \%$ \\
\hline Gas Clothes Dryer & $1980-1998$ & 0.7 million & 18.2 million & 0.593 & $90 \%$ \\
\hline Dishwasher & $1980-1998$ & 2.7 million & 69.7 million & 0.450 & $84 \%$ \\
\hline $\begin{array}{l}\text { Room Air } \\
\text { Conditioner }\end{array}$ & $1980-1998$ & 2.4 million & 63.3 million & 0.478 & $85 \%$ \\
\hline $\begin{array}{l}\text { Selective Window } \\
\text { Coatings }\end{array}$ & $1992-2000$ & 4.8 million m ${ }^{2}$ & 157.4 million $\mathrm{m}^{2}$ & 0.394 & $83 \%$ \\
\hline
\end{tabular}

Source: John A. Laitner and Alan H. Sanstad, "Learning-by-Doing on Both the Demand and the Supply Sides: Implications for Electric Utility Investments in a Heuristic Model,” Table 1, EXCETP Workshop, Paris, January 22-23, 2003, accessed July 31, 2008, at http://www.iea.org/dbtw-wpd/textbase/work/2003/extool-excetp6/IV-laitner.pdf.

\section{C.5 Returns to Scale and Scale Elasticities for HPVs}

Returns to scale can be calculated by looking at the scale elasticity or the cost elasticity (which are inverses of each other, such that $S E_{i}=\left(E C Q_{i}\right)^{-1}$ ). In this case, increasing returns to scale are consistent with a scale elasticity greater than one or, equivalently, a cost elasticity less

\footnotetext{
73 Tsuchiya and Kobayashi, "Mass Production Cost of PEM Fuel Cell by Learning Curve,” p. 990.

${ }^{74}$ Ogden, Williams, and Larson, "Toward a Hydrogen-Based Transportation System," p. 15.

${ }^{75}$ Tsuchiya and Kobayashi, "Mass Production Cost of PEM Fuel Cell by Learning Curve,” p. 988.
} 
than one. Estimates for the automobile industry find that as a factory approaches full capacity, cost elasticity increases, and the degree of increasing returns to scale diminish. Various auto industry studies have been carried out. It has been suggested that the cost elasticity estimate is directly related to the size of a nation's industry. For example, the cost elasticity estimate is 0.758 in Spain, ${ }^{76} 0.85$ in Canada, 0.91 in Germany and in the U.S., 0.98 in Japan, ${ }^{77}$ and 0.98 in Mexico. ${ }^{78}$ Van Biesebroeck gives a wider range of estimates for the United States: 0.873 to $1.15 .^{79}$

Scale elasticity is also a function of level of capacity utilization. Some research has found evidence for this at a minimum level of output, where cost elasticity is estimated to be 0.013 , significant at the $0.5 \%$ level, while at maximum level, cost elasticity is estimated to be 1.293 , significant at the $10 \%$ level, with 0.758 at mean output, significant at $0.5 \%$ level. ${ }^{80}$

\section{C.6 Summary}

Table C-3 summarizes the elements of the total cost of a hydrogen vehicle: the glider, the fuel cell, the storage tank, control electronics, and the motor, and compares them to the cost of a non-hydrogen vehicle.

In their study of market transformation scenarios, Greene and Leiby state that glider costs are the same across all technology types and are assumed to be a constant $\$ 20,000$ over time. ${ }^{81}$ From the paper by Eaves and Eaves, a conventional drive train is derived to cost about $\$ 3,800,{ }^{82}$ and from the International Energy Association's study, a conventional engine is implied to cost about $\$ 2,400,{ }^{83}$ bringing the subtotal for these two components to $\$ 6,200$. Thus, a non-hydrogen vehicle is estimated cost around $\$ 26,200$ at the present time $(=\$ 20,000+\$ 6,200)$.

The current cost of an HPV is estimated from several sources. As noted above, the glider cost of $\$ 20,000$ from Greene and Leiby is used. A fuel cell cost of $\$ 144,000$ is taken from an International Energy Association study. ${ }^{84}$ The cost of a hydrogen storage tank, control

\footnotetext{
${ }^{76}$ Lila J. Truett and Dale B. Truett. "The Spanish Automotive Industry: Scale Economies and Input Relationships,” Applied Economics Vol. 33 (2001), p. 1508.

${ }^{77}$ Melvyn A. Fuss and Leonard Waverman, Costs and Productivity in Automobile Production: The Challenge of Japanese Efficiency (Cambridge: Cambridge University Press, 1992), Table 5.4, p. 122.

${ }^{78}$ James R. Tybout and M. Daniel Westbrook, “Trade Liberalization and the Dimensions of Efficiency Change in Mexican Manufacturing Industries,” Journal of International Economics Vol..39, Issues 1-2 (August 1995), p. 70.

79 Johannes Van Biesebroeck, "Productivity Dynamics with Technology Choice: An Application to Automobile Assembly," The Review of Economic Studies 70 (2003), p. 192.

${ }^{80}$ Truett and Truett. “The Spanish Automotive Industry: Scale Economies and Input Relationships,” p. 1508.

${ }^{81}$ Greene, Leiby, and Bowman, Integrated Analysis of Market Transformation Scenarios with HyTrans, p. 13.

${ }^{82}$ Eaves and Eaves, “A Cost Comparison of Fuel-Cell and Battery Electric Vehicles,” p. 210.

${ }^{83}$ International Energy Association, "Prospects for Hydrogen and Fuel Cells," p. 101, Table 3.5.

${ }^{84}$ Ibid.
} 
electronics, and an electric motor were derived from the paper by Eaves and Eaves and found to be about $\$ 6,000 .^{85}$ Thus, the total estimated current cost for an HPV is about $\$ 170,000$.

We include future costs of the HPV under two different sets of assumptions. First, we give the cost if an annual HPV volume of 500,000 vehicles is assumed. The fuel cell cost associated with this volume found in the DOE's 2009 progress report is $\$ 73$ per $\mathrm{kW}$ or $\$ 5,840$ for an $80-\mathrm{kW} \mathrm{HPV}{ }^{86}$ The second case gives both a range of fuel cell costs and a range of the combined costs of fuel cell tank, control electronics, and electric motor under high future annual HPV volume.

Table C-3: Current and Future Cost Estimates of Mid-Sized Sedan, by Component

\begin{tabular}{|c|c|c|c|c|c|}
\hline Vehicle Costs & Glider & $\begin{array}{l}\text { Conventional } \\
\text { Engine and } \\
\text { Drive Train }\end{array}$ & $\begin{array}{l}\text { Hydrogen } \\
\text { Fuel Cell }\end{array}$ & $\begin{array}{c}\text { Hydrogen } \\
\text { Storage Tank, } \\
\text { Control } \\
\text { Electronics, } \\
\text { and Electric } \\
\text { Motor }\end{array}$ & Total \\
\hline $\begin{array}{l}\text { Conventional } \\
\text { Vehicle }\end{array}$ & $\$ 20,000^{81}$ & $\$ 6,200^{88,89}$ & - & - & $\$ 26,200$ \\
\hline $\begin{array}{l}\text { Hydrogen Vehicle } \\
\text { (today) }\end{array}$ & $\$ 20,000^{81}$ & - & $\$ 144,000^{89}$ & $\$ 6,000^{88}$ & $\$ 170,000$ \\
\hline $\begin{array}{l}\text { Hydrogen Vehicle } \\
(2007, \text { if annual } \\
\text { volume were } \\
500,000)\end{array}$ & $\$ 20,000^{81}$ & - & $\$ 5,840^{86}$ & $\$ 6,000^{88}$ & $\$ 31,840$ \\
\hline $\begin{array}{l}\text { Hydrogen Vehicle } \\
\text { (future, high volume) }\end{array}$ & $\$ 20,000^{81}$ & - & $\begin{array}{l}\$ 1,200^{-} \\
\$ 3,040^{87}\end{array}$ & $\begin{array}{r}\$ 6,000^{88}- \\
\$ 7,500^{89} \\
\end{array}$ & $\begin{array}{r}\$ 27,200- \\
\$ 30,540 \\
\end{array}$ \\
\hline
\end{tabular}

Fuel cell costs range from $\$ 1,200$ to $\$ 3,040,{ }^{87}$ based on results obtained by Tsuchiya and Kobayashi for rapid and moderate progress. Costs for hydrogen storage tank, control electronics, and electric motor range from $\$ 6,000^{88}$ to $\$ 7,500^{89}$, taking results derived from Eaves and Eaves, and the International Energy Association, respectively.

Depending on the estimated cost of the fuel cell, an 80-kw fuel cell HPV could cost from $\$ 1,000$ to $\$ 4,600$ more than a non-hydrogen vehicle in the future, although an HPV currently costs over $\$ 140,000$ more than a non-hydrogen vehicle today. The exact cost is not certain. There is some promise that the cost of the electric motor, control electronics, and especially hydrogen storage tank will decline over time. ${ }^{90}$ Moreover, the hydrogen storage tank is expected

\footnotetext{
${ }^{85}$ Eaves and Eaves, “A Cost Comparison of Fuel-Cell and Battery Electric Vehicles,” p. 210-211.

${ }^{86}$ Satyapal, "Hydrogen Program Overview, 2009 DOE Hydrogen Program and Vehicle Technologies Program,” p. 5.

${ }^{87}$ Tsuchiya and Kobayashi, "Mass Production Cost of PEM Fuel Cell by Learning Curve,” p. 990.

${ }^{88}$ Eaves and Eaves, “A Cost Comparison of Fuel-Cell and Battery Electric Vehicles,” p. 210-211.

${ }^{89}$ International Energy Association, "Prospects for Hydrogen and Fuel Cells," p. 101, Table 3.5.

${ }^{90}$ Sam Hawkins and Nick Hughes, "Technological Characteristics of Hydrogen Fuel Cell Vehicles," UKSHEC Social Science Working Paper No. 22 (London: Policy Studies Institute, 2006).
} 
to experience more relative cost reductions compared to other components. Further reductions from learning by doing in electric motors and control electronics would be expected to be low given that these technologies are not new and that there are similar components in non-hydrogen vehicles which would be expected to experience similar cost reductions.

The final column of Table C-3 shows the resulting estimates of the future possible prices of HPVs at unspecified dates in the future. These prices are in the vicinity of the hydrogen vehicle prices in the scenarios of the present study. 